\title{
EVOLUTION OF A NORMAL FAULT SYSTEM, NORTHERN GRABEN, TARANAKI BASIN, NEW ZEALAND
}

Hamish Ewan Cameron

A thesis submitted to Victoria University of Wellington in partial fulfilment of requirements for the degree of

Master of Science

In Petroleum Geoscience

School of Geography, Environment, and Earth Sciences Victoria University of Wellington 



\section{Abstract}

This study investigates the evolution (from initiation to inactivity) of a normal fault system in proximity to active petroleum systems within the Taranaki Basin, New Zealand. The aim of this research is to understand the evolution, interaction, and in some cases, death of normal faults in a region undergoing progressive regional extension. This research provides insight into the geometry, development, and displacement history of new and reactivated normal fault evolution through interpretation of industry standard seismic reflection data at high spatial and temporal resolution. Insight into normal fault evolution provides information on subsidence rates and potential hydrocarbon migration pathways.

Twelve time horizons between 1.2 and $35 \mathrm{Ma}$ have been mapped throughout 1670 square kilometres of the Parihaka and Toro 3D seismic reflection surveys. Fault displacement analysis and backstripping have been used to determine the main phases of fault activity, fault growth patterns, and maximum Displacement/Length ratios. The timing, geometry, and displacement patterns for 110 normal faults with displacements $>20 \mathrm{~m}$ have been interpreted and analysed using Paradigm SeisEarth and TrapTester 6 seismic interpretation and fault analysis software platforms.

Normal faults within the Parihaka and Toro 3D seismic surveys began developing at $~ 11$ $\mathrm{Ma}$, with the largest faults accruing up to $1500 \mathrm{~m}$ of displacement in <10 Myr (mean throw displacement rate of $0.15 \mathrm{~mm} / \mathrm{yr}$ ). Approximately $50 \%$ of the 110 mapped faults are associated with pre-existing normal faults and have typical cumulative displacements of $\sim 20-1000 \mathrm{~m}$, with strike parallel lengths of $<1-23 \mathrm{~km}$. In contrast, new faults have typically greater displacements of $20-1400 \mathrm{~m}$, and are generally longer with, with strike parallel lengths of $\sim 1-33 \mathrm{~km}$.

New faults were the first faults within the system to become inactive when strain rates decreased from $0.06-0.03$ between 3.6 and 3.0 Ma. Eight of the largest faults with > $1000 \mathrm{~m}$ cumulative displacement reach the seafloor and are potentially active at present day. An earthquake on one of these faults could be expected to produce $M_{W}$ 2.2 based on the maximum strike-parallel length of the fault plane. 


\section{Acknowledgements}

The past 2 years have been some of the most memorable of my life so far. Here I will attempt to thank everyone that has had an impact on this thesis - without you it would not have been possible.

First I must thank my wonderful and immensely patient supervisors from both Victoria and GNS Science. Tim Little, thank you for your brutal yet constructive criticisms, and ruthless dissection of written work. Thanks for always having an open door when I needed assistance, and putting me right when I wandered off course. Your vast scientific knowledge, and impeccable ability for logical, concise writing, has been inspirational throughout the writing of this thesis.

Hannu Seebeck, thank you for your technical assistance with this project. You have taught me invaluable skills with seismic interpretation that formed the basis of this thesis, and I will value them for life. Thanks for getting me started on the project, even when it had shaky beginnings. Thanks for being so incredibly patient, and always being there to assist with my infinite questions, no matter how stupid they may have been.

Andy Nicol, thanks for introducing me to Hannu, and suggesting I undertake this project in the first place. To the staff at GNS Science, thanks for making me feel so at home during my time there. It has been an awesome experience working and conversing with scientists at the forefront of their fields, and I feel truly privileged to have been accepted into your community. Special thanks must also go to Mark Lawrence and Suzanne Bull, who introduced me to the wonderful world of Petroleum Geoscience. Mark, thank you for overstepping your role and helping me obtain the contacts within GNS that led to this project getting off the ground.

Finally, I must thank my friends and family for being so supportive during my time at University. To my parents, thank you for infinite support, hot meals, and never giving up on me through my constant indecision about my future. Without you I would never even be close to where I am today. Thanks to my loving partner Lucy, for always being there for me, and staying supportive no matter how much of our time this thesis ate into. I will always be thankful for you sticking with me through the good and the bad. 
Finally, thanks to my friends and fellow students at Vic, for helping me take much needed breaks from writing.

"A learning experience is one of those things that says, 'You know that thing you just did? Don't do that."

- Douglas Adams, The Salmon of Doubt 


\section{Table of Contents}

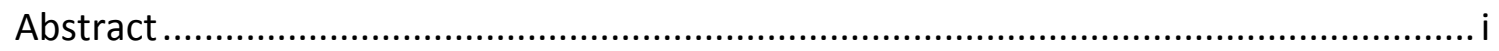

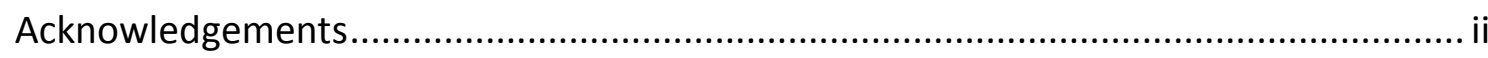

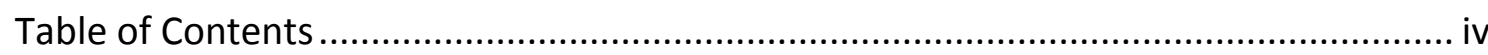

Table of Figures ............................................................................................. vii

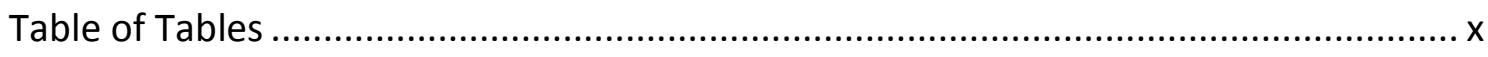

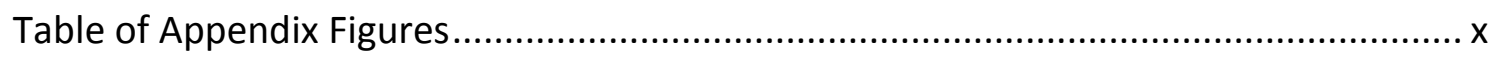

Table of Appendix Tables ................................................................................... xii

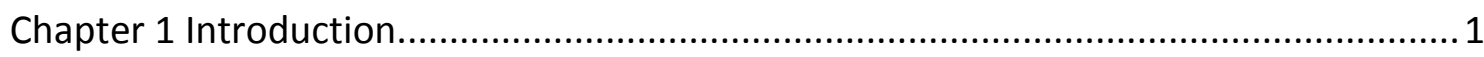

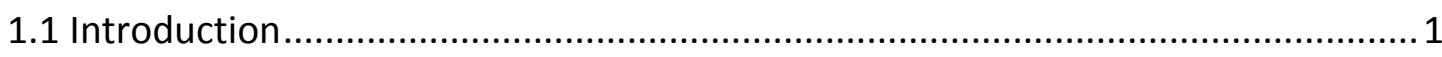

1.2 Study Area

1.3 Petroleum System in the Study Area ……………………………………....

1.4 Petroleum Exploration in the Study Area - Past and Present................................ 8

1.5 Petroleum Exploration Permits in the Study Area ……………………….......... 8

1.6 Existing Research on Normal Fault Evolution and the Petroleum Systems of the

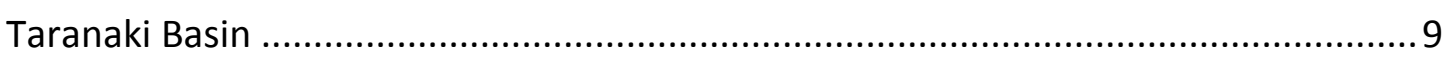

1.7 Goals - How Will This Thesis Improve Research? ……....................................... 13

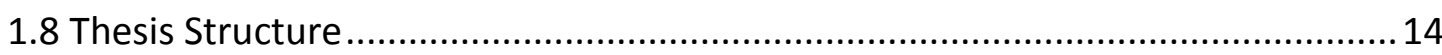

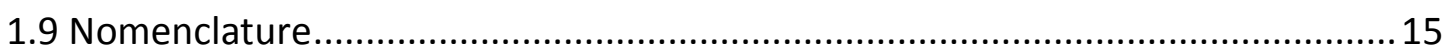

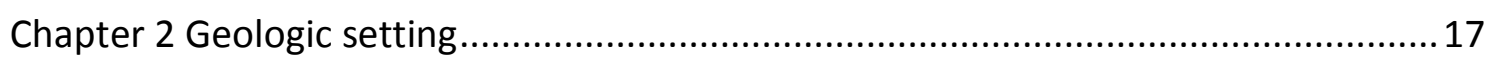

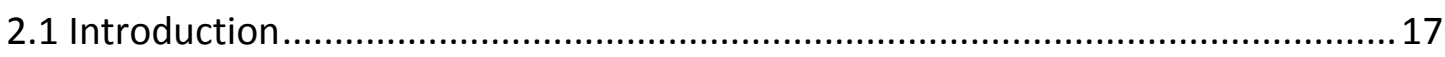

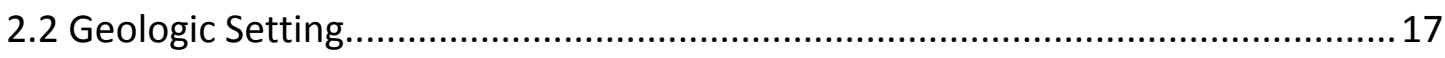

2.3 Present Day New Zealand Plate Kinematics....................................................... 18

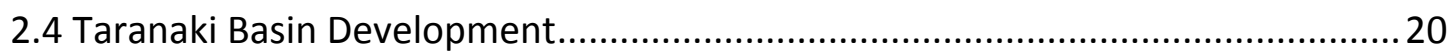


2.4.1 Taranaki Basin Structural Components ...................................................2 21

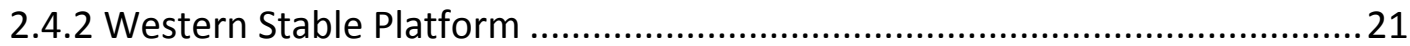

2.4.3 Eastern Mobile Belt ........................................................................... 21

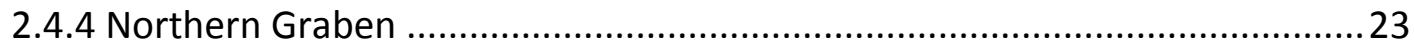

2.4.5 Taranaki Basin Tectonic and Stratigraphic Summary ..................................24

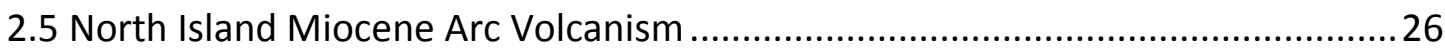

2.5.1 North Island Miocene Volcanic Arc Migration ............................................2 27

2.5.2 North Island Volcanic Arc Migration - Slab Rollback ...................................28

2.5.3 North Island Volcanic Arc Migration - Mantle Instability ................................30

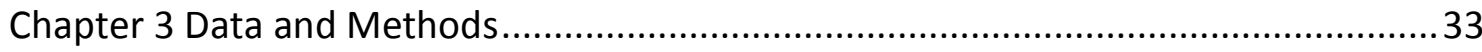

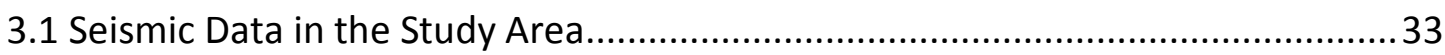

3.1.1 Parihaka 3D Seismic Reflection Survey ........................................................33

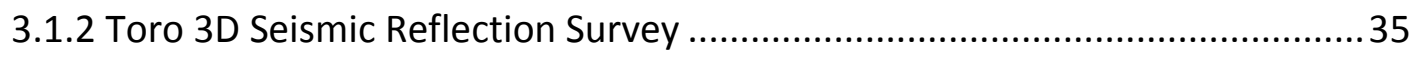

3.1.3 Uncertainties and Margins of Error .......................................................... 35

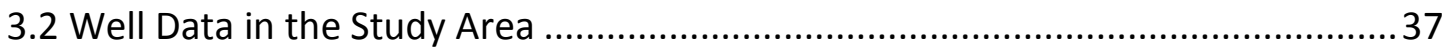

3.2.1 Taranaki Basin Stratigraphy and Biostratigraphy ........................................ 37

3.2.2 Seismic Time Horizons in the Study Area ....................................................39

3.2.3 Time/Depth Relationship in the Study Area .............................................. 41

3.2.4 Well Correlation in the Study Area ........................................................ 42

3.3 Seismic Mapping and Fault Analysis................................................................. 46

3.3.1 Part 1: Data Acquisition and Seismic Interpretation in Paradigm ..................46

3.3.2 Part 2: Data Processing and Fault analysis with TrapTester..........................51

3.3.3 Part 3: Data Analysis and Hypothesis Testing..............................................54

Chapter 4 Geometry of a Normal Fault System ......................................................5 57

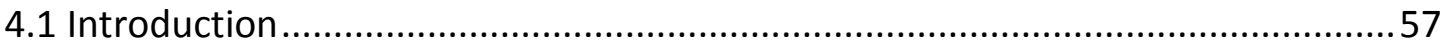

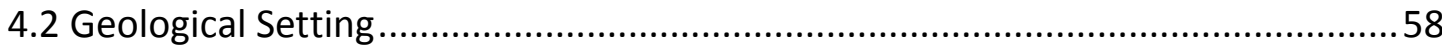

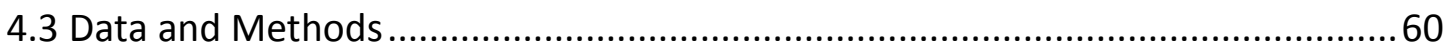

4.4 Normal Fault Geometry and Kinematics ..........................................................64

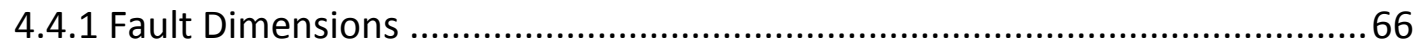




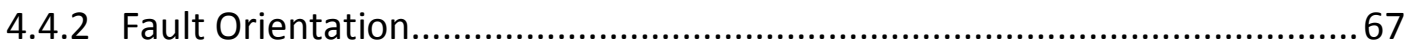

4.4.3 Extension and Subsidence in the Northern Graben ...................................70

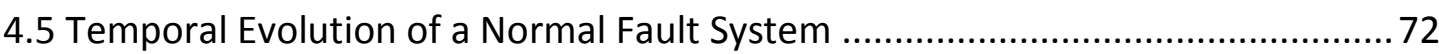

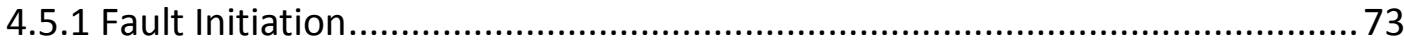

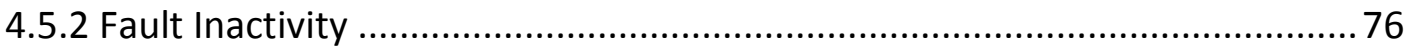

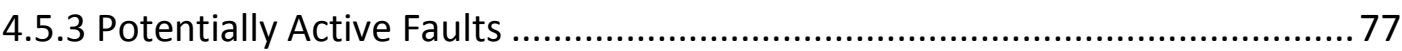

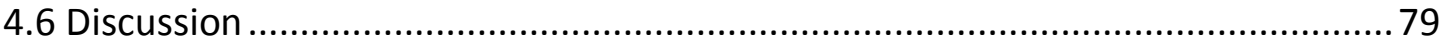

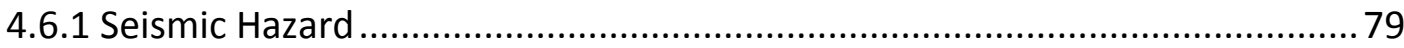

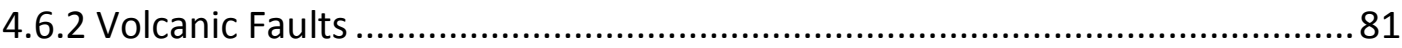

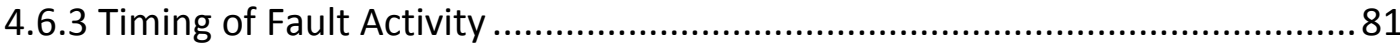

4.6.4 Fault Dips and the Non Rotation of Faults ............................................... 82

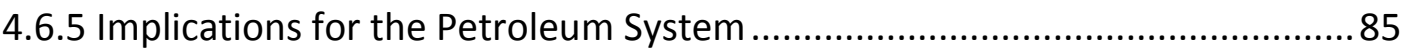

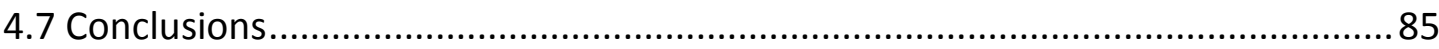

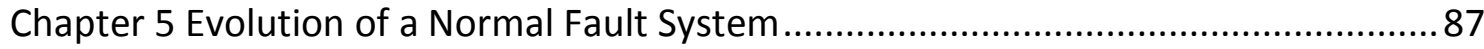

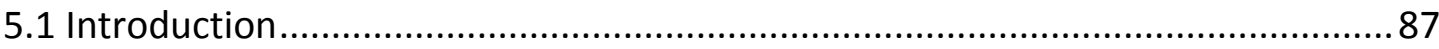

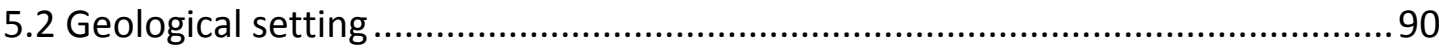

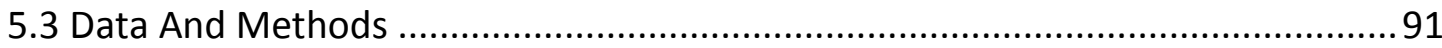

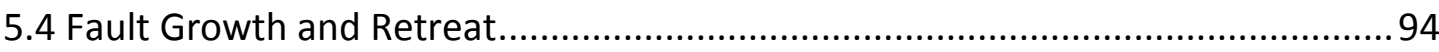

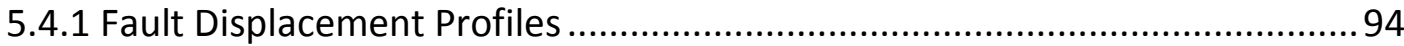

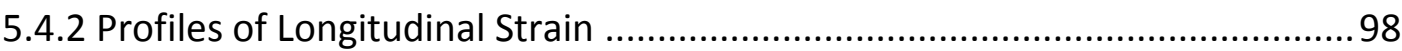

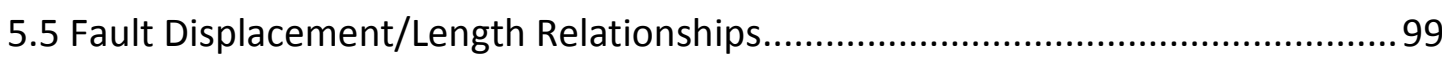

5.5.1 Fault Displacement/Length Relationships in the Northern Graben.............102

5.5.2 Backstripped Fault Growth Profiles ............................................................ 106

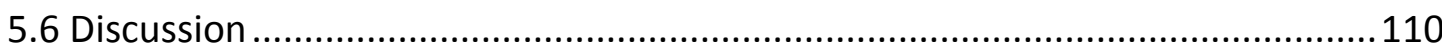

5.6.1 Support for Fault Growth Models ........................................................... 110

5.6.2 Implications for Crustal Scale Tectonics .................................................. 112

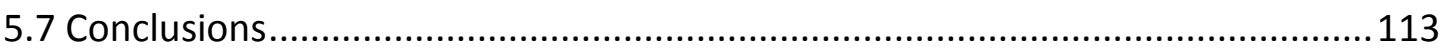

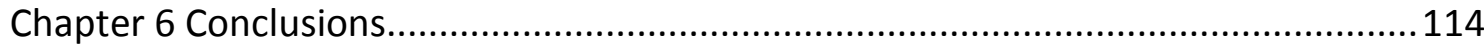


Appendix

\section{Table of Figures}

Figure 1.1 Map displaying the location of the study area and its tectonic setting. 3

Figure 1.2 Maps displaying Late Cretaceous to Recent fault activity in the study area........ 4

Figure 1.3 Map displaying source rock kitchens in the study area.................................... 5

Figure 1.4 Petroleum system components diagram for the Taranaki Basin......................... 8

Figure 2.1 Map displaying the New Zealand tectonic setting.......................................... 18

Figure 2.2 Maps displaying New Zealand's Miocene Euler pole and associated rotation

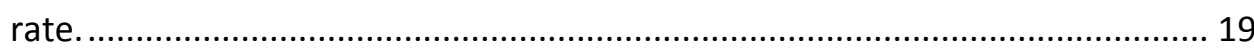

Figure 2.3 Images displaying the kinematics of the block rotation model for New Zealand's

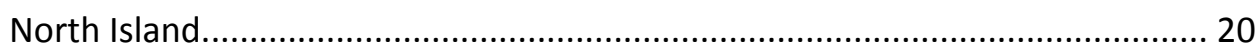

Figure 2.4 Map displaying the location of major structural components of the Taranaki Basin in map view.

Figure 2.5 Stratigraphic summary of the Taranaki Basin.

Figure 2.6 Map of volcanic arc migration eastward across New Zealand's North Island.... 28

Figure 2.7 Map and cross sections of volcanic arc migration eastward across New Zealand's North Island.

Figure 2.8 Diagram of the Rayleigh-Taylor mantle instability model.

Figure 2.9 Maps displaying apparent rotation of arc volcanism in the North Island. 32

Figure 3.1 Map of 2D seismic reflection data distribution, offshore western-central North Island, New Zealand.

Figure 3.2 Generalised stratigraphic column for the Taranaki Basin.

Figure 3.3 Chronostratigraphic column displaying the Zealandia-wide seismic time horizon naming scheme to which time horizons mapped in this thesis comply

Figure 3.4 Time/depth relationship for borehole checkshot Two Way Travel Time (TWTT) vs. true vertical depth sub-sea (TVDSS) within the study area.

Figure 3.5 Map displaying locations of the four key well ties within the Parihaka and Toro 3D seismic reflection volumes.

Figure 3.6 Section view of the Taimana-1 to Arawa-1 to Witiora-1 well tie line. 44 
Figure 3.7 Section view of crossline 8454 through Arawa-1.....................................44

Figure 3.8 Section view of the loop tie surrounding Arawa-1.....................................45

Figure 3.9 Section view of the Taimana-1 to Okoki-1 well tie.......................................45

Figure 3.10 Isochron map showing the sediment thickness between the oldest $35 \mathrm{Ma}$ (P50) and youngest $0 \mathrm{Ma}$ (Seabed) mapped time horizons, and hence all major sedimentary structures observed in the study area.

Figure 3.11 Map showing an example of the location, orientation, and density of final time horizon grid picks using Basal Top Set time horizon picks for the 1.6 Ma (N85) time horizon.

Figure 4.1 Fault map displaying the locations and dip directions of all faults analysed in this study.

Figure 4.2 Examples of coherency seismic attribute features as seen in the Parihaka 3D coherency volume.

Figure 4.3 Illustration of fault initiation and cessation measurements demonstrating how fault initiation and cessation/inactivity timing was calculated from seismic data.

Figure 4.4 Section View of Crossline 8254 showing faults appearing to have initiated before $11 \mathrm{Ma}$

Figure 4.5 Zoomed section view of the red rectangle in Figure 4.4.

Figure 4.6 Figure displaying the number of faults of each type within the study area..... .65

Figure 4.7 Section view image showing examples of the four types of faults observed in the study area.

Figure $4.8 \quad$ Rose plots for the four key time horizons in the study area. ........................68

Figure 4.9 Rose plots for each of the four fault types in the study area..........................69

Figure 4.10 Images displaying kinematic markers crossing a fault. ..................................70

Figure 4.11 Image displaying kinematic markers crossing a fault.................................. 70

Figure 4.12 Map displaying patterns of extension and subsidence in the study area..........71

Figure 4.13 Maps displaying which faults were active at which depths at each of the $11-3.6$ Ma time horizons.

Figure 4.14 Maps displaying which faults were active at which depths at each of the $3 \mathrm{Ma}-$ 0 Ma time horizons. 
Figure 4.15 Figure showing the location of all faults in the study area, coloured to denote the time horizon nearest their estimated initiation (or reactivation in some cases).

Figure 4.16 Displacement profiles for each of the three Parihaka Fault segments.

Figure 4.17 Figure showing the location of all faults in the study area, coloured to denote the time horizon nearest the cessation of their activity (the last time horizon to be displaced by the fault).

Figure 4.18 Map showing locations of faults intersecting the seabed.

Figure 4.19 Section view of crossline 10254, showing fault intersections with the Seabed time horizon.

Figure 4.20 Zoomed section view of crossline 10254, showing fault intersections with the Seabed time horizon.....

Figure 5.1 Conceptual models illustrating incremental changes in fault growth behavior.....

Figure 5.2 Illustration of fault displacement methodology. 90

Figure 5.3 Image displaying the relationship between seismic coherency data and fault displacement profiles, using fault 5_090 (with retreating tips) as an example.. 93

Figure 5.4 Displacement profile for the southern segment of the Parihaka Fault (Fault Z.1003) with stationary tips.

Figure 5.5 Displacement profile for fault 5_090, showing retreating fault tips. 95

Figure 5.6 Displacement profiles of three adjacent faults displaying kinematic coherence between the faults.

Figure 5.7 Profiles displaying longitudinal strain in the study area over time.

Figure 5.8 Schematic of Displacement/Length growth trends for coherent (a) and isolated

(b) fault growth models. 101

Figure 5.9 Log/log plot displaying a compilation of maximum global normal fault Displacement/Length data.

Figure 5.10 Log/log Displacement/Length plot for a compilation of global normal fault data

Figure 5.11 Log/log Maximum Displacement/Length plot for Taranaki Basin data. 105

Figure 5.12 Log/log maximum Displacement/Length plot for all faults except those antithetic to reactivated structures. 
Figure 5.13 Backstripped Displacement/Length profiles for new faults, displaying fault length against cumulative throw.

Figure 5.14 Backstripped Displacement/Length Profiles for reactivated faults, displaying fault length against cumulative throw. 108

Figure 5.15 Backstripped Displacement/Length Profiles for volcanic faults, displaying fault length against cumulative throw. 109

Figure 5.16 Plot of maximum cumulative fault throw vs. onset of inactivity. 110

\section{Table of Tables}

Table 3.1 Table showing the theoretical limits of vertical and horizontal seismic resolution at various depths in the Parihaka and Toro 3D Seismic surveys. 37

Table 3.2 Table of seismic horizons mapped in this study. .40

Table 4.1 Table of moment magnitude $M_{\mathrm{w}}$ for potentially active faults. 80

\section{Table of Appendix Figures}

Appendix Figure 1 Map displaying the geometry and location of inlines and crosslines in the

Parihaka 3D seismic reflection volume.

Appendix Figure 2 Map displaying the geometry and location of inlines and crosslines in the

Toro 3D seismic reflection volume.

Appendix Figure 3 3D view of fault throw contours and fault intersection polygons for all faults in the study area, as seen in TrapTester.

Appendix Figure 4 3D view of fault throw contours with fault intersection polygons removed for all faults in the study area, as seen in TrapTester. 129

Appendix Figure 5 Horizon grids for the Seabed and Unconformity time horizons. 130

Appendix Figure 6 Horizon grids for the N85 and Intra Top Set time horizons. .131

Appendix Figure 7 Horizon grids for the Basal Top Set and N75 time horizons. 132

Appendix Figure 8 Horizon grids for the N70 and N60 time horizons. 133

Appendix Figure 9 Horizon grids for the N50 and N40 time horizons. 134

Appendix Figure 10 Horizon grids for the N50 and N40 time horizons. .135

Appendix Figure 11 Isochron (time-thickness) maps for time horizons between 0 and $3.6 \mathrm{Ma}$. 
Appendix Figure 12 Isochron (time-thickness) maps for time horizons between 3.6 and 35

Ma.

Appendix Figure 13 Rose plots of the $0 \mathrm{Ma}$ (Seabed) and 1.2 Ma (Unconformity) time horizons

Appendix Figure 14 Rose plots of the 1.6 Ma (N85) and $2 \mathrm{Ma}$ (Intra Top Set) time horizons....

Appendix Figure 15 Rose plots of the 2.4 Ma (Basal Top Set) and $3 \mathrm{Ma}$ (N75) time horizons...

Appendix Figure 16 Rose plots of the 3.6 Ma (N70) and 5.3 Ma (N60) time horizons. 141

Appendix Figure 17 Rose plots of the 7.2 Ma (N50) and $11 \mathrm{Ma}$ (N40) time horizons 142

Appendix Figure 18 Rose plots of the 15.9 Ma (N30) and $35 \mathrm{Ma}$ (P50) time horizons. 143

Appendix Figure 19 Fault initiation maps for the $11-3.6$ Ma time horizons. 144

Appendix Figure 20 Fault initiation maps for the 3-1.2 Ma time horizons 145

Appendix Figure 21 Fault inactivity maps for the $11-3.6$ Ma time horizons. 146

Appendix Figure 22 Fault inactivity maps for the 3-0 Ma time horizons. 147

Appendix Figure 23 Map displaying locations of new faults. 148

Appendix Figure 24 Map displaying locations of reactivated faults 148

Appendix Figure 25 Map displaying locations of faults antithetic to reactivated structures.149

Appendix Figure 26 Map displaying locations of volcanic faults. 150

Appendix Figure 27 Coherency attribute images displaying stationary fault tip locations (Part 1 - Fault Z.1003). 151

Appendix Figure 28 Coherency attribute images displaying stationary fault tip locations (part 2 - Fault Z.1003)

Appendix Figure 29 Coherency attribute images displaying retreating fault tip locations (part 1 - Fault 5_090). 153

Appendix Figure 30 Coherency attribute images displaying retreating fault tip locations (part 2- fault 5_090) 153

Appendix Figure 31 Coherency attribute images displaying potentially propagating fault tip locations (part 1 - Fault- z.1002).

Appendix Figure 32 Coherency attribute images displaying potentially propagating fault tip locations (part 2 - Fault- z.1002). 155 
Appendix Figure 33 Coherency time slice at $2820 \mathrm{~ms}$ displaying polygonal faults observed in the Parihaka 3D coherency volume....................................................... 156

Appendix Figure 34 Plot displaying raw strain profiles as seen in TrapTester................... 157

Appendix Figure $35 \mathrm{Log} / \log$ Displacement/Length plot for all data gathered in the study area, combined with unpublished Taranaki data from A Nicol.. 158

\section{Table of Appendix Tables}

Appendix Table 1 Fault activity table displaying the time horizons at which each fault in the study area was active, along with its type - part 1 of 3.

Appendix Table 2 Fault activity table displaying the time horizons at which each fault in the study area was active, along with its type - part 2 of 3.

Appendix Table 3 Fault activity table displaying the time horizons at which each fault in the study area was active, along with its type - part 3 of 3. 126 


\section{Chapter 1 Introduction}

\subsection{Introduction}

Faults are a first order structural component of the Earth's crust developed through the motions of tectonic plates and associated brittle deformation. Faults provide a record of paleo-strain and paleo-stress directions and magnitudes within a region that that has undergone brittle deformation (e.g. Watterson (1986)). Faults can act as barriers and/or conduits to fluid flow. As barriers to fluid flow, faults can compartmentalise and trap migrating fluids, such as hydrocarbons, against low permeability fault rocks. As conduits to fluid flow, faults can form preferential high permeability pathways connecting source regions to reservoirs, for example, or allowing migrating fluids to leak to the surface. Whether a fault has the potential to be open or sealing is primarily controlled by its stress state and how close it is to failure (Townend \& Zoback, 2000).

Understanding the geometry and displacement history of faults places important constraints on the impact the evolution of a fault system has on the prospectivity of a petroleum system. How fault systems evolve in time is still a relatively poorly understood phenomenon, and many questions remain about how faults growth in displacement, such as: are fault lengths set instantaneously at initiation, or does length increase with increasing displacement?; does fault evolution follow a coherent or isolated fault growth model?; will all faults in a given population evolve in length and displacement in the same manner regardless of size? (Walsh \& Watterson, 1988a; Cowie \& Scholz, 1992; Dawers et al., 1993; Jackson, 1999; Meyer et al., 2002; Walsh et al., 2002; Childs et al., 2003; Kim \& Sanderson, 2005; Xu et al., 2005; Childs et al., 2009; Giba et al., 2010; Giba et al., 2012; Giba et al., 2013; Reilly et al., 2015).

Aspects of fault development in displacement and length can only be explored in locations with significant fault populations, age control, and sedimentation rates that have kept pace with or outstripped throw displacement rates during fault growth (Childs et al., 2003). The combination of these factors, where evaluated with industry 
standard 3D seismic reflection data, allow the timing and geometry of fault history to be mapped with high spatial and temporal resolution. The Northern Graben, Taranaki basin, New Zealand, is an ideal place to study the development of both new and reactivated faults due to high sedimentation rates during Late Miocene - Recent rifting.

3D seismic interpretation constrained by four exploration wells allows the detailed mapping of Late Eocene to Recent strata and normal faults in the Northern Graben, Taranaki Basin, New Zealand, to the limit of seismic resolution ( $\sim \mathrm{m}$ ) over an area of $1670 \mathrm{~km}^{2}$. These normal faults predominantly strike NE-SW, with maximum normal displacements ranging from $\sim 20-1500 \mathrm{~m}$, and lengths ranging from $\sim 1->20$ kilometres. Concurrent normal faulting and rapid sedimentation in the Northern Graben has led to the creation of syn-sedimentary fault growth strata, which can be used to investigate the evolution of a normal fault system.

\subsection{Study Area}

The Taranaki Basin is situated off the western coast of New Zealand's North Island (Figs. 1.1, 1.2), covering an area of $\sim 100,000 \mathrm{~km}^{2}$ (King \& Thrasher, 1996). To date, the Taranaki Basin has been the only New Zealand basin to produce commercial quantities of hydrocarbons. While still underexplored by global standards, it is New Zealand's most extensively explored petroleum basin. Over 400 onshore and offshore exploration and production wells have been drilled since 1950, in conjunction with the acquisition of hundreds of thousands of kilometres of 2D seismic reflection profiles (New Zealand Petroleum and Minerals, 2015). Within the last decade, 3D seismic reflection data have become publically available and form the principal data for this study.

The area of the Taranaki Basin specific to this thesis is encompassed by the Parihaka and Toro 3D seismic reflection volumes $\left(1670 \mathrm{~km}^{2}\right)$. Prior to 3D seismic coverage, 2D seismic data coverage was either of low quality or coarse grid spacing. The combined Parihaka and Toro 3D seismic reflection volumes are tied to four exploration wells that intersect Paleocene to Recent strata (Fig. 1.1). These 35 - 0 Ma strata are constrained 
by recent, high frequency biostratigraphic sampling of Morgans (2006b), which are tied to the standardized New Zealand timescale of Strogen and King (2014).

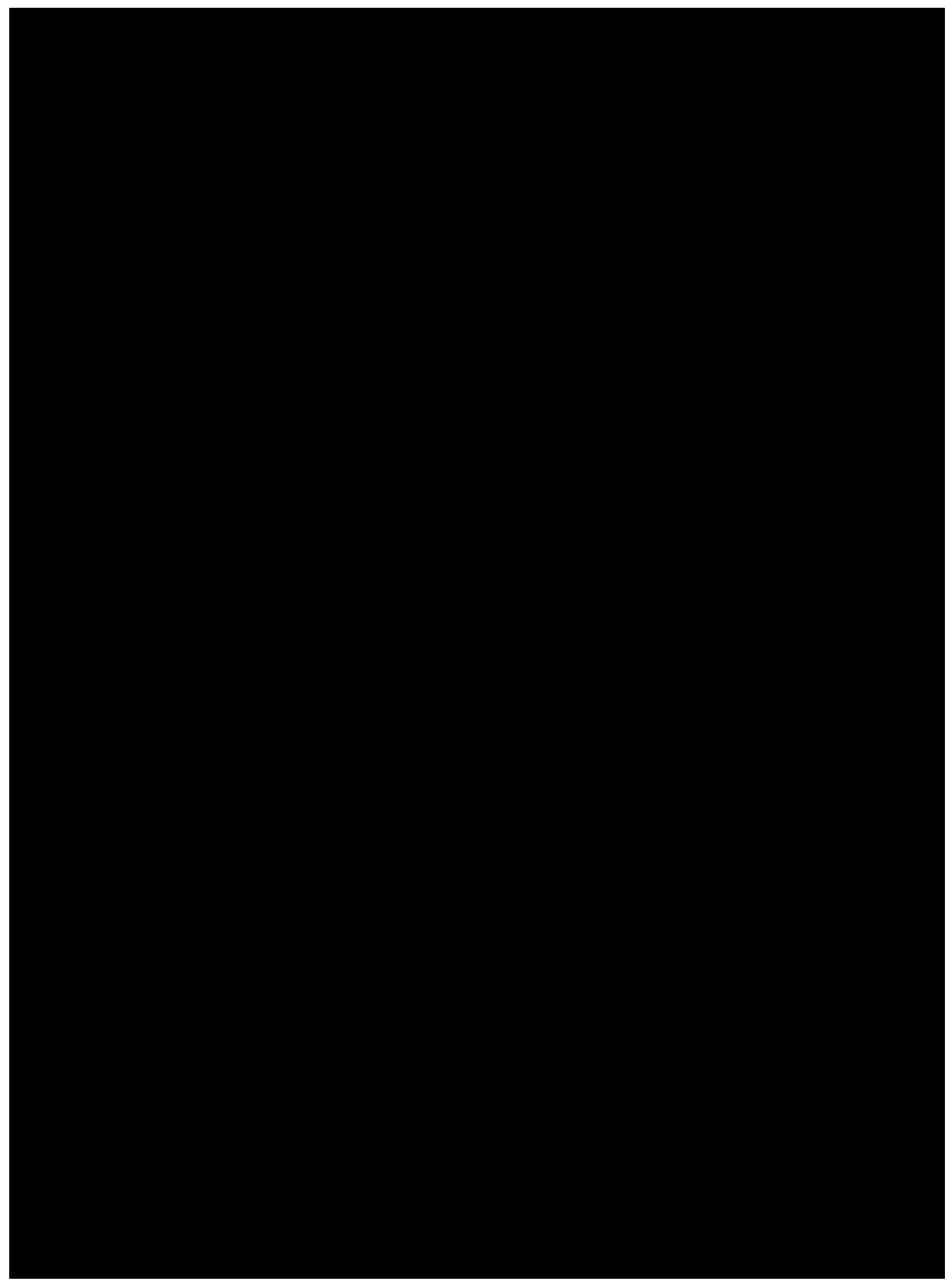

Figure 1.1 Map displaying the location of the study area and its tectonic setting. The study area is defined by the locations of the Parihaka (green polygon), and Toro 3D seismic reflection surveys (blue polygon). Exploration wells relevant to this study are underlined in green. The tectonic setting of the area is also shown, with normal faults active in the early Pliocene displayed as black polylines with dip ticks, with Miocene - Pliocene reverse faults shown as black polylines annotated as thrusts for reference. The Miocene - Recent Mohakatino Volcanic Complex is represented by grey shading in the large scale map. Image adapted from Giba et al. (2012). 


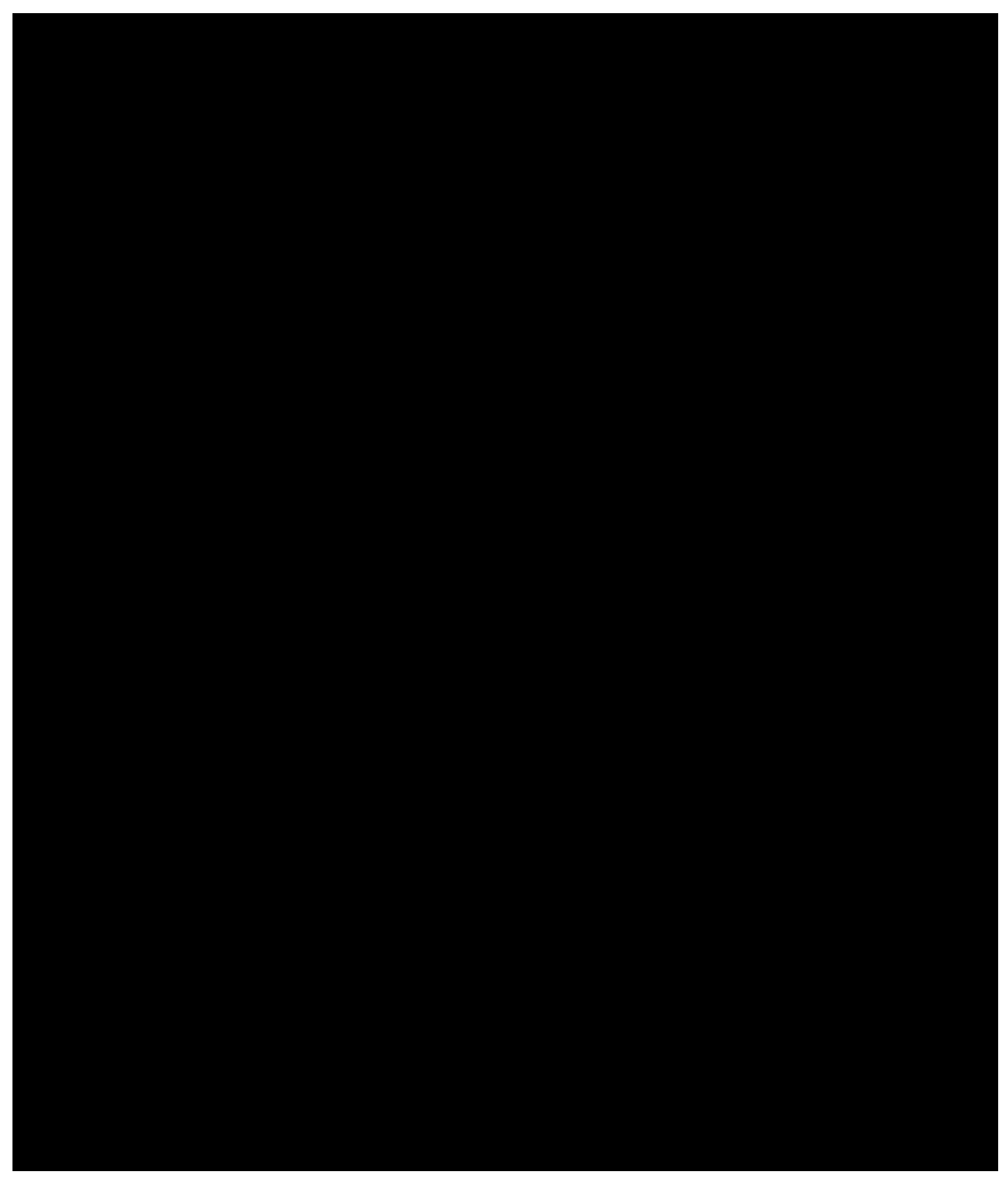

Figure 1.2 Maps displaying Late Cretaceous to Recent fault activity in the study area. Locations of the Parihaka 3D survey (black polygon), and Toro 3D survey (blue polygon) are given. The modern day tectonic setting is shown in (a), with (b), (c), and (d) showing progressive changes in fault trends and activity in the area since the Late Cretaceous. The Parihaka fault is highlighted at each stage with grey shading. Wells used in the study are indicated by named dots. Map adapted from Giba et al. (2012). 


\subsection{Petroleum System in the Study Area}

The study area appears to have all necessary elements for a viable petroleum system, is proximal to the producing Pohukura gas field, and is in a geologically similar setting to the giant Maui gas field. See Figure 1.4 for a petroleum system components diagram. The following petroleum system elements are known to be present in the study area:

Source - Late Cretaceous coal measures (Rakopi Formation equivalent, the source of the majority of Taranaki's oil and gas) are thought to exist at maturity since $10 \mathrm{Ma}$ in the study area (Lovitz \& Bates, 2008a). Mapped potential kitchen areas are presented in Figure 1.3.

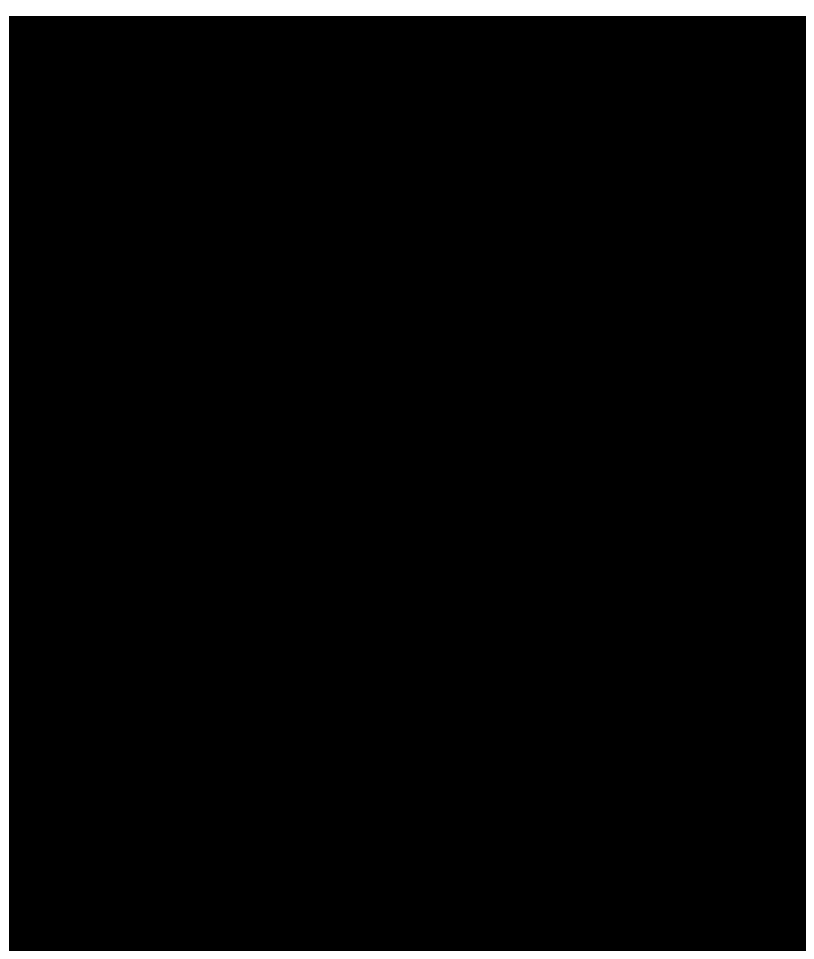

Figure 1.3 Map displaying source rock kitchens in the study area. Theorised locations of mature Rakopi source rock kitchens in and around the study area are shown. Kitchens are contoured by oil thought to have been expelled in $\mathrm{MMbbl} / \mathrm{Km}^{2}$, with a scale provided at the bottom right of the map. Leads identified in the studies of Lovitz and Bates (2008), are shown in blue. The Parihaka and Toro 3D seismic reflection surveys are shown by black and red polygons, respectively. Image modified from Lovitz and Bates (2008b).

Seal - Potential Paleocene - Eocene reservoirs could be sealed by the mudstones and siltstones of the Eocene Turi Formation, while Miocene level reservoirs could be sealed by the mudstones and siltstones of the Pliocene Manganui Formation (Fig. 1.4) 
Reservoir - Reservoir quality sandstones are abundant throughout the Northern Taranaki Basin (Fig. 1.4). The Pohukura gas field produces from the Eocene Mangahewa Formation (a clean shoreface sandstone with porosities of 6 - 10\%), but younger formations are also viable reservoir within the study area. Okoki-1 targeted both the Late Miocene Moki Formation sandstones (porosities of $7-25 \%$ ), and the Eocene Kapuni Group sandstones (porosities of 3 - 10\%) (Crowley \& Crocker, 1989). Arawa-1 also targeted Late Miocene Moki Formation sandstones (porosity 20\%) (ARCO Petroleum, 1992). Witiora-1 targeted both the Miocene Mokau Formation sandstones (Porosities 20 - 25\%), and the Paleocene Kapuni Formation sandstones (found to be unsuitably tight) (NZ Oil \& Gas Ltd, 1984a). Taiamana-1 encountered no viable reservoir interval (Diamond Shamrock Exploration Oil Co (NZ), 1984).

Trap - Minor anticlines in the study area could facilitate structural trapping of hydrocarbons (Figs. A.5 - A.10). Stratigraphic fault-bounded trapping of hydrocarbons is also plausible, with 110 faults providing potential migration conduits as well as barriers to fluid flow. While out of the scope of this study, shale/gouge ratio analysis of individual faults could provide an assessment of the sealing properties of faults in the study area.

Migration and timing - Migration of hydrocarbons in the study area is facilitated by buoyancy forces acting on hydrocarbons, generated from $\sim 8 \mathrm{~km}$ of overburden. Normal faults provide migration pathways for buoyant hydrocarbons. Cretaceous Rakopi Formation source rock in the Taranaki Basin has been mature from 10 Ma to present on average (Telford \& Murray, 2008). Normal faulting in the study area began in the Neogene, and could provide migration pathways from the deep source rocks to shallower reservoir lithologies (Ilg et al., 2012). Reservoir and seal rocks have been deposited since the late Cretaceous (King \& Thrasher, 1996). Late Miocene and PlioPleistocene reservoir rocks have available potential charge pathways through normal faults that has been active between $11 \mathrm{Ma}$ and present day (King \& Thrasher, 1996; Giba et al., 2010). Potential structural and stratigraphic traps were developed by this faulting episode, with two subeconomic traps identified by Lovitz and Bates (2008) (Fig. 


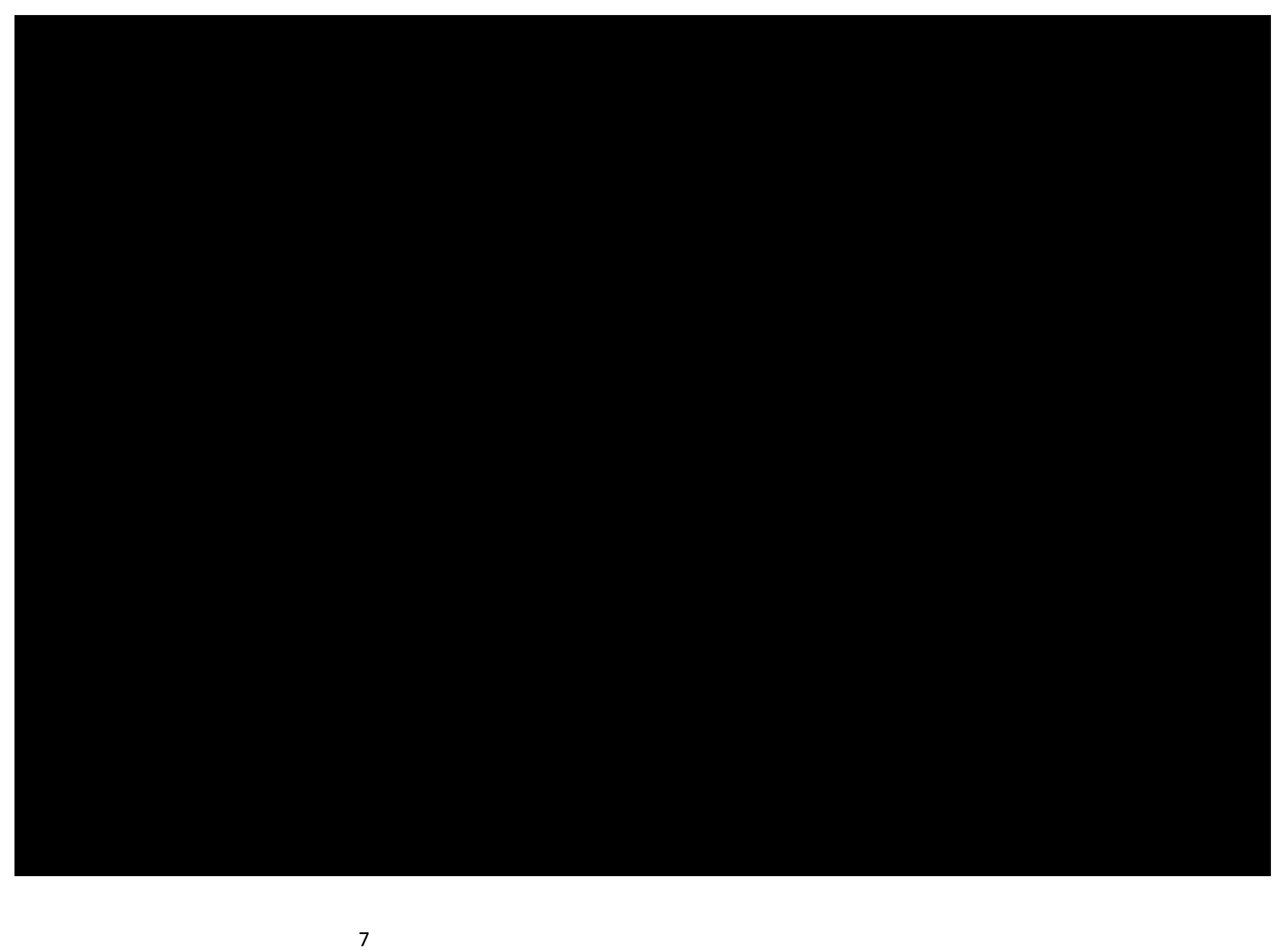


Figure 1.4 Petroleum system components diagram for the Taranaki Basin. To the left of the diagram is a chronostratigraph column. This column is linked with a cross section diagram displaying lithologies and their approximate distributions within the Taranaki Basin, along with associated sequence stratigraphy. A legend displaying lithology type is at the bottom of the image, along with a map displaying the orientation of the cross section. Timing of structural events and hydrocarbon maturity is shown to at the right of the image. The approximate location of the study area is shown with a red polygon. Adapted from Telford and Murray (2008).

\subsection{Petroleum Exploration in the Study Area - Past and}

\section{Present}

The study area has had no commercially viable petroleum discoveries to date, despite all elements of the petroleum system being theoretically present. No hydrocarbons appear to have escaped, as features (such as pockmarks) that are indicative of focused fluid escape at the seafloor appear not to be present in the study area, though this could be a further avenue of research. The study area is well explored with respect to seismic reflection data, with both historic 2D surveys of various vintages (1967 -1996) (Section 3.1), and the Parihaka and Toro 3D seismic reflection volumes of 2005 and 2007 respectively, which are tied to 4 exploration wells. A brief summary of each is detailed below.

Taimana-1 - A 4195 m exploration well by drilled by Diamond Shamrock Exploration Oil Co (NZ), completed in 1984. This well was found to be dry.

Witiora-1 - A 4229 m exploration well drilled by NZ Oil and Gas Ltd (NZOG), completed in 1984. This well had gas shows.

Okoki-1- A 4249.5 m exploration well drilled by TCPL Resources Ltd, completed in 1989. This well had oil shows

Arawa-1 - A 3055 m exploration well drilled by ARCO Petroleum NZ Inc, completed in 1992. This well had gas shows.

\subsection{Petroleum Exploration Permits in the Study Area}

The study area was part of two separate Petroleum Exploration Permits (PEP's). PEP 38488 for the Parihaka 3D area, and PEP 38489 for the Toro 3D area. Pogo Producing 
Company was awarded both of these permits during the 2003 New Zealand Petroleum and Minerals Block Offer process, and was the primary shareholder of both (New Zealand Petroleum and Minerals, 2014b). Pogo Producing Company relinquished both PEP's in Feb 2009 after failing to locate commercial quantities of hydrocarbons (McDouall Stuart Research, 2009). What was PEP 38488 was taken up again by various other joint ventures as PEP 51558, notably parties in this investment were Todd Energy, and New Zealand Oil and Gas as 50\% shareholders. During this time reprocessing of the Parihaka 3D survey was carried out (WesternGeco, 2012).

Currently the north western segment of the Parihaka 3D is being re-explored as part of PEP 57075. This permit has an area of $1,365 \mathrm{~km}^{2}$, and is part of a 12 year offshore permit owned by OMV New Zealand. OMV has a varied committed work plan for this permit, including geological studies, reprocessing 2D and 3D seismic data, reservoir quality, migration pathways and advanced seismic processing (New Zealand Petroleum and Minerals, 2014a). The remainder of the study area is currently under block offer.

\subsection{Existing Research on Normal Fault Evolution and the}

\section{Petroleum Systems of the Taranaki Basin}

Research into normal fault evolution as discussed in this study is summarised in Childs et al., (2003), with fault growth models theorised in Walsh and Watterson (1988a); Dawers et al. (1993); Walsh et al. (2002); Childs et al. (2003); Kim and Sanderson (2005); Soliva et al. (2005); Xu et al. (2005); Schlagenhauf et al. (2008); Childs et al. (2009). Recent research into North Island tectonics from Ballance (1976); Walcott (1987); King and Thrasher (1996); King (2000); Wallace et al. (2004); Stern et al. (2006); Nicol and Wallace (2007) is used to describe the geologic setting and tectonic background for this study. This is further supported by research into the geology and evolution of faulting in the Taranaki Basin by King and Thrasher (1996); Giba et al. (2010). Existing research into normal faulting in the Taranaki Basin is from Nicol et al. (2005); Giba et al. (2010); Giba et al. (2012); Reilly et al. (2015). The most recent research in the study area is that of Victoria University student Aaron Johnson, which looks into interactions between faults and channels within the Parihaka 3D seismic 
reflection volume (Johnston, 2014). This thesis incorporates some of the mapped time horizons developed in this study.

The majority of work undertaken in the study area specifically to date has focused on petroleum prospectivity, such as that of Diamond Shamrock Exploration Oil Co (NZ) (1984); NZ Oil \& Gas Ltd (1984b); Crowley and Crocker (1989); ARCO Petroleum (1992); Lovitz and Bates (2008a), with a summary of petroleum systems in the area presented in King and Thrasher (1996). Significant research into how fault activity relates to subduction processes has been carried out in the study area, such as that by Ballance (1976); Stern et al. (2006); Giba et al. (2010); Giba et al. (2012); Seebeck et al. (2014a). This research provides an understanding of large scale tectonic processes, which provides context for the development of the normal fault system. This work also includes an analysis of how a single major fault has evolved, using reasoning and methodology from Childs et al. (2003), which is applied to many more faults in this project. Childs et al. (2003), also developed a method for the analysis of fault growth based upon syn-sedimentary growth strata, a technique that is used in this thesis. This work is based on normal fault growth strata in the Timor Sea, a geologically similar setting to the Taranaki Basin in that it is currently a rift setting containing a population of normal faults that are inactive or becoming inactive.

Fault initiation and growth has been described by two competing models. The first of these is the isolated fault model of Walsh and Watterson (1988a), which suggests that faults form separately (hence isolated), and initiate as a "single, smooth continuous surface of displacement discontinuity, which becomes longer as the slip increases" (Kim \& Sanderson, 2005). This model suggests that as a volume of rock is subjected to increasing strain, a number of small distributed faults will begin to form. As strain continues to accrue, these small faults will grow in both displacement and length and eventually begin interacting and linking with similar nearby faults when their strain fields begin to overlap. These linked and intersecting faults then begin to preferentially accrue displacement at the expense of smaller faults due to their greater size. This process is thought to result in the creation of large localised faults, and the abandonment of small faults. 
The second model is the coherent fault model of Childs et al. (2009). This model proposes that "apparently individual fault segments are part of a larger and geometrically coherent underlying fault structure" (Giba et al., 2012). The model suggests that as strain is applied to the volume of rock, faults would initiate with low displacements but with lengths at or near maximum. This length would then either remain fixed or decrease with displacement until what started as many small displacement faults is now only a few large displacement faults that have accrued the majority of the strain in the volume. This model requires faults to have higher Displacement/Length ratios than the isolated fault model as fault displacement will develop more rapidly than fault length. The model does not differ from the end result of the isolated fault model (a small number of large displacement faults left), but differs in describing how an area gets to that stage.

Few studies investigate the cessation of slip on a fault (i.e., fault death). Jackson (1999) discusses fault death and proposes several reasons for faults becoming inactive. These include progressive fault rotation resulting in misorientation and frictional lockup, truncation of misoriented faults by new, more favourably oriented ones, and interactions between nearby faults whereby slip on one fault can inhibit or enhance slip on another (Jackson, 1999). Jackson (1999) concludes that "whether fault inactivity is permanent, temporary or episodic is not always clear, and so the causes of death are largely conjectural", and highlights one of the major uncertainties encountered studying fault death. Ways in which these hypotheses are tested are discussed in Section 3.3. The work of Jackson (1999) was limited at the time by lack of high quality data suitable for studying fault evolution - one of the main limitations of previous studies on the cessation of fault activity has been their low spatial and temporal resolution where the dating of cessation is poorly constrained.

This thesis also investigates the relationship between the maximum displacement and length of faults in the study area. The fault Displacement/Length relationship is considered to be directly related to the processes associated with fault growth and evolution through repeated earthquake cycles. Displacement/Length ratios have been extensively studied (e.g. Walsh and Watterson (1988a); Cowie and Scholz (1992); Dawers et al. (1993); Soliva et al. (2005); Xu et al. (2005)), with a review published in 
Kim and Sanderson (2005). One major issue with fault growth models that are evaluated using fault Displacement/Length ratios is that most combine data from different tectonic regimes and rock types. Between these studies, fault displacements and lengths often range over ten orders of magnitude. Few fault studies include data from the same area spanning more than three orders of magnitude of displacements and lengths due to scaling limitations imposed by types of data or observations. It is questionable how reliable combining data in this way is to developing robust Displacement/Length relationships (Kim \& Sanderson, 2005). This thesis is not going to resolve the order of magnitude issue with respect to Displacement/Length sampling; however, it will provide data to test existing fault Displacement/Length models over a range of two orders of magnitude of fault displacements and lengths (displacements from $1-1500 \mathrm{~m}$, lengths from $1-40 \mathrm{~km})$.

For the Parihaka 3D seismic reflection volume, seismic mapping and interpretation has been undertaken by Veritas Singapore (a summary of structure, lithology, key time horizons and their well ties, and faults can be found in Cohen et al. (2006). The Toro 3D seismic reflection volume has also been mapped and interpreted in the same manner as the Parihaka 3D by Veritas, with a summary document published in Morgans (2006a). These studies used similar 3D seismic mapping techniques to those employed in this thesis, but were from conducted an industry perspective and focused on locating viable oil and gas prospects. While faults were mapped, no research into their evolution was conducted. Biostratigraphic dating from the four available well ties used for creating time horizons is summarised in the work of Morgans (2006a). Well data is described in detail in petroleum reports PR1824 for Arawa-1, PR1495 for Okoki-1, PR1107 for Witiora-1, and PR1026 for Taimana-1.

In summary, this project will utilise methods described by Childs et al. (2003), and Giba et al. (2012) for the analysis of normal fault displacements and tip line behaviour within the Parihaka and Toro 3D seismic reflection volumes. Fault geometry and growth history data are used to describe the initiation, main growth phase, and fate of this evolving normal fault system. I will show how some faults initiated $\sim 11 \mathrm{Myr}$ ago are still potentially active at present. A comparison and evaluation of these data with two existing fault growth models will also be undertaken. 


\subsection{Goals - How Will This Thesis Improve Research?}

This thesis has been undertaken with the chief goal of understanding how normal faults evolve geometrically over time.

The main goals of this thesis can be summarized as follows:

- Map the geometry of new and reactivated normal faults in the study area.

- Map twelve time horizons constraining the main phases of fault development.

- Create displacement history plots to study fault geometric development.

- Compare fault displacement analysis to existing fault growth models.

- Discuss implications of fault geometric development for regional tectonics, the petroleum system, and generic models of fault growth and development.

The work of Cowie and Scholz (1992); Dawers et al. (1993); Jackson (1999); Meyer et al. (2002); Childs et al. (2003); Kim and Sanderson (2005); Childs et al. (2009); Giba et al. (2010) highlights many unanswered questions and points of uncertainty surrounding the topic of fault growth, such as: are fault lengths set instantaneously at initiation, or does length increase with increasing displacement?; does fault evolution follow a coherent or isolated fault growth model?; will all faults in a given population evolve in length and displacement in the same manner regardless of size?

The study area contains a population of high quality 3 dimensionally imaged faults within a continuous Cretaceous - Recent sedimentary sequence, with excellent seismic resolution in the Neogene - Recent section studied in this thesis. Sedimentation has kept pace with or exceeded fault displacement through the Late Miocene to Recent, allowing for high resolution analysis of growth faults. Normal faults have lengths and maximum displacements and lengths that range over two to three orders of magnitude ( 20 to $1500 \mathrm{~ms},<1$ to $>20$ kilometres, respectively). These factors indicate the study area has all the required elements to investigate questions surrounding the evolution of normal fault systems. 


\subsection{Thesis Structure}

The thesis is structured as a hybrid between a traditional thesis, and two semistandalone papers that are intended for journal submission. This introduces some repetition, as the two papers have their own introduction, geologic setting, data and methods, and conclusion sections, as does the overall thesis. For the sake of simplicity, a single reference list and appendix are used. The thesis is structured as follows:

Chapter 1 - Introduction: This chapter details the reasons for undertaking the study. The research objectives of the study are discussed, along with previous work related to both fault geometric evolution and petroleum geology. The study area is introduced, with an explanation of how it can help achieve the research objectives.

Chapter 2 - Geologic setting: This chapter provides the location of the study area. Local and regional geology are discussed, along with past and present Pacific Australian plate boundary kinematics.

Chapter 3 - Data and Methods: This chapter describes the seismic and well data used in this study. A discussion of how the data were used to inform questions about the evolution of a normal fault system is presented.

Chapter 4-Geometry of a Normal Fault System: This chapter discusses the observable geometric characteristics of faults in the study area. A discussion of the spatiotemporal distribution of faulting in the study area is also presented, and the data compared with existing New Zealand plate tectonics models.

Chapter 5 - Evolution of a Normal Fault System: This chapter discusses existing models of fault growth in displacement and length. A discussion of fault tip line evolution and fault Displacement/Length plots for time horizons between 11 - $0 \mathrm{Ma}$, as well as different fault types is presented. The data are compared with existing fault growth models, along with existing New Zealand plate tectonics models

Chapter 6 - Conclusions: This chapter discusses and summarises the results of the previous chapters. 


\subsection{Nomenclature}

3D seismic reflection volume: $A$ volume of closely spaced $(12.5 \mathrm{~m}$ in the case of the Parihaka and Toro 3D seismic reflection surveys) seismic reflection lines that are converted using seismic processing techniques (based on survey parameters such as inline spacing, fold, source and receiver spacing) into a 3 dimensional data volume. This volume can then be "sliced" and viewed at any orientation.

Inline: Seismic line making up part of a 3D survey that is parallel to (or in-line with) the data acquisition direction. Inlines that make up 3D marine seismic are seismic lines directly corresponding to the direction in which the survey vessel was travelling while gathering data.

Crossline: Seismic line making up part of a 3D survey that is perpendicular to the data acquisition direction. Crosslines are not actually directly acquired, but are extrapolated from closely spaced inlines.

Seismic section: 2D image of seismic data, usually looking at an inline or crossline in the vertical plane (essentially the same as a geological cross section). In a 3D seismic volume a seismic section can be taken in any direction.

Paradigm SeisEarth: Industry standard 3D seismic interpretation software package used for seismic interpretation and mapping. Created by Paradigm ${ }^{\circledR}$.

TrapTester 6: Industry standard 3D seismic interpretation and fault analysis software package. TrapTester allows for automated extraction of fault dimensions and an extensive range of fault attributes from interpreted 3D seismic data. TrapTester is produced by Badleys Geoscience Itd.

3D Canvas: Component of Paradigm SeisEarth that allows interpretation data to be viewed and modified in three dimensions.

Volume Editor: Component of TrapTester similar to Paradigm's 3D canvas, that allows interpretation data to be viewed and modified in three dimensions. 
Seismic coherency: "Coherence is a measure of similarity between waveforms or traces". (Chopra \& Marfurt, 2007). A typical seismic section displays seismic waveforms that are the response of a seismic wavelet convolved with subsurface geology. These waveforms vary laterally (in amplitude, frequency, and phase) because of varying acoustic impedance contrasts above and below the reflecting boundary. Acoustic impedance contrasts are in turn governed by the characteristics of the strata in which they are measured in (Chopra \& Marfurt, 2007). Lateral changes in strata (such as faults or channels) will lead to lateral changes in impedance contrast, and hence lateral changes in waveforms and traces. Since coherence is a measure of the similarity between waveforms or traces, it can be used to observe lateral changes in strata, such as faults and channels.

Time slice: Map view of a 3D seismic coherency cube, showing the seismic reflections present on every trace in a 3D volume at a given depth in TWTT.

Syn - sedimentary growth strata: Strata that form when sedimentation rates are equal to or greater than the throw displacement rate of a fault. Growth strata will appear thicker on the downthrown side of a normal fault. Assuming constant sedimentation rates, the onset of growth strata can be used to approximate timing of fault

initiation. 


\section{Chapter 2 Geologic setting}

\subsection{Introduction}

The Taranaki Basin is on the west coast of New Zealand's North Island, covering an area of approximately $100,000 \mathrm{~km}^{2}$ (King \& Thrasher, 1996; Wood et al., 1996). The basin has a multiphase history dominated by subduction and passive margin processes (King \& Thrasher, 1996; Giba et al., 2010). The basin was developed from the Late Cretaceous in association with the breakup of Gondwana and the opening of the Tasman Sea. Since that time, the basin has experienced a transgressive passive margin phase which culminated in the Late Eocene - Early Oligocene. Since the Early Miocene, subduction processes have dominated the sedimentary and structural evolution of the basin (King \& Thrasher, 1996; Stagpoole \& Nicol, 2008; Giba et al., 2010; Bache et al., 2012).

\subsection{Geologic Setting}

New Zealand is tectonically active, sitting astride the Pacific - Australian plate boundary (Fig. 2.1). The way in which the Pacific and Australian plates interact changes from north to south. To the north, the Pacific Plate subducts westward beneath the Australian plate along the Tonga-Kermadec Trench. The Tonga-Kermadec subduction zone continues southward through to the Hikurangi Trough, off the East Coast of New Zealand's North Island where subduction ceases near the Chatham Rise. There the plate boundary changes southward from subduction to strike-slip and transpression along the Marlborough and Alpine Fault systems in the South Island. In the south west of the South Island, the plate boundary transitions back to subduction, where the Australian Plate subducts eastward beneath the Pacific plate along the Puysegur Trench (King \& Thrasher, 1996). 

components of New Zealand and its plate boundary are shown. Plate convergence rates relative to a fixed Australian Plate are given in $\mathrm{mm} / \mathrm{yr}$ are displayed. Stars represent locations of volcanic activity. From Bradley and Cubrinovski (2011).

\subsection{Present Day New Zealand Plate Kinematics}

Present day relative plate motion between the Pacific and Australian plates along the Hikurangi Margin is approximately $40 \mathrm{~mm} / \mathrm{yr}$ westward with respect to a fixed Australian Plate (Wallace et al., 2004). Convergence rates vary along strike of the plate boundary, ranging from the Pacific Plate subducting westward beneath the Australian Plate at 41 - $48 \mathrm{~mm} / \mathrm{yr}$ along the Hikurangi Trough as described in Wallace et al. (2004), 
to the Australian Plate subducting eastward beneath the Pacific Plate at $30-35 \mathrm{~mm} / \mathrm{yr}$ along the Puyseger subduction system as described in Walcott (1987) (Fig. 2.1). Wallace et al. (2004) suggest that southward thickening of the subducting Hikurangi Plateau leads to the Pacific Plate transitioning to unsubductable continental crust at the southern extremity of the Hikurangi Trough (Chatham Rise) seen in Figure 2.1. At this zone, strain is accommodated through rotation and strike slip faulting of the overriding continental crust of the Australian plate. This rotation is accommodated on tectonic blocks with varied rotation rates and Euler pole locations as discussed in Walcott (1987); Wallace et al. (2004) (Figs. 2.2 -2.3).

Figure 2.2 Maps displaying New Zealand's Miocene Euler pole and associated rotation rate. The Miocene rotation of the North Island relative to a fixed Australian Plate is given in (a), with a zoomed version showing rates of rotation and magnitudes extension in the central and southern Taranaki Basin shown in (b). The Northern Graben area is seen to have experienced 2-3 km of extension during the Miocene. From Walcott (1987). 


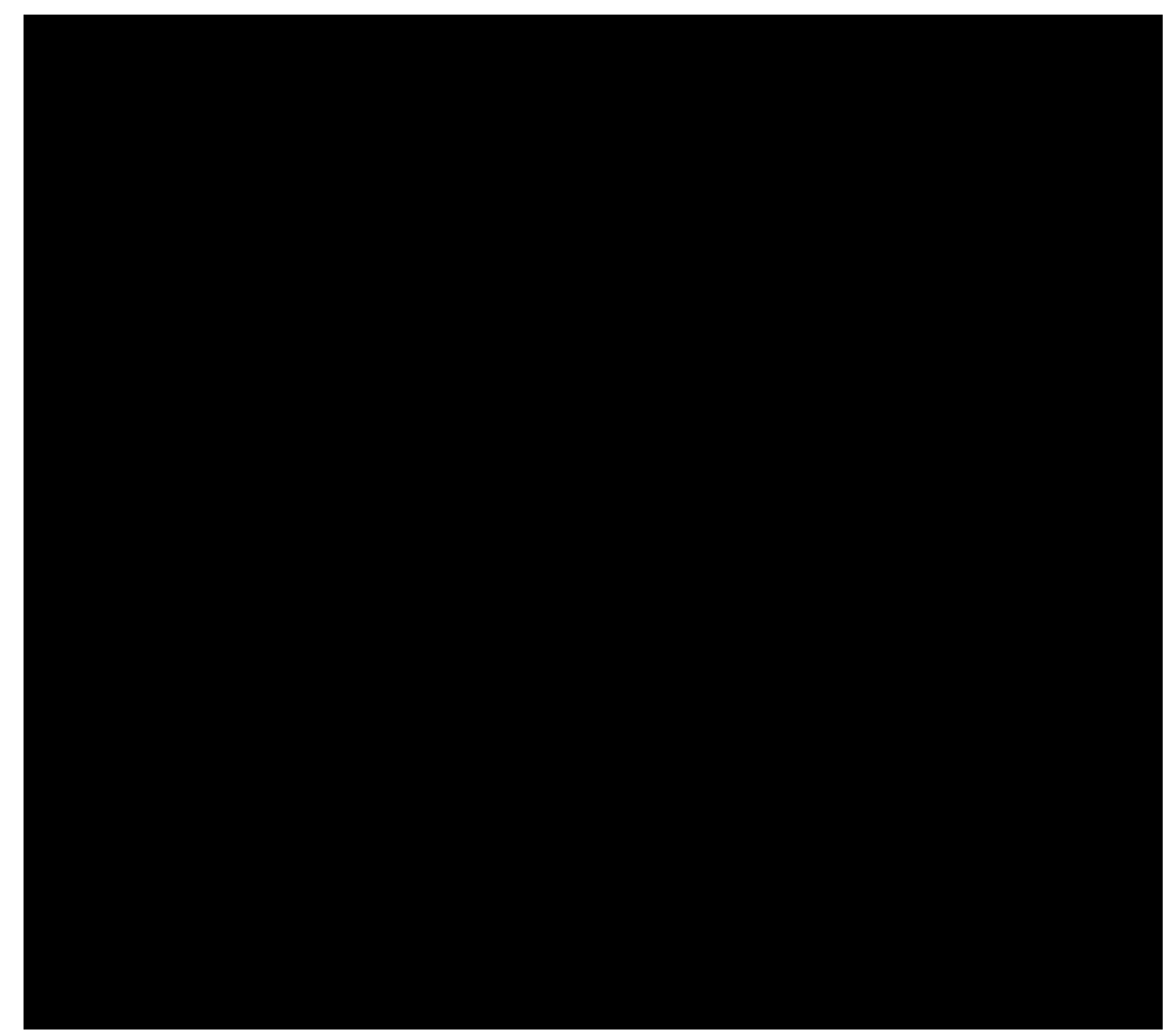

Figure 2.3 Images displaying the kinematics of the block rotation model for New Zealand's North Island. Figures display (a) Decades of GPS velocity field data for the North Island, relative to a fixed Australian Plate. (b) Rotations of a series of tectonic blocks relative to the Australian Plate. Euler poles for each tectonic block relative to a fixed Australian Plate are shown with rotation rates in deg/Myr. (c) A diagram summarising the block rotation model for the North Island. The thick, buoyant continental crust at the Chatham Rise is believed to slow subduction of the Pacific Plate in the southern Hikurangi Margin compared to the north, which is thin oceanic crust and able to subduct relatively easily. This applies a torque to the eastern North Island, causing it and the Hikurangi Trench subduction zone to rotate clockwise relative to the Australian Plate. From Wallace et al. (2004).

\subsection{Taranaki Basin Development}

The Taranaki basin has been formed through three main stages of tectonic development (King \& Thrasher, 1996). The first of these was a late Cretaceous to Paleocene intra-continental rift. This period of basin development was characterized by limited sedimentation in restricted, normal fault controlled basins. Plate kinematics involved extensional tectonics and thermal subsidence associated with spreading of the Tasman Sea and the breakup of Eastern Gondwana. The basin is considered to still 
have been part of the Pacific Plate during this period. The second stage of basin development was a Paleocene to Eocene passive margin. This period of basin development was characterized by post rift thermal subsidence typically associated with a passive margin. This tectonic quiescence created steady basin wide marine transgression, and peneplanation of the adjacent hinterland. The third phase of basin development is an Eocene to Recent active marginal basin. This period of basin development was characterized by the basin being on the outer limit of broad scale deformation associated with the re-establishment of subduction along the Pacific Australian plate boundary. With the development of the Alpine Fault in the Early Miocene, the basin evolved regions of both active normal and reverse faulting to the west, along with tectonic quiescence and passive margin subsidence to the east (King \& Thrasher, 1996). The following section (2.4.1) defines these structural components in more detail.

\subsubsection{Taranaki Basin Structural Components}

The Taranaki Basin has two first order structural zones - The Eastern Mobile Belt, and the Western Stable Platform (King \& Thrasher, 1996), see Figure 2.4. These are described further in Sections 2.4.2 - 2.4.3.

\subsubsection{Western Stable Platform}

The Western Stable Platform has been largely undeformed during the formation of the present day Pacific - Australian plate boundary, and is geologically simple. It has been characterised by tectonic quiescence since its development in the Late Cretaceous. It contains between 2000 - 8000 m of Late Cretaceous - Recent sediment, with textbook examples of both transgressive and regressive depositional settings (King \& Thrasher, 1996).

\subsubsection{Eastern Mobile Belt}

The Eastern Mobile Belt (EMB) is a structurally complex region that has undergone multiple phases of deformation since the Late Cretaceous. It is comprised of a series of interconnected sub-basins, which are attributed to both Cretaceous and Neogene 


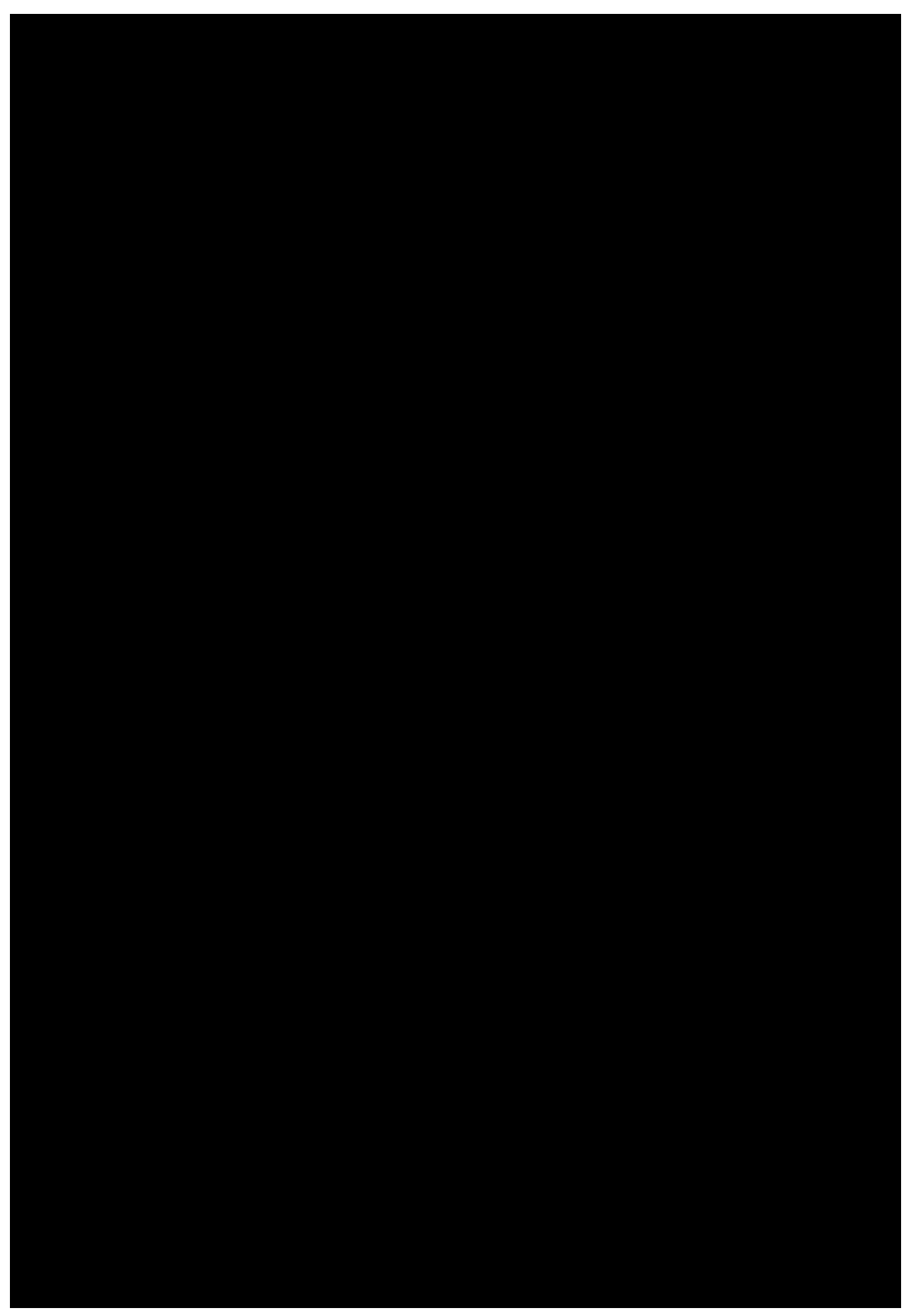

Figure 2.4 Map displaying the location of major structural components of the Taranaki Basin in map view. . The locations of the andesitic Miocene arc volcanoes of the Mohakatino Volcanic Complex are included (dotted polygons). The Parihaka and Toro 3D seismic reflection surveys are shown by green and red polygons, respectively. Three main zones of tectonic activity described in Reilly et al. (2015) are surrounded by coloured polygons. Adapted from King and Thrasher (1996). 
extension and Neogene contraction. The EMB is bounded to the east by the Taranaki Fault - a large basement reverse fault. The geometry of reverse and extensional faulting during the Neogene was strongly influenced by Late Cretaceous rift faults reactivated during the formation of the transpressional Alpine Fault component of New Zealand's plate boundary in the Early Miocene (King \& Thrasher, 1996).

The EMB is further subdivided into three regions (northern, central, and southern) that have differed in their tectonic style over time (Fig. 2.4). The northern EMB region has been predominantly extensional in nature, and contains the northern (focus of this study) and central grabens of the Taranaki Basin. The central and southern EMB regions have a complicated tectonic history. The central EMB region has experienced Late Cretaceous extension, followed by Miocene contraction, and finally Late MioceneNeogene extension. The southern EMB region (Southern Inversion Zone) experienced Late Cretaceous extension, followed by Miocene - Neogene contraction. The extreme south of the Southern Inversion Zone is still being subjected to compression (King \& Thrasher, 1996).

\subsubsection{Northern Graben}

The Northern Graben is one of the sub-basins of the Taranaki Basin. It is a $40-50 \mathrm{~km}$ wide graben situated to the north west of the Taranaki Peninsula (Fig. 2.4). The Northern Graben is bounded to the west by the Cape Egmont Fault Zone, and to the east by the Turi Fault Zone (Fig. 2.4). These two fault zones strike NNE, and NE, respectively, and intersect at the southern limit of the graben. The Cape Egmont Fault Zone comprises large, sub-parallel normal faults with a primarily eastward dip direction. The Turi Fault Zone comprises large, sub-parallel normal faults with a primarily northwest dip direction (King \& Thrasher, 1996). The Cape Egmont Fault Zone has been subject to extensive post Mid-Late Miocene extension related subsidence, which appears to be still active today (see Section 4.4). As a result of tectonic subsidence, the graben has remained $\sim 500-1000 \mathrm{~m}$ deeper than the rest of the Taranaki Basin, and experienced more rapid sedimentation. Total sediment thickness is $\sim 9 \mathrm{~km}$ at the deepest point in the graben (King \& Thrasher, 1996). Fault throw displacement rates in the Northern Graben during the Late Miocene - Pliocene has 
been $\sim 0.16 \mathrm{~mm} / \mathrm{yr}$. Sedimentation rates through the same period have been $~$ $0.6 \mathrm{~mm} / \mathrm{yr}$ (King \& Thrasher, 1996).

\subsubsection{Taranaki Basin Tectonic and Stratigraphic Summary}

The Taranaki Rift System initiated in the late Cretaceous (c $85 \mathrm{Ma}$ ), when the New Zealand region was still part of the Gondwana Subduction Margin (King \& Thrasher, 1996). The rift system was a series of north and northeast striking normal faults that formed a series of sub-basins, which were associated with development of the Tasman Sea (King \& Thrasher, 1996; Wood et al., 1996). These sub-basins were filled with the terrestrial organic syn-rift sediments (Figs. 1.4, 2.5), which host the majority of hydrocarbons produced in New Zealand today.

As opening of the Tasman Sea during the Paleocene slowed, the Taranaki Basin developed as a passive margin experiencing slow thermal subsidence (King, 2000). Subsidence caused sedimentation to become transgressive, and led to the deposition of predominantly fluvial sandstones, coastal and marginal marine sandstones, and terrestrial and marginal marine sandstones. In some places, these have been named the Farewell, Kaimiro, and Mangahewa Formations, respectively. Elsewhere, similar units with other names are present as can be seen in Figures. 1.4 and 2.5 (King \& Thrasher, 1996).

During the Early Oligocene ( $33 \mathrm{Ma})$ the deposition of marginal marine sediments terminated in the majority of the Taranaki Basin. Passive margin subsidence in the basin slowed, and terrestrial sediment supply waned during the lead up to Oligocene glacial period. This period of reduced sedimentation led to the regional unconformity visible in Figures 1.4 and 2.5. During the Oligocene, there followed an abrupt change in Taranaki Basin sedimentation as the Pacific - Australian subduction zone began to develop to the east of New Zealand, along with the Taranaki Thrust Fault (Wood et al., 1996). The Taranaki Basin subsided to bathyal depths, facilitating deposition of the Oligocene Tikorangi Limestone Formation (limestone was commonly deposited around much of New Zealand at this time). 
The end of Tikorangi Formation deposition was brought about by newly convergent margin conditions that led to the creation of a fold - thrust belt in Taranaki, and increased uplift in the Taranaki Basin (King et al., 2013). In the Late Miocene, clockwise rotation of the North Island relative to the Australian Plate initiated as a result of retarded subduction of thick continental crust near the Chatham Rise. This rotation of the North Island relative to the Australian Plate resulted in extension of continental crust in the North Island, and initiation of intra-arc rifting in the Taranaki Basin. This intra-arc rifting caused a renewal of Taranaki Basin subsidence. Sedimentary deposits in the Taranaki Basin from the Late Miocene are as a result broadly regressive in nature. These sediments include the basin floor turbidite deposits of the Moki formation, and the basin and slope fan turbidites of the Mt Messenger Formation. Intra-arc rifting in the Taranaki Basin also allowed the formation of Miocene andesitic arc volcanics from $16 \mathrm{Ma}$.

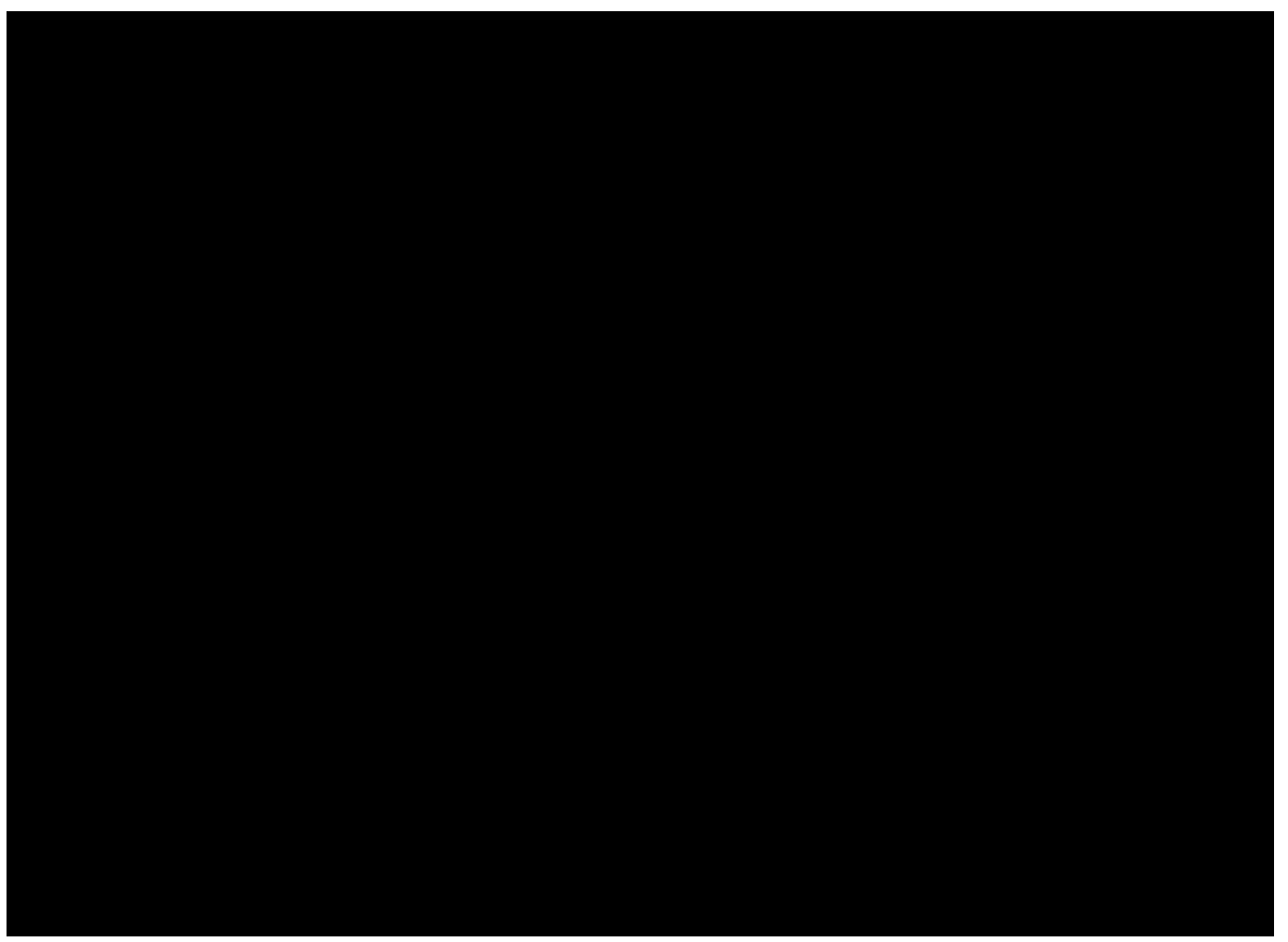

Figure 2.5 Stratigraphic summary of the Taranaki Basin. Chronostratigraphic column displaying major Taranaki basin sedimentary packages and their ages. A facies association diagram is given to the right of the image. Hydrocarbon occurrences are organised by both the formation and well in which they occur. From King and Thrasher (1996). 


\subsection{North Island Miocene Arc Volcanism}

The evolution of volcanic arcs in the North Island provides important constraints on the large scale geometry of the subduction system generating magmas with arc affinities. Volcanic arcs generally form parallel to the strike of the underlying slab, where migration or change in strike of progressively younger volcanism indicate a change in the dip and/or strike of the subducting slab (Syracuse \& Abers, 2006). As such, if the volcanoes in the Taranaki Basin proximal to the study area are arc related, their age and distribution should offer insights into past subduction geometry.

Along the western margin of the Northern Graben are the Mohakatino Volcanic Centres (Fig. 2.4). These volcanic centres are a NNW trending, linear series of twenty submarine volcanoes and volcanic intrusions. Seismic stratigraphy and radiometric dating indicate the majority of the volcanism occurred between 14 and 11 Ma (Giba et al., 2013). Minor volcanism continued after this period, with the last known eruptive event (excluding Mt Taranaki) occurring between 8 and 7 Ma. Volcanism has migrated southward at $4-18 \mathrm{~mm} / \mathrm{yr}$ since it began at $16 \mathrm{Ma}$ (King \& Thrasher, 1996).

Based on modelling of aeromagnetic data constrained by isostatic gravity and seismic reflection surveys, Hatherton et al. (1979) suggest the Mohakatino volcanic centres in offshore Taranaki have large intrusive bodies beneath them, up to ten times more voluminous than those known to exist beneath active arc volcanoes (Taranaki and Ruapehu) further to the east, suggesting a separate origin. However, drill samples from Kora, a long-lived (19-8 Ma) submarine stratovolcano on the western margin of the Northern Graben indicate geochemistry consistent with arc-related volcanism (Bergmann, 1991). The origin of the Mohakatino volcanic centres is presently debated with geophysical models inferring volcanism in this area is the result of decompression melting associated with mantle instabilities (Stern et al., 2006; Stern et al., 2013). Alternately, geochemical evidence suggests a subduction-related source (Bergmann, 1991; Price et al., 2005; Giba et al., 2013).

The study area contains at least three intrusive volcanic complexes. The largest of these is located roughly in the centre of the Parihaka 3D survey, and has been called 
the Southern Intrusive Complex by Johnston (2014). This complex has never been subaerial, and its intrusion through $\sim 8 \mathrm{~km}$ of Miocene - Pliocene strata has created synclines both to the east and west of the complex (Figs. A.5 - A.10). Mapping of the intrusion during this thesis uncovered no major throughgoing faults. Minor faults were mapped within the top $\sim 500 \mathrm{~m}$ of the complex, with their high frequency and localisation suggesting that they are caused by gravitational collapse of the volcanic complex rather than by extensional tectonics as discussed in Section 4 (Giba et al., 2010).

\subsubsection{North Island Miocene Volcanic Arc Migration}

The strike of two well defined volcanic arcs volcanic arcs through the North Island over the past 20 Myr places first-order constraints on the geometry of the subduction system along the Hikurangi margin. These are the Colville - Coromandel arc, and the Kermadec - Taupo Volcanic Zone arc. The Colville - Coromandel arc is correlated in both space and time with the $18-4 \mathrm{Ma}$ Mohakatino volcanic centres in the Taranaki Basin as described in Giba et al. (2010). The Kermadec - Taupo Volcanic Zone arc which runs into the central North Island is younger, only being active within the past $2 \mathrm{Myr}$ (Brothers, 1984; Seebeck et al., 2014a). These volcanic arcs are broadly parallel through the North Island at a strike of $\sim 040^{\circ}$ (Fig. 2.6). The arcs are separated by $\sim 150$ $\mathrm{km}$ and $\sim 4$ - 8 Myrs, indicating that the subducting slab has experienced change in dip but not in strike over this period (Brothers, 1984; Syracuse \& Abers, 2006; Seebeck et al., 2014a).

Several models have been proposed to account for apparent trends of volcanic centres over time. From the distribution of low-potash volcanic centres in the central North Island, Stern (1987) proposed a $25^{\circ}$ clockwise rotation of the volcanic arc over the last 4 Myrs ( $>6^{\circ} / \mathrm{Myr}$ ). This is supported by forearc depositional and paleomagnetic data indicating that the southern and central sections of the Hikurangi forearc have rotated $\geq 50^{\circ}$ over the last $25 \mathrm{Myr}$ (rates of 7-8 ${ }^{\circ}$ over the last $10 \mathrm{Myr}$ ) (Cole \& Lewis, 1981; Walcott, 1987; Mumme et al., 1989; Lamb, 2011). Present GPS derived estimates for rotation of the forearc indicate rotation rates less than half than those proposed from paleomagentic studies ( $3^{\circ} / \mathrm{Myr}$ ) (Wallace et al., 2004). Strain gradients across the 
North Island indicate that rotation of the forearc is not uniform and decreases west towards the Taranaki Basin (Walcott, 1987; Wallace et al., 2004; Nicol \& Wallace, 2007). In contrast, paleomagnetic data from the northern Hikurangi Margin show no significant rotation over the last 20 Myr with respect to the Australian Plate and the Western Stable Platform (Mumme et al., 1989).

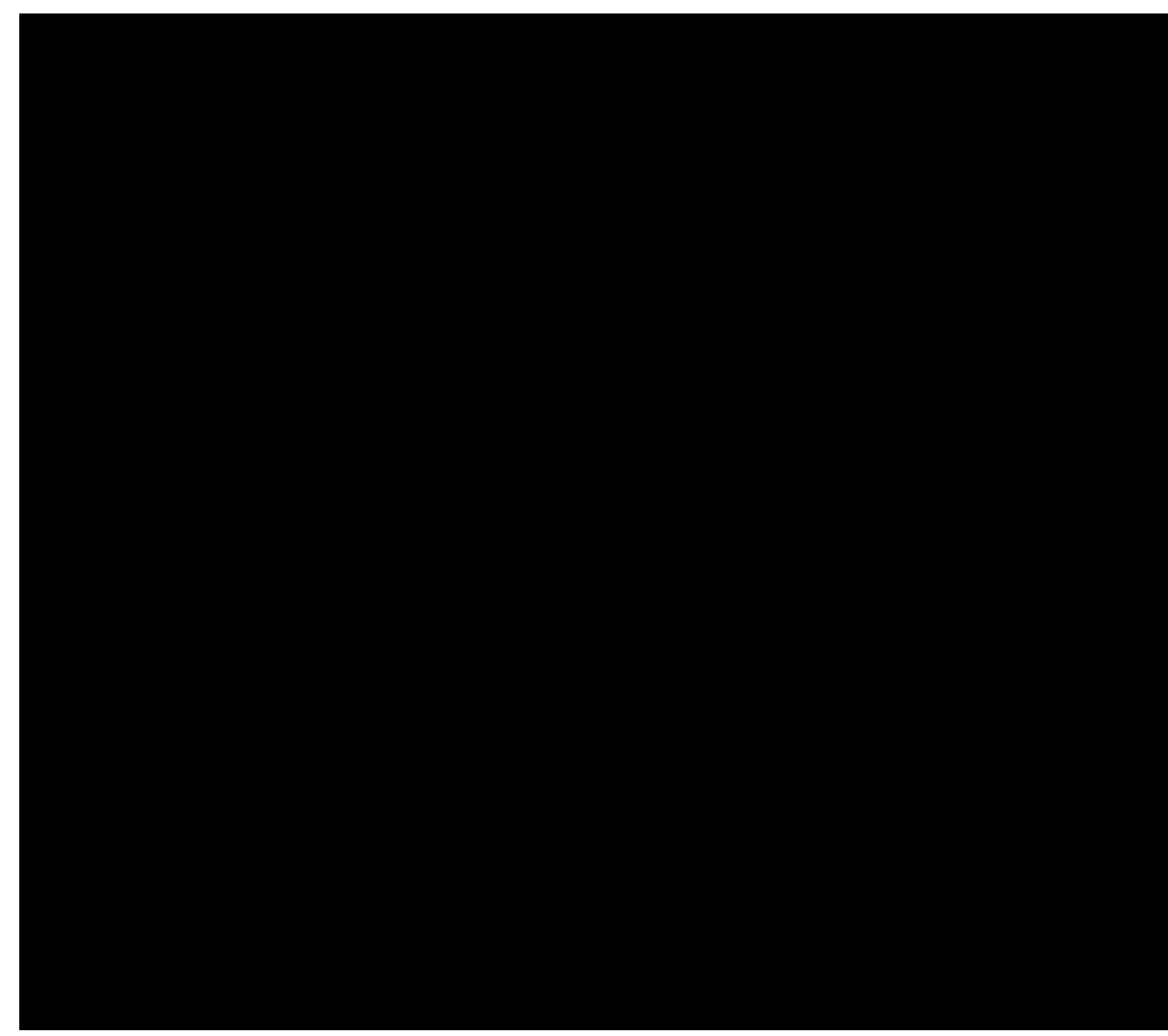

Figure 2.6 Map of volcanic arc migration eastward across New Zealand's North Island. The locations of the two main volcanic arcs through New Zealand's North Island are shown. White dots represent volcanoes formed at $\sim 18 \mathrm{Ma}$, grey dots represent volcanoes formed at $\sim 8 \mathrm{Ma}$, and black dots represent volcanoes formed within the past 1 Myr. The Colville-Kermadec arc has both 16 and 8 Ma components within the Taranaki Basin. Adapted from Seebeck et al. (2014a).

\subsubsection{North Island Volcanic Arc Migration - Slab Rollback}

The absence of a significant paleomagnetic rotation in the northern Hikurangi margin raises questions about the rotation of the forearc east of the Taupo Volcanic Zone. The broadly uniform strike of volcanic arcs through the Taranaki Basin-Taupo Volcanic Zone through to the Coleville-Kermadec Ridges over the $16 \mathrm{Myr}$, coupled with tomographic images of the subducting slab at depth, led Seebeck et al. (2014a) to propose that the strike of the subducting slab has not changed significantly over this time (Fig. 2.7). 
Early models using fewer data than the Seebeck et al. (2014a) study also suggested the trends of volcanic arcs through the North Island (and therefore the strike of the subducting slab) have not changed significantly over the last 20 Ma (e.g. Brothers (1984); Kamp (1984)).

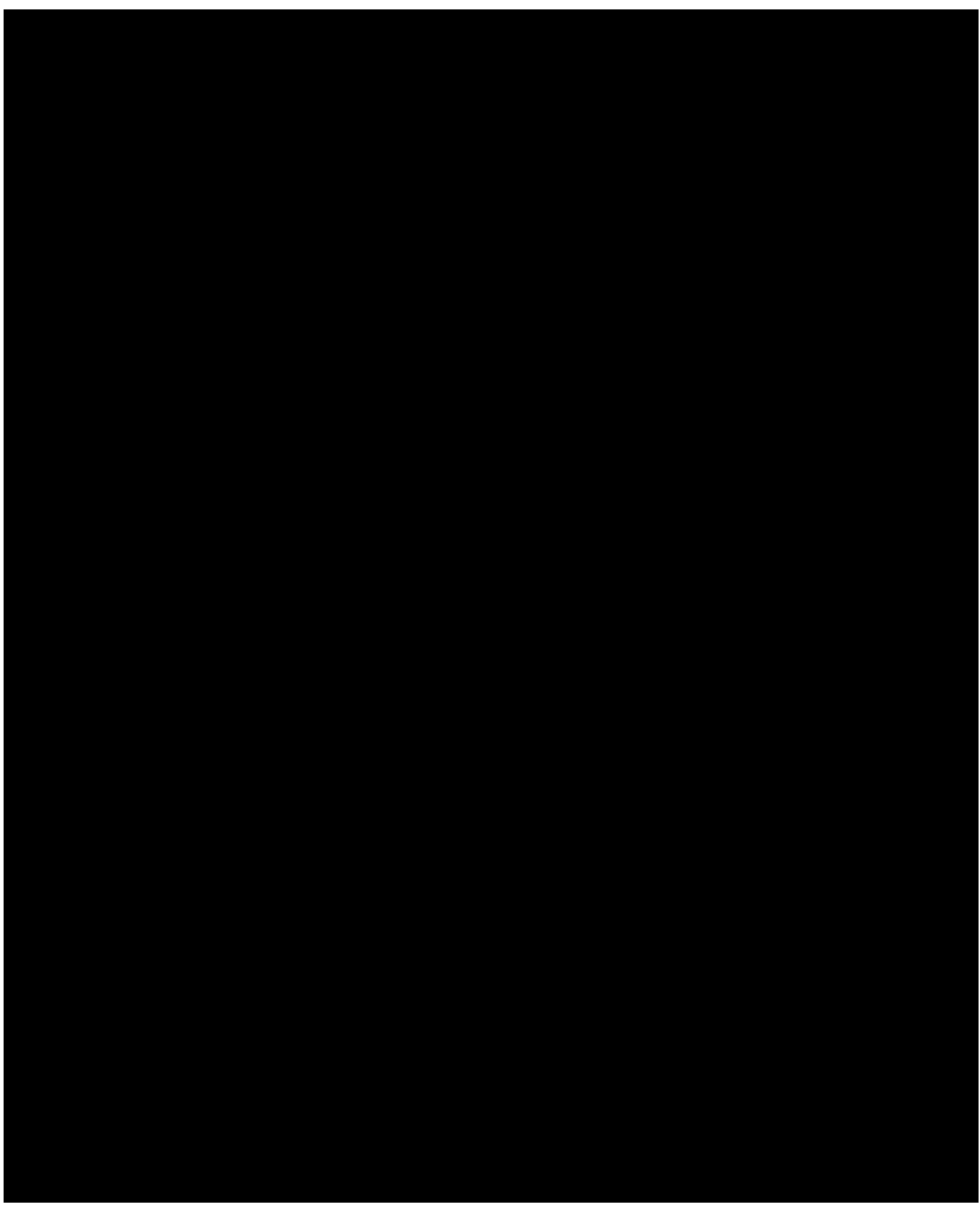

Figure 2.7 Map and cross sections of volcanic arc migration eastward across New Zealand's North Island. Locations of active arc volcanism in the North Island at 16, 8, and $0 \mathrm{Ma}$ are displayed in both map and cross section view. In map view, white dots represent volcanoes formed at 18 Ma, grey dots represent volcanoes formed at $8 \mathrm{Ma}$, and black dots represent volcanoes formed within the past 1 Myr. The grey shaded polygon on each map represents the lower limit of Benioff zone seismicity unfolded to its horizontal extent. In section view, active arc volcanism is displayed in red, and extinct arc volcanism is displayed in black. Adapted from Seebeck et al. (2014a). 
The broadly parallel southeast migration of the volcanic arcs over the past $16 \mathrm{Ma}$ has been explained by rollback of the subduction hinge in Ballance (1976), whereby the hinge point of the subducting slab migrates seaward as in Figure 2.7 (slab rollback model of Brothers (1984). Slab rollback combined with a synchronous steepening of the subducting slab are theorised to account for the majority of separation between the Colville and Kermadec arcs as seen in Figure 2.7 (Brothers, 1984; Seebeck et al., 2014a).

\subsubsection{North Island Volcanic Arc Migration - Mantle Instability}

An alternative model to slab rollback is that the initiation and migration of volcanism has been governed by Rayleigh - Taylor instabilities in the mantle beneath the North Island (Stern et al., 2006). Extensional basin development and offshore igneous volcanism in North Taranaki is postulated to occur as a response to thickened mantle lithosphere breaking off and descending into the lower density asthenosphere. This deformation of the mantle will progressively thicken and thin the overlying crust (Fig. 2.8), which the numerical modelling work of Stern et al. (2013) suggests has manifested as a 'topographic wave' (wavelength $\sim 250 \mathrm{~km}$, amplitude $\pm \sim 1 \mathrm{~km}$ ) which has propagated southward at $\sim 30 \mathrm{~mm} / \mathrm{yr}$ over the past $12 \mathrm{Myr}$ coeval with removal of mantle lithosphere. These instabilities are thought to first develop between 15-5 Ma in response to Miocene crustal thickening in the Taranaki Fault Zone.

Based on locations of low-potash andesitic volcanism in the Taupo Volcanic Zone associated with the $80-100 \mathrm{~km}$ contour of Benioff zones as described in England et al. (2004) (Fig. 2.9), Stern et al. (2006) suggest that instead of arc volcanism migrating southeast approximately parallel to the present trend as in Figures 2.6 and 2.7, that the trend of arc volcanism has rotated clockwise $\sim 25-30^{\circ}$ with respect to the Australian Plate over the past $4 \mathrm{Ma}$ at rates of $6.25^{\circ}-7.5^{\circ} / \mathrm{Myr}$ (Fig.2.9). Implicit in this research is that the apparent rotation of low-potash volcanism trends reflects a rotation of the rotation of the $80-100 \mathrm{~km}$ contour of the Benioff zone beneath New Zealand, hence the rotation of the entire subduction system beneath New Zealand, including the subducting slab. 
The difference between these tectonic models relates to subduction geometry and the response of the Hikurangi forearc to the changing boundary conditions associated with oblique convergence. In the mantle instability and rotating arc model, changes in the strike of the subducting slab induce complementary changes in the overriding crust and trend of the volcanic arc. In the roll-back model, the dip of the slab increases while the strike remains the same. This model requires that parts of the forearc rotate relative to the strike of the subducting slab. In the model of (Seebeck et al., 2014a) this would require the $\geq 50^{\circ}$ rotation of parts of the Hikurangi forearc to be accommodated by interplate slip on the subduction interface.

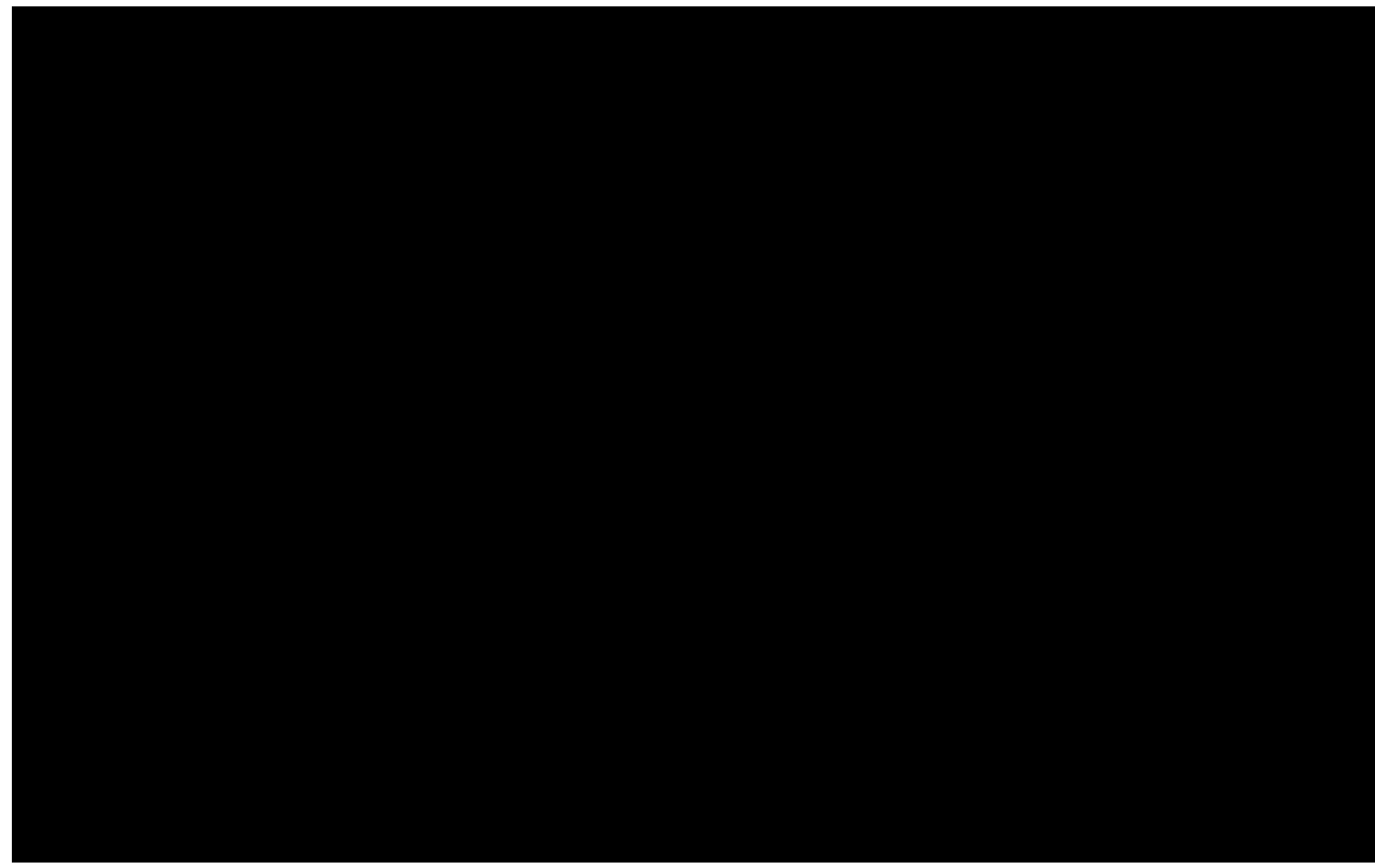

Figure 2.8 Diagram of the Rayleigh-Taylor mantle instability model. Three images display the three stages of a developing Rayleigh-Taylor mantle instability that is theorised to exist beneath the western-central North Island. The profile is oriented west - east. From left to right, the images show (a) Lithospheric thickening by horizontal shortening between $25-5 \mathrm{Ma}$, (b) Convective thinning of mantle lithosphere by the Rayleigh-Taylor instability between $10-5 \mathrm{Ma}$ (c) Release and subsidence of the Rayleigh-Taylor instability at $\sim 5 \mathrm{Ma}$. Each section is annotated with geologic events observed in the western-central North Island at that time. From Stern et al. (2006). 


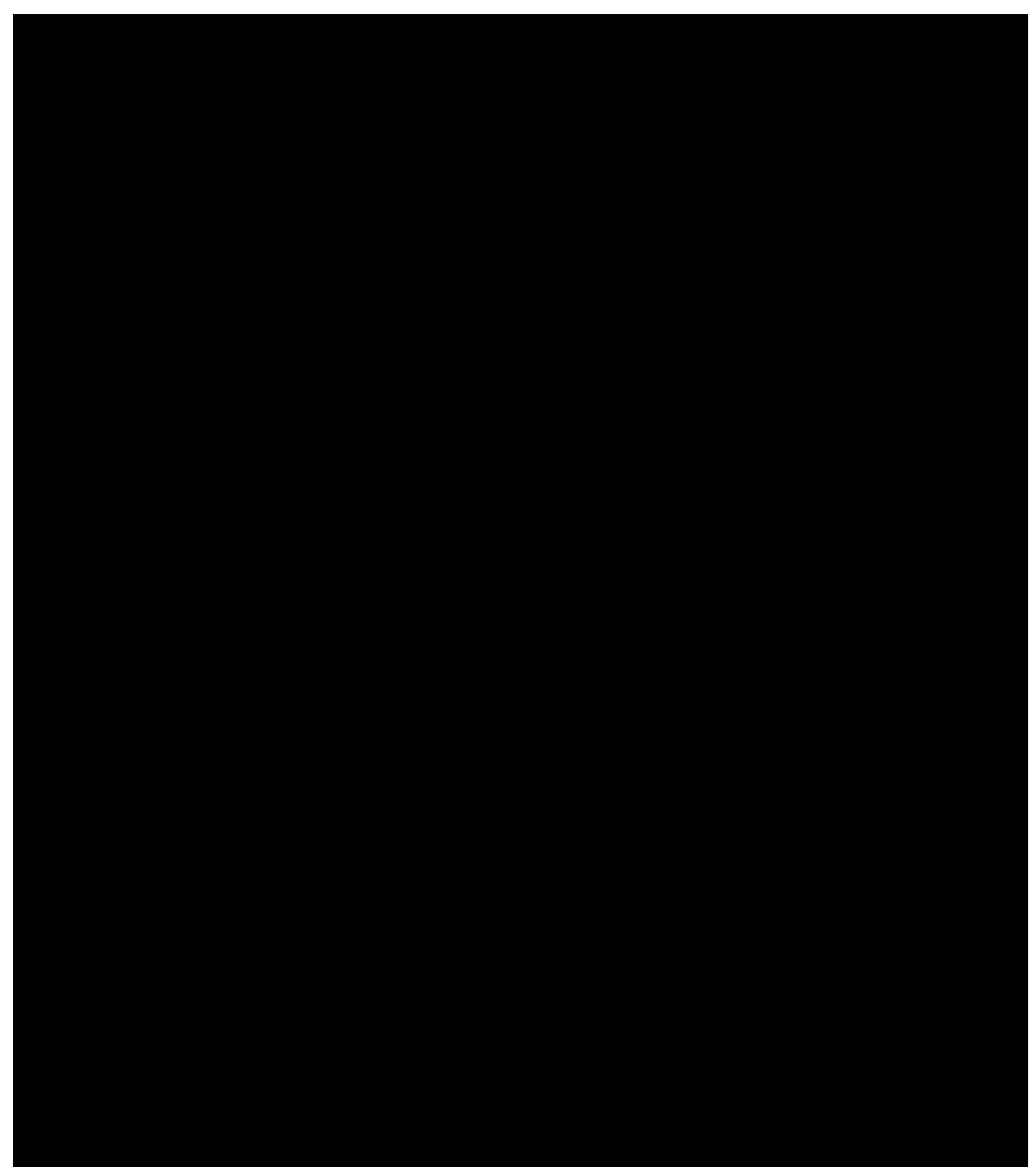

Figure 2.9 Maps displaying apparent rotation of arc volcanism in the North Island. Images show in (a) Positions and ages of high and low-potash andesites in the central North Island. Low-potash andesites occur above the 80-100 km contour of Benioff zones. Margins of error are given, along with the number of samples used for dating. (b) Interpretations of 4, 2, and $0 \mathrm{Ma}$ arcs based on low-potash andesites alone. A pole of rotation for these arcs is shown. Figure from Stern et al. (2006). 


\section{Chapter 3 Data and Methods}

\subsection{Seismic Data in the Study Area}

All mineral and oil exploration data collected within New Zealand are available to the public after 5 years under normal circumstances. Data are made available via the New Zealand Petroleum and Minerals GOLD database. The Parihaka and Toro 3D volumes used in this thesis were retrieved from this database in SEGY format, along with the petroleum reports (PR's) referenced throughout this thesis. All data in the New Zealand Petroleum and Minerals GOLD database are also collated and referenced in interactive map format on GNS Science's Petroleum Basin Explorer (PBE) website, in order to easily locate data for a given area. All available seismic reflection data in the study area, along with 2D seismic reflection data in the wider Taranaki Basin and its distribution is shown in Figure 3.1.

In order to analyse fault evolution in the Northern Graben, the Parihaka and Toro 3D seismic reflection surveys have been interpreted (survey locations are shown in Fig.3.1). The surveys are adjacent, and encompass $1670 \mathrm{~km}^{2}$ combined (Veritas DGC Asia Pacific Ltd, 2005; Veritas Geophysical Asia Pacific Pte. Ltd, 2007). Both surveys have inline/crossline spacing of 12.5/25 m, and offer high resolution subsurface images (maximum theoretical resolution is $\sim 4 \mathrm{~m}$ at $500 \mathrm{~m}$ depth, see Section 3.1.3). The datasets are internally consistent, meaning any horizon discontinuity between seismic lines is typically user error.

\subsubsection{Parihaka 3D Seismic Reflection Survey}

The Parihaka 3D dataset covers an area of $1520 \mathrm{~km}^{2}$, and was commissioned in 2005 by Pogo New Zealand Itd. Seismic reflection data was acquired by Veritas Itd. using the surveying vessel, Viking /I towing eight streamers $4500 \mathrm{~m}$ in length. Streamers were spaced $100 \mathrm{~m}$ apart, and towed $9 \mathrm{~m}$ deep. Each streamer had 360 receiver groups, with a group spacing of $12.5 \mathrm{~m}$. Four airguns were grouped into two pairs for the source, with the two sources fired alternately and $50 \mathrm{~m}$ apart. Data was recorded at 2 ms intervals, and up to $6 \mathrm{~s}$ two way travel time (TWTT). The total area of the survey 
equipment was $3.15 \mathrm{~km}^{2}$ (Cohen et al., 2006). During the survey, 64,805 $\mathrm{km}$ of prime CMP line was acquired, along with $2393 \mathrm{~km}$ of infill. Faults with $\sim 4 \mathrm{~ms}$ throw are theoretically detectable up to $3 \mathrm{~km}$ depth (see Section 3.1.3), though in reality the practical limit of seismic resolution is at least an order of magnitude lower.

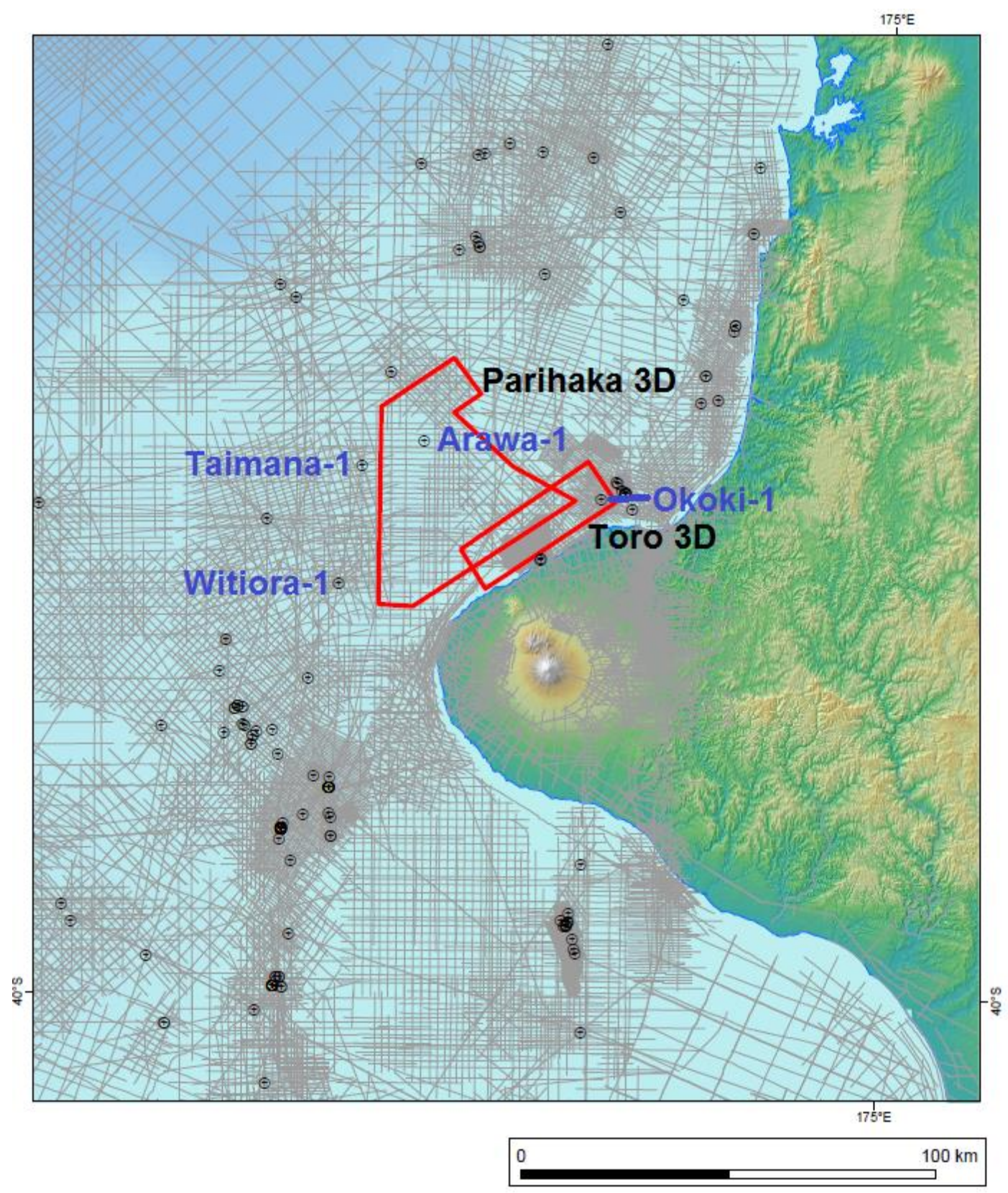

A

Figure 3.1 Map of 2D seismic reflection data distribution, offshore western-central North Island, New Zealand. The above figure displays the distribution of 2D seismic lines (grey lines) in the central Taranaki Basin. The locations of the Parihaka and Toro 3D seismic surveys are given by annotated red polygons. The four exploration wells used in the study are named in purple. 


\subsubsection{Toro 3D Seismic Reflection Survey}

The Toro 3D dataset covers an area of $150 \mathrm{~km}^{2}$ and was commissioned in 2007 by Pogo New Zealand Itd. Seismic data was acquired by Veritas Itd. using the surveying vessel, Pacific Titan, in 17 days, towing two streamers of $6100 \mathrm{~m}$ length. Streamers were spaced $100 \mathrm{~m}$ apart, and towed $7 \mathrm{~m}$ deep. Streamers each had 480 receiver groups, with a group spacing of $12.5 \mathrm{~m}$. Two airguns were used for the source, with the two sources $50 \mathrm{~m}$ apart. Data was recorded at $2 \mathrm{~ms}$ intervals, and up to $6 \mathrm{~s}$ TWTT (Veritas Geophysical Asia Pacific Pte. Ltd, 2007). During the survey, 5,773 km of prime CMP line-km was acquired, along with $300 \mathrm{~km}$ of infill. Brute stacks were completed aboard Pacific Titan, and processing and interpretation were completed onshore. The results of the processing and interpretation of the Toro 3D were published by Lovitz and Bates (2008a). The Toro 3D was acquired to add detail to the Eastern side of the Parihaka 3D survey, which was difficult to interpret due to the presence of the Turi fault zone. Two leads were found in the vicinity during Pogo's processing of the Parihaka 3D and required further delineation. As such the acquisition parameters of the Toro 3D are as similar as possible to those of the Parihaka 3D (Veritas Geophysical Asia Pacific Pte. Ltd, 2007). Faults with $\sim 4 \mathrm{~ms}$ throw are theoretically detectable up to $3 \mathrm{~km}$ depth (see Section 3.1.3), though in reality the limit of resolution is at least an order of magnitude lower.

\subsubsection{Uncertainties and Margins of Error}

The biggest restriction on the accuracy of the results of this thesis is seismic resolution. It limits the minimum size and offset of faults that can be interpreted, and means that all seismic interpretation will always be contained within a margin of error. Seismic resolution is a function of the ability to distinguish between separate features, and is defined as "the minimum distance between two features so that the two can be defined separately rather than as one" (Badley, 1985). Resolution is the single biggest issue with seismic imaging of the subsurface. The capability of seismic surveying to resolve changes in lithology similar to what we would observe at outcrop scale is almost non-existent. Seismic surveying involves both vertical and horizontal resolution components. 
The vertical component of resolution is dependent on seismic wavelength. In general, vertical resolution is equal to $1 / 4$ of the wavelength at a given location. It can be up to $1 / 8^{\text {th }}$ of the wavelength in some circumstances in the near surface where high frequency energy creates constructive interference. In order to calculate vertical resolution, knowledge of the frequency and velocity at a location is needed, from which the wavelength can be calculated using wavelength $=$ velocity/frequency. This can then be quartered to get resolution (Badley, 1985). The Horizontal component of resolution is defined as "how close two reflecting points can be situated horizontally, and yet be recognised as two separate points rather than one" (Badley, 1985). Calculating horizontal seismic resolution is based on the principles of Fresnel zones. A Fresnel zone is the zone which reflects a seismic waveform (the wave is reflected by a zone rather than a single point as a waveform has a sinusoidal shape). Any geological features within this zone are typically non-differentiable.

Horizontal resolution depends on seismic wave frequency and velocity, and is calculated using the following equation from Badley (1985), where w = width of Fresnel zone, and $d=$ depth.

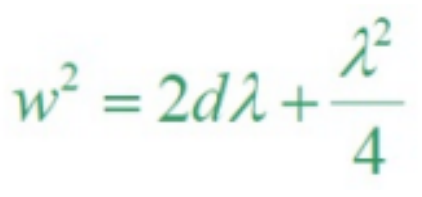

An example table of resolutions at depth based is presented in Table 3.1, based on time variant high-cut filter frequencies applied to both the Parihaka and Toro 3D datasets during processing (Veritas DGC Asia Pacific Ltd, 2005; Veritas Geophysical Asia Pacific Pte. Ltd, 2007). Resolutions can be seen to decrease with depth and decreased filter frequency. 
\begin{tabular}{|l|l|l|l|l|l|l}
\hline Frequency $(\mathrm{Hz})$ & Velocity $(\mathrm{m} / \mathrm{sec})$ & Depth $(\mathrm{m})$ & Wavelength $(\mathrm{m}) @ 110 \mathrm{~Hz}$ & Vertical resolution $(\mathrm{m})$ & Horizontal resolution $(\mathrm{m})$ \\
\hline
\end{tabular}

\begin{tabular}{|r|r|r|r|r|r|}
\hline 110 & 1000 & 500 & 9.09 & 2.27 & 2.78 \\
\hline 90 & 1000 & 1000 & 11.11 & 3.57 & 149.17 \\
\hline 70 & 1000 & 2000 & 14.29 & 3.45 & 239.15 \\
\hline 40 & 1350 & 4000 & 33.75 & 8.44 & 519.89 \\
\hline
\end{tabular}

Table 3.1 Table showing the theoretical limits of vertical and horizontal seismic resolution at various depths in the Parihaka and Toro 3D Seismic surveys. Maximum frequencies at each depth are used, and are taken from time variant high-cut filtering during processing of the surveys.

Ductile deformation involving drag folding of strata near faults may lead to significant under sampling of fault throw (up to $500 \mathrm{~ms}$ faults with $>1000 \mathrm{~ms}$ offset within the Parihaka and Toro 3D seismic reflection volumes). This will lead to underestimation of maximum displacement values, with Displacement/Length plots displaying relationships that are inaccurate towards the maximum end of the scale. This issue is discussed further by Kim and Sanderson (2005).

\subsection{Well Data in the Study Area}

Well correlation was achieved via a series of well ties within the study area, based on biostratigraphy from four exploration wells (Witiora-1, Taimana-1, Okoki-1, and Arawa1) tied to the Parihaka and Toro 3D seismic reflection volumes, as described in Morgans (2006a). Where possible, time horizons were tied across fault relay ramps, to ensure that mis-picks across faults were not a factor limiting well tie accuracy. Biostratigraphy is rarely going to match up exactly between wells (especially in an area of rapid sedimentation); however, every effort was made to ensure unbroken, coherent time horizons were chosen for well correlation. As such, time horizons are confidently tied between wells, but may be diachronous.

\subsubsection{Taranaki Basin Stratigraphy and Biostratigraphy}

Taranaki Basin fill began predominantly in the Late Cretaceous, and deposition has been broadly continuous since, though spatially varied in sediment composition. A generalised visual stratigraphic summary of the Taranaki Basin can be seen in Fig. 3.2. A more detailed stratigraphic summary including depositional environments and timing of petroleum system elements can be seen in Section 1.3. Biostratigraphy for the four wells within the 3D surveys was revised by (Morgans, 2006a), and is 
considered as accurate and up to date as possible using modern optimised biostratigraphic methods. While the four wells have biostratigraphic control down to $35 \mathrm{Ma}$, strata of ages between 0 and $1.6 \mathrm{Ma}$ (i.e. the $1.2 \mathrm{Ma}$ unconformity time horizon) are estimated assuming a constant sedimentation rate, as there is no usable biostratigraphic evidence in this interval.

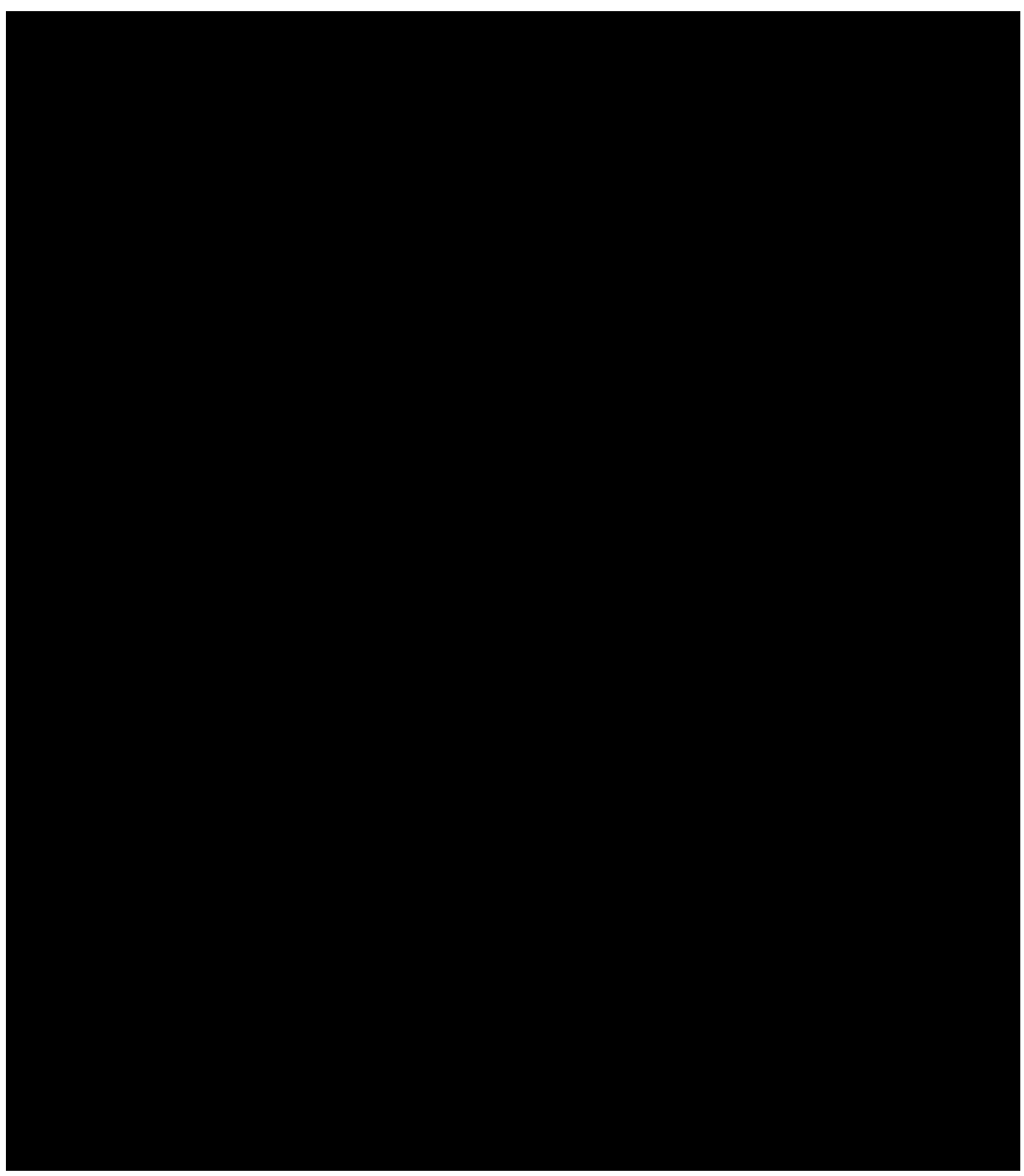

Figure 3.2 Generalised stratigraphic column for the Taranaki Basin. Generalised stratigraphy and associated ages within the Taranaki Basin is shown, from earliest Cretaceous basin fill to Recent. The general stratigraphy specific to the study area is enclosed in a red polygon. Adapted from New Zealand Petroleum and Minerals (2015). 


\subsubsection{Seismic Time Horizons in the Study Area}

Fifteen pre-existing time horizons exist in the study area, and are detailed in Cohen et al. (2006); Giba et al. (2012); Johnston (2014). Existing interpretations range in age from 0.7 to $84 \mathrm{Ma}$, and are deemed temporally accurate to within $\pm 10 \%$ of the true time horizon age (Giba et al., 2012). Existing time horizons older than $35 \mathrm{Ma}$ are outside the scope of this study and not used. Existing time horizons between 0 and 1.6 Ma are also ignored as they have no biostratigraphic age control. This thesis uses twelve time horizons between the present day seafloor and the base Oligocene (35 Ma). From top to bottom, five of these are interpreted. The 0 Ma (Seabed) time horizon is new and based on the location of the seabed reflector in the four wells. The 1.2 Ma (Unconformity) time horizon is new and based on the location of a strong unconformity surface that truncated underlying reflectors. The age of this time horizon is approximated using sedimentation rates. The 7.2 Ma (N50) time horizon is new and based on biostratigraphic correlation between wells. The 2 Ma (Intra Top Set) and 2.4 Ma (Basal Top Set) time horizons are new, but interpreted based on pre-existing interpretation from Johnston (2014). The remaining seven time horizons are preexisting time horizons associated with the GNS Science 4D Taranaki seismic facies mapping project described in Giba et al. (2010).

All time horizons used in this study, whether new, based on pre-existing interpretations in the literature, or imported from pre-existing projects, have been checked for internal consistency through well correlation, examination of arbitrary tie lines, and preliminary analysis of isochron (time-thickness) maps (Figs. A.11-A.12). A table showing which time horizons were new or edited from existing interpretations can be seen in Table 3.2. Naming conventions and ages for the time horizons with the prefix N or P follow the work of Strogen and King (2014), who have created a standard seismic time horizon naming scheme to allow easy cross referencing of seismic time horizons from different locations around New Zealand (Fig. 3.3). In some section images, Late Cretaceous (Basement), $66 \mathrm{Ma}$ (Top Cretaceous) and $56 \mathrm{Ma}$ (Top Paleocene) time horizons are added to better display structures. 


\begin{tabular}{|l|c|l|l|l|l|l|}
\hline Horizon Name & Age & New/edited & Witiora-1 & Taimana-1 & Arawa-1 & Okoki-1 \\
\hline Seabed & 0.0 & New & First Arrival & First Arrival & First Arrival & First Arrival \\
Unconformity & $\sim 1.2$ & New & Wn-Rec & Wc & Top Wn-Wc & Tk \\
\hline N85 & 1.6 & Edited & Wn & Top Wn & Top Wn & N/A \\
\hline Intra Top Set & 2.0 & New & Wn & Wn & Wn & N/A \\
Basal Top Set & 2.4 & New & Early Wn & Early Wn & Wn & N/A \\
\hline N75 & 3.0 & Edited & Top Wm & Earliest Wn & Early Wn & N/A \\
N70 & 3.6 & Edited & Wo & Upper Manganui Fmn & Upper Manganui Fmn & N/A \\
\hline N60 & 5.3 & Edited & Late Tk & Top Tt-Tk & Top Tt-Tk & Top Tt-Tk \\
\hline N50 & 7.2 & New & Late TK & Tt & Tt & Urenui Fmn \\
N40 & 11.0 & Edited & Early Tt & Lower Manganui Fmn & Manganui Fmn & Top Sw \\
N30 & 15.9 & Edited & Late PI & Late PI & Late PI & Mid PI \\
P50 & 35.0 & Edited & Top Ab & Top Ab & Top Ab & Top Ab-Ak \\
\hline
\end{tabular}

Table $3.2 \quad$ Table of seismic horizons mapped in this study. Ages of time horizons, and a statement of whether they are new or have been edited from existing interpretation data are shown. The biostratigraphic well marker at which each time horizon passes through each of the four wells is shown.

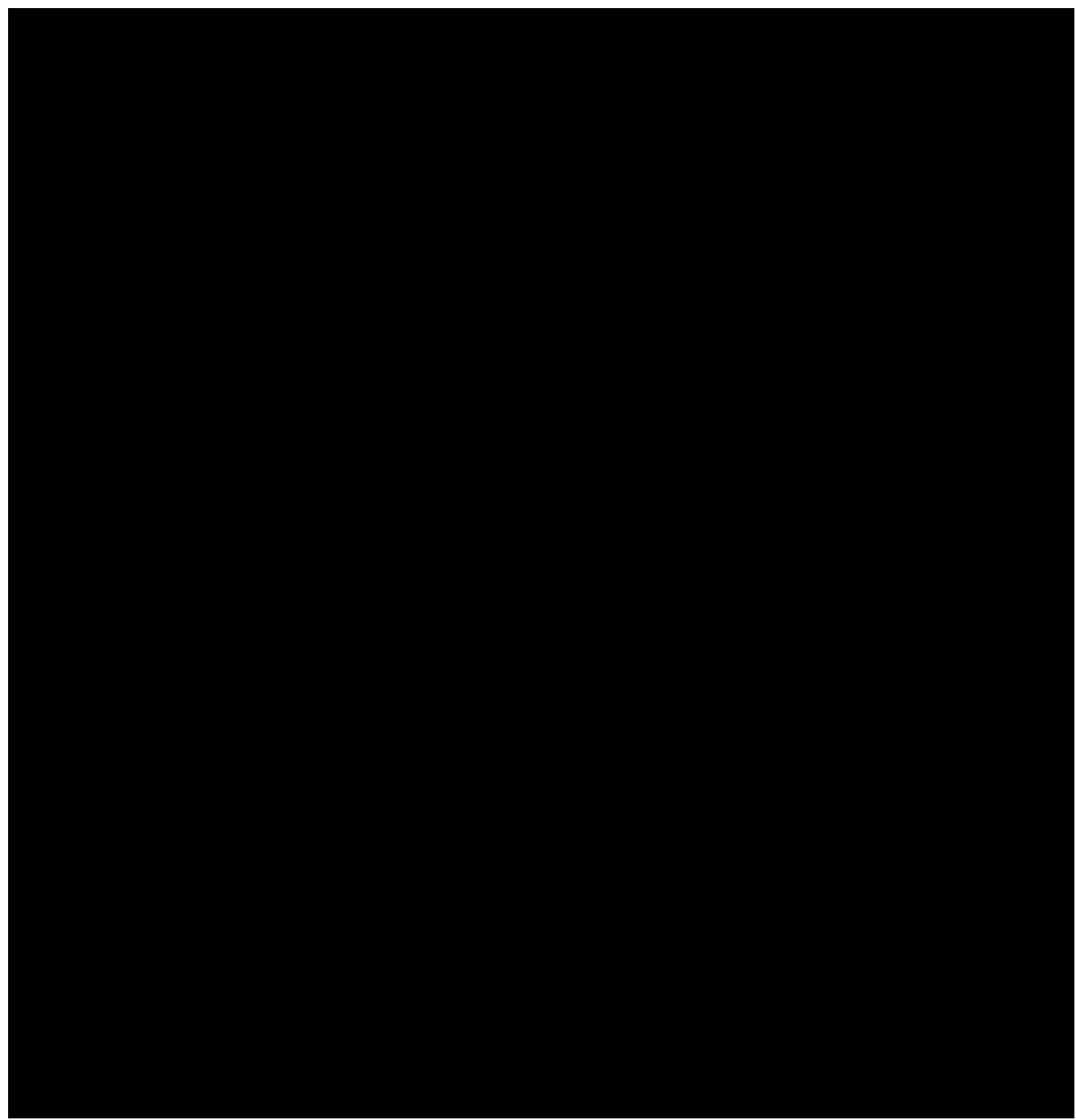

Figure 3.3 Chronostratigraphic column displaying the Zealandia-wide seismic time horizon naming scheme to which time horizons mapped in this thesis comply. The twelve time horizons used in this thesis are highlighted to the right of the timescale. From Strogen and King (2014). 


\subsubsection{Time/Depth Relationship in the Study Area}

Figure 3.4 shows the borehole checkshot TWTT vs. true vertical depth sub-sea (TVDSS) plotted for the four wells within the Parihaka and Toro 3D seismic reflection volumes. The gently sloping geometry of resulting polynomial trendlines suggest that the majority of the study area has undergone normal compaction (Diamond Shamrock Exploration Oil Co (NZ), 1984; NZ Oil \& Gas Ltd, 1984a; Crowley \& Crocker, 1989; ARCO Petroleum, 1992). Figure 3.4 shows that the Arawa-1, Witiora-1, and Taimana-1 wells all have a similar time/depth relationship, whereas the Okoki-1 well is significantly different. The area associated with the Okoki-1 well has been uplifted and eroded, and therefore displays higher seismic velocities representative of uplifted sediments from deeper in the section that have undergone normal compaction and are closer to the surface than in the other 3 wells (Lovitz \& Bates, 2008b). This elevated velocity caused by erosion and uplifted sediments is observed within all wells within or east of the Turi Fault Zone (King \& Thrasher, 1996).

Based on Figure 3.4, it can be said that the TVDSS-TWTT relationship displayed in the Okoki-1 well is not representative of the study area as a whole, and that the remaining three wells provide a better estimation of the depth-TWTT relationship within the study area. This relationship is almost 1:1 within the first 2 kilometres depth (where the interpretations used in this thesis reside). In this thesis, therefore, TWTT in ms approximates depth. Depth conversion would not significantly modify the first order results presented here. 


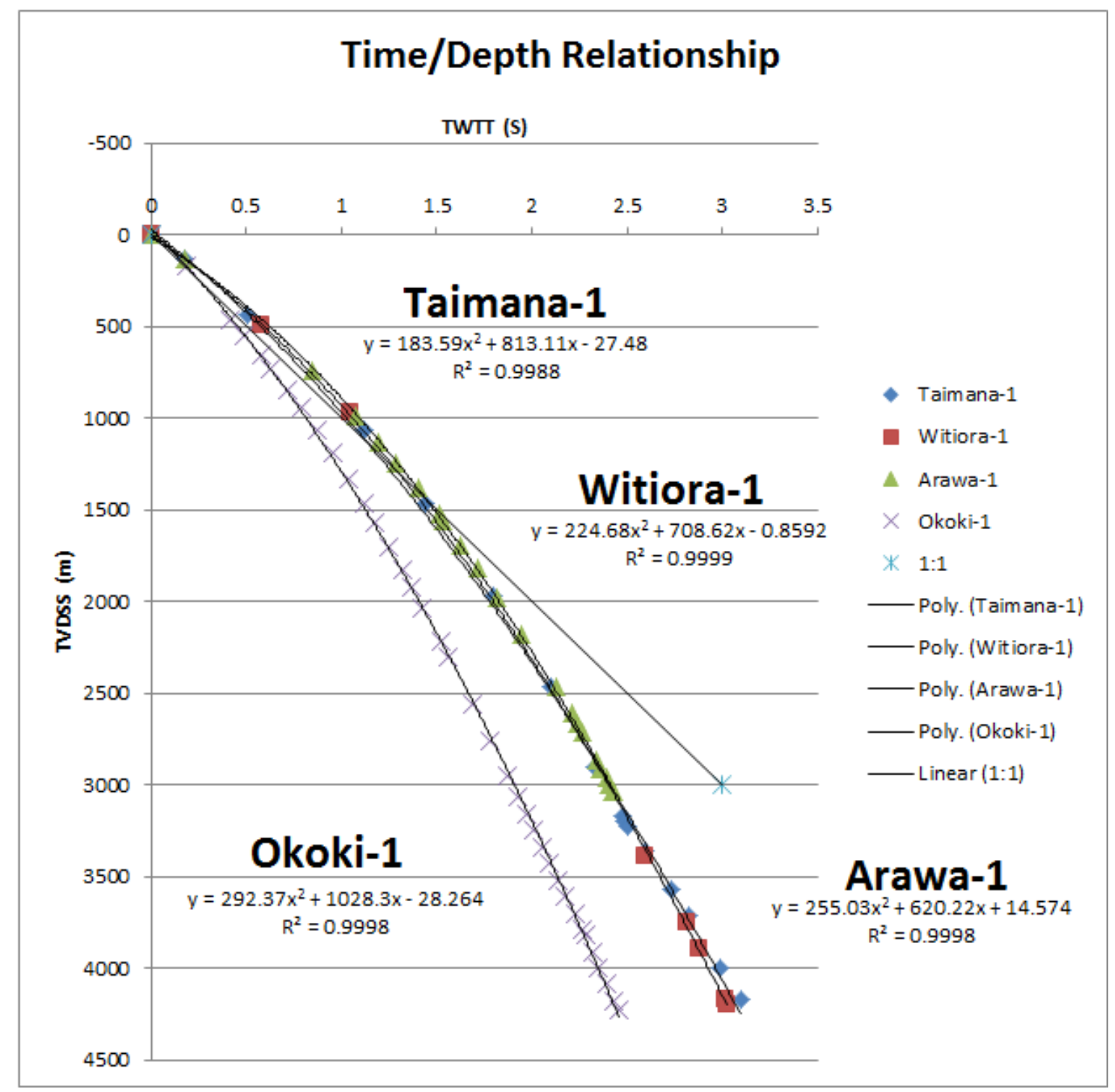

Figure 3.4 Time/depth relationship for borehole checkshot Two Way Travel Time (TWTT) vs. true vertical depth sub-sea (TVDSS) within the study area. A second order polynomial equation and $\mathrm{R}^{2}$ value for each trend line is shown for reference. Checkshot data is from Petroleum Reports PR1026; PR1107; PR1495; PR1824. A 1:1 curve is shown to highlight the near linear relationship between TVDSS and TWTT up to a depth of $2000 \mathrm{~m}$.

\subsubsection{Well Correlation in the Study Area}

Time horizons were mapped on the following four tie lines (Figs. 3.6 - 3.9) before systematic mapping throughout the Parihaka and Toro 3D volumes. The tie lines were designed to intersect as few faults as possible, in order to minimize errors associated with incorrect reflector correlation across faults. Locations of tie lines can be seen in Figure 3.5. Time horizons were picked such that they were the best possible match between ages shown by biostratigraphic markers in wells, as well as honoring the 
same reflectors throughout the seismic data as well as possible. Not all time horizons could be correlated across all wells. The 1.6 Ma (N85), $2 \mathrm{Ma}$ (Intra Top Set), 2.4 Ma (Basal Top Set), 3 Ma (N75), 3.6 Ma (N70), and 5.3 Ma (N60) time horizons are truncated by an unconformity towards the Okokoi-1 Well (Fig. 3.9).

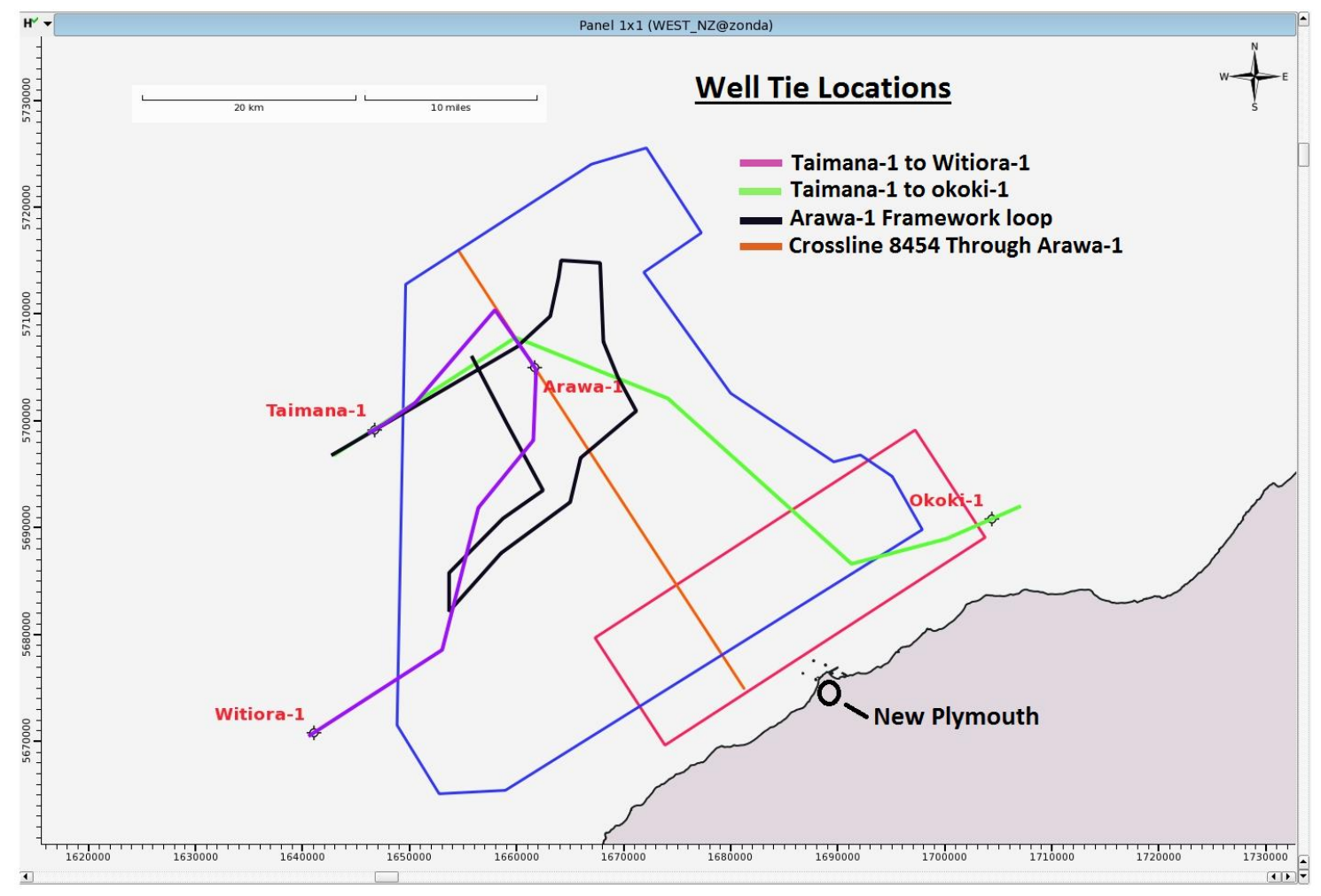

Figure 3.5 Map displaying locations of the four key well ties within the Parihaka and Toro 3D seismic reflection volumes. Well ties are displayed as coloured lines, with the Parihaka 3D seismic reflection survey represented by a blue polygon, and the Toro survey represented by a red polygon. Where possible, well ties were taken through relay zones of the Parihaka fault to make sure time horizons were not mis-correlated over the largest fault in the study area. Firstly, all twelve time horizons were mapped along the tie line between the Taimana-1, Arawa-1, and Witiora-1 wells, as these wells are situated in a relatively undeformed region of the study area that could be used as a control for all other seismic interpretation in this study. This allowed for seismic interpretation practice, and familiarization with the seismic expression of each of the twelve time horizons (Fig. 3.6). A supplementary tie line along crossline 8454 through the Arawa-1 well was interpreted in order to propagate the twelve time horizons south east across the Parihaka Fault. This line is interrupted by intersection with the Southern Intrusive Complex (Fig. 3.7). 


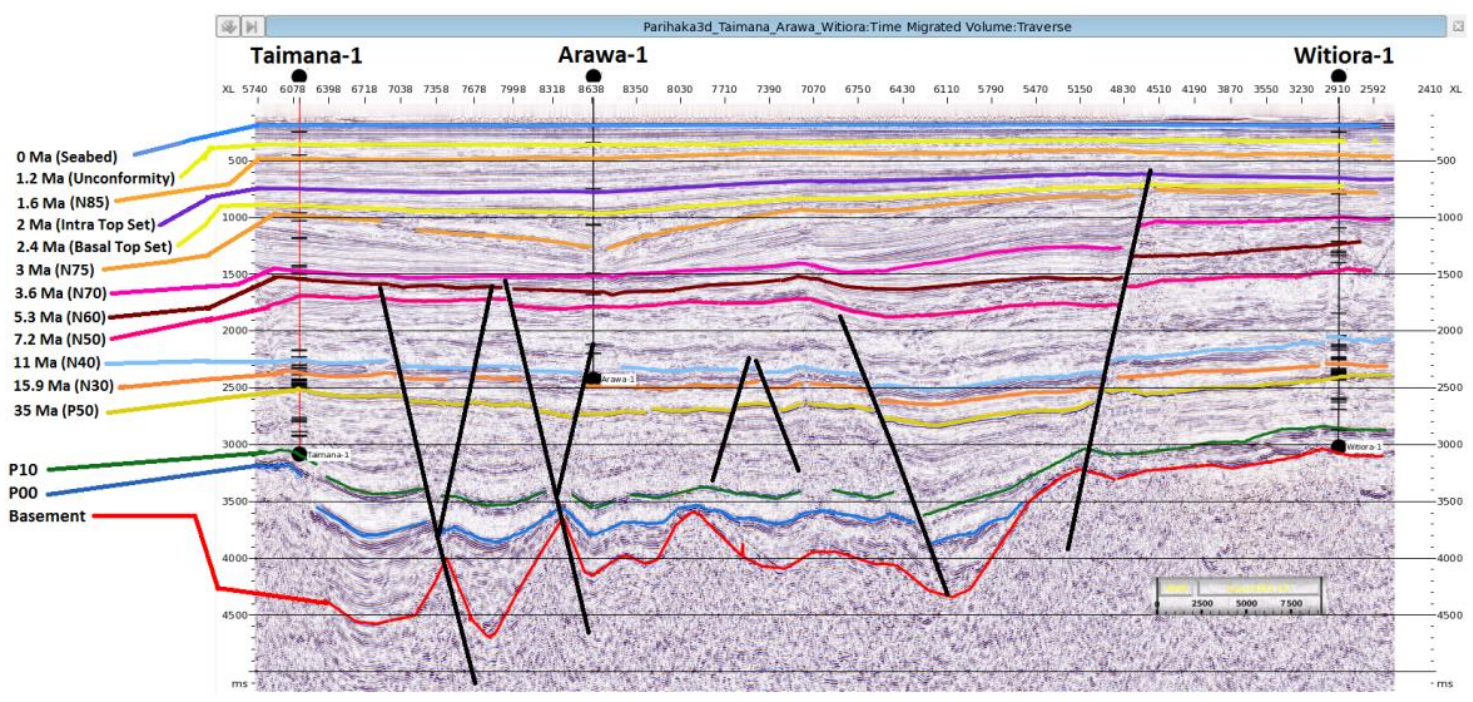

Figure 3.6 Section view of the Taimana-1 to Arawa-1 to Witiora-1 well tie line. The location of the section can be seen in map view in Figure 3.5. $Y$ axis units are milliseconds.

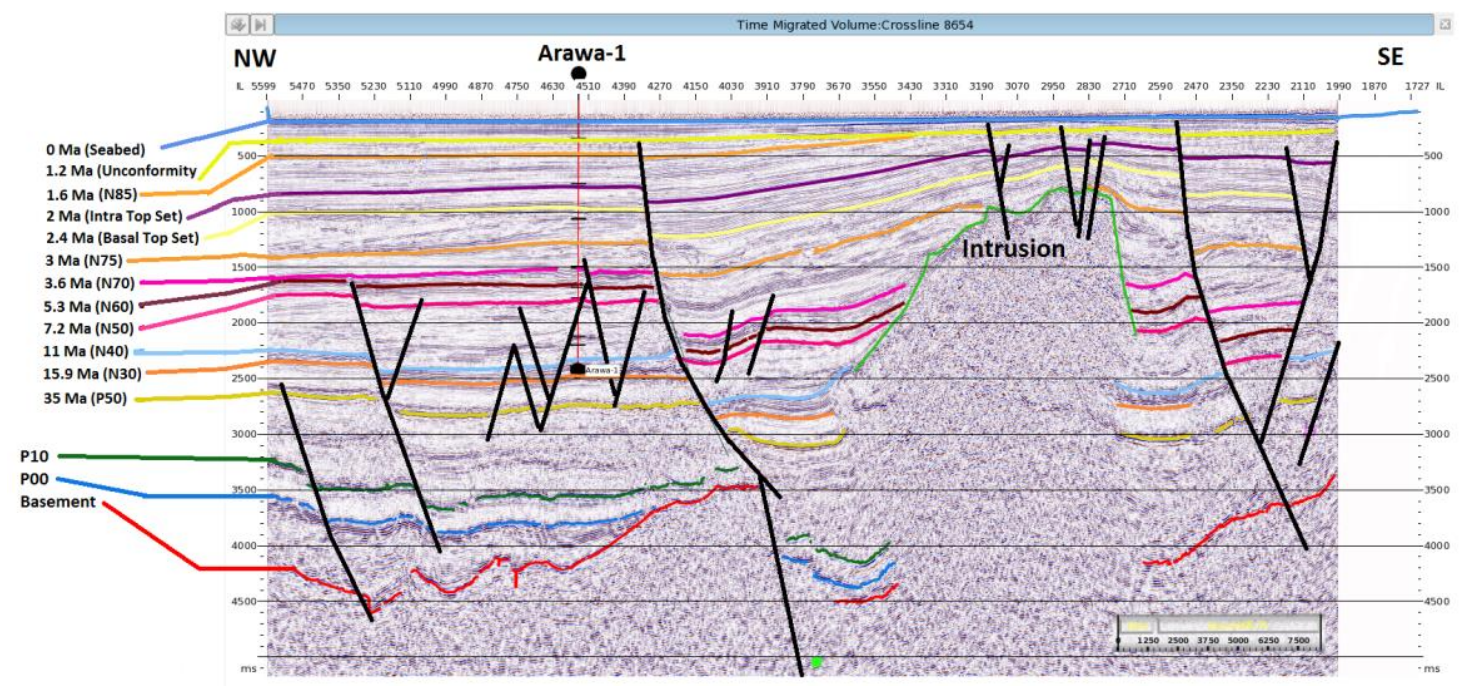

Figure 3.7 Section view of crossline 8454 through Arawa-1. The location of the section can be seen in map view in Figure 3.5. The tie line is disrupted to the east by the Southern Intrusive Complex. $\mathrm{Y}$ axis units are milliseconds.

A framework loop tie was interpreted in order to propagate time horizons down relay ramps on the Parihaka Fault (Fig. 3.8). This ensured time horizons were not incorrectly mapped across the largest displacement fault in the study area (up to $1500 \mathrm{~m}$ maximum throw). Finally, a tie line was interpreted between the Taimana-1 and Okoki1 wells (Fig. 3.9). This was done last, as the Okoki-1 well is located within the structurally complex Turi Fault Zone, and is difficult to accurately correlate time horizons to. 


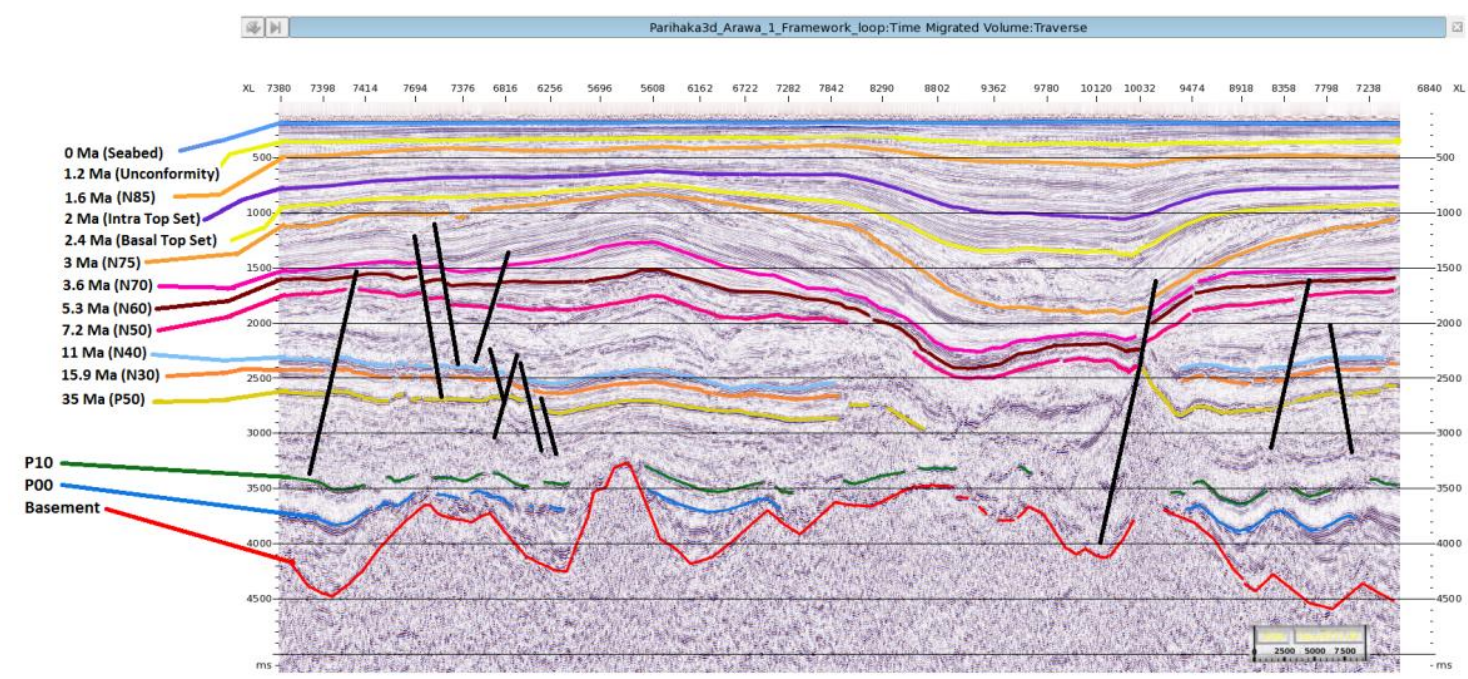

Figure 3.8 Section view of the loop tie surrounding Arawa-1. The location of the section can be seen in map view in Figure 3.5. This arbitrary traverse through the 3D seismic volume was to find the best way down a relay ramp of the Parihaka Fault to allow the best chance of correlation across the fault. $Y$ axis units are milliseconds.

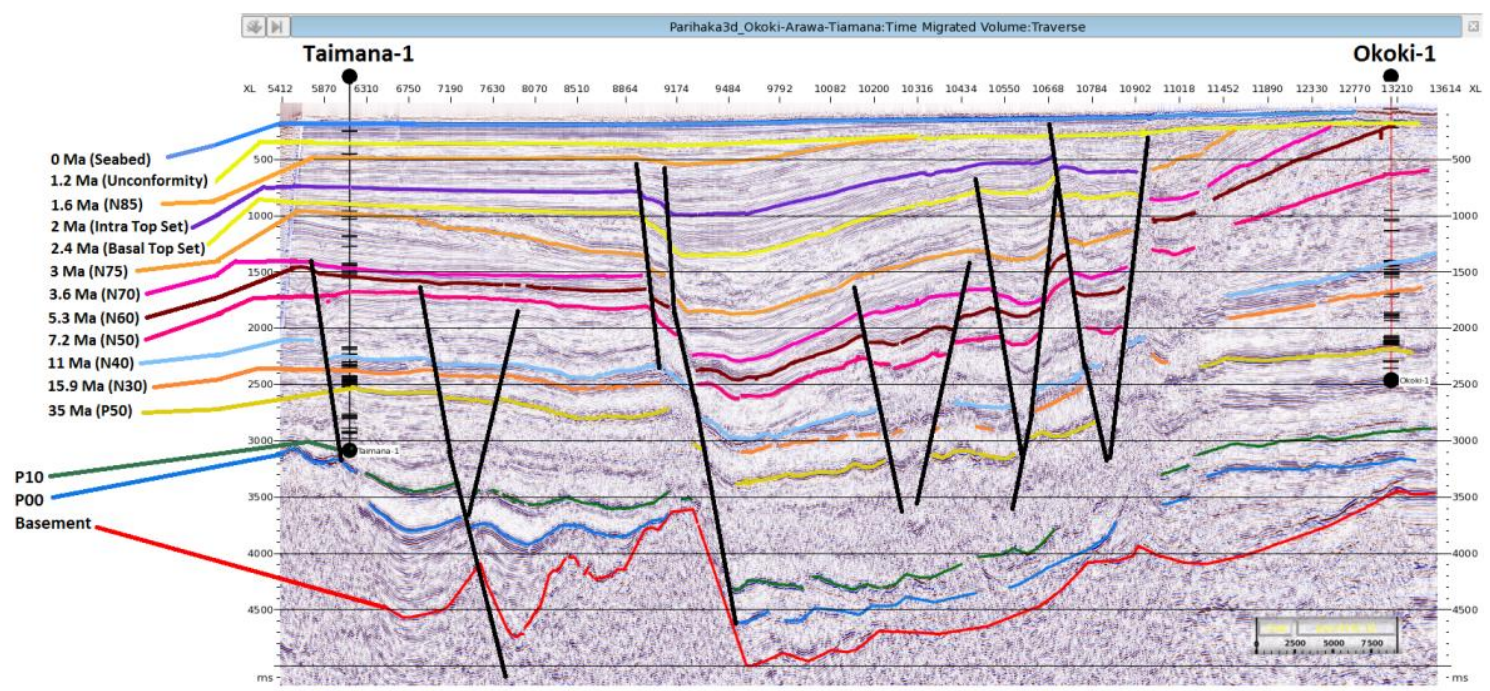

Figure 3.9 Section view of the Taimana-1 to Okoki-1 well tie. The location of the section can be seen in map view in Figure 3.5. This tie was completed last, as it has the most uncertainty of the 4 ties. This uncertainty is owing to the uplift, erosion, and faulting towards Okoki-1 making ties difficult. Biostratigraphic markers are also limited in Okoki-1, adding further uncertainty. $Y$ axis units are milliseconds. 


\subsection{Seismic Mapping and Fault Analysis}

Interpretation of 3D seismic data is the focus of this thesis. The identification and mapping of the faults and time horizons in this study follow well established methods described in Veeken (2006). Two software packages were used for this study: Paradigm SeisEarth was used for seismic interpretation, and TrapTester 6 was used for fault analysis. Both software packages were run on a purpose built Linux workstation at GNS Science. This methodology section is split into three parts: data acquisition and seismic interpretation in Paradigm, data processing and fault analysis with TrapTester, and data analysis and hypothesis testing.

\subsubsection{Part 1: Data Acquisition and Seismic Interpretation in}

\section{Paradigm}

The Parihaka and Toro 3D seismic reflection surveys were loaded into Paradigm ${ }^{\circledR}$ SeisEarth in 16 bit integer format. An existing GNS Science well database developed and quality controlled for the 4D Taranaki Project was utilised during the course of the interpretation. GNS Science also made available well sheets that contained the original sedimentary and age interpretations, along with the updated versions of these interpretations (Strogen \& King, 2014). 3D seismic reflection volumes tied to a regional 2D seismic framework, along with pre-existing interpretations were also provided by GNS Science. The 3D surveys were then interpreted within Paradigm ${ }^{\circledR}$ SeisEarth seismic interpretation software platform, a capable and easy to use platform for the viewing, interpretation, and analysis of seismic data.

Twelve time horizons (listed earlier in this chapter) were developed throughout the Parihaka and Toro 3D volumes. The time horizons were interpreted in a grid using every $100^{\text {th }}$ inline and every $50^{\text {th }}$ crossline $(1250 \mathrm{~m})$, resulting in areas of $1.5625 \mathrm{~km}^{2}$ bounded by seismic interpretation. Seven of the pre-existing time horizons interpreted by Hannu Seebeck were checked for consistency and edited and infilled where required. The remaining five time horizons were created for this study.

Data acquisition within Paradigm followed the following steps: 
1. Time horizon mapping began by placing first order picks of the twelve time horizons on transects that intersected the four exploration wells tied to the Parihaka 3D seismic volume (Okoki-1, Arawa-1, Taimana-1, and Witiora-1) as a reference point on which to pick time horizons on all intersecting lines (Figs. 3.6 - 3.9). The twelve time horizons were then picked throughout the volume using a systematic pattern of inlines and crosslines to build a 1250×1250 m grid. The seabed time horizon differed from the $1250 \mathrm{~m}$ spacing grid, and was mapped on every single inline and crossline, using Paradigm's automatic horizon propagator tool, seeded by picks along the loop ties. This was possible due to the presence of a strong, continuous first arrival reflector throughout the 3D volume. Where possible, time horizons were picked through fault relay zones so as to minimise any error caused by picking time horizons across faults. For areas where this was not possible (namely the Turi Fault Zone), Paradigm's fault correlation polygon tool was used to compare strata on both sides of the fault to maintain a consistent interpretation.

2. Faults with displacements $>50 \mathrm{~ms}$ were then interpreted using the same crossline grid as time horizon picks to ensure consistency of interpretation and ease of reference. Faults were only picked on crosslines, as they are at near right angles to fault planes. A smaller interpretation grid spacing $(625 \mathrm{~m})$ was used to more accurately locate fault tips.

3. After all twelve time horizons and faults with displacements $>50$ ms were interpreted throughout the Parihaka 3D seismic reflection volume, it became apparent that the Parihaka 3D did not image the Turi Fault Zone well. To remedy this, the Toro 3D seismic reflection volume (which was shot to cover the Turi Fault Zone) was added to the study, as it would add clarity to the eastern part of the Parihaka 3D survey which imaged larger displacement (>200 ms) faults.

4. The twelve time horizons were then picked throughout the Toro 3D, which required no mistie adjustment in order to be contiguous with the Parihaka 3D volume. The same $1250 \times 1250 \mathrm{~m}$ grid spacing was used, apart from the Seabed 
time horizon which again was picked automatically on every inline and crossline using Paradigm's propagator tool.

5. Faults with displacements $>50$ ms were then picked within the Toro 3D using the same seismic lines as time horizon picks to ensure consistency of interpretation and ease of reference. Faults were picked only on crosslines, as they are near normal to fault planes. Faults picked at this stage were named numerically with the prefix 5 (e.g. fault 5_125) to comply with existing GNS Science interpretation projects in the Taranaki Basin. The example fault above would be the $125^{\text {th }}$ fault picked in the project it belonged to. See Tables AT.1 AT.3 for a list of all faults interpreted in this study.

6. As time horizons were picked separately in both the Parihaka and Toro 3D surveys, they were merged post - picking to create continuous time horizons using Paradigm's mathematical operations tool.

7. 3 dimensional triangulated fault $T$ surfaces (surfaces approximating the fault plane based on fault picks) were then created for both surveys.

8. Fault intersection polygons (polygons approximating where time horizon interpretation intersected with the hangingwall and footwall of faults) were created based on the intersection of time horizon picks with fault T surfaces (Fig. A.3). These polygons were created in order to better constrain the time horizon gridding.

9. Once time horizons were merged, and fault $T$ surfaces and intersection polygons created, time horizon gridding was undertaken. First order grids of each of the twelve time horizon interpretations were created. Interpretation picks in both surveys were interrogated then modified where required in regions of anomalous surface geometry. Any modification to interpretation picks required recreation of fault $T$ surfaces and fault intersection polygons prior to the recreation of a time horizon grid.

10. Once all twelve time horizons were satisfactorily gridded, grids were then used to create eleven isochron (time-thickness) maps to check sediment thicknesses 
between time horizons as a quality control check (Figs. A.11-A.12). Analysis of isochron maps ensured that the interpretation was geologically reasonable based on the thickness between interpreted time horizons with respect to the wells and faults.

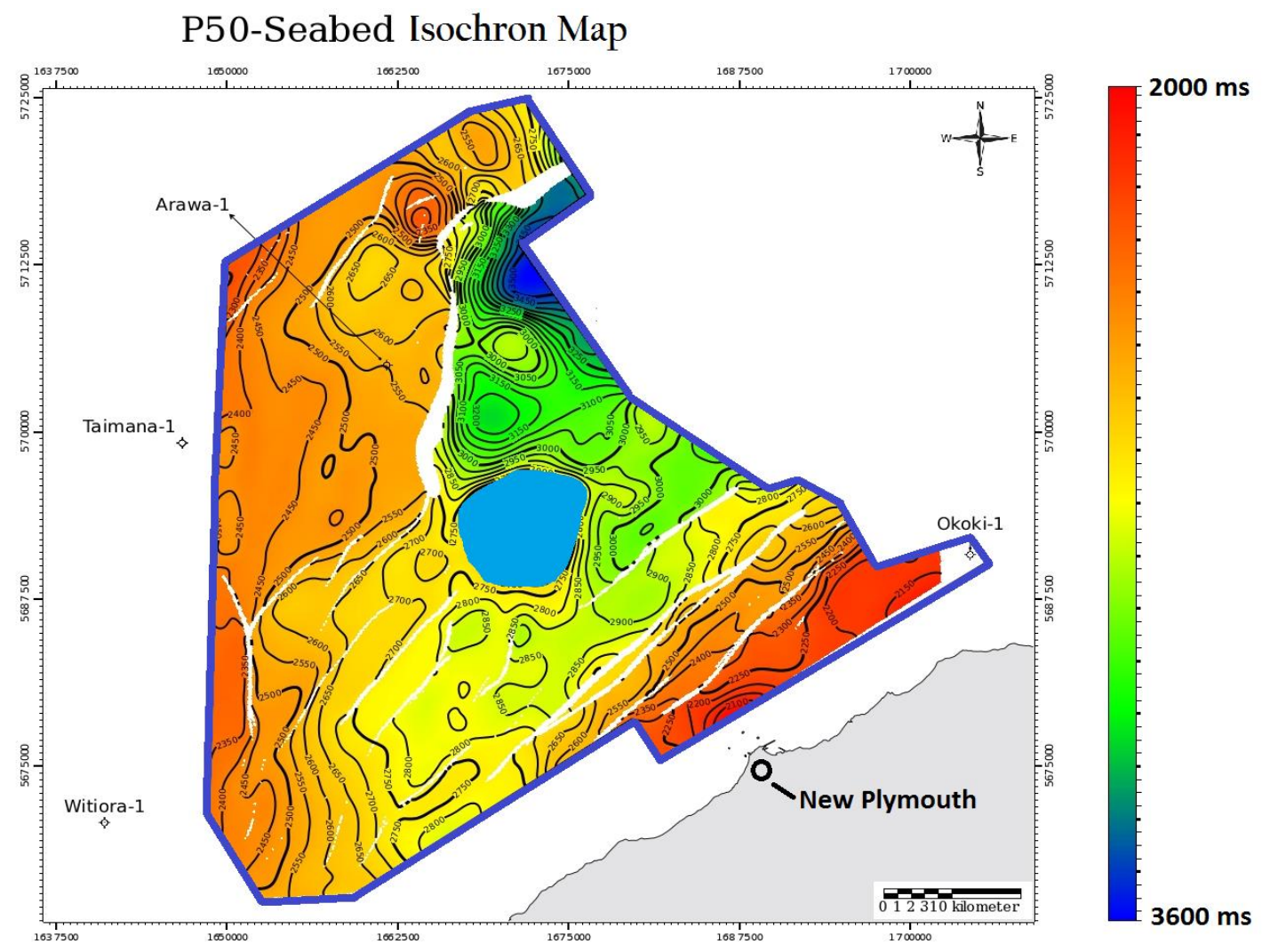

Figure 3.10 Isochron map showing the sediment thickness between the oldest $35 \mathrm{Ma}$ (P50) and youngest $0 \mathrm{Ma}$ (Seabed) mapped time horizons, and hence all major sedimentary structures observed in the study area. The Parihaka Fault can be seen to the North, and the Turi Fault Zone to the South east. The Southern Intrusive Complex is seen in the centre of the map. Synclinal structures either side of the complex are host to the thickest sediments, especially to the north of the map between the Parihaka Fault and Southern Intrusive Complex. Figures A.11 - A.12 show the remaining isochron maps. Contours are at $\mathbf{5 0} \mathbf{~ m s}$ intervals, with a sediment thickness scale provided to the right of the map. The blue polygon in the centre of the image masks the Southern Intrusive Complex. The blue border polygon is the combined Parihaka and Toro 3D seismic reflection survey gridding boundary. The XY coordinate grid is NZ Geodetic 2000.

11. Analysis of time horizon grids and isochron maps required the development of a denser interpretation grid (625 m instead of $1250 \mathrm{~m}$ ) near faults to improve fault intersection polygon geometry, and by extension the accuracy of the results of the thesis. 
12. Faults with displacements of $20-50 \mathrm{~ms}$ were then picked in order to gather a more comprehensive dataset for testing fault length - displacement relationships within the study area. Faults picked at this stage were named numerically with the prefix Z.100 (e.g. fault Z.1008) to differentiate them from the original $>50 \mathrm{~ms}$ displacement fault picks. See Tables AT.1 - AT.3 for a list of all faults. The example fault above would be the $8^{\text {th }}$ fault picked in the project it belonged to. An exception to this small fault naming convention was made when three segments of the Parihaka fault needed to be re-picked (Faults Z.1000, Z.1002, Z.1003). As not all faults were contained entirely within the Parihaka and Toro 3D surveys, faults that extended out of the surveys were traced outside of the surveys on 2D seismic reflection lines in order to measure both true length and max displacement where possible.

13. The interpretation grid was then improved near faults, so that it had interpretations on every $50^{\text {th }}$ inline and every $25^{\text {th }}$ crossline $(625 \mathrm{~m})$, in order to provide denser data points for carrying out more accurate fault analysis. See Figure 3.11 for final interpretation grid density.

14. Steps 7-10 were then repeated to produce the final time horizon grids used for fault displacement analysis.

15. To determine which of the faults in the study area were reactivated from preexisting faults, pre-existing Cretaceous and Basement level time horizons were utilised at the location of maximum displacement for each fault. The rationale of this approach is that if the Cretaceous and/or Basement time horizon has a greater displacement than that of the P50 (Base Oligocene) time horizon (or if an existing structure older than P50 could be clearly seen at the base of the picked fault) it is inferred that the fault has been reactivated. See Tables AT.1 AT.3 for a list of which faults are reactivated, and Section 4.4 for an example of a reactivated fault in section view.

16. Once all interpretation data was of an acceptably high standard, it was exported in ASCII format prior to loading into TrapTester for analysis. 


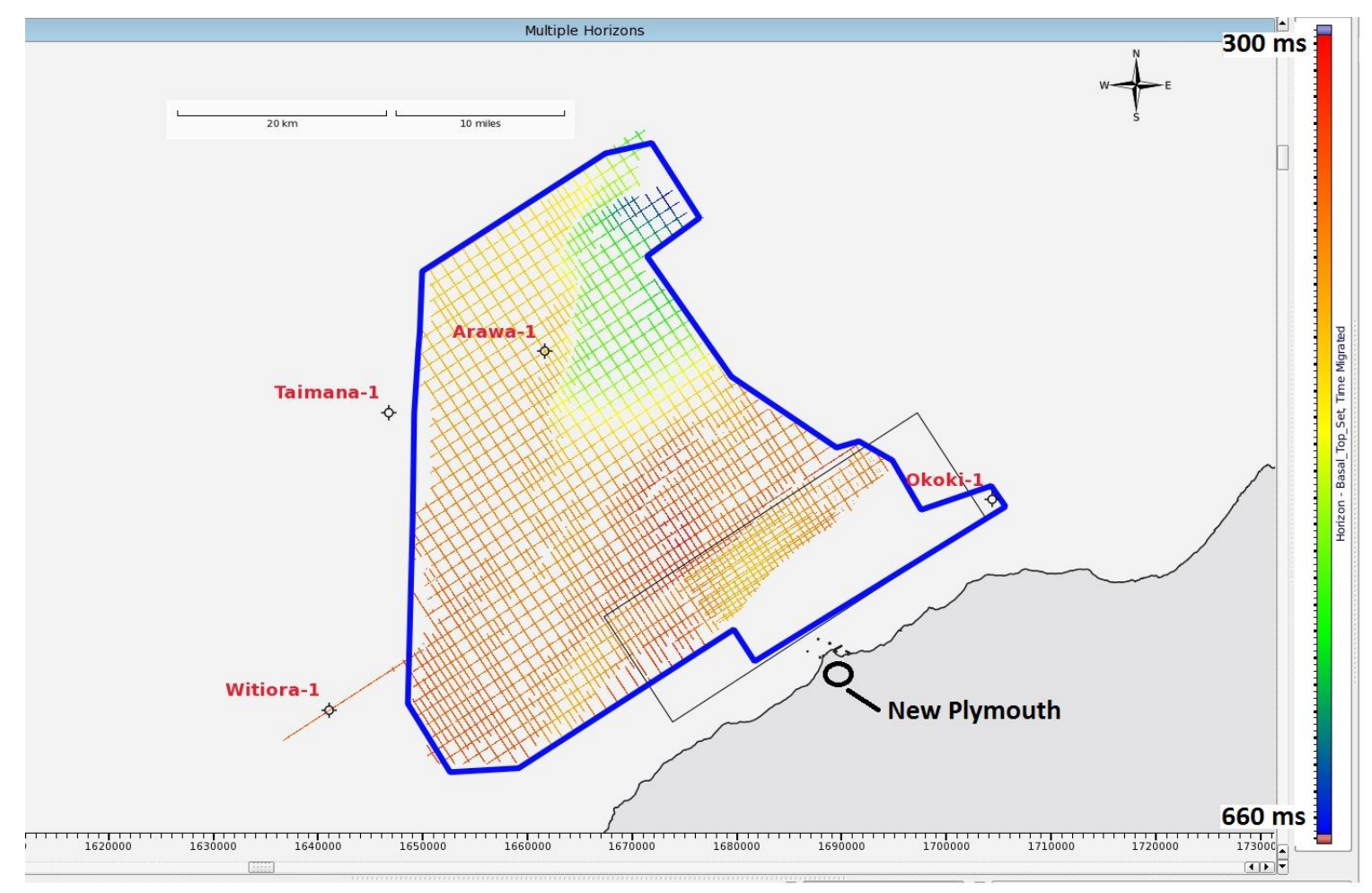

Figure 3.11 Map showing an example of the location, orientation, and density of final time horizon grid picks using Basal Top Set time horizon picks for the $1.6 \mathrm{Ma}$ (N85) time horizon. The blue border polygon is the combined Parihaka and Toro 3D seismic reflection survey gridding boundary. A colour - depth scale is to the right of the map. The XY coordinate grid is NZ Geodetic 2000.

\subsubsection{Part 2: Data Processing and Fault analysis with TrapTester}

Badleys Geoscience fault analysis software TrapTester 6 was chosen as a tool for fault analysis as it enables simple, accurate, and automated calculations of most commonly derived fault statistics. Data processing within TrapTester followed the following steps:

1. Time horizon and fault interpretation data were imported from Paradigm SeisEarth into TrapTester in ASCII format.

2. Fault T surfaces were regenerated in TrapTester (these could not be transferred from Paradigm SeisEarth).

3. Fault intersection polygons (approximating the hangingwall and footwall locations of time horizon intersections on a fault) were recalculated in TrapTester, for all 110 faults. These fault intersection polygons form the basis of most of the fault displacement analysis. 
4. Fault displacement profiles were generated from fault intersection polygons. Fault displacement profiles are profiles of normal displacement in TWTT vs. Distance along fault strike sampled at $100 \mathrm{~m}$ intervals. The resulting data were exported as ASCII files and loaded into Microsoft Excel for analysis and plotting (see Section 5).

5. Fault maximum Displacement/Length data was collated for all possible faults in the study area. TrapTester was used to determine which time horizon fault intersection polygon at each fault had the greatest displacement, and measure its length. As a number of faults extend outside of the area covered by the 3D seismic volumes, their maximum displacement may not be captured in the previous steps. Whether or not the maximum displacement of the fault was captured within the 3D seismic data was determined using fault displacement profiles. For example, if the profile showed displacement increasing up to the boundary of the study area, the maximum displacement was typically located outside of it. For faults where this was the case, the maximum displacement was determined using $2 \mathrm{D}$ seismic reflection profiles adjacent to the study area. Again, these data were exported as ASCll files and loaded into Microsoft Excel for analysis and plotting (see Section 5.5).

6. To check the accuracy of the TrapTester generated Displacement/Length data, fault tip locations for examples of retreating, potentially propagating, and stationary fault tips were tracked (Figs. A.27 - A.32). These tip locations were observed using coherency time slices at the average depth in TWTT of each of the time horizons intersected by each of the faults. By stepping between time slices, it was possible to observe fault tip behaviour. Time slice coherency images of faults are compared to TrapTester generated lengths used in Displacement/Length analysis in Section 5.5.

7. Coloured throw contours were created in TrapTester for every fault as a visual guide of where the area of maximum displacement was located on each fault. Hot colours indicated greater throw, and cooler colours less throw. These contours are also used to judge whether neighbouring faults are interacting 
(throw appears anomalously low compared to rest of fault where two fault tips are proximal), and as a quality control check for time horizon interpretation and gridding surfaces (see results in Figure A.3).

8. To observe longitudinal strain within the study area, longitudinal strain profiles at each time horizon level were generated using TrapTester. Strain is approximated along sampling lines oriented at $\sim 120^{\circ}$ (approximately normal to average fault strike in the study area) at $200 \mathrm{~m}$ intervals on a sampling grid oriented at $\sim 030^{\circ}$. Sampling began on lines in the south west, and ended on lines in north east. Strain was approximated on each line in the sampling grid using strain $=H /(L-H)$, where $H$ is the sum of fault heaves on the sample line and $\mathrm{L}$ is the interpreted time horizon line length. $\mathrm{L}-\mathrm{H}$ is an estimate of the original time horizon line length. This method of sampling resulted in a graph displaying strain vs. distance along sampling grid, running from the south west to north east for each of the twelve time horizons. This provides an estimation of the magnitude of strain at a given time horizon, and where it was concentrated in the study area (see Section 5.4).

9. Rose plots were created using TrapTester to show average fault strike and dip for all faults at each of the twelve time horizons. TrapTester calculates average strike by measuring the strike of each fault intersection polygon intersecting a time horizon at $100 \mathrm{~m}$ intervals. The plot is most densely populated in the region of average strike. Dip is calculated by measuring the angle between the hangingwall and footwall fault intersection polygons for each fault at each time horizon at $100 \mathrm{~m}$ intervals, and plotted on the rose plot (See Figures A-13 A.18).

10. The time period through which each fault was active was determined from Displacement/Length data, using the assumption that the time horizon on which that synsedimentary fault accrued maximum cumulative displacement was the approximate time the fault initiated (Walsh et al., 2002; Childs et al., 2003; Giba et al., 2012; Reilly et al., 2015). The cessation of fault activity was estimated by the location between the most recent time horizon to be 
displaced by a fault and a shallower, unfaulted time horizon. The initiation and cessation ages of all faults in the study area can be seen in Tables AT.1 - AT.3.

\subsubsection{Part 3: Data Analysis and Hypothesis Testing}

Once fault displacement data were generated, quality controlled, and analysed in TrapTester, the data were ready to be used to determine the geometry, timing, and cessation of fault activity in the study area. Hypothesis testing followed the following steps:

1. The ability to compare spatiotemporal patterns of fault activity in the study area with those implicitly or explicitly described in regional tectonic models in the literature, such as Ballance (1976); Stern et al. (2006), was required. Ten maps were created to display which faults were active at each time horizon (Section 4.5). These maps allow simple visual interpretation of patterns of the initiation and cessation of fault activity. Two further maps were also created, to summarise the overall timing and distribution of fault activity in the study area through time (Section 4.5).

2. In order to test if fault rotation resulting in frictional lockup was the cause of fault inactivity, rose plots (Figs. A.13 - A.18) were compared to see if the average strike, and more importantly dips of faults changed significantly between the oldest and youngest time horizon. Andersonian fault mechanics using Byerlee friction values state that the optimal slip angle for a normal fault in an ideal extensional stress regime is $60^{\circ}$. If fault dip exceeds $\pm 30^{\circ}$ if this optimal angle, the frictional force between the hangingwall and footwall fault blocks will exceed the normal stress acting on the fault, and frictional lockup will typically occur (unless forces such as elevated pore fluid pressure are reducing the friction coefficient of the fault). At this point it becomes easier to develop new faults than continue to develop the existing one (Anderson, 1951).

3. In order to test if progressive localisation of strain onto larger faults was the cause of fault death in the volume, strain profiles and fault displacement 
profiles of large faults were analysed (Section 5.4). If the hypothesis were true, the displacement profiles of large faults would show increases in displacement with fault age, with complementary decreases in the displacement profiles of smaller faults leading to eventual inactivity.

4. To test if the coherent or isolated fault model best describes fault activity in the study area, fault displacement profiles, and Displacement/Length plots are used (Section 5.5). If the coherent fault model is appropriate, faults should initiate with low displacements but with lengths at or near maximum. This length would then either remain stationary, or retreat with increasing displacement (high Displacement/Length ratios). Changes in fault displacement profiles throughout the study area would be expected to be complement one another (Section 5.4), as the coherent fault growth model requires that seemingly isolated faults are in fact part of a larger, kinematically related structure. If the isolated fault model were the most appropriate for the study area, faults would initiate with small displacement and lengths. These lengths would then increase along with displacement (low, constant displacement/length ratio) until the faults began to either interact with other faults, or cease activity.

5. Determining which of the two fault growth models is more appropriate in the study area addresses the question of whether fault lengths are set instantaneously at initiation, or are developed over the duration of fault activity (Walsh et al., 2002). To examine if Displacement/Length relationships are different for new or reactivated faults in the study area, colour coded Displacement/Length plots were created to compare and contrast the two (see Section 5.5).

6. To further test if and how displacement - length relationships are different for new and reactivated faults, fault length was plotted against cumulative fault throw for all faults of each type (See Section 5.5). Plotting fault length against cumulative throw shows growth profiles for individual faults (which is not observed in Displacement/Length plots). 
7. To test the hypothesis that large faults grow in preference to small faults (and are the last to cease activity), the maximum throw of each fault was plotted against the time horizon at which the fault ceased accruing displacement (last time horizon displaced by a fault). If the hypothesis were true, faults with the highest displacements would be the last to cease activity, and vice versa. See section 5.5 for results.

8. Models of large scale subduction processes such as slab rollback (Ballance, 1976), and Rayleigh-Taylor mantle instability and volcanic arc rotation (Stern et al., 2006), include predictions for the timing and geometry of faults that might be associated with these phenomena (Section 2.5). The spatiotemporal patterns of fault displacement and geometry data displayed in this study are compared and contrasted to those prescribed in these models. 


\section{Chapter 4 Geometry of a Normal Fault System}

\subsection{Introduction}

The development of normal faults in a petroleum system can have a profound impact on the migration and trapping of hydrocarbons. Faults can behave as both barriers and/or conduits for fluid flow (Finkbeiner et al., 1997; Faulkner et al., 2010). If the development of faults is synchronous with hydrocarbon expulsion and migration, this can result in migrating hydrocarbons bypassing seal lithologies through faults and/or faults acting as high permeability pathways to reservoir lithologies. Whether faults are open or closed to up fault fluid flow is considered strongly dependent on whether a fault is active and/or its proximity to failure under present or paleo-stress conditions (Faulkner et al., 2010). Faults with sufficient displacement can be sealing to across fault fluid flow due to very fine grain low permeability rock occupying the fault zone, as well as potentially creating structural traps with side seals by juxtaposing reservoir and seal lithologies (Yielding et al., 2010).

The kinematics of fault slip provide important information on the style of deformation, the magnitude and orientation of near and far field strain magnitudes at a given time, and the likely drivers of regional extension. If oblique extension is recorded by evolving faults, fault zones will be more complex (with greater complexity at lower angles of obliquity) than if pure extension is recorded. Oblique extension can result in the creation of high permeability fault zones through block rotation within fracture networks, ideal for hydrocarbon migration (Zhang et al., 1996; Ferrill \& Morris, 2003). Regions undergoing oblique extension may have high along-plane permeabilities where faults intersect or interact in relay zones (Ferrill \& Morris, 2003). The magnitude and orientation of strain observed in an evolving fault population may therefore provide both information on far field stress through time, and the first order hydromechanical response of the rock volume to deformation.

In the Northern Graben of New Zealand's Taranaki Basin, elements of a viable petroleum system are known to exist. Cretaceous coaly source rocks are present in the 
area, considered to be mature at depths of $4-8 \mathrm{~km}$, and may have been expelling hydrocarbons since $\sim 10$ Ma (Lovitz \& Bates, 2008a). Late Cretaceous/Paleocene marine-derived source rocks may also be present. These source rocks have generated oil discovered in the Kora-1 well, $70 \mathrm{~km}$ north of the study area (Zink \& Sykes, 2009). Viable Eocene - Miocene reservoir lithologies are present (porosities ranging from 5 25\%) (King \& Thrasher, 1996). Potentially sealing lithologies are present at Eocene and Miocene levels. Both stratigraphic and structural traps have been identified through seismic interpretation at the eastern and western margins of the Northern Graben, though, though these have been classified as sub-economic at best (Lovitz \& Bates, 2008b).

Seismic interpretation and mapping of Late Eocene to Recent strata in the Parihaka and Toro 3D seismic reflection volumes has allowed for the detailed investigation of a normal fault system to a resolution of $\sim 4 \mathrm{~m}$ vertically and $\sim 315 \mathrm{~m}$ horizontally. The geometry and displacement on 110 normal faults have been mapped. These normal faults strike predominantly NE-SW $\left(038-045^{\circ} \mathrm{E}\right)$, and are of lengths ranging from $<1$ to >20 kilometres, with maximum displacements ranging from $\sim 20-1500 \mathrm{~ms}$. Fault geometry varies from linear to segmented or en-echelon structures. About $25 \%$ of faults in the study area are reactivated Late Cretaceous structures. Normal fault activity began in the study area around $11 \mathrm{Ma}$, peaked at $5.3 \mathrm{Ma}$, and largely ceased by 1.2 Ma. Eight faults are interpreted to intersect the seafloor reflector, and may be presently active. Maximum fault dimensions are used to calculate the potential seismic hazard posed by these potentially active faults.

\subsection{Geological Setting}

The Taranaki Basin is situated on the west coast of New Zealand's North Island, covering an area of approximately $100,000 \mathrm{~km}^{2}$ (King \& Thrasher, 1996; Wood et al., 1996). The basin has a multiphase history dominated by subduction and passive margin processes. The Taranaki Basin has experienced at least two episodes of extension since $\sim 85 \mathrm{Ma}$ (King \& Thrasher, 1996). The first from $\sim 85$ - $55 \mathrm{Ma}$ as part of a Latest Cretaceous syn-rift sequence, and the second between $\sim 11$ - $0 \mathrm{Ma}$ as a Late Miocene-Pleistocene syn-rift sequence (King \& Thrasher, 1996; Giba et al., 2012). 
Faulting in the Taranaki Basin is predominantly normal with little evidence for a significant strike-slip component (King \& Thrasher, 1996; Giba, 2010). The reader is referred to a more detailed geological setting is presented in Section 2.

The Parihaka Fault is a large reactivated Cretaceous normal fault in the Northern Graben with $\sim 1500 \mathrm{~m}$ maximum displacement and $\sim 35 \mathrm{~km}$ length (shown as faults Z.1000, Z.1002, and Z.1003 in Figure 4.1). The entire length of the Parihaka Fault has undergone a $\sim 20^{\circ}$ clockwise change in fault plane strike up dip between the Late Cretaceous and Pliocene, attributed to the change in extension direction from approximately east-west to northwest-southeast over the same time period seen in Figure 1.2 (Giba et al., 2012). There have been at least 2 episodes of rifting within the study area. The first was a Late Cretaceous episode that accommodated east-west extension. The second took place between $11 \mathrm{Ma}$ and present day on faults that accommodated a north west - south east extension direction (King \& Thrasher, 1996; Giba, 2010). The latter is the focus of this thesis. The fault plane of the Parihaka Fault has a vertically twisted, en echelon geometry, which is attributed to oblique reactivation of the Late Cretaceous in basement from at $11 \mathrm{Ma}$ (Giba et al., 2012).

The Northern Graben is a sub-basin of the Taranaki Basin formed during the Late Miocene. It is a $40-50 \mathrm{~km}$ wide graben situated to the north west of the Taranaki Peninsula. The Northern Graben is bounded to the west by the Cape Egmont Fault Zone, and to the east by the Turi Fault Zone. The Cape Egmont Fault Zone comprises large, sub-parallel normal faults with a primarily eastward dip direction. The Turi Fault Zone comprises large, sub-parallel normal faults that primarily dip to the north west (King \& Thrasher, 1996). These two fault zones strike NNE, and NE, respectively, and intersect one another at the southern limit of the graben where extension ceases. Further south, contraction has dominated subduction processes since the Miocene. This region underwent Miocene vertical axis rotation about an axis coincident with the southern termination of the graben, relative to a fixed Australian Plate at rates of $0.2^{\circ} / \mathrm{Myr}$ (Walcott, 1987). 


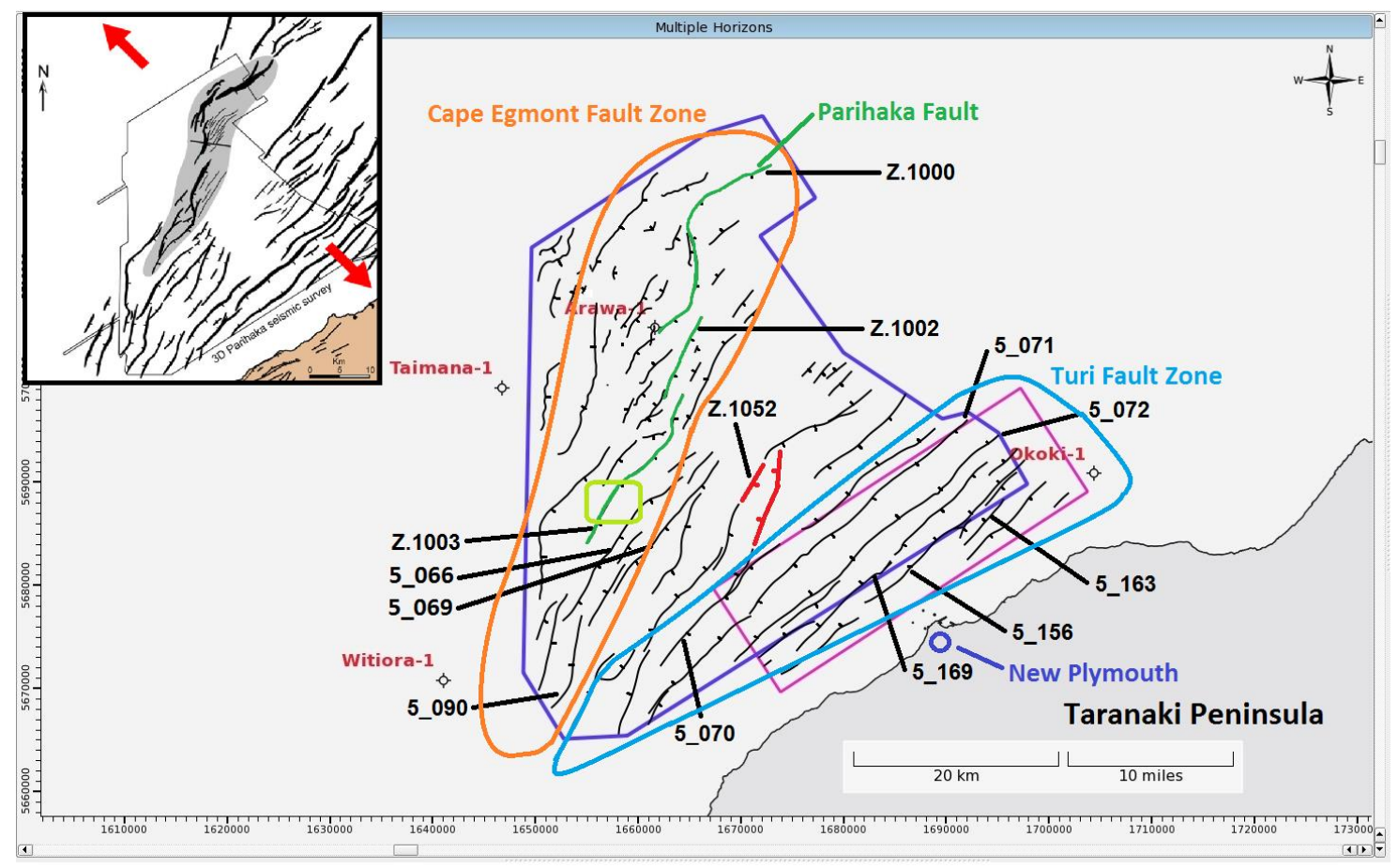

Figure 4.1 Fault map displaying the locations and dip directions of all faults analysed in this study. Names are provided for any faults referred to in the text. The Cape Egmont ant Turi fault zones within the study area are surrounded by orange and light blue polygons, respectively. The Parihaka fault is coloured green, and faults of volcanic origin coloured red. All faults that are analysed but not directly referred to in the text are shown as black polylines. The light green rectangle shows the location of the coherency attribute images in Figures 4.10-4.11. The boundary of the Parihaka 3D seismic reflection survey is shown in dark blue, and the boundary of the Toro 3D seismic reflection survey in purple. The inset shows Pliocene faults outside of the mapped 3D surveys along with the regional extension direction as mapped in Giba et al. (2012) (red arrows). The XY coordinate grid is NZ Geodetic 2000.

\subsection{Data and Methods}

3D seismic interpretation of twelve time horizons constrained by four exploration wells allows the detailed mapping of Late Eocene to Recent strata and normal faults to the limit of seismic resolution ( $4 \mathrm{~m}$ above $2 \mathrm{~s}$ two way travel time (TWTT) over an area of $1670 \mathrm{~km}^{2}$. The ratio between seismic reflection TWTT to depth is approximately 1:1 down to $2 \mathrm{~s}$ TWTT (Section 3.2.3). Depth conversion therefore does not change the first order conclusions of this chapter and has not been conducted. From here onward, faults with displacements $<2000$ ms TWTT have lengths labelled in metres. The majority of and methods relevant to this chapter have been presented in detail in Section 3. 
Fault strikes for key time horizons are presented in Figure 4.8. TrapTester calculates average fault strike by measuring the strike of each fault intersection polygon intersecting a time horizon at $100 \mathrm{~m}$ intervals in $10^{\circ}$ bins. The average fault strike and dip for all twelve horizons were plotted to analyse any systematic changes over time (Figs. A.16 - A.21). The average strike and dip of the four types of fault detailed in Section 4.4 are shown in Figure 4.9. The plots are displayed in Figures A.16 - A.21. Rose plots comparing the average strike and dip of the four types of faults in the study were also created, and are displayed in Figure 4.9. A Coherency volume was also used to constrain fault geometry, particularly fault tip locations (see Section 1.9 for more detail on the coherency seismic attribute). An example of a coherency time slice can be seen in Figure 4.2, showing the outlines of tectonic, sedimentary, and volcanic structures highlighted by the coherency attribute.

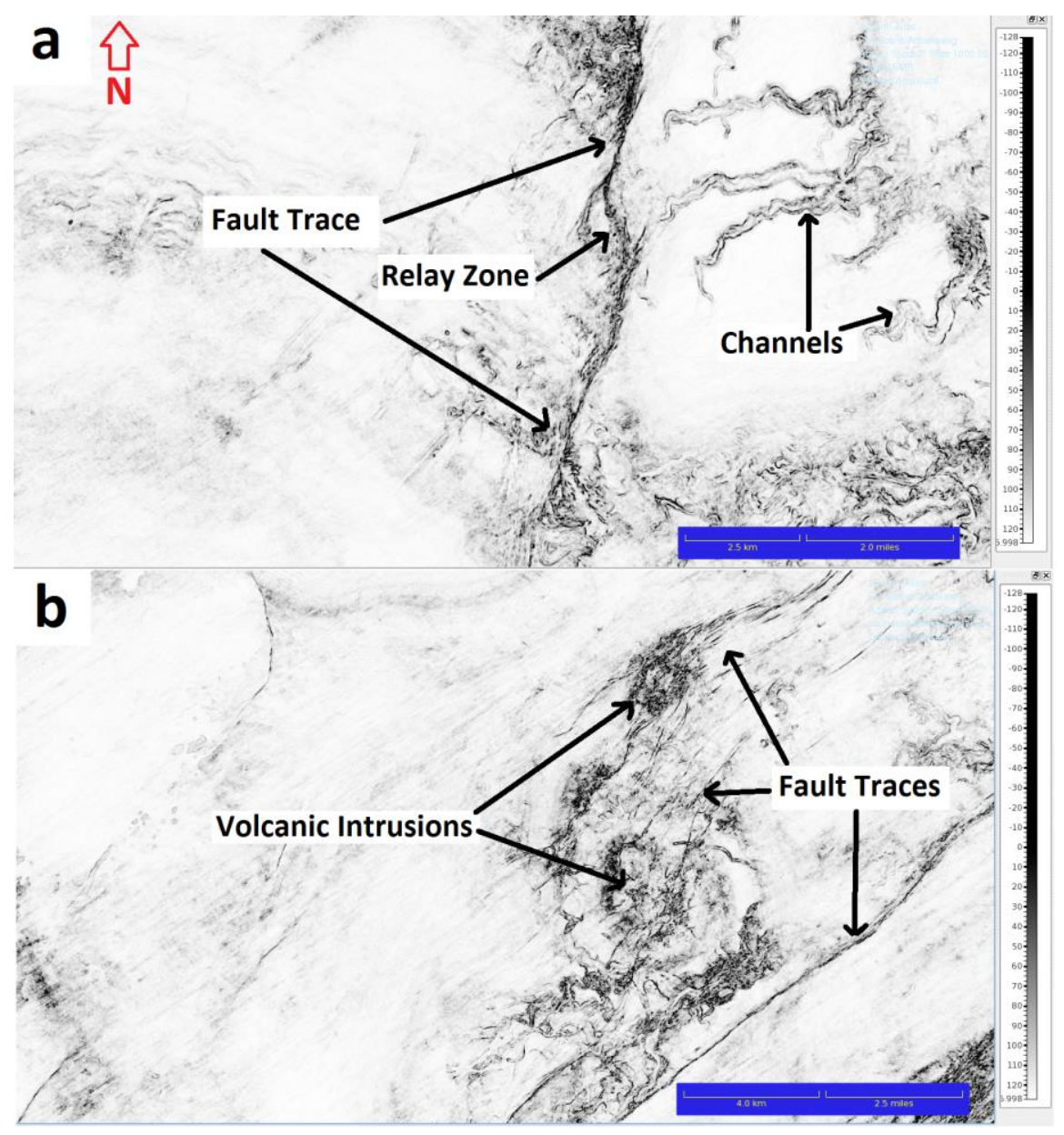

Figure 4.2 Examples of coherency seismic attribute features as seen in the Parihaka 3D coherency volume. Two coherency time slices are displayed, showing (a) Examples of fault traces and relay zones (dark lines), and sedimentary channels (dark meandering structures) at 1500 ms TWTT (b) Examples of fault traces (dark lines), and volcanic intrusions (dark speckled areas) at $780 \mathrm{~ms}$ TWTT. 
As faults in the study area are predominantly synsedimentary, the time horizon with the greatest displacement at each fault is inferred to have been deposited at the time at which the fault initiated (Walsh et al., 2002; Childs et al., 2003; Giba et al., 2012; Reilly et al., 2015). This can be evaluated by plotting fault throw at each time horizon against Myr before present. The inflection point of this curve (time associated with maximum fault throw) approximates the time displacement began accruing on the fault. The cessation of fault activity was estimated to have taken place between the time at which the most recent time horizon to be displaced by a fault was deposited and that at which a shallower, unfaulted time horizon was deposited (Giba et al., 2012). An example of fault initiation and cessation estimates at the location of maximum displacement is shown in Figure 4.3. The timing of all fault initiation and cessation estimates is provided in Tables AT.1 - AT.3.

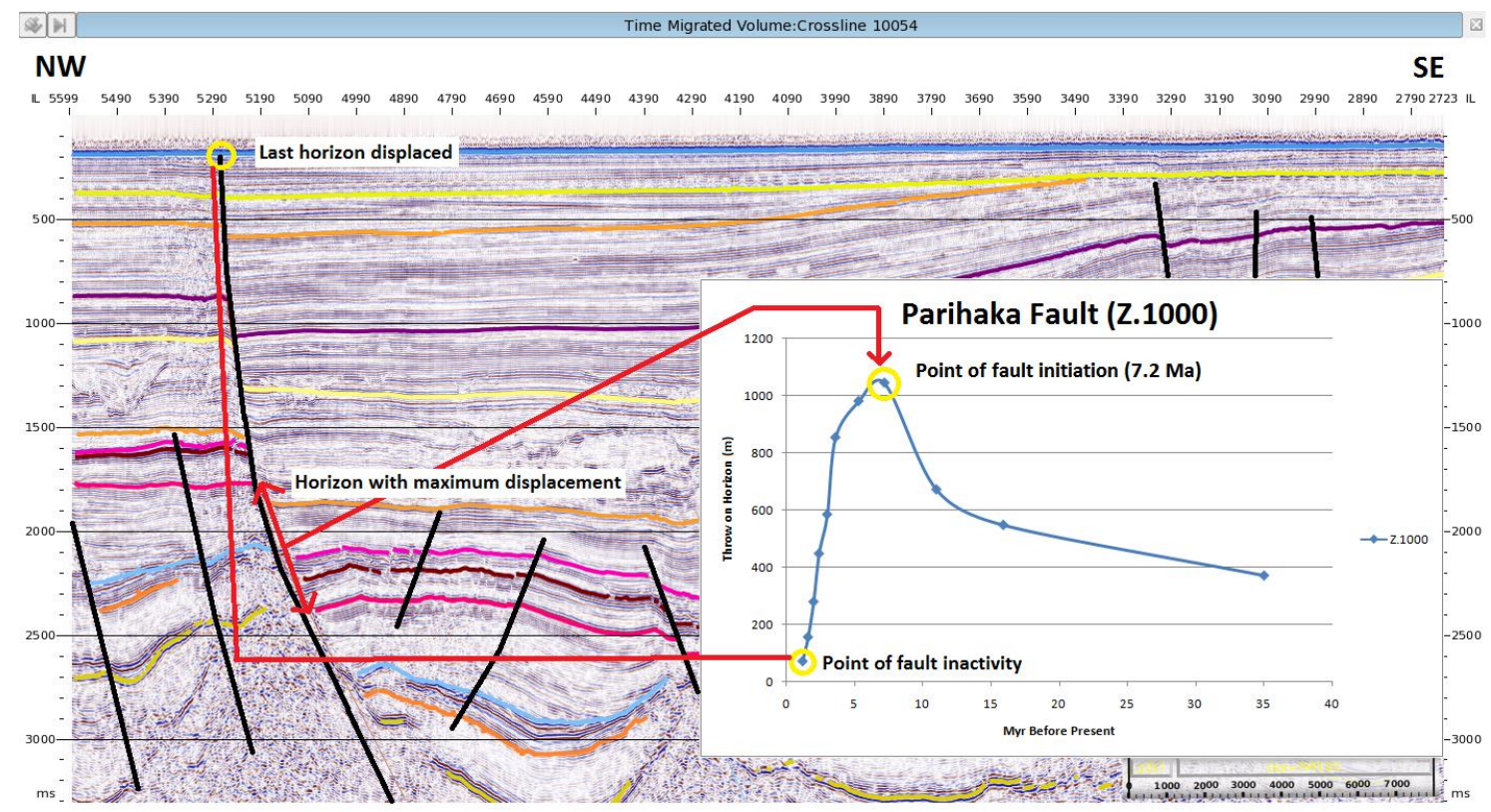

Figure 4.3 Illustration of fault initiation and cessation measurements demonstrating how fault initiation and cessation/inactivity timing was calculated from seismic data. The age of fault initiation for each of the $\mathbf{1 1 0}$ faults in the study area is estimated by plotting fault throw at each time horizon against Myr before present (e.g. Parihaka Fault segment Z.1000 in the above image). The inflection point of this curve (point of maximum fault throw and its associated time in Myr before present) approximates the time displacement began accruing on the fault. The cessation of fault activity was estimated by the location between the most recent time horizon to be displaced by a fault and a shallower, unfaulted time horizon

This method for estimating the onset of fault activity assumes all faults in the study area are growth faults. During the Late Miocene and Plio - Pleistocene, my results 
show that fault throw displacement rates in the Northern Graben have averaged $\sim 0.16$ $\mathrm{mm} / \mathrm{yr}$. Sedimentation rates through the same period have averaged $\sim 0.6 \mathrm{~mm} / \mathrm{yr}$ (King \& Thrasher, 1996). Therefore, sediment supply outstripped fault activity over this period, allowing fault growth strata to be recorded. This method provides a good estimate of the initiation age of most faults in the study area due to high sedimentation rates. The fact that some faults appear to initiate before the apparent $11 \mathrm{Ma}$ period of fault initiation in the study area seen in Figure 4.13 (also described in the Parihaka Fault study of Giba et al. (2012) highlights a possible issue with using this method to determine fault initiation timing. This error typically occurs on faults with displacements $<50 \mathrm{~ms}$, at depths of $>2000 \mathrm{~ms}$, where a slight time horizon mispick, or attenuation of seismic data will cause a fault to appear to have its maximum displacement (and hence initiation point) older than $11 \mathrm{Ma}$. For these reasons, initiation ages older than $11 \mathrm{Ma}$ have been excluded from the analysis.

Faults near the boundary of the Parihaka and Toro 3D seismic reflection volumes typically enter the study area at several kilometres depth and do not intersect with the mapped time horizons (as seen in Figures $4.3-4.5$ ). This leads to erroneous fault initiation and inactivity ages being estimated, because if a fault intersects time horizons older than $11 \mathrm{Ma}$, but its maximum displacement lies outside the study area, its maximum displacement and apparent initiation age within the study area will be incorrect. Similarly, as fault inactivity was determined by the location between the most recent time horizon to be displaced by a fault and a shallower, unfaulted time horizon, if this location lies outside the study area, the age of fault cessation would be underestimated. These issues were corrected using the 2D seismic reflection data surrounding the study area wherever possible. In these cases, mapped time horizons were extended sufficiently to encompass the location of maximum displacement, cessation of activity, and fault tip extent. The Turi Fault Zone was problematic due to poor data quality and the complexity of the fault zone, and therefore maximum displacements recorded in this zone have a higher uncertainty than other well constrained faults in the study area. 


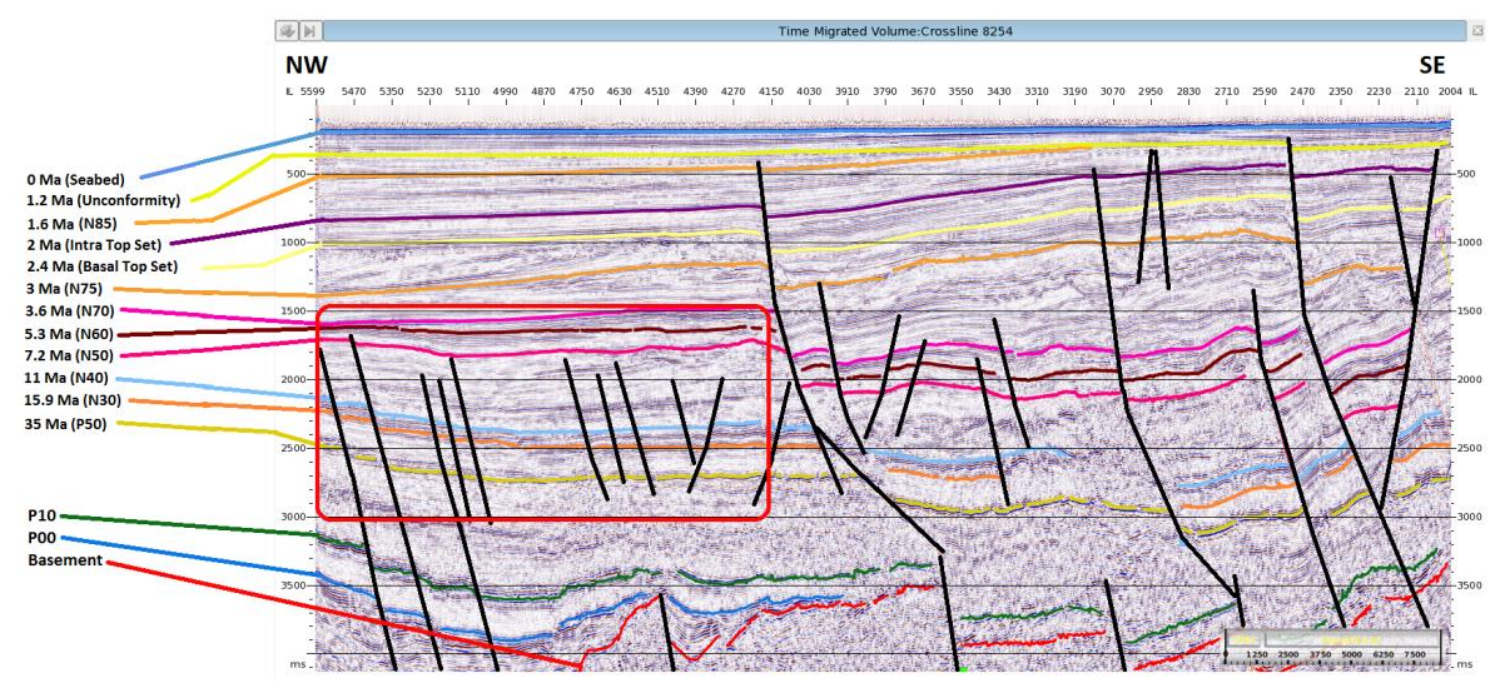

Figure 4.4 Section View of Crossline 8254 showing faults appearing to have initiated before 11 Ma. This observation is based on maximum displacements being on time horizons older than 11 Ma. A zoomed view is visible in Figure 4.5.

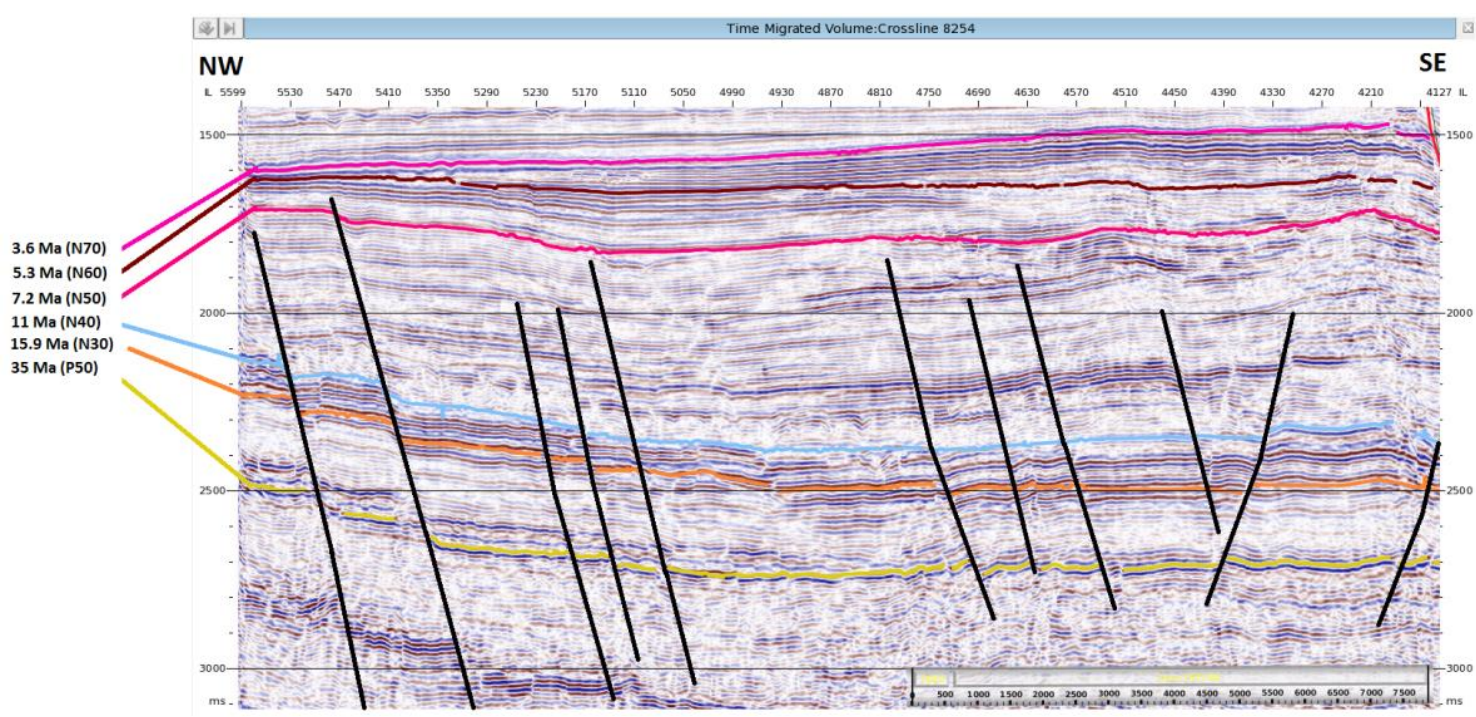

Figure 4.5 Zoomed section view of the red rectangle in Figure 4.4. Faults can be seen with greater displacements on $15.9 \mathrm{Ma}$ (N30) and $35 \mathrm{Ma}$ (P50) time horizons than on the $11 \mathrm{Ma}$ (N40) time horizon, which is the current best estimate of the age at which fault initiation began in the study area (Giba et al., 2012).

\subsection{Normal Fault Geometry and Kinematics}

Faults within the study area can be divided into four categories: large normal faults that initiated in the Late Miocene-Pleistocene (displacements of $20-1400 \mathrm{~m}$, lengths of $\sim 1-33 \mathrm{~km}$ ); large normal faults that have reactivated Late Cretaceous structures between 11 and $2 \mathrm{Ma}$ (displacements of $\sim 20-1000 \mathrm{~m}$, lengths of $\sim 1-23 \mathrm{~km}$ ); small 
normal faults formed antithetic to reactivated Late Cretaceous structures (displacements of $\sim 20-200 \mathrm{~m}$, lengths of $\sim 1-11 \mathrm{~km}$ ); small normal faults potentially associated with the gravitational collapse of intrusive Pliocene arc magmatism (displacements of $\sim 20-450 \mathrm{~m}$, lengths of $\sim 1-7 \mathrm{~km}$ ). Figures A.23 - A.26 show the locations of faults of each of these types. The number of faults of each type is shown in Figure 4.6, with examples of each type in section view displayed in Figure 4.7.

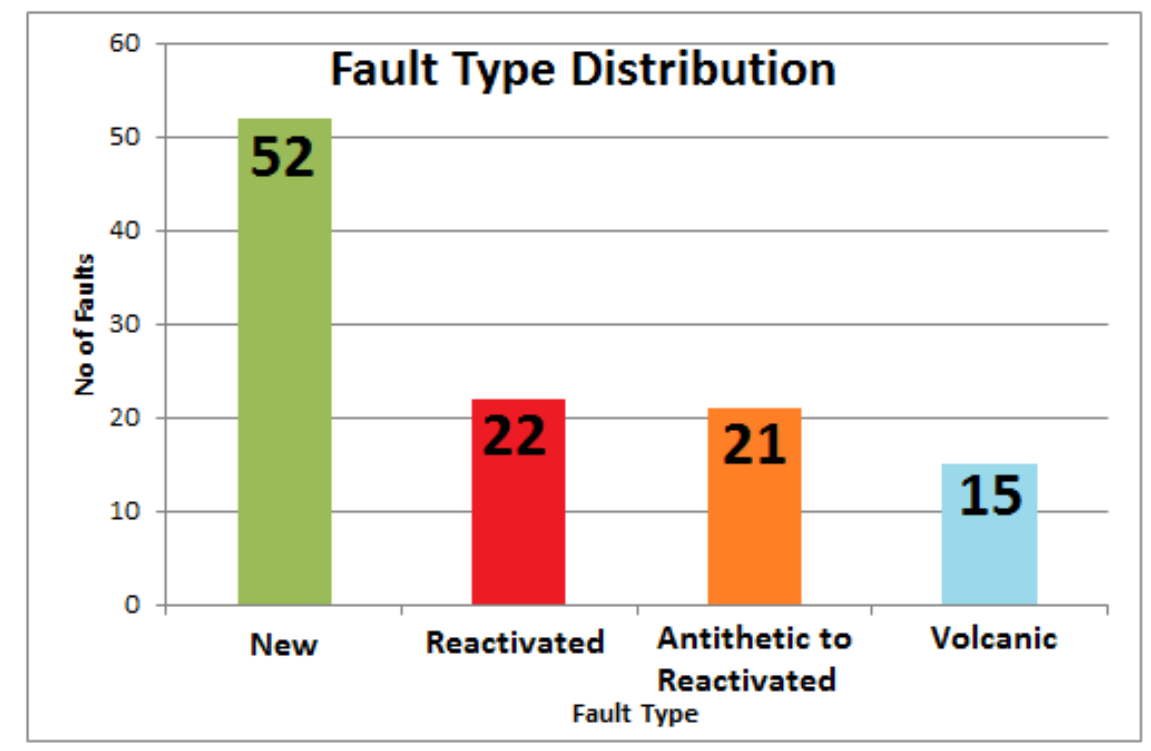

Figure 4.6 Figure displaying the number of faults of each type within the study area.

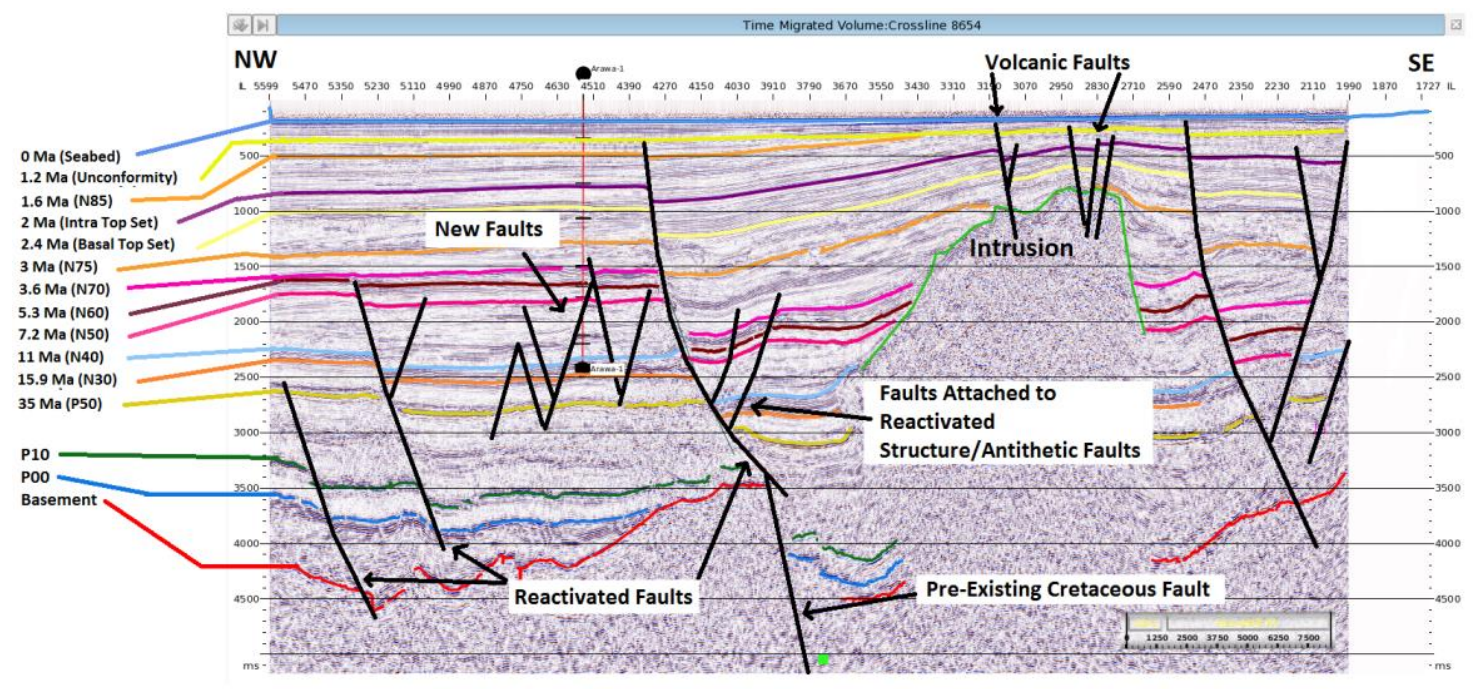

Figure 4.7 Section view image showing examples of the four types of faults observed in the study area. 


\subsubsection{Fault Dimensions}

Each of the four fault types displays similar geometry but differs from the rest in terms of scale. Normal faults initiated in the Late Miocene-Pleistocene (new faults) have typical displacements of $\sim 20-1400 \mathrm{~m}$, with lengths of $\sim 1-33 \mathrm{~km}$. These faults typically displace two to eight of the twelve mapped time horizons, and tend to propagate vertically through 200 - 8000 ms TWTT of strata. The faults are broadly linear in both map (Fig. A.23) and section view (Fig. 4.7), with variation in strike $\sim 30^{\circ}$ either side of the $040^{\circ}$ average in the study area (Fig. 4.9). Most are located within 5 $\mathrm{km}$ of the two large antithetic graben bounding fault zones in the study area (Turi and Cape Egmont Fault Zones, see Section 2).

Normal faults that are reactivated Late Cretaceous structures have typical displacements of $\sim 20-1000 \mathrm{~m}$, with lengths of $<1-23 \mathrm{~km}$. These faults typically displace ten or more of the twelve mapped time horizons, and propagate vertically between $200-6000$ s TWTT of strata. These faults are curved in both map (Fig. A.24) and section view (Fig. 4.7), with variation in strike $\sim 40^{\circ}$ either side of the $040^{\circ}$ average in the study area. Reactivated faults are typically segmented and have relay zones that connect between the segments (e.g. Fig. 4.2). These faults are mainly situated within the two large antithetic graben bounding fault zones in the study area (Turi and Cape Egmont Fault Zones, see Section 2).

Normal faults formed antithetic to reactivated Late Cretaceous structures have typical displacements of $\sim 20-200 \mathrm{~m}$, with lengths of $\sim 1-11 \mathrm{~km}$. These faults typically displace two to four of the twelve mapped time horizons, and propagate vertically between 50 - 2000 s TWTT of strata. These faults appear linear in map view (Fig. A.25) and are antithetic to the principal fault (Fig. 4.7). Variation in strike $\sim 30^{\circ}$ either side of the $040^{\circ}$ average in the study area is observed on these faults. The faults intersect and accommodate changes in the geometry of the fault plane up sequence from the original geometry of the Cretaceous fault.

Normal faults associated with intrusive Pliocene magmatism have typical displacements of $\sim 20-450 \mathrm{~m}$, with lengths of $\sim 1-7 \mathrm{~km}$. These faults typically displace two to four of the twelve mapped time horizons, and propagate vertically between 50 
- 2000 s TWTT of strata. These faults appear linear in map view (Fig. A.26), with variation in strike $\sim 25^{\circ}$ either side of the $040^{\circ}$ average in the study area observed on these faults. The faults are located exclusively above and within the Southern Intrusive Complex.

\subsubsection{Fault Orientation}

Within uncertainty, fault strikes in the study area show are uniform at each of the main phases of fault activity (11 Ma (N40) as the onset of faulting; $5.3 \mathrm{Ma}$ (N60) as the period of maximum fault initiation and accrual of displacement; 2 Ma (Intra Top Set) as $\sim 70 \%$ of faults were ceasing to accrue displacement; and $0 \mathrm{Ma}$ (Seabed) as the last potentially active faults) (Fig. 4.8). The average fault strike and dip for each of the twelve horizons can be found in Figures A.13 - A.18. Average fault strikes are within \pm $5^{\circ}$ of normal to the regional $310^{\circ}$ extension direction (estimated by interpretation of patterns of Taranaki Basin fault geometry and focal mechanisms) suggested by King and Thrasher (1996), and within $\pm 10^{\circ}$ of normal to the $315^{\circ}$ extension direction (estimated by patterns of Taranaki Basin fault geometry) suggested by Giba et al. (2010); Giba et al. (2012).

Fault strike is shown to vary within a range of $355^{\circ}-080^{\circ}$ at each time horizon level, but average fault strike at each time horizon is between $038^{\circ}-045^{\circ}$, with the average being $040^{\circ}$ (Fig. 4.8). This result is consistent with the faults striking normal to the regional Late Miocene - Pliocene northwest-southeast extension direction (King \& Thrasher, 1996; Giba, 2010; Giba et al., 2012). Figure 4.8 shows a $7^{0}$ clockwise rotation in average fault strike from $11 \mathrm{Ma}$ to present, though this is within the $\pm 10^{\circ}$ uncertainty for each of the main phases of fault activity. These data suggest that the extension direction has not changed over the past 11 Myr in the study area. Additionally, to test whether different fault types (new, reactivated, antithetic to reactivated, or volcanic) have any systematic differences in geometry, average fault strike and dip were plotted (Fig. 4.9). Average fault strikes for each fault type vary from $033^{\circ}-042^{\circ}$ and within uncertainty are indistinguishable from one another. Reactivated faults have the greatest variation in strike range, varying between $350^{\circ}-075^{\circ}$, due 
predominantly to the influence of underlying north-south Cretaceous fault trends and the structures developed to accommodate the most recent phase of extension.

Fault dip also varies between $30-80^{\circ}$ at each time horizon level, with variability being greater for older time horizons (Figs. A.13 - A.18). Average fault dips shallow with increasing time horizon age, with average dips at $35 \mathrm{Ma}$ (P50) being $40-70^{\circ}$, while dips at the $1.2 \mathrm{Ma}$ (Unconformity) and $0 \mathrm{Ma}$ (Seabed) time horizons are between $60-80^{\circ}$. Only data from $\leq 2 \mathrm{~ms}$ TWTT are included in this analysis, as data from $>2 \mathrm{~ms}$ TWTT no longer has a 1:1 TWTT/depth relationship which leads to a distortion of the true geometry as viewed in TWTT.
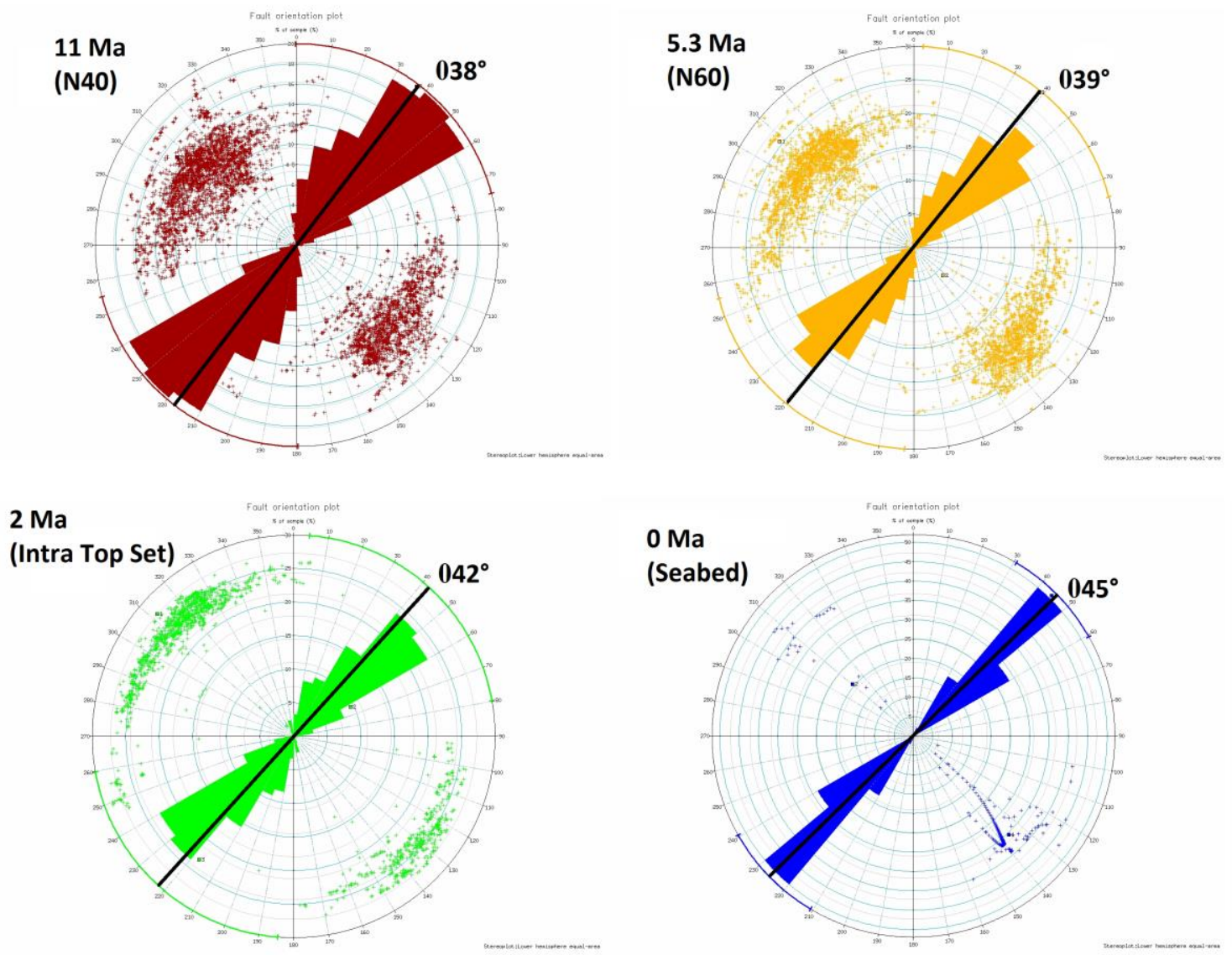

Figure 4.8 Rose plots for the four key time horizons in the study area. The range of fault strike directions is given by the coloured part of the outer circle, and black circles represent fault dip. The average fault strike direction for the time horizon is given by an annotated solid black line. Poles to fault planes are plotted in order to observe fault dip distribution. 


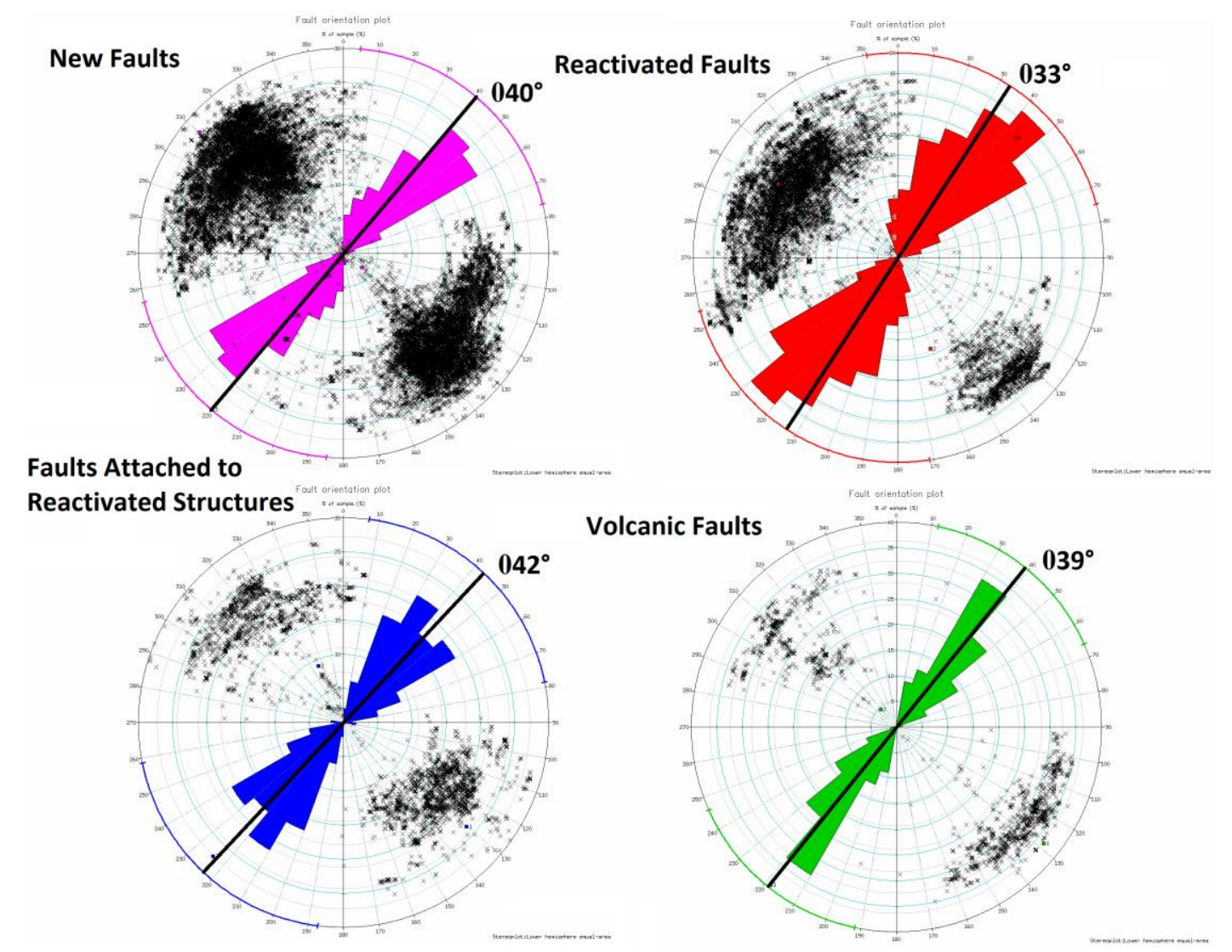

Figure 4.9 Rose plots for each of the four fault types in the study area. . The range of fault strike directions is given by the coloured part of the outer circle, and black circles represent fault dip. The average fault strike direction for the time horizon is given by an annotated solid black line. Poles to fault planes are plotted in order to observe fault dip distribution.

While there is little evidence to suggest fault strike has changed significantly in the study area over the last 11 Ma, the kinematics of rifting may have changed during this time. To investigate this, linear features crossing faults (i.e. channels) were analysed for evidence of horizontal displacement along a fault trace. The Parihaka 3D coherency attribute volume was flattened on the 7.2 Ma (N50) and 2.4 Ma (Basal Top Set) time horizon grids (oldest and youngest time horizon levels clearly resolved in coherency attribute data). Flattening on a horizon removes the normal component of displacement and restores features crossing the faults to their original position. Kinematic indicators placed horizontally across a normal fault would indicate an extension direction different to that estimated by fault geometry alone. Figures $4.10-$ 4.11 at two different flattened horizons (7.2 and $2.4 \mathrm{Ma}$ ) show no resolvable evidence for channels being offset across normal faults. This suggests that normal faults in this area have not accommodated any resolvable component of strike-slip since their initiation. 

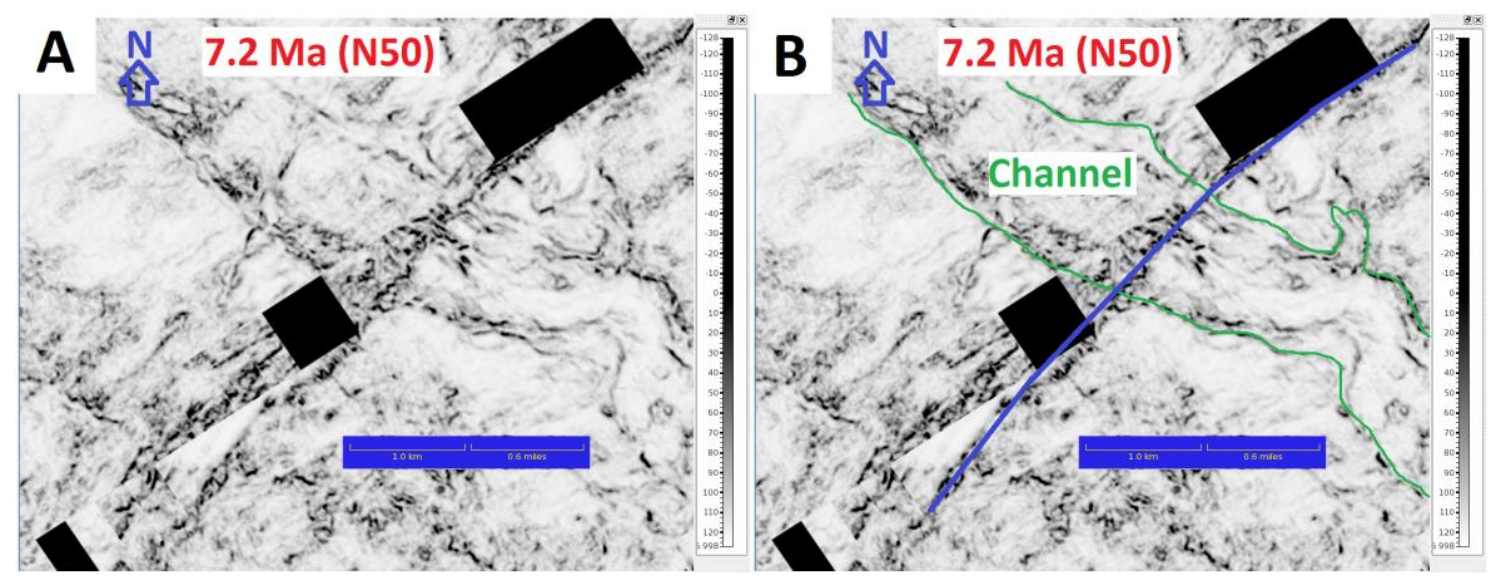

Figure 4.10 Images displaying kinematic markers crossing a fault. The images above show a coherency time slice flattened on the 7.2 Ma (N50) time horizon grid ( 1800 ms TWTT). The locations of these images are provided in Figure 4.1. In (A) an uninterpreted version of the image is shown, and in (B) an interpreted version is shown. At the available resolution, linear channel features crossing the fault do not appear to have been offset in a strike slip fashion. Fault traces are shown by purple lines, and channels are outlined in green. Black filled polygons are flattening artefacts.

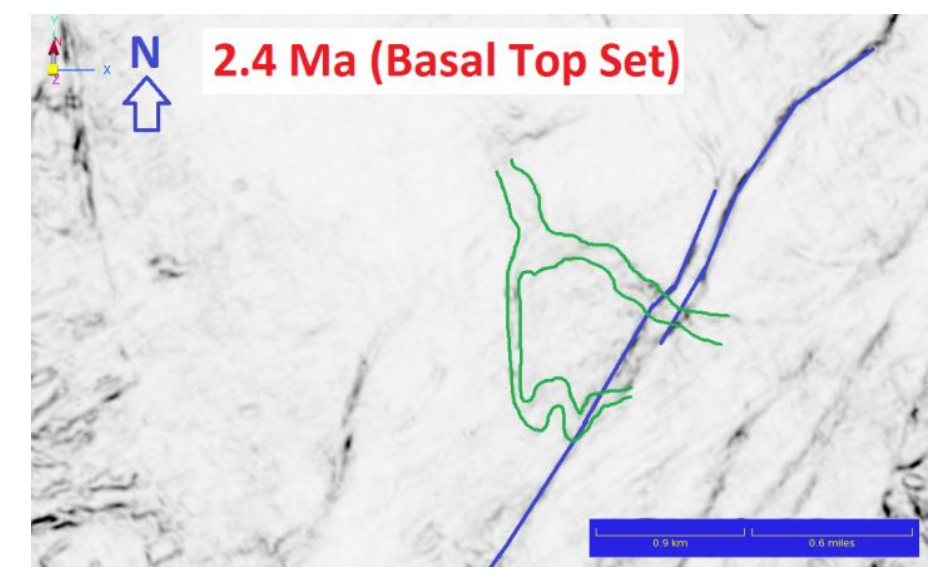

Figure 4.11 Image displaying kinematic markers crossing a fault. The image above shows a coherency time slice flattened on the $2.4 \mathrm{Ma}$ (Basal Top Set) time horizon grid ( 1000 ms TWTT). The locations of this image is provided in Figure 4.1. At the available resolution, linear channel features crossing the fault do not appear to have been horizontally offset. Fault traces are shown by purple lines, and channels are outlined in green.

\subsubsection{Extension and Subsidence in the Northern Graben}

Late Miocene - Pliocene faulting in the Northern Graben has allowed for $\sim 1 \mathrm{~km}$ and $\sim 3$ $\mathrm{km}$ of extension in the southern and northern ends of the graben, respectively, with the graben opening in a fan-like fashion since the Late Miocene (King \& Thrasher, 1996). The Parihaka Fault has accommodated most of this extension, accounting for $\sim 2$ $\mathrm{km}$ in the northern extremity of the graben. This extension allowed for up to $2 \mathrm{~km}$ of Late Miocene - Pliocene subsidence relative to the graben flanks. Total sediment 
thickness in the Northern Graben is $\sim 9 \mathrm{~km}$ (King \& Thrasher, 1996). The extent and distribution of Late Miocene - Pliocene extension (in $\mathrm{km}$ ) and subsidence throughout the Northern Graben can be seen in time horizon grids (Figs. A.5 - A.10) and sediment isochore maps (Figs. A.11 - A.12). Extensional faulting and related subsidence can be seen to be at a local maximum in a depression near the extreme north of the study area, next to Parihaka Fault segment (Z.1000) (Fig. 4.12). This zone of subsidence is bounded to the south by the Southern Intrusive Complex, which has dragged sediments within $\sim 0-2 \mathrm{~km}$ of it upward during intrusion. This intrusion has created a synclinal structure that has increased sediment accommodation space between the Southern Intrusive Complex and Parihaka Fault. The zone is named the Arawa SubBasin in the work of Johnston (2014). The 3.6 Ma (N70) time horizon grid is shown in Figure 4.12 as an example of how extension and subsidence are distributed throughout the study area (the red line in the figure shows the approximate location of maximum extension across the study area).

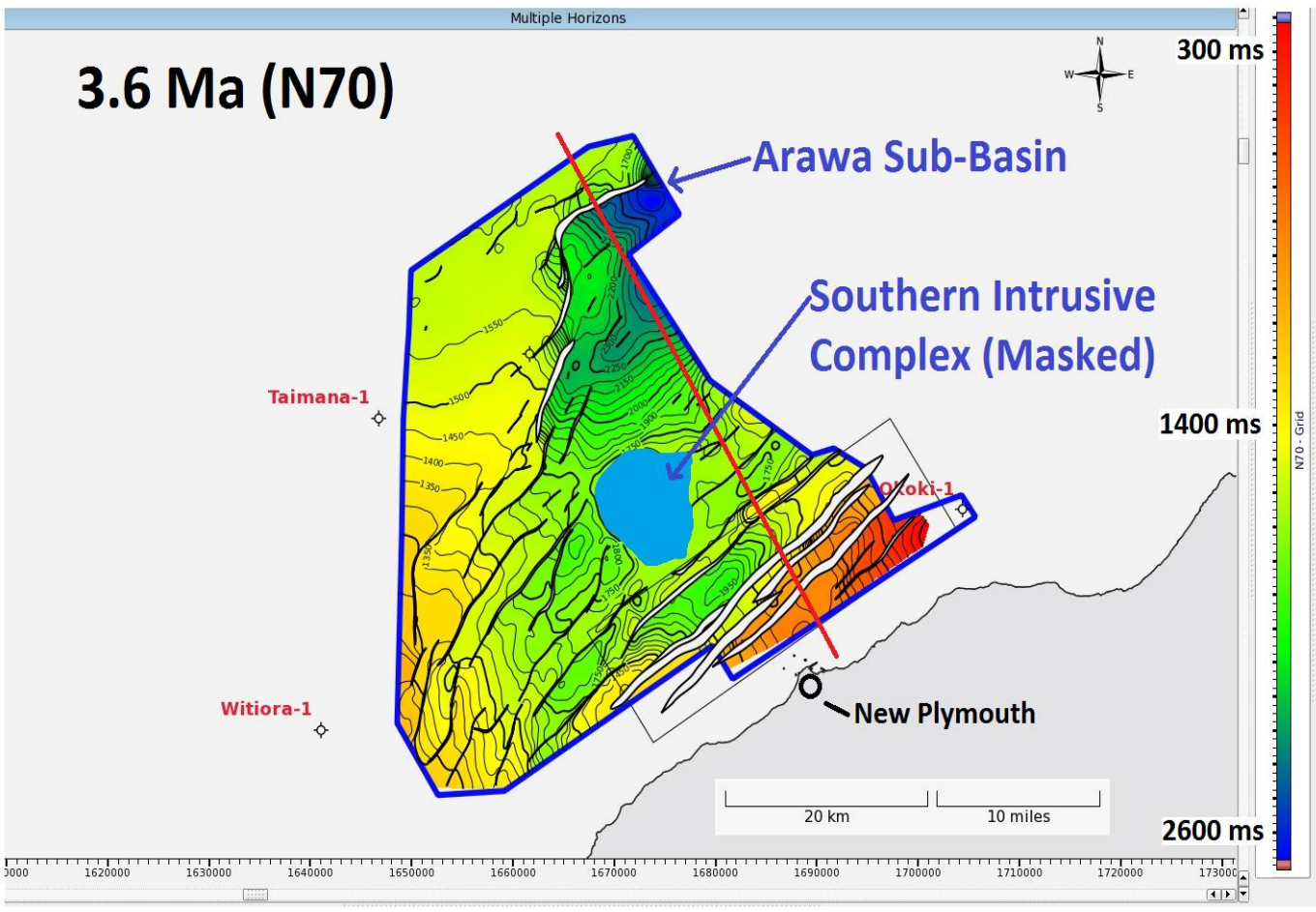

Figure 4.12 Map displaying patterns of extension and subsidence in the study area. The 3.6 Ma (N70) time horizon grid is displayed in the above map. Faults are represented by black polylines, with depth contours at $\mathbf{5 0}$ ms intervals. The blue polygon in the centre of the image masks the Southern Intrusive Complex. The blue border polygon is the combined Parihaka and Toro 3D seismic reflection survey gridding boundary, and the thin black polygon is the Toro 3D seismic reflection survey boundary. The red line displays the approximate location of maximum extension in the study area. The XY coordinate grid is NZ Geodetic 2000. 


\subsection{Temporal Evolution of a Normal Fault System}

The latest phase of fault activity within the Parihaka and Toro 3D seismic reflection surveys developed between $\sim 11$ - 0 Ma as part of a Late Miocene-Recent syn-rift sequence in the Taranaki Basin. Spatiotemporal patterns of fault evolution over this period are displayed as a series of ten maps showing faults that were active at each of the mapped time horizons in Figures 4.13 - 4.14. These maps display active faults as coloured fault planes, superimposed on a map from the time of peak fault activity at $5.3 \mathrm{Ma}(\mathrm{N} 60)$.

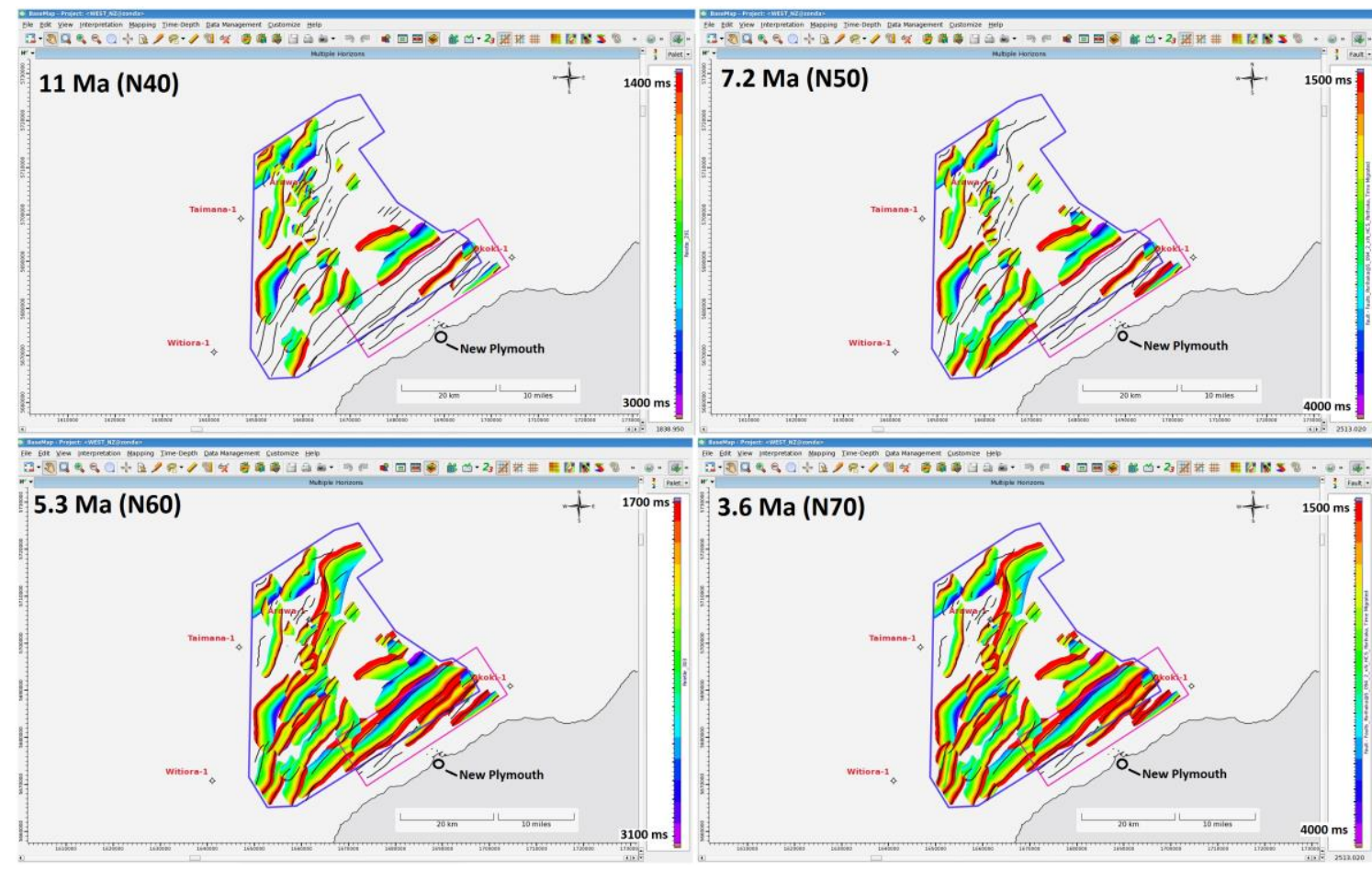

Figure 4.13 Maps displaying which faults were active at which depths at each of the $11-3.6 \mathrm{Ma}$ time horizons. Whole fault planes are displayed, with coloured contours representing the depth to which they penetrate. A colour-depth scale is given to the right of each map. The XY coordinate grid is NZ Geodetic 2000. 


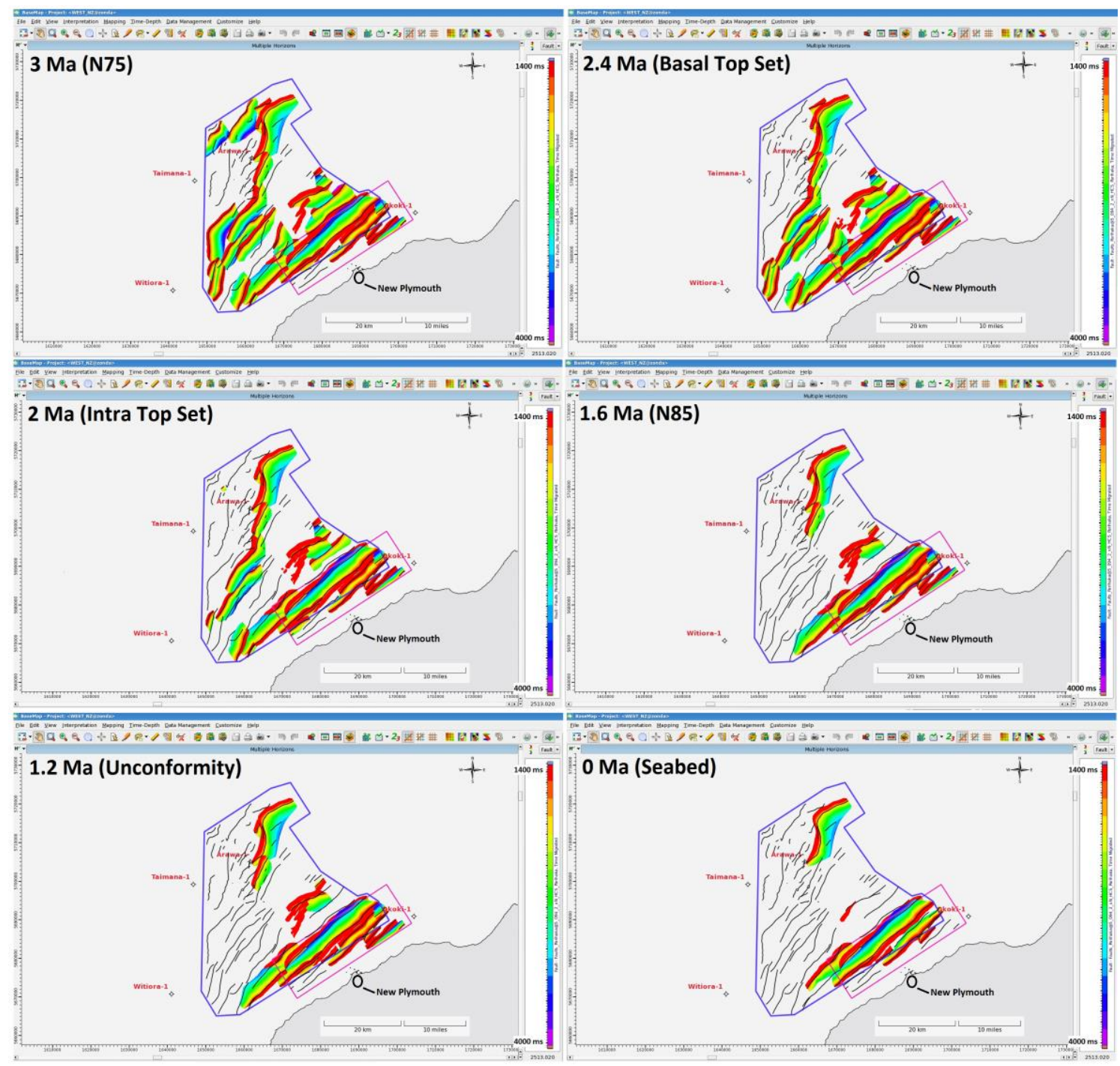

Figure 4.14 Maps displaying which faults were active at which depths at each of the $3 \mathrm{Ma}-0 \mathrm{Ma}$ time horizons. Whole fault planes are displayed, with coloured contours representing the depth to which they penetrate. A colour-depth scale is given to the right of each map. The XY coordinate grid is NZ Geodetic 2000.

\subsubsection{Fault Initiation}

Within the resolution and/or uncertainty of this study, no faults are interpreted to be active before $11 \mathrm{Ma}$ (e.g. Figure 4.3). The absence of fault activity before this time is supported by the presence of a network of polygonal faults that were observed in the north west corner of the study area between the $35 \mathrm{Ma}$ (P50) and $11 \mathrm{Ma}$ (N40) time horizons (Fig. A.33), suggesting tectonic quiescence at that period in time. Polygonal faults develop by dewatering and dissolution of very low permeability hemipelagic sediments, and are interpreted to cease formation with the deposition of coarser grained sediments (e.g. such as those typically associated with tectonic activity) 
(Cartwright, 2011). Figure 4.15 provides a summary of the time horizon interpreted with maximum displacement for each fault in the study, which in turn approximates the time at which each fault initiated. At $11 \mathrm{Ma}$ faults in the study area begin to develop. This result is consistent with existing research by Giba et al. (2010); Giba et al. (2012). Faults initiating at this time are almost exclusively located on the western side of the Parihaka 3D seismic reflection volume, clustered around the Parihaka Fault, though the Parihaka Fault itself was not active then. Between 11 and 7.2 Ma faults in the study area began to initiate/reactivate. At 7.2 Ma (N50), displacement on faults that had already initiated continued to accrue, mainly on large reactivated faults within the Cape Egmont and Turi fault zones.

Displacement profiles (Fig. 4.16) show the Parihaka fault began accruing displacement at 5.3 Ma (N60), which differs from the 3.7 Ma proposed in Giba et al. (2012). All segments of the Parihaka fault mapped in this study have initiation ages older than 3.7 Ma. The disparity in initiation ages between this study and Giba et al. (2012) is the increased temporal resolution. Giba et al. (2012) mapped time horizons for 3.7 and 8 $\mathrm{Ma}$, while this study mapped two additional time horizons at $5.3 \mathrm{Ma}$ (N60) and 7.2 $\mathrm{Ma}$ (N50) between these times. Figure 4.16 displays displacement profiles for three Parihaka Fault segments (Z.1000, Z.1002 and Z.1003), and has the points of max cumulative throw (estimated time of fault initiation) for all three segments at $5.3 \mathrm{Ma}$ (N60).

By 5.3 Ma (N60) over $70 \%$ of faults in the study area were active and accruing displacement. A similar proportion of faults were active in the study area at $3.6 \mathrm{Ma}$ (N70). This peak in number of active faults indicates that this period of time corresponded with peak extension in the study area (Section 5.4). Faults initiating after $3 \mathrm{Ma}$ (N75) were typically associated with the Southern Intrusive Complex. 


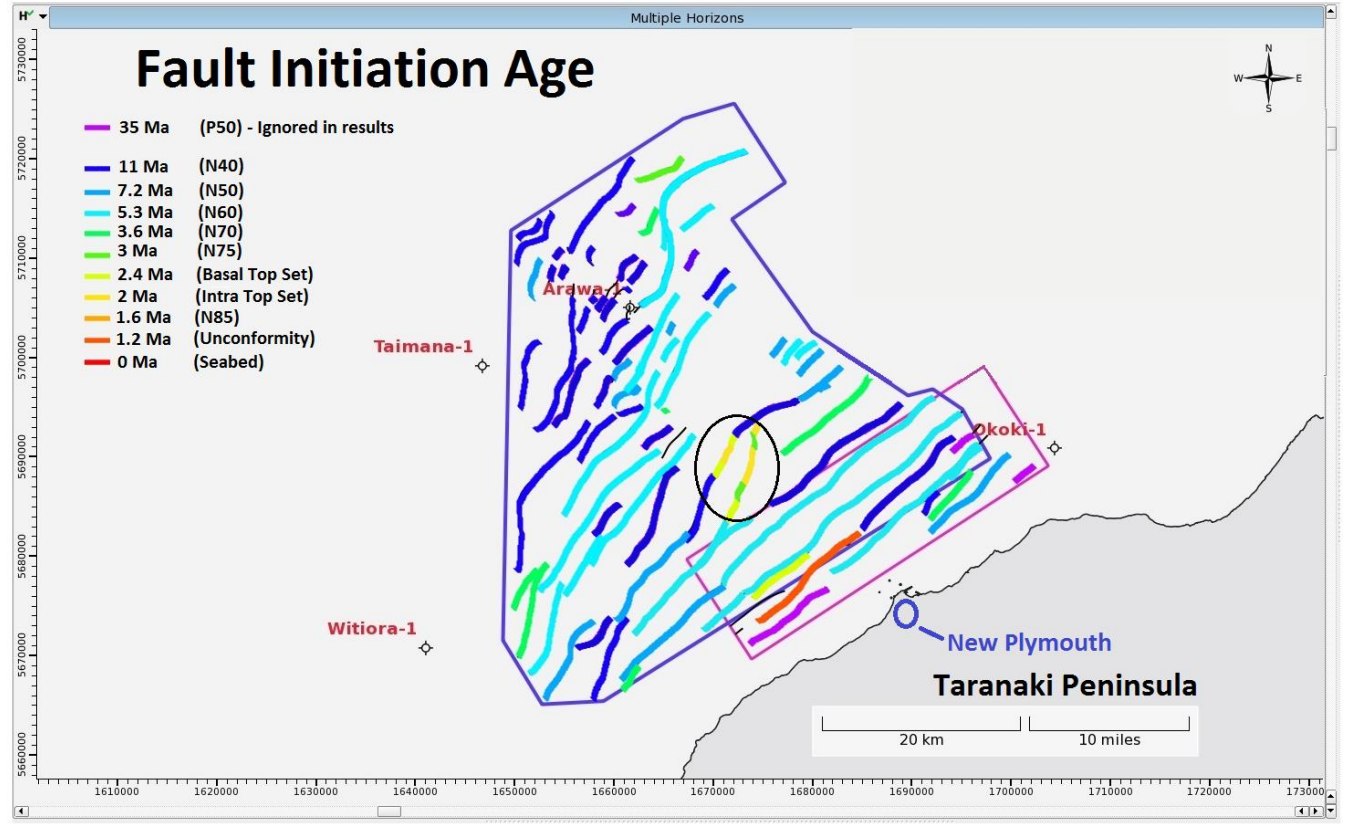

Figure 4.15 Figure showing the location of all faults in the study area, coloured to denote the time horizon nearest their estimated initiation (or reactivation in some cases). The boundary of the Parihaka 3D seismic reflection survey is shown in blue, and the boundary of the Toro 3D seismic reflection survey in purple. The approximate location of the Southern Intrusive Complex is given with a black oval. A further summary map of fault initiation locations is provided in Figures A.19 - A.20. The XY coordinate grid is NZ Geodetic 2000.

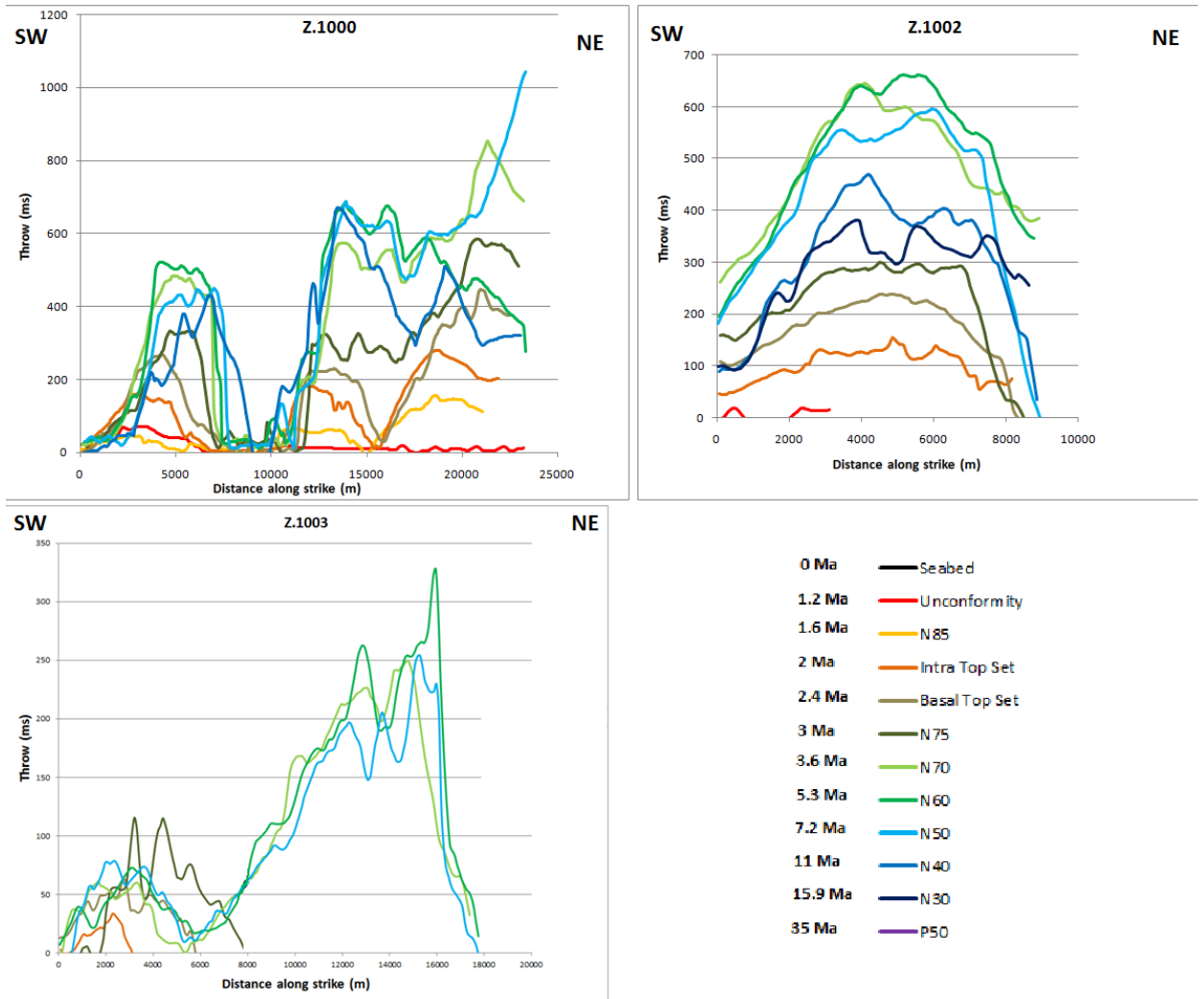

Figure 4.16 Displacement profiles for each of the three Parihaka Fault segments. The 5.3 Ma (N60) time horizon shows maximum displacement on each of these profiles, and approximates the initiation age of the fault. Locations of the segments are given in Figure 4.1. 


\subsubsection{Fault Inactivity}

Accrual of displacement on faults across the study area began to wane from $3 \mathrm{Ma}$ (N75), with $70 \%$ of faults inactive by $2 \mathrm{Ma}$ (Intra Top Set) (Figs. $4.13-4.17$ ). The time at which fault activity ceased was estimated as the last time horizon which was displaced by a fault (Fig. 4.3). Figure 4.17 provides a visual summary of patterns of fault inactivity/death. The majority of faults ceased activity at or near mapped horizons. For faults ceasing activity between mapped horizons the next unfaulted horizon is taken as the age of inactivity within uncertainty. Tables AT.1 - AT.3 list the period through which individual faults were active.

From 3.0 Ma (N75), smaller faults (lengths of $2-10 \mathrm{~km}$, displacements of $20-100 \mathrm{~m}$ ) that are peripheral to the large, reactivated structures cease accruing displacement (Fig. 4.17). This trend is most pronounced to the north west of the study area and continues through the $2.4 \mathrm{Ma}$ (Basal Top Set) and $2 \mathrm{Ma}$ (Intra Top Set) time horizons. By the $1.6 \mathrm{Ma}$ (N85) time horizon, all faults in the western side of the study area are inactive, including large reactivated faults (displacements $\sim 20-1000 \mathrm{~m}$, lengths $<1-$ $23 \mathrm{~km})$.

By the 1.2 Ma (Unconformity) time horizon, The Turi Fault Zone and the Parihaka Fault (northern segment of the Cape Egmont Fault Zone) are the last large faults remaining active (displacements $\sim 20-1000 \mathrm{~m}$, lengths $<1-20 \mathrm{~km}$ ) (Fig. 4.17). Some minor faults (displacements $\sim 20-450 \mathrm{~m}$, lengths $\sim 1-7 \mathrm{~km}$ ) associated with the Pliocene intrusion of the Southern Intrusive Complex may be still active. In general, a south east migration in the locus of fault activity is observed. Faults typically cease activity to the north west at older ages than to the south east. 


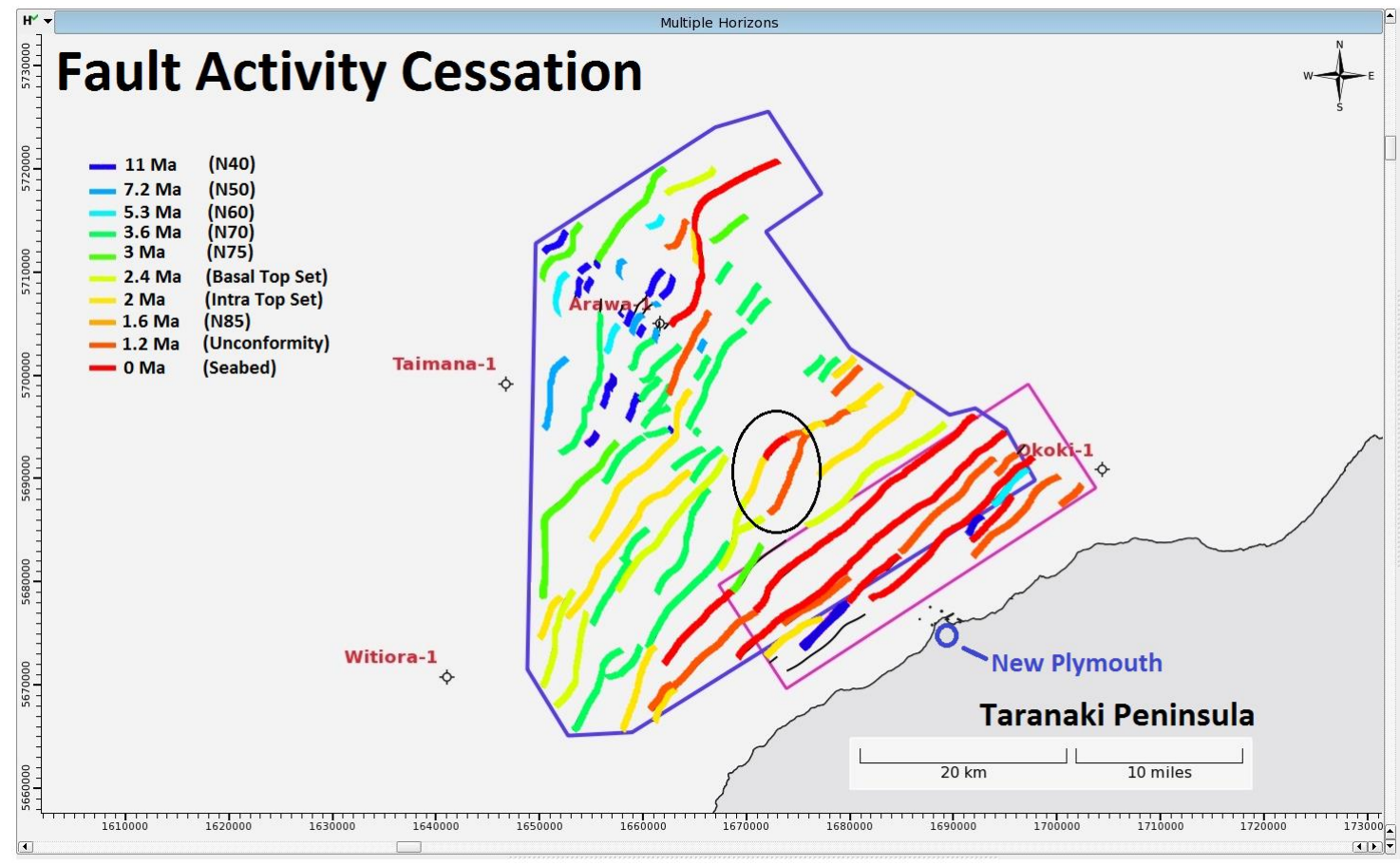

Figure 4.17 Figure showing the location of all faults in the study area, coloured to denote the time horizon nearest the cessation of their activity (the last time horizon to be displaced by the fault). The boundary of the Parihaka 3D seismic reflection survey is shown in blue, and the boundary of the Toro 3D seismic reflection survey in purple. The approximate location of the Southern Intrusive Complex is given with a black oval. A further summary map of fault inactivity locations is provided in Figures A.21 - A.22. The XY coordinate grid is NZ Geodetic 2000.

\subsubsection{Potentially Active Faults}

Eight faults in the study area displace the seabed or the reflector immediately below the seabed reflector, and could be considered potentially active (Figs. 4.18-4.20). This is illustrated in Figures $4.18-4.20$ where displaced or deformed reflections can be seen to reach the seabed first arrival. The age of the present seafloor is unknown and assumed to be younger than $\sim 10$ kyrs (beginning of present interglacial period). These potentially active faults are all large reactivated faults, with the exception a fault (Z.1052) associated with the Southern Intrusive Complex. 


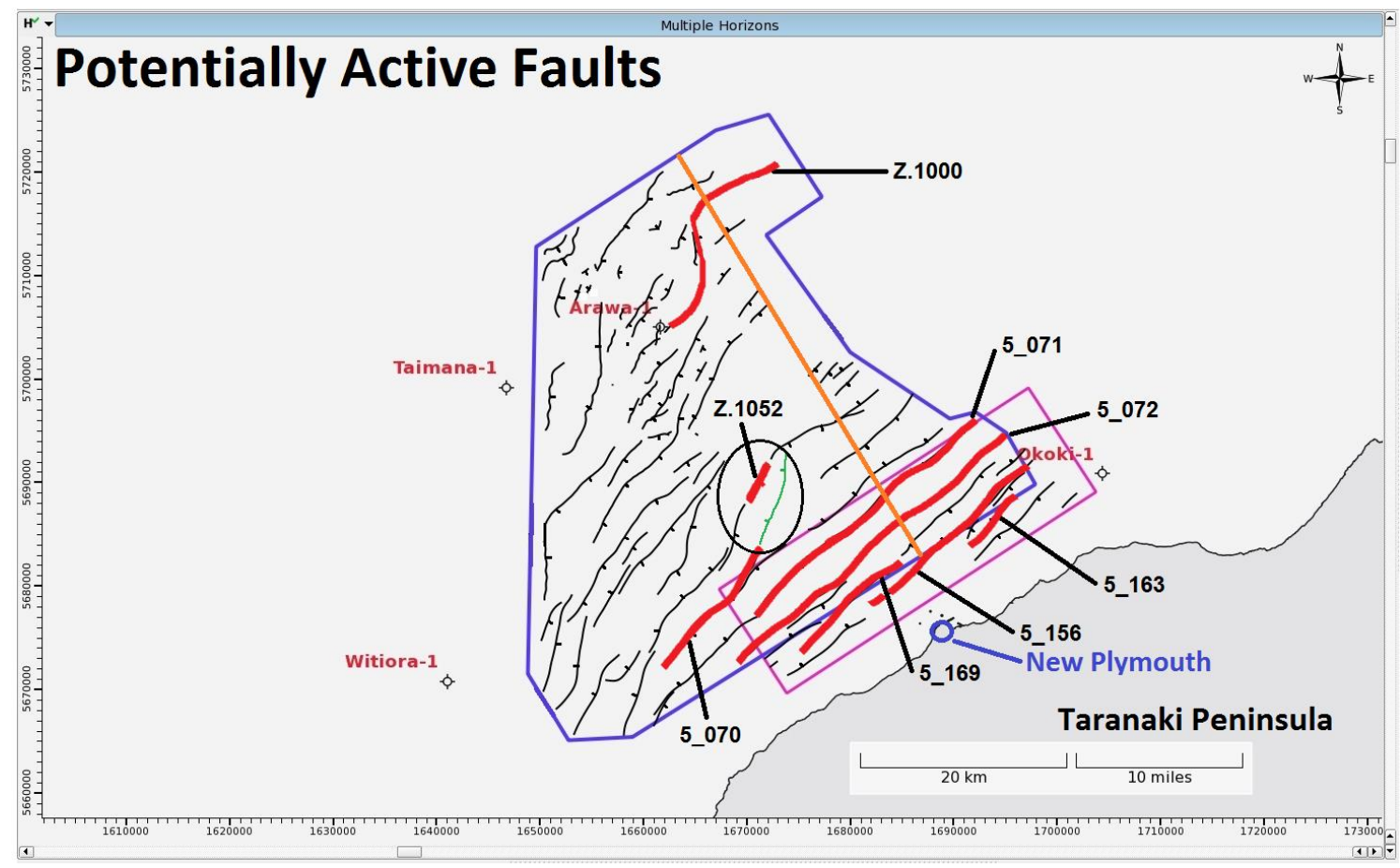

Figure 4.18 Map showing locations of faults intersecting the seabed. Faults intersecting the seabed time horizon are displayed in red, with fault names provided for the eight faults. All other faults in the study area are also shown as black polylines, with dip directions provided. Faults shown in green are those of volcanic origin, with the approximate location of the Southern Intrusive Complex given by a black oval. An orange line depicts crossline 10254, which is shown in section view in Figure 4.19. The boundary of the Parihaka 3D seismic reflection survey is shown in blue, and the boundary of the Toro 3D seismic reflection survey in purple. The XY coordinate grid is NZ Geodetic 2000.

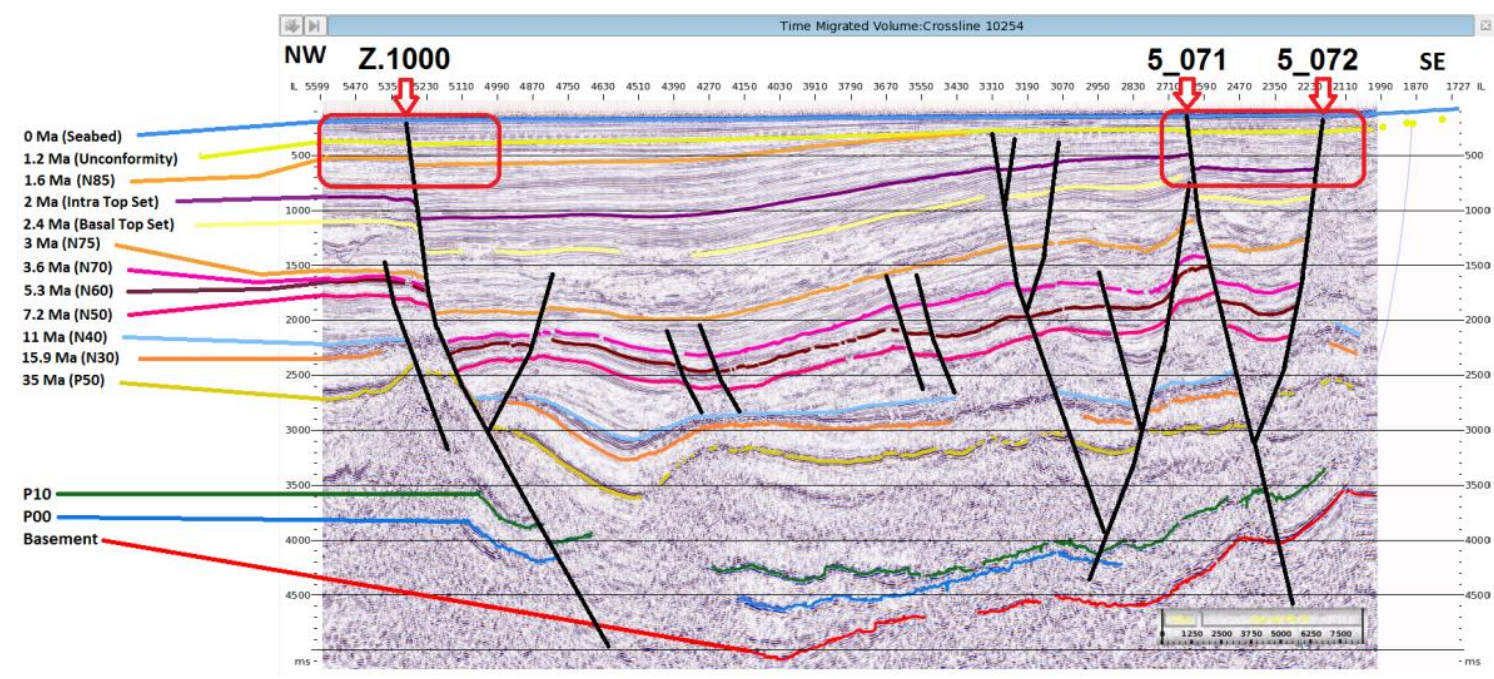

Figure 4.19 Section view of crossline 10254, showing fault intersections with the Seabed time horizon. Red polygons display areas that are shown at larger scale in Figure 4.20. 


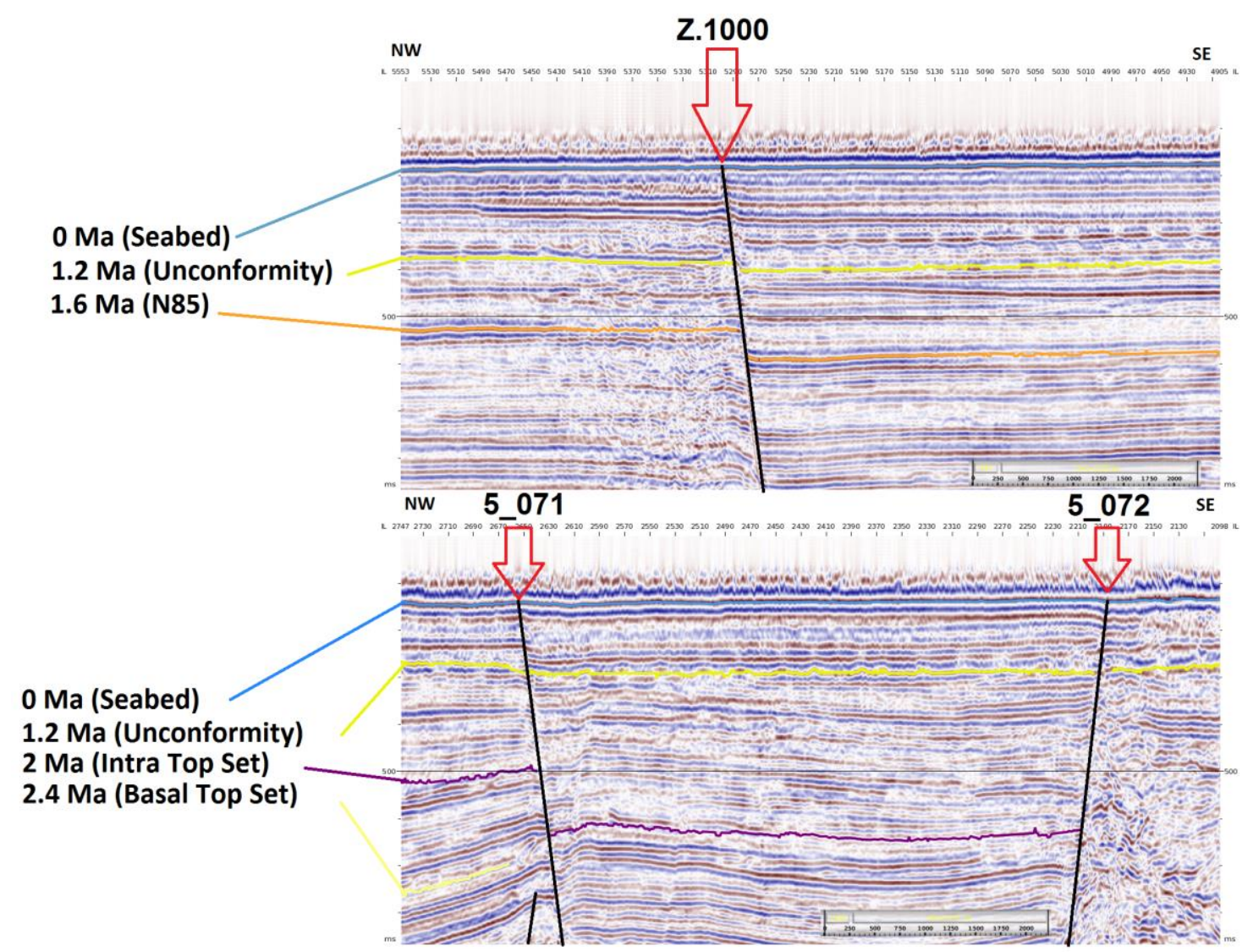

Figure 4.20 Zoomed section view of crossline 10254, showing fault intersections with the Seabed time horizon Deformed reflections can be seen at or immediately below the first arrival seafloor reflector.

\subsection{Discussion}

\subsubsection{Seismic Hazard}

Given the proximity of the study area to New Plymouth (Fig. 4.18), with its 69,000 residents and significant oil and gas infrastructure, it is worthwhile analysing the potential risk posed by the eight potentially active faults discussed in the previous section. A maximum moment magnitude $\left(\boldsymbol{M}_{\mathbf{W}}\right)$ was calculated for each of the eight faults shown in Figure 4.18. Fault area was considered rectangular, and calculated using fault area $=$ fault length $\times$ fault width (where fault width is the maximum dip parallel dimension of a given fault plane). The magnitude calculation was performed using both the trace length of the faults at the seabed and the maximum fault length (Table 4.1). An average single event displacement of $4 \mathrm{~m}$ was obtained from paleoseismic data from onshore Taranaki Peninsula to the south of the study area 
(Mouslopoulou et al., 2012). The moment magnitude $\boldsymbol{M}_{\mathbf{w}}$ for each of the faults was calculated using the equation $M_{\mathrm{W}}=\frac{2}{3} \log _{10}\left(M_{0}\right)-10.7$ after Kanamori and Anderson (1975). To calculate $M_{W}$, the seismic moment $\left(M_{0}\right)$ must first be calculated. This is achieved using the equation $\boldsymbol{M}_{0}=\boldsymbol{\mu A D}$ where $\boldsymbol{\mu}=$ shear modulus of the rocks offset by the fault (in $\mathrm{Pa}$ ), $\mathbf{A}=$ area of the fault surface involved in a rupture event (in $\mathrm{m}^{2}$ ), and $\mathbf{D}$ $=$ average displacement of the fault during the rupture event (in $\mathrm{m}$ ). A shear modulus of $30 \mathrm{GPa}$ was chosen in an attempt to represent both the sandstone and shale components of rock in the study area (King \& Thrasher, 1996). The $\boldsymbol{M}_{\mathbf{0}}$ calculated for each fault is displayed in Table 4.1, along with its associated $\boldsymbol{M}_{\mathbf{w}}$.

\begin{tabular}{|c|c|c|c|c|c|c|c|c|}
\hline Fault ID & Fault Width (m) & Fault Length (Surface) (m) & \multicolumn{2}{|c|}{ Fault Length (Maximum) (m) } & \multicolumn{2}{|c|}{ Fault Area (Surface Length) (m2) } & Fault Area (Maximum Length) $(\mathrm{m} 2)$ & Average Displacement (m) \\
\hline$z .1000$ & $3,754.83$ & $17,153.73$ & \multicolumn{2}{|c|}{22260.48} & \multicolumn{2}{|c|}{\begin{tabular}{|c|}
$64,409,340.02$ \\
\end{tabular}} & $83,584,318.12$ & 4 \\
\hline Z.1052 & $1,369.72$ & $1,257.09$ & \multicolumn{2}{|l|}{6604.06} & \multicolumn{2}{|c|}{$1,721,861.31$} & $9,045,713.06$ & 4 \\
\hline 5_070 & $3,325.12$ & $1,819.54$ & \multicolumn{2}{|l|}{16448.02} & \multicolumn{2}{|c|}{$6,050,188.84$} & $54,691,640.26$ & 4 \\
\hline 5_071 & $4,603.32$ & $17,477.38$ & \multicolumn{2}{|l|}{28115.96} & \multicolumn{2}{|c|}{$80,453,972.90$} & $129,426,760.99$ & 4 \\
\hline 5 & $4,515.11$ & $19,590.41$ & \multicolumn{2}{|l|}{33796.04} & \multicolumn{2}{|c|}{$88,452,856.10$} & $152,592,838.16$ & 4 \\
\hline 5_156 & $3,745.41$ & $15,191.72$ & \multicolumn{2}{|l|}{20611.72} & \multicolumn{2}{|c|}{$56,899,220.01$} & $77,199,342.21$ & 4 \\
\hline 5_163 & $2,548.88$ & $2,781.15$ & \multirow{2}{*}{\multicolumn{2}{|c|}{$\begin{array}{l}5692.14 \\
5423.22\end{array}$}} & \multirow{2}{*}{\multicolumn{2}{|c|}{$\begin{array}{l}7,088,817.61 \\
5,555,588.03\end{array}$}} & $14,508,581.80$ & 4 \\
\hline \multirow[t]{10}{*}{ 5_169 } & $1,215.71$ & $4,569.83$ & & & & & $6,593,062.79$ & 4 \\
\hline & & Shear modulus $(\mathrm{Pa})$ & Surface $M_{0}$ & \multicolumn{2}{|c|}{ laximum $M_{0}$} & Surface $M_{w}$ & Maximum $M_{\mathrm{w}}$ & \\
\hline & & \begin{tabular}{|c|}
$3.00 \mathrm{E}+10$ \\
\end{tabular} & $7.73 \mathrm{E}+18$ & & $0 \mathrm{E}+19$ & 1.89 & 1.97 & \\
\hline & & $3.00 E+10$ & $2.07 E+17$ & & $9 E+18$ & 0.84 & 1.32 & \\
\hline & & $3.00 E+10$ & $7.26 \mathrm{E}+17$ & & $6 \mathrm{E}+18$ & 1.21 & 1.84 & \\
\hline & & $3.00 E+10$ & $9.65 \mathrm{E}+18$ & & $5 E+19$ & 1.96 & 2.09 & \\
\hline & & $3.00 E+10$ & $1.06 \mathrm{E}+19$ & & $3 E+19$ & 1.98 & 2.14 & \\
\hline & & $3.00 \mathrm{E}+10$ & $6.83 E+18$ & & $26 \mathrm{E}+18$ & 1.86 & 1.94 & \\
\hline & & $3.00 E+10$ & $8.51 E+17$ & & $4 \mathrm{AE}+18$ & 1.25 & 1.46 & \\
\hline & & $3.00 E+10$ & $6.67 E+17$ & & $31 E+17$ & 1.18 & 1.23 & \\
\hline
\end{tabular}

Table 4.1 Table of moment magnitude $M_{\mathrm{W}}$ for potentially active faults. Table displaying data used to calculate the maximum potential $M_{\mathrm{W}}$ for the eight faults reaching the seabed in the study area. From left to right and top to bottom, columns are: Fault names/ID; Fault Widths in m; Strike parallel fault lengths at the seabed (surface) in $\mathrm{m}$; Maximum strike parallel fault lengths in $\mathrm{m}$; Fault surface areas calculated using fault lengths at the surface in $\mathrm{m}^{2}$; Fault surface areas calculated using maximum fault lengths in $\mathrm{m}^{2}$; Average single slip event fault displacements in $\mathrm{m}$; Shear modulus in $\mathrm{Pa}$; Seismic moments calculated using fault lengths at the surface; Seismic moments calculated using maximum fault lengths; Moment magnitudes calculated using seismic moments from fault lengths at the surface; Moment magnitudes calculated using seismic moments from maximum fault lengths.

The calculated $\boldsymbol{M}_{\mathrm{w}}$ values for the eight faults range between 0.84 and 2.14 . The maximum potential $M_{\mathrm{W}}$ of $\leq 2.14$ for the eight faults is not significant enough as to warrant concern. However, in a paleoseismic study of faults in the Taupo Volcanic Zone, Villamor and Berryman (2001) interpret ground rupturing faults as generated by $M_{\mathbf{w}} \geq 6$. It is presently uncertain how the faults in the study area have interacted with the present seafloor and what seismic hazard they may represent. Sherburn and White (2006) detail active seismicity within $10-120 \mathrm{~km}$ east of the study area at depths of 7.5 - $35 \mathrm{~km}$, magnitudes of $M_{\mathrm{L}} 1.4-4.0$, with predominantly strike-slip and normal focal mechanisms. This suggests the $M_{w}$ values calculated for the eight faults in this 
thesis of between 0.84 and 2.14 may be too low. It is possible that measuring the dimensions of individual faults rather than the dimensions of kinematically coherent groups of faults (e.g. Fig. 5.6) as done for magnitude calculations in this study leads to undersampling of true fault dimensions, and by association $\boldsymbol{M}_{\mathrm{w}}$ values. Another potential hazard associated with faults so close to shore is tsunami generation. According to a review of paleotsunamis in New Zealand by Power (2013), all paleotsunamis identified near the study area appear to have been generated by high magnitude, overseas earthquake events. This database is not comprehensive, so exploring the generation and occurrence of paleotsunamis in the Taranaki region could be an avenue of further study.

\subsubsection{Volcanic Faults}

Normal faults associated with displacements of $\sim 20-450 \mathrm{~m}$, and lengths of $\sim 1-7 \mathrm{~km}$ trending north east developed above the Southern Intrusive Complex around $3 \mathrm{Ma}$ (Fig. 4.15). Typically, igneous intrusion will result in a radial pattern of faulting within and immediately surrounding the intrusion as described in Nakamura and Jacob (1976). The Southern Intrusive Complex has intruded through $>6 \mathrm{~km}$ of Cretaceous Miocene strata which has experienced localized drag folding, but no visible radial faulting. Instead, the normal faults above the Southern Intrusive Complex have all formed with strikes normal to the regional Miocene - Plio-Pleistocene extension direction of $\sim 310^{\circ}$. These faults are smaller than tectonic faults in the study area (typical displacements of $\sim 20-1400 \mathrm{~m}$, and lengths of $\sim 1-33 \mathrm{~km}$ ), and have been

attributed to Pliocene - Recent gravitational collapse of the Southern Intrusive Complex (Giba et al., 2013).

\subsubsection{Timing of Fault Activity}

The timing of observed fault activity in the study area is approximately synchronous with changes in the subduction geometry beneath the North Island. Normal faulting began in the study area around $11 \mathrm{Ma}$, followed by peak extension and fault displacement around 5.3 Ma. A major cessation of activity on faults (all faults decrease in length by $20-60 \%$ ) in the study area occurred between $3.6 \mathrm{Ma}$ (N70) to $3 \mathrm{Ma}$ (N75), 
with $\sim 80 \%$ of faults inactive by $1.2 \mathrm{Ma}$. The $5.3 \mathrm{Ma}$ period of peak extension and fault activity coincides with the initiation of Havre Trough opening between the Colville Coromandel and Kermadec - Taupo Volcanic Zone arcs (Fig. 2.6) 200 km north east along strike from the study area at $\sim 5.5 \mathrm{Ma}$ (Wright et al., 1996; Wysoczanski et al., 2010).

The parallelism of the Colville and Kermadec Ridges with the Kermadec Trench (Section 2.5) indicates that changes in the location of the subduction hinge (slab rollback) or steepening of the slab dip have been the primary driver of extension in this region. Seaward directed changes in subduction geometry potentially lead to suction forces (e.g. Sdrolias and Muller (2006) and references therein), resulting in extension of the overriding plate. The timing of peak fault initiation and displacement accrual (5.3 Ma) coincides with present estimates for the opening of the Havre Trough $400 \mathrm{~km}$ to the north east of the study area at $5.5 \mathrm{Ma}$ (Wright et al., 1996; Wysoczanski et al., 2010). The onset of fault initiation in the study area at $11 \mathrm{Ma}$ (Section 4.5 ) suggests a period of prolonged extension prior to the apparent separation of the Colville and Kermadec Ridges at $\sim 5.5 \mathrm{Ma}$. In general, a south east migration in the locus of fault activity is observed. Faults typically cease activity to the north west at older ages than to the south east (Fig. 4.17). This is consistent with a south east migration in the location of maximum strain as might be expected with seaward directed changes in the geometry of the underlying slab.

\subsubsection{Fault Dips and the Non Rotation of Faults}

In an extensional stress regime, when normal fault dip becomes sufficiently shallow (outside of $60^{\circ} \pm 30^{\circ}$ ), the frictional force between fault blocks will exceed the normal stress driving normal faulting and frictional lockup of the fault will occur (barring special circumstances that reduce the friction coefficient of a fault, such as elevated pore fluid pressure in a fault zone (Axen, 1992). At this point it easier to form new faults than continue slip on an existing one (Anderson, 1951). The observed mean fault dips in the study area are within the $60^{\circ} \pm 30^{\circ}$ that Anderson (1951) states is suitable for normal fault activity in an ideal extensional stress regime. This suggests that frictional lockup has not been important in the study area. 
Faulting and arc volcanism in the Northern Graben is largely controlled by subduction, however this is complicated by the unsubductable continental crust of the Chatham Rise at the southern end of the Hikurangi Trough (Fig. 2.1) (King \& Thrasher, 1996; Wallace et al., 2004; Xu et al., 2005; Giba, 2010; Giba et al., 2010). The Chatham Rise is described as "a tectonic indenter that defines the southern termination of the subduction zone in the northern part of South Island" in Wallace et al. (2004) (see Section 2 for further details). The presence of the Chatham Rise at the southern extremity of the Hikurangi Subduction Zone, along with the relative plate motion between the Pacific and Australian plates along the Hikurangi Margin of $\sim 40 \mathrm{~mm} / \mathrm{yr}$ westward, has led to a clockwise torque force being applied to the North Island. This torque force has led to $\geq 50^{\circ}$ clockwise rotation of parts of the Hikurangi forearc about a vertical axis during the Neogene, with debate whether or not the subducting Pacific Plate has rotated with the forearc during the Miocene (e.g. Walcott (1987); Mumme et al. (1989); King and Thrasher (1996); Wallace et al. (2004); Nicol and Wallace (2007); Paterson et al. (2010); Lamb (2011); Seebeck et al. (2014a).

Estimates for the present day orientation of SHmin between $10-50 \mathrm{~km}$ south of the study area from first motion inversion and focal mechanisms indicate an east - west direction of extension $\left(262-270^{\circ}\right)$ (Sherburn \& White, 2006). At $2 \mathrm{Ma}, \geq 70 \%$ of faults in the study area had ceased accruing displacement, and had a north west - south east extension direction of $\sim 310^{\circ}$. If the faults in the study area formed as pure dip-slip faults, this implies an anticlockwise rotation in the extension direction of $40-48^{\circ}$ ( $\left.20^{\circ} / \mathrm{Myr}\right)$. To the east of the study area however, at the southern limit of rifting in the Taupo Volcanic Zone (TVZ), mid crustal extension directions are oriented northwest-southeast at $322-328^{\circ}$ (Sherburn \& White, 2006). These are more consistent with the extension direction of $\sim 310^{\circ}$ and average strike of $\sim 40^{\circ}$ observed for normal faults in this study.

Present day estimates of extension direction in the southern TVZ imply either a clockwise rotation in regional extension direction of $12-18^{\circ}$ over the past $2 \mathrm{Myr}$, or that the faults in the study area are accommodating a small component of strike-slip. Passive markers crossing the faults show no evidence of horizontal displacement (Figs. $4.10-4.11)$, suggesting any right lateral motion is most likely being accommodated on 
structures below the spatial resolution of this study. The east-west extension direction observed in Sherburn and White (2006) may be associated with basement fabric orientation as suggested by Seebeck et al. (2014b), or the Taranaki Fault, both of which strike predominantly north-south. In the Taupo Rift, rift faults $<300 \mathrm{kyr}$ in age predominantly strike $041^{\circ}$, with an average extension direction of $317^{\circ}$ (Seebeck et al., 2014b). The small component of right-lateral shear associated with the $\sim 6^{\circ}$ clockwise rotation of the extension direction relative to the pure dip-slip direction for these normal faults is interpreted to be accommodated predominantly by strike-slip on north-south trending, steeply dipping bedding planes, which is potentially analogous to faults in the study area (Seebeck et al., 2014b). This type of kinematic partitioning between the normal and strike-slip components would be consistent with the faults in the study area (e.g .Giba (2010)), and consistent with the focal mechanisms to the south beneath the Taranaki Peninsula (e.g. Sherburn and White (2006)).

The absence of fault strike rotation between 7.2 Ma and present is inconsistent with the arc rotation model of Stern et al. (2006) discussed in Section 2.5.3. This model suggests that the volcanic arc front has rotated clockwise $\sim 25-30^{\circ}$ with respect to the Australian Plate over the past $4 \mathrm{Ma}$ (rates of $6.25-7.5^{\circ} / \mathrm{Myr}$ ). The geometry of a volcanic arc is parallel to the underlying subducting slab (e.g. Syracuse and Abers (2006) and references therein). The arc rotation model would require a rotation in the strike of the subducting slab of similar magnitude. A rotation of this magnitude in the strike of the underlying plate would be expected to result in a corresponding change in the regional extension direction, which in turn would result in the up dip rotation of normal fault strikes or kinematics over the same time period (Seebeck et al., 2014a).

The uniformity of normal fault strikes over the past $11 \mathrm{Ma}$ in the study area (Section 4.4) is more consistent with the slab rollback model first proposed by Ballance (1976). The $\sim 110 \mathrm{~km}$ separation between the uniform $\sim 35^{\circ}$ strikes of the Colville and Kermadec arcs imply the kinematics of extension have been fairly uniform since the separation of the two arcs $\sim 4$ - 5 Myr ago (Wright et al., 1996). Seebeck et al. (2014a) proposed that rollback and/or steepening of the subduction zone hinge under the North Island over the past $\sim 16 \mathrm{Ma}$ is responsible for changes in patterns of faulting and volcanism over that period. The similarity between arc trends and normal fault strikes 
indicates the kinematics of rifting have not varied significantly over the last 4 Myr, indicating changes in the dip and/or location of the slab hinge are the most likely mechanisms controlling the geometry of rift faults in the study area.

\subsubsection{Implications for the Petroleum System}

The geometry and timing of normal faults in the study area has created potential hydrocarbon migration pathways crucial for the development of a viable petroleum system. Mapped normal faults typically displace between two and twelve of the mapped time horizons, propagating vertically up to $9 \mathrm{~km}$ (6 s TWTT) of strata. Faults are more likely to be permeable to up fault fluid flow when active (Faulkner et al., 2010). This suggests that the period of maximum fault initiation and displacement accrual at $\sim 5.3 \mathrm{Ma}$ would be the most likely time for hydrocarbon migration. To better understand the efficacy of fault permeability and sealing in the study area, the undertaking of a shale/gouge ratio study would be beneficial. This would provide an approximation of how permeable faults may or may not be based on the amount of fine grained material likely present in the fault zone.

Reactivated faults in the study area provide potential migration pathways due to their connection with Late Cretaceous normal faults that intersect potential Cretaceous source rocks. Potential Cretaceous source rocks have been modeled to be mature and expelling hydrocarbons from $\sim 10 \mathrm{Ma}$ (Lovitz \& Bates, 2008a). As such, potential migration pathways exist between Cretaceous source rocks and the abundant viable Eocene - Miocene reservoir lithologies present in the study area with porosities ranging from $5-25 \%$ (King \& Thrasher, 1996). It is also possible that any migrating hydrocarbons have bypassed reservoirs and escaped to the seafloor through these recently active faults.

\subsection{Conclusions}

- Two predominant fault types are identified in this study. New faults (inclusive of faults associated with Pliocene intrusive volcanism) make up $50 \%$ of faults analysed. The remaining $50 \%$ of faults are reactivated (inclusive of faults that are antithetic to reactivated faults). 
- Faults began to initiate at $11 \mathrm{Ma}$ in the west of the study area, with peak normal displacement and fault initiation at 5.3 Ma. Initiation of and accrual of displacement on smaller faults (displacements $\sim 20-500 \mathrm{~m}$, lengths $\sim 1-10$ $\mathrm{km}$ ) continued from $3 \mathrm{Ma}$, with $80 \%$ of faults inactive by $1.2 \mathrm{Ma}$.

- Eight faults displace the seafloor or underlying reflection and are considered potentially active. Estimated maximum $M_{\mathrm{w}} 2.14$ indicates these faults pose minimal seismic hazard, however there is uncertainty about the likely $\boldsymbol{M}_{\mathbf{w}}$ of an earthquake on these faults.

- Faults observed in this study are predominantly dip slip in nature and show no evidence for either up dip rotation in strike of the fault planes, or strike-slip motion during their growth. Comparison with normal fault trends in the TVZ < $300 \mathrm{kyr}$ in age indicates little difference in the kinematics of rifting over the past $11 \mathrm{Ma}$, and indicates the locus of extension has migrated south east with time. 


\section{Chapter 5 Evolution of a Normal Fault System}

\subsection{Introduction}

The accumulation of fault slip during earthquakes results in the growth of faults. When sedimentation rates outstrip normal fault throw rates, sediment thickness variations across syn-sedimentary faults, although modified by compaction, allow fault displacement histories (fault throw subsequent to the deposition of stratal horizons) to be determined (Childs et al., 2003; Nicol et al., 2005). Industry standard 3D seismic reflection data allows the analysis of syn-sedimentary thickness changes along the length of individual faults, highlighting both displacement and propagation (or growth) history (Childs et al., 2003; Nicol et al., 2005).

Historical and paleoearthquake studies indicate that both earthquake slip and finite displacement increase according to a linear relationship with fault length (Elliott, 1976; Scholz, 1982; Bonilla et al., 1984; Watterson, 1986; Walsh \& Watterson, 1988b; Marrett \& Allmendinger, 1991; Cowie \& Scholz, 1992; Gillespie et al., 1992; Dawers et al., 1993; Wells \& Coppersmith, 1994; Schlische et al., 1996; Nicol et al., 2005). This relationship is most often interpreted to reflect fault growth, such that sequential slip events on a fault produce cumulative increases in fault surface dimensions (displacement and/or length). Among others, two fault growth models have been presented that may explain this pattern of fault evolution: the coherent fault growth model of Childs et al. (2009), and the isolated fault growth model of Walsh and Watterson (1988a).

The coherent fault growth model proposes that "faults segments are part of a larger and geometrically coherent structure" (Childs et al., 2009). This model suggests that as a volume of rock is subjected to strain, a number of faults will form and have their lengths and geometry 'set' at initiation, often as a result of the reactivation of preexisting faults underlying the newly faulted strata. As strain is applied to the volume of rock, faults in this model would initiate with low displacements but with lengths at or near maximum. This length would then either remain stationary, increase slightly, or retreat with displacement. In this model many small displacement faults develop at 
the initial stages and progressively reduce in number through strain localisation onto a few larger faults as strain accrues in a volume of rock.

The isolated fault growth model suggests that faults form separately (hence isolated), and initiate as a "Single, smooth continuous surface of displacement discontinuity, which becomes longer as slip increases" (Walsh \& Watterson, 1988a). This model suggests that as a volume of rock is subjected to increasing strain, a number of small distributed faults will begin to form. As strain continues to accrue, these small faults grow larger in displacement and length by interacting and linking with similar nearby faults. These linked and intersecting faults then begin to preferentially accrue displacement. This process is thought to result in the creation of large localised faults, and the abandonment of small faults.

Understanding the way in which faults have evolved in length and displacement is important for understanding the migration and trapping of hydrocarbons. Faults can behave as both barriers and/or conduits for fluid flow (Finkbeiner et al., 1997; Faulkner et al., 2010). If the development of faults is synchronous with or later than hydrocarbon expulsion, this may result in migrating hydrocarbons bypassing sealing lithologies (Cartwright, 2011). In this way, faults may act as high permeability pathways to either reservoir lithologies or the seafloor. Whether faults are open or closed to up fault fluid flow is considered strongly dependent on whether a fault is active and/or its proximity to failure under present or paleo-stress conditions (Faulkner et al., 2010). Faults with sufficient displacement can be sealing to across fault fluid flow due to the incorporation and generation of very fine grain low permeability rock within fault zones, as well as potentially creating structural traps with side seals through juxtaposition of reservoir and seal lithologies (Yielding et al., 2010).

3D seismic interpretation constrained by four exploration wells allows the detailed mapping of Late Eocene to Recent strata and Late Miocene-Pliocene normal faults over an area of $1670 \mathrm{~km}^{2}$ within the Northern Graben, Taranaki Basin, New Zealand. Concurrent faulting and rapid sedimentation in the Northern Graben between the Late Miocene and present day has led to the creation of syn-sedimentary fault growth strata, which can be used to investigate the evolution of a normal fault system (Nicol 
et al., 2005; Giba, 2010; Giba et al., 2012; Reilly et al., 2015). Three key types of fault displacement behaviour have been documented globally (Meyer et al., 2002; Nicol et al., 2005; Schlagenhauf et al., 2008). The three behaviours are that of fault growth in displacement with stationary tips, fault growth in displacement with retreating tips, and fault growth in displacement with propagating tips. The relative position of fault tips provides information about how faults are growing and/or interacting. Idealised, modelled examples of these three fault growth behaviours are illustrated in Figure 5.1. An illustration displaying how fault displacement is calculated from interpretation data is provided in Figure 5.2

Fault displacements analysed in this study can be used to test models of fault growth and evolution. The following questions on fault growth are addressed in this chapter: are fault lengths set instantaneously at initiation, or does length increase with increasing displacement?; Does fault evolution follow a coherent or isolated fault growth model?; do all faults in a given population evolve in the same way regardless of size?; does strain initially accommodated on many small faults eventually localise on only a few large faults during the evolution of a fault system?

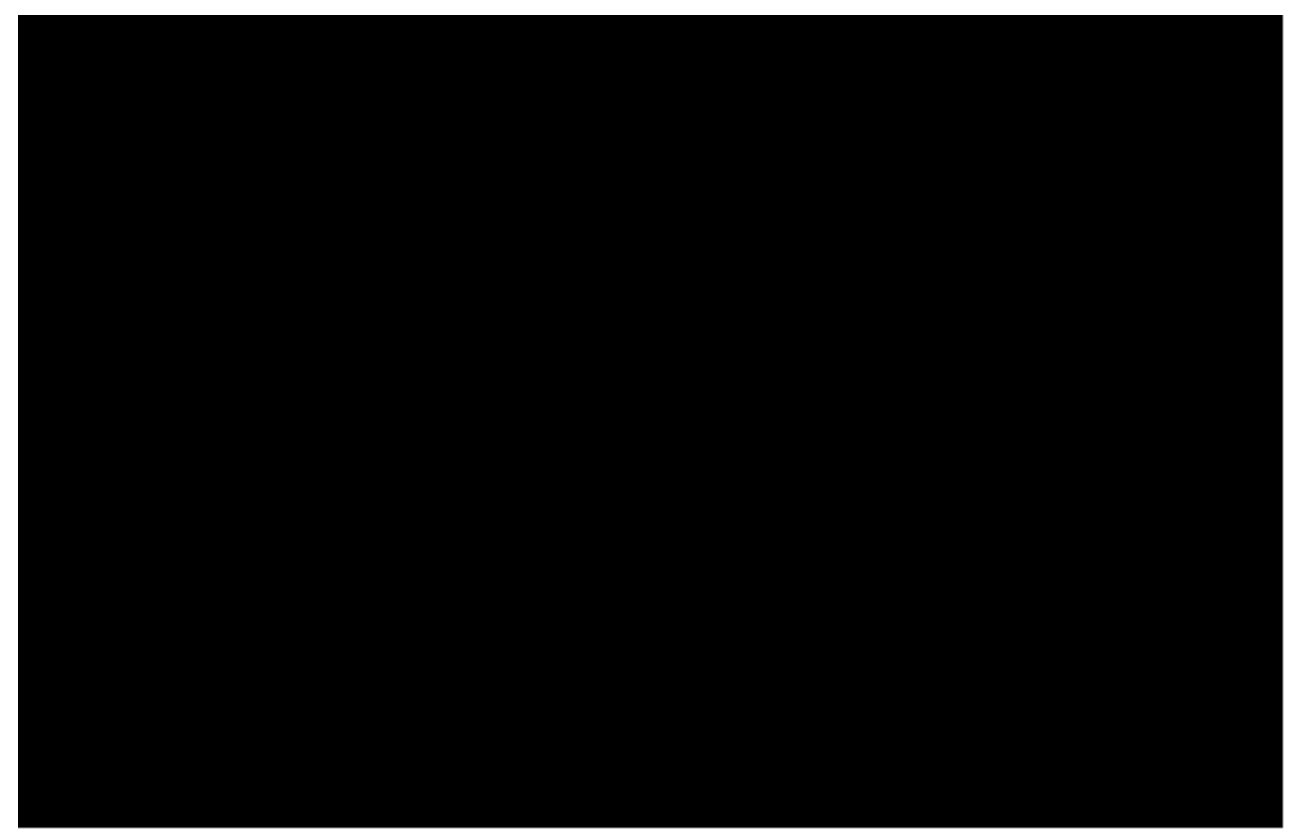

Figure 5.1 Conceptual models illustrating incremental changes in fault growth behavior. Examples of observations of stationary, retreating, and propagating fault tips are shown adjacent to the conceptual model for reference. Progressive displacement from earliest to latest is shown by increasing number (A Nicol, unpub. data). Models of fault displacement are from Meyer et al. (2002); Nicol et al. (2005); Schlagenhauf et al. (2008). 


\section{Fault Geometry and Displacement}

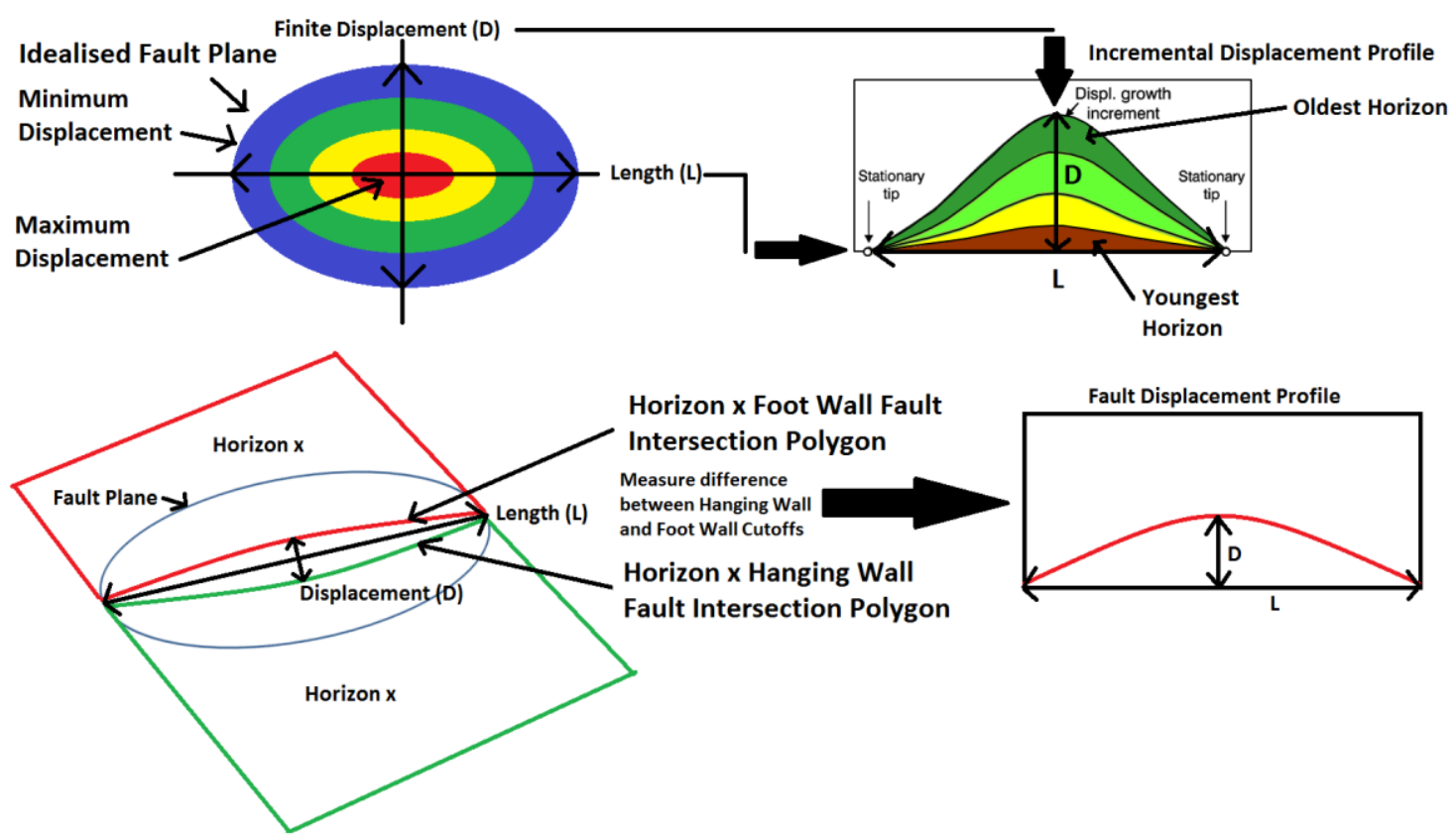

Figure 5.2 Illustration of fault displacement methodology. An idealised fault plane (top left) is coloured to represent the finite magnitude of displacement at each part of the fault plane (warm colours represent greater finite displacements). The fault displacement profile derived from the displacement distribution over the fault plane (top right) is coloured to represent four displaced time horizons. Displacement on time horizons increases from youngest (brown) to oldest (green). The bottom half of the illustration shows how fault displacement profiles are generated from fault intersection polygons (i.e. the footwall and hangingwall intersection of a time horizon with a fault plane).

\subsection{Geological setting}

The Taranaki Basin is situated to the west coast of New Zealand's North Island, covering an area of approximately $100,000 \mathrm{~km}^{2}$ (King \& Thrasher, 1996; Wood et al., 1996). The basin has a multiphase history dominated by subduction and passive margin processes. The Taranaki Basin has experienced at least two episodes of extension since $\sim 85 \mathrm{Ma}$ (King \& Thrasher, 1996). The first from $\sim 85$ - 55 Ma as part of a Latest Cretaceous syn-rift sequence, and the second between $\sim 11-0 \mathrm{Ma}$ as a Miocene-Pleistocene syn-rift sequence (King \& Thrasher, 1996; Giba et al., 2012). Faulting in the Taranaki Basin is predominantly normal with little evidence of strike-slip (King \& Thrasher, 1996; Giba, 2010). The reader is referred to a more detailed geological setting is presented in Section 2. 
The Northern Graben is a sub-basin of the Taranaki Basin formed during the Late Miocene. It is a $40-50 \mathrm{~km}$ wide graben situated to the north west of the Taranaki Peninsula. The Northern Graben is bounded to the west by the Cape Egmont Fault Zone, and to the east by the Turi Fault Zone. The Cape Egmont Fault Zone comprises large, sub-parallel normal faults with a primarily eastward dip direction. The Turi Fault Zone comprises large, sub-parallel normal faults with a primarily northwest dip direction (King \& Thrasher, 1996). These two fault zones strike NNE, and NE, respectively, and intersect at the southern limit of the graben where extension ceases. Further south, contraction has dominated subduction processes since the Miocene. This region therefore underwent Miocene vertical axis rotation relative to a fixed Australian Plate, about an axis coincident with the southern termination of the graben at rates of $0.2^{\circ} / \mathrm{Myr}$ as seen in Figure 2.2 (Walcott, 1987). A vertical axis rotation rate of the eastern graben margin relative to the west during the past $5.3 \mathrm{Ma}$ (calculated from strain profiles in this chapter) is similar to this measurement, at $0.34^{\circ} / \mathrm{Myr}$.

\subsection{Data And Methods}

3D seismic interpretation of twelve time horizons constrained by four exploration wells allows the detailed mapping of Late Eocene to Recent strata and normal faults to the limit of seismic resolution ( $4 \mathrm{~m}$ above $2 \mathrm{~s}$ Two Way Travel Time (TWTT) over an area of $1670 \mathrm{~km}^{2}$. The relationship between seismic wave TWTT and depth is approximately 1:1 down to 2 s TWTT (Section 3.2.3), and therefore depth conversion would not change the first order conclusions of this chapter and has not been conducted. From here onward, fault displacements measured above $2 \mathrm{~s}$ TWTT have lengths estimated in metres. Fault throw displacement rates in the Northern Graben have averaged $\sim 0.16$ $\mathrm{mm} / \mathrm{yr}$. Sedimentation rates through the same period have averaged $\sim 0.6 \mathrm{~mm} / \mathrm{yr}$ (King \& Thrasher, 1996). The combination of these factors has led to the creation of syn-sedimentary fault growth strata, which can be used to investigate the evolution of the normal fault system in the study area. The majority of data and methods relevant to this section have been presented in Section 3, with the Parihaka and Toro 3D reflection volumes and associated well data described in Sections $3.1-3.2$, and the seismic mapping of these 3D volumes described in Section 3.3. 
Fault displacement profiles have been generated from footwall/hanging wall cutoffs (fault intersection polygons) for twelve time horizons (Section 3.2.3). Fault displacement profiles show normal fault displacement in $\mathrm{m}$ vs. distance along the fault sampled at $100 \mathrm{~m}$ intervals for each time horizon. For fault Displacement/Length data, fault displacement is defined as the maximum throw of a fault on the time horizon for which the length was measured. Fault length is defined as the strike parallel length of a fault at a given time horizon measured between fault tips. The Parihaka and Toro 3D seismic coherency volumes were used to constrain fault tip locations (and therefore fault length at any given time horizon). Figure 5.3 illustrates the relationship between fault tips defined in the coherency volumes and the corresponding fault displacement profile. Displacement backstripping was applied to Displacement/Length data for the analysis of cumulative fault throw (Figs 5.13 - 5.15), with separate graphs made for each of the fault types described in Section 4.4. Cumulative fault throw plots highlights fault tip behavior, which informs on which fault growth model is appropriate. It also allows the evolution of individual faults to be tracked, and any differing trends between fault types to be observed. The fault Displacement/Length data generated by TrapTester has been checked and cleaned to remove erroneous measurements (such as negative values). Displacements and lengths of faults partially imaged by the 3D seismic reflection volumes have been corrected using the surrounding $2 \mathrm{D}$ seismic reflection profiles to establish the true dimensions.

Displacement backstripping is achieved by "sequential subtraction of throws on younger time horizons from throws on underlying older time horizons to generate fault growth curves" (Giba et al., 2012). Maximum Displacement/Length data was analysed to estimate the time horizon at which each fault initiated (Section 4), and the displacement then backstripped between the points of initiation and inactivity. Displacement backstripping has significant uncertainty in relation to the length of faults at times older than that recording maximum displacement. A fault overprints its past length history as it propagates (an increase in fault length will generate a new length that overprints any length the fault has previously had), unlike displacement histories which are recorded by synsedimentary stratal thicknesses. Only retreating or stationary fault lengths can be measured with certainty (Kim \& Sanderson, 2005). A 
study of propagating fault lengths is described in the work of Schlagenhauf et al. (2008), who carried out a sandbox experiment using laser interferometry to continuously measure millimeter scale normal fault displacement and length development (Fig. 5.1).

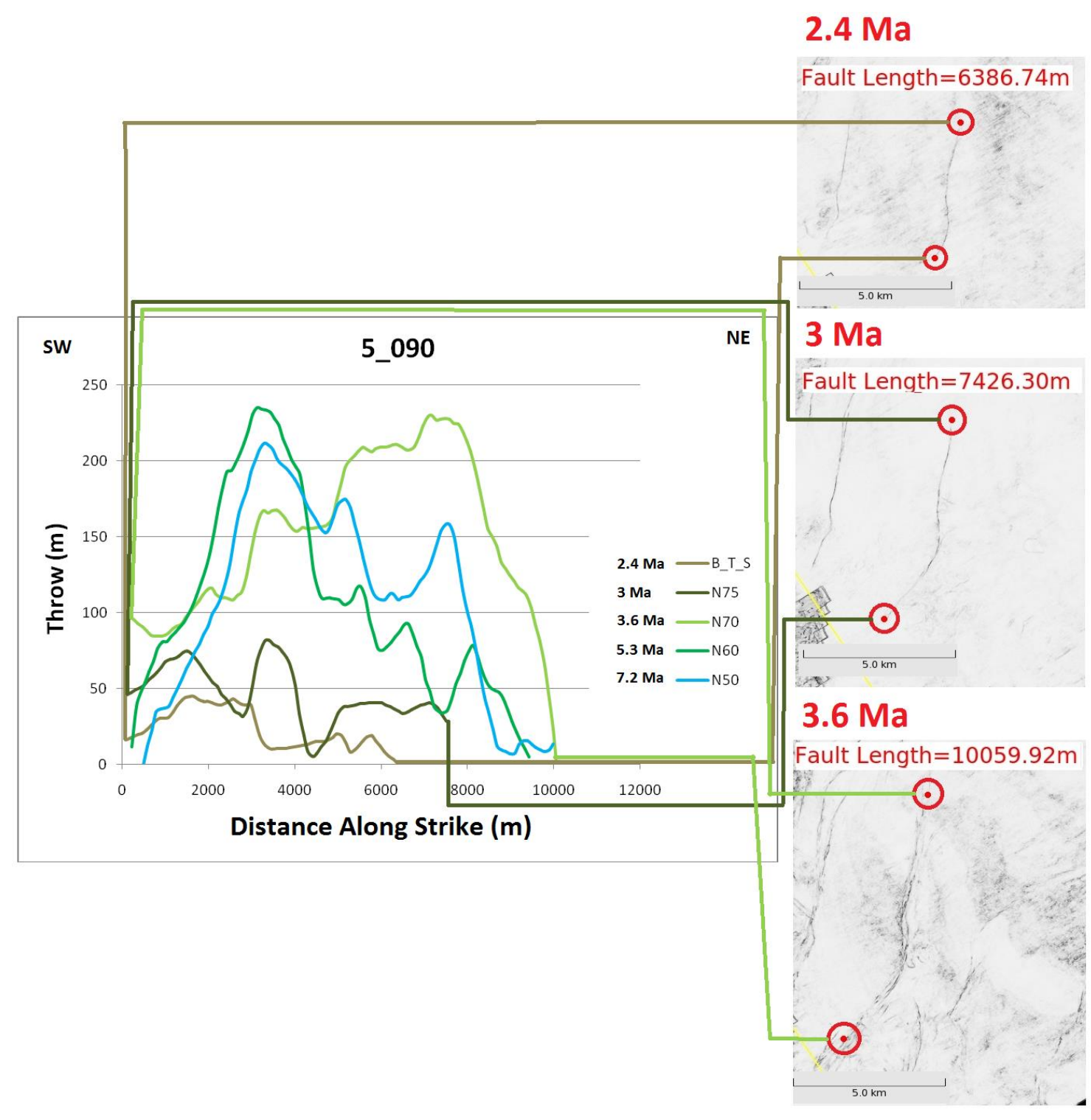

Figure 5.3 Image displaying the relationship between seismic coherency data and fault displacement profiles, using fault 5_090 (with retreating tips) as an example. Fault lengths are measured from fault intersection polygons, which terminate at fault tips (shown as red bullseyes) at each time horizon. Displacement/Length data is generated from this same data. 


\subsection{Fault Growth and Retreat}

\subsubsection{Fault Displacement Profiles}

Normal faults displaying displacement behavior characteristic of stationary and retreating fault tips are predominantly observed in the study area. Within uncertainties, no well constrained examples of propagating fault tips have been identified (examples of each of the three types of displacement profiles are shown in Figure 5.1). Over $95 \%$ of faults in the study area display retreating fault tips for time horizon ages younger than 5.3 Ma. Well constrained examples of stationary fault tip behavior are rare. Faults that do show stationary fault tip behavior do not maintain this behavior throughout their evolution, with tips transitioning to retreating within $1-$ 4 Myrs of fault initiation. Every fault in the study area displays retreating tips at some point in its evolutionary history. Examples of fault displacement profiles as seen in the study area are shown in Figures 5.4 - 5.6.

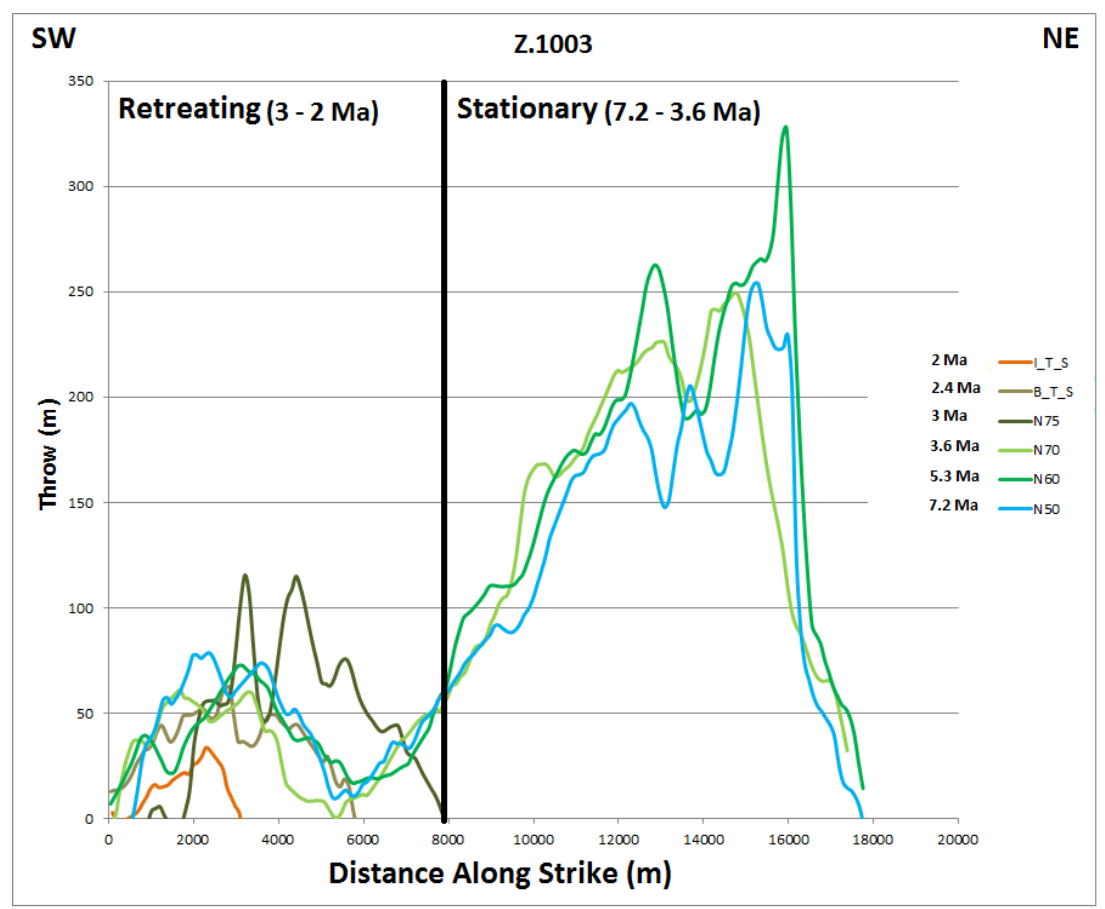

Figure 5.4 Displacement profile for the southern segment of the Parihaka Fault (Fault Z.1003) with stationary tips. The profile shows that two fault segments have been interpreted as a single fault. The north east segment displays stationary tips, while the south west segment is an example of a fault with retreating tips. No displacement is recorded on the north east segment after $3.6 \mathrm{Ma}$, suggesting a complementary increase in displacement may be observed after this time on a nearby fault. 
Accrual of fault displacement with stationary fault tips can indicate a fault is interacting with a neighbouring fault (Childs et al., 2003). Five faults in the study area display stationary tips for $\sim 2$ - 4 Myrs of their evolutionary history, after which fault tips retreat (see Section 5.5.2). The southern segment of the Parihaka Fault (Z.1003) seen in Figure 5.4 can be seen to have stationary tips between 7.2 and $3.6 \mathrm{Ma}$, after which fault tips retreat. Fault tips in Figure 5.4 retreat by $10 \mathrm{~km}$ between $3.6 \mathrm{Ma}$ (N70) and $3 \mathrm{Ma}$ (N75), a decrease of over $50 \%$ of fault length in $\sim 0.6$ Myrs. Decrease in fault length over this period is observed on most faults in the study area (e.g. Figure 5.5), and is consistent with strain profiles of the study area (Fig. 5.7).

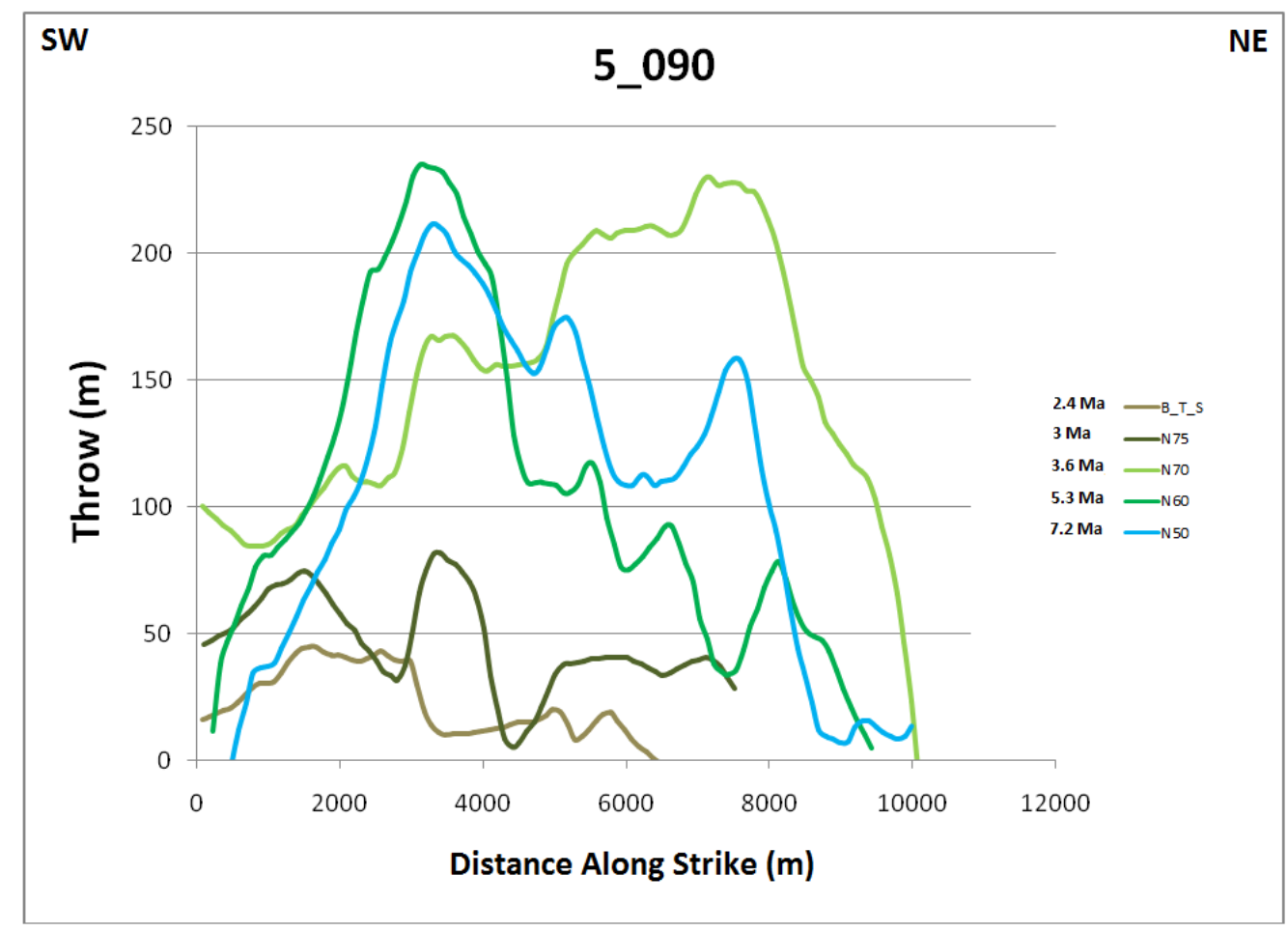

Figure 5.5 Displacement profile for fault 5_090, showing retreating fault tips.

Retreating fault tips either indicate that a fault is accommodating decreasing strain and becoming inactive, or interacting with and losing displacement to a neighbouring fault (Childs et al., 2003). Over 95\% of faults in the study area display retreating tips since initiation, and all faults display retreating tips 1-2 Ma before inactivity. Fault 5_090 in Figure 5.5 above, and a segment of fault Z.1003 in Figure 5.4 are two examples of faults displaying retreating tips. As with fault Z.1003 in Figure 5.4, fault 5_090 displays significant decreases in displacement $(150 \mathrm{~m})$ and length $(\sim 3000 \mathrm{~m})$ between $3.6 \mathrm{Ma}$ (N70) and $3 \mathrm{Ma}$ (N75). Fault 5_090 shows an asymmetric displacement distribution 
(Fig. 5.5). At 7.2 $\mathrm{Ma}(\mathrm{N} 50)$ and $5.3 \mathrm{Ma}$ (N60) displacement predominantly accrues towards the south west end of the fault. This distribution is reversed at 3.6 Ma (N70), with displacement accruing to the north east.

This asymmetry in displacement distribution along fault 5_090 suggests displacement transfer between faults. This is examined further in Figure 5.6, where fault 5_090 and two adjacent faults (5_066 and 5_069, locations given in Figure 4.1) have their displacement profiles for both the 5.3 Ma (N60) and 3.6 Ma (N70) time horizons displayed adjacent to one another, plotted on graphs of throw vs. distance along fault strike. Where the faults overlap, their throw is summed and displayed as a combined profile. Where fault 5_090 shows a decline in throw to the north east, the adjacent fault 5_066 shows a complementary increase. The same is seen for faults 5_066 and 5_069. A significant gap in displacement $(\sim 170 \mathrm{~m})$ is visible in the summed profile of the 5.3 Ma displacement profiles between faults 5_090 and 5_066 (Fig. 5.6a). This gap is no longer apparent in the summed profile of the 3.6 Ma displacement profiles (Fig. 5.6b). This is consistent with the asymmetry observed in the 3.6 Ma (N70) time horizon displacement profile of fault 5_090 (Fig 5.5). Fault length is also approximately constant at both 5.3 and $3.6 \mathrm{Ma}$ on all three fault profiles, indicating changes of fault displacement occurring independent of fault length. This behaviour may be explained by the increasing kinematic coherence of individual fault segments over time, consistent with the coherent model of fault growth described by Childs et al. (2009).

Approximately $50 \%$ of the faults in the study area develop from or are antithetic to reactivated Cretaceous structures (Section 4.4). These reactivated faults appear in this analysis to have initiated in the Plio-Pleistocene (Section 4.5), when in reality these faults may have initiated in the Late Cretaceous and have experienced a hiatus in displacement until $11 \mathrm{Ma}$ when the latest episode of normal faulting commenced (Giba et al., 2010). See Tables AT.1 - AT.3 for a list of all faults both new and reactivated. The temporal resolution of this study has sufficient detail in horizons older than Late Miocene to be confident of the timing of maximum displacement for the latest 11 - 0 Ma phase of rifting. However, while it is clear some faults are reactivated from large Cretaceous faults (e.g. the Parihaka Fault, as discussed in Giba et al. (2012) it is unclear whether the majority of smaller faults observed in the $11-0$ Ma rifting 
phase simply tip out in older Cretaceous structures, or have actually been reactivated. These exact relationships are out of the scope of this study, but may form the basis for future work. For this study, any fault intersecting a pre-existing Cretaceous structure is considered reactivated.

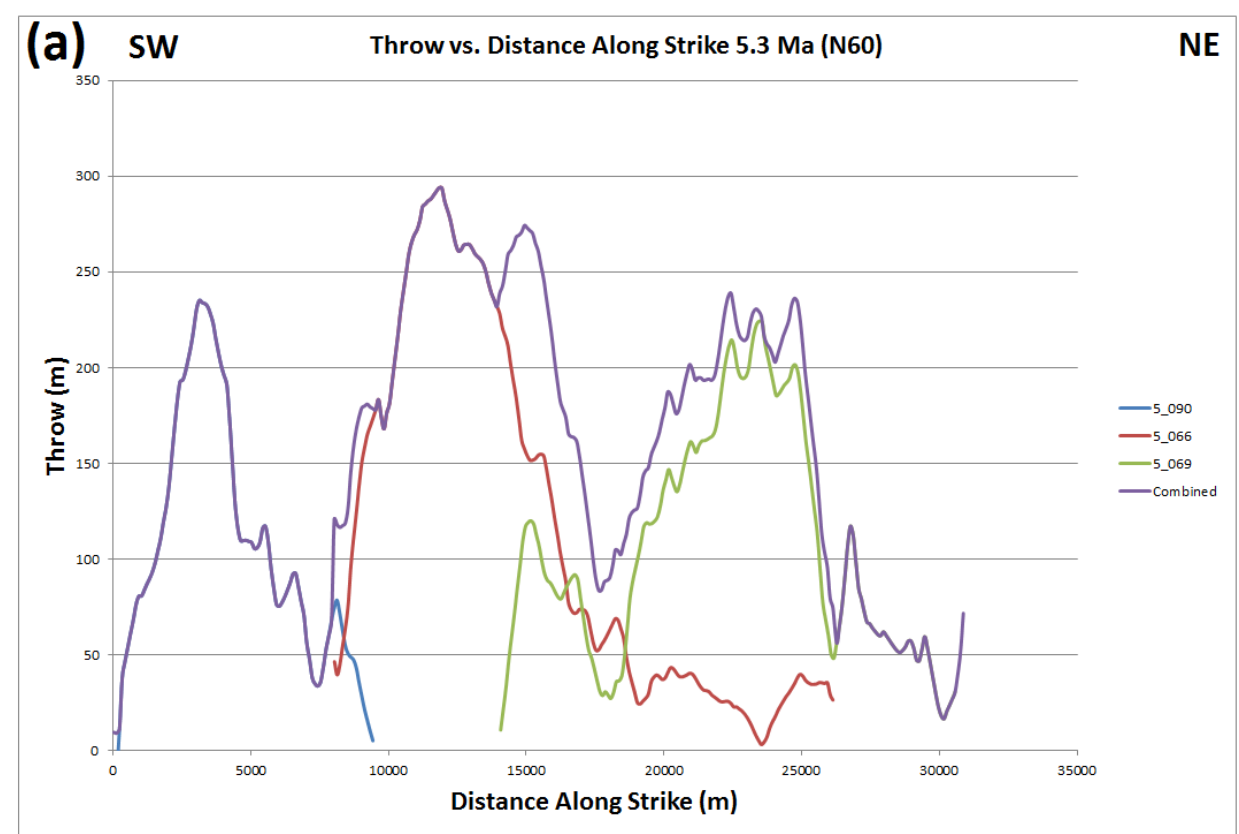

(b) SW Throw vs. Distance Along Strike 3.6Ma (N70) NE

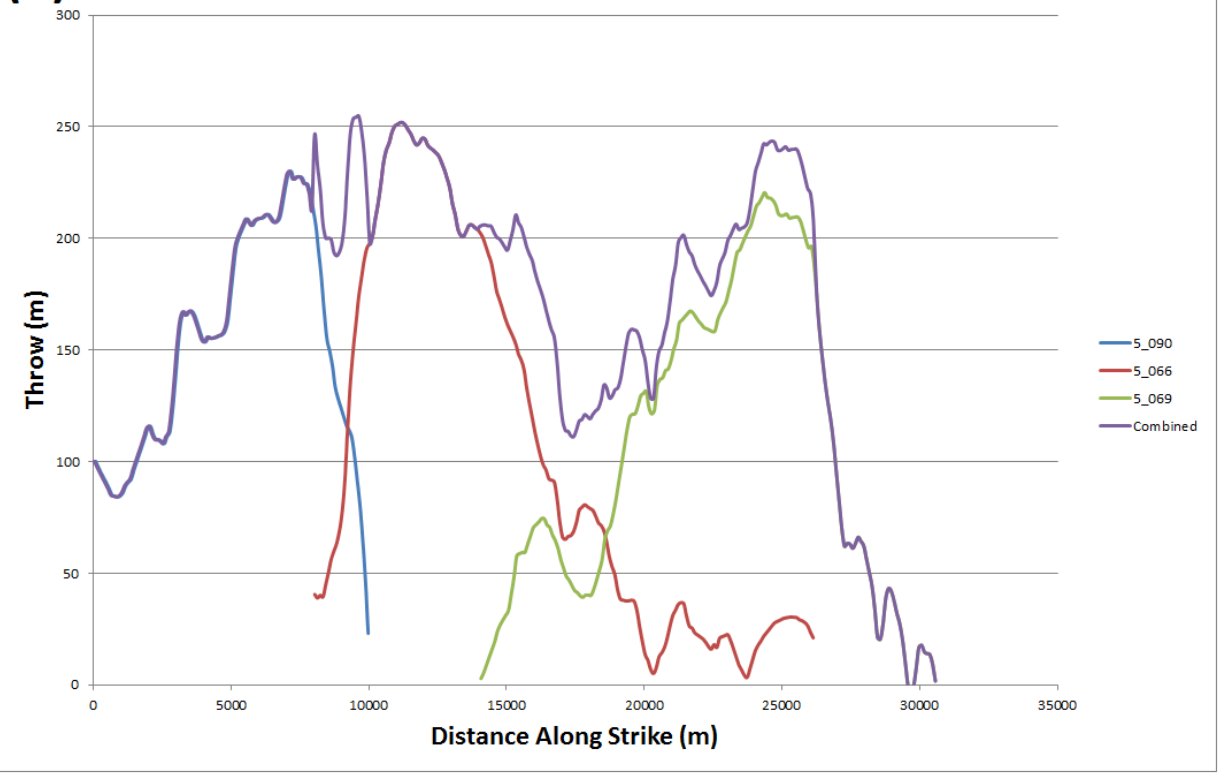

Figure 5.6 Displacement profiles of three adjacent faults displaying kinematic coherence between the faults. Displacement profiles are added where they overlap for faults 5_090, 5_066, and 5_069 in order to demonstrate that changes in displacement on one fault will lead to complementary changes is displacement on another, as described in the coherent fault growth model. Profiles of the three faults are shown in (a) at 5.3 $\mathrm{Ma}$ (N60), and in (b) at 3.6 Ma (N70). 


\subsubsection{Profiles of Longitudinal Strain}

Longitudinal Strain distribution within the study area has been estimated through the generation of north west-south east oriented profiles (approximately normal to fault strike) spaced at $200 \mathrm{~m}$ intervals through the study area. From south west-north east, strain was approximated on each profile in the sampling grid using strain $=H /(L-H)$, where $\mathrm{H}$ is the sum of fault heaves on the profile line and $\mathrm{L}$ is the interpreted time horizon line length. $\mathrm{L}-\mathrm{H}$ is an estimate of the original time horizon line length along the sampling profile. This method of sampling results in a graph displaying strain vs. distance along sampling grid, running from the south west to north east of the study area for each of the twelve time horizons. Since longitudinal strain is calculated as a ratio at each time horizon, the resulting profiles do not have the same vertical scale (Fig. A.34). To account for this, a plot using a uniform vertical scale sampling the original data at $2500 \mathrm{~m}$ intervals was produced, and is shown in Figure 5.7.

The majority of strain in the study area is accommodated in the north east of the Northern Graben (Fig.5.7). Strain can be seen to be minimal towards the south west of the study area $(\leq 0.02)$, with the majority of strain (0.07) being accommodated on faults to the north east of the study area throughout the past $11 \mathrm{Ma}$. Peak strain of 0.07 is observed on the 5.3 $\mathrm{Ma}$ (N60) time horizon at a sampling grid distance of $\sim 35$ $\mathrm{km}$. Increasing north westward strain implies this section of the Northern Graben has undergone vertical axis rotation of the eastern margin relative to the west during the past 5.3 Ma. The magnitude of this rotation can be calculated. The maximum present day width and length of the study area are $46 \mathrm{~km}$ and $52 \mathrm{~km}$, respectively. Substituting an $L$ value of 1 into the strain $=H /(L-H)$ equation $(0.07=H /(1-H)$, an $H$ value of 0.0654 is calculated. Dividing $46 \mathrm{~km}$ by 1.0654 calculates the maximum width of study area at 5.3 Ma, $43.18 \mathrm{~km}$. Applying trigonometry to the $5.3 \mathrm{Ma}$ and present maximum study area widths, combined with an assumed fixed study area length of $52 \mathrm{~km}$, tangent angle values for each are 39.71 and 41.50 , respectively. This suggests a $1.79^{\circ}$ rotation of the eastern margin of the study area relative to the west over the past $5.3 \mathrm{Myr}$ $\left(0.34^{\circ} / \mathrm{Myr}\right)$. This is comparable with Miocene-Recent regional estimates of $0.1^{\circ}$ 0.2\% Myr (Walcott, 1987; Giba et al., 2010). 


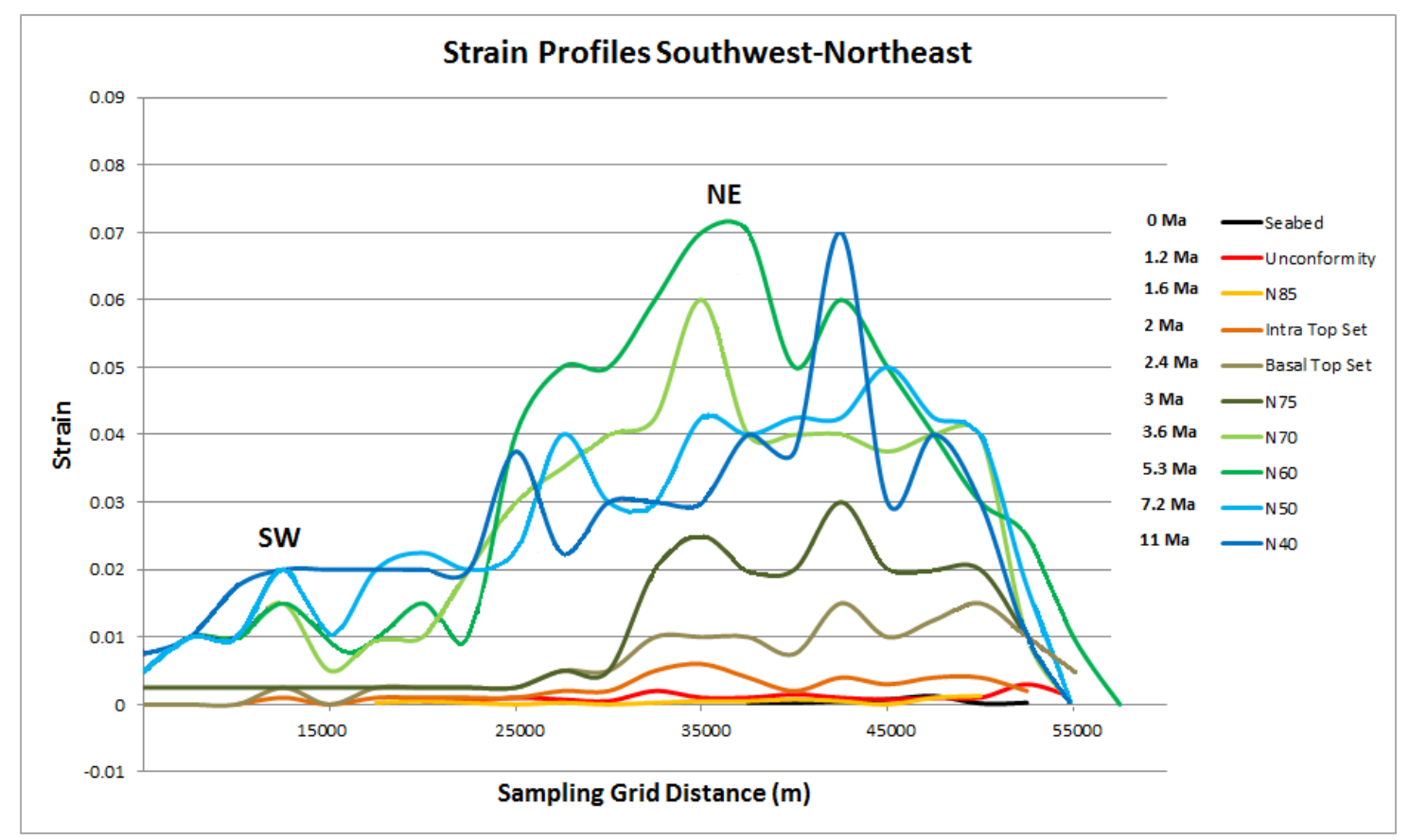

Figure 5.7 Profiles displaying longitudinal strain in the study area over time. This graph samples the raw strain profile data shown in Figure A.34 at $\mathbf{2 5 0 0} \mathrm{m}$ intervals in order to display all strain profiles with the same vertical scale. Sampling grid distance in metres is on the $x$ axis, while strain is on the $y$ axis.

\subsection{Fault Displacement/Length Relationships}

Fault growth is facilitated by repeated earthquakes that may increase fault displacement and/or length as strain is accommodated by a volume of rock, and as such a fault growth model must provide a link between the scaling properties of fault dimensions and earthquake events (Elliott, 1976; Scholz, 1982; Bonilla et al., 1984; Watterson, 1986; Walsh \& Watterson, 1988b; Marrett \& Allmendinger, 1991; Cowie \& Scholz, 1992; Gillespie et al., 1992; Dawers et al., 1993; Wells \& Coppersmith, 1994; Schlische et al., 1996; Nicol et al., 2005). While general fault Displacement/Length relationships are well established, how faults grow to reach a particular Displacement/Length ratio is still debated.

Much of the debate about how faults achieve their Displacement/Length ratio stems from an inherent problem when analysing fault data: scaling. Generally any one study is only able to capture 2-3 orders of magnitude in displacement and length scale compared to the $8-10$ orders of magnitude typical fault scales range across. A typical seismic reflection survey for example, will provide data on fault displacements and 
lengths ranging from tens of metres to tens of kilometres (three orders of magnitude), but will not have sufficient resolution to accurately locate fault tips, resulting in under sampling of true fault displacement and length. For large faults (>1 km in length) this under sampling represents a small proportion ( $5-10 \%)$ of total fault length and has little impact on Displacement/Length ratios. For small faults ( $<1 \mathrm{~km}$ length) the continuation of sub-resolution faulting beyond a seismically resolved fault tip may result in significant underestimation of fault length. In this study, the majority of fault lengths are $>1000 \mathrm{~m}$ and the undersampling of fault lengths is unlikely to have significant effect on the results presented here. As well as scale issues, fault growth in displacement and length is known to be controlled by material properties of faulted rocks; the type of fault; the earthquake rupture and slip/propagation history of the fault; whether the fault is segmented or linked; and if a fault has been reactivated. (Walsh \& Watterson, 1988a; Cowie \& Scholz, 1992; Dawers et al., 1993; Walsh et al., 2002; Kim \& Sanderson, 2005; Soliva et al., 2005; Xu et al., 2005).

To provide more robust estimates of Displacement/Length trends, additional methods, such as outcrop studies, can be employed to produce more meaningful results by using data from a wider range of fault lengths. It is best if any outcrop data employed are from the same study area and rock type, as the Displacement/Length ratio of faults is altered by material properties of rock; thus any scaling relationship determined from geologically diverse areas is likely illusory (Cowie \& Scholz, 1992). Outcrop studies measure fault displacements and lengths on scales of millimetres to tens of metres (three orders of magnitude) but generally under sample faults of seismically resolvable scale. Therefore there is on-going debate as to what is the most plausible model of fault growth is, and whether the Displacement/Length relationships are scale invariant (Walsh \& Watterson, 1988a; Cowie \& Scholz, 1992; Dawers et al., 1993; Walsh et al., 2002; Kim \& Sanderson, 2005; Soliva et al., 2005; Xu et al., 2005).

The relationship between maximum cumulative fault displacement $\left(\mathbf{d}_{\max }\right)$ and strike parallel fault length $(\boldsymbol{L})$ is $\left(\mathbf{d}_{\max }\right)=\boldsymbol{c} \boldsymbol{L}^{n}$, where $\mathbf{n}$ is the exponent value (and slope of the Displacement/Length trendline) which ranges from $0.5-2.0$, and $\mathrm{c}$ is an expression of fault displacement at unit length (if $n=1, c=n$ ). The value of $n$ is of interest. If $n$ is $\sim 1$, it indicates a linear scaling law exists between fault displacement and length and faults 
grow in a scale invariant manner. If $n \neq 1$, it indicates a scale dependant relationship exists between fault displacement and length (Watterson, 1986; Walsh \& Watterson, 1988b; Marrett \& Allmendinger, 1991; Cowie \& Scholz, 1992; Gillespie et al., 1992; Dawers et al., 1993; Scholz et al., 1993; Clark \& Cox, 1996; Schlische et al., 1996; Fossen \& Hesthammer, 1997).

The $\mathrm{n}$ value of fault Displacement/Length data has implications for whether a coherent or isolated fault model best describes the growth of faults. The coherent fault model predicts initial Displacement/Length ratios would be high with an $\mathrm{n}$ value $>1$, as faults would initiate with low displacements but with lengths at or near maximum (Childs et al., 2009). In this model, with increasing strain Displacement/Length ratios would increase (Fig. 5.8a). The isolated fault model predicts initial Displacement/Length ratios would be low with an $\mathrm{n}$ value of $\sim 1$, as faults would initiate at low displacement and length. Displacements would then increase along with lengths in a scale invariant manner, maintaining a constant Displacement/Length ratio until the faults began to either interact with or intersect other faults as seen in Figure5.8b (Walsh \& Watterson, 1988a).

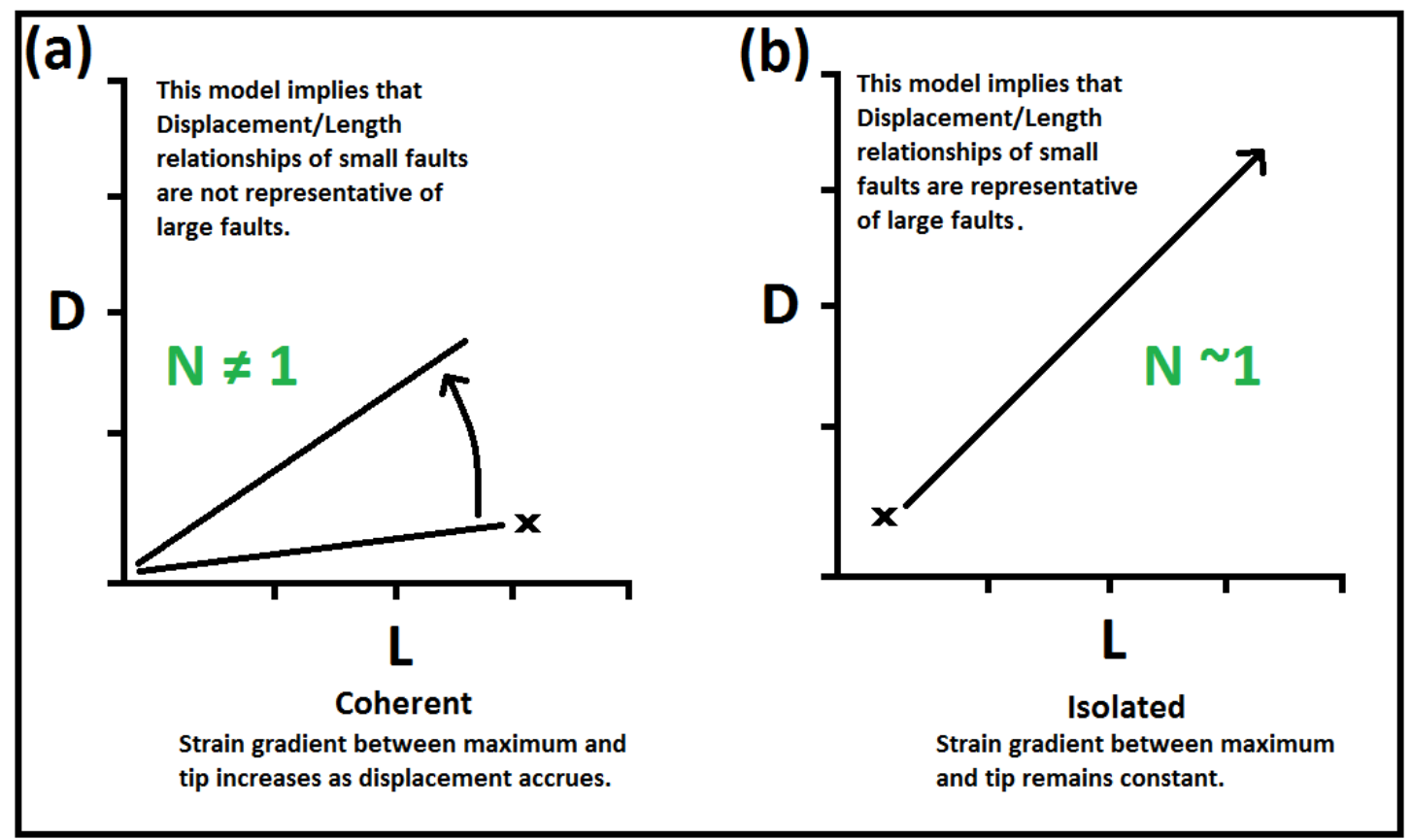

Figure 5.8 Schematic of Displacement/Length growth trends for coherent (a) and isolated (b) fault growth models. The differences in each model are stated and illustrated on the figure. 
Figure 5.9 shows a compilation of global normal fault displacement/Length data (Kim \& Sanderson, 2005). This compilation highlights the requirement to compare data from different sources in order to establish a Displacement/length relationship over scales typically observed for faults. The Displacement/Length ratio shown in this compilation is $\sim 10^{-2}$, with an $\mathrm{n}$ value (trendline slope) of 1 , suggesting that normal fault Displacement/Length relationships are scale invariant.

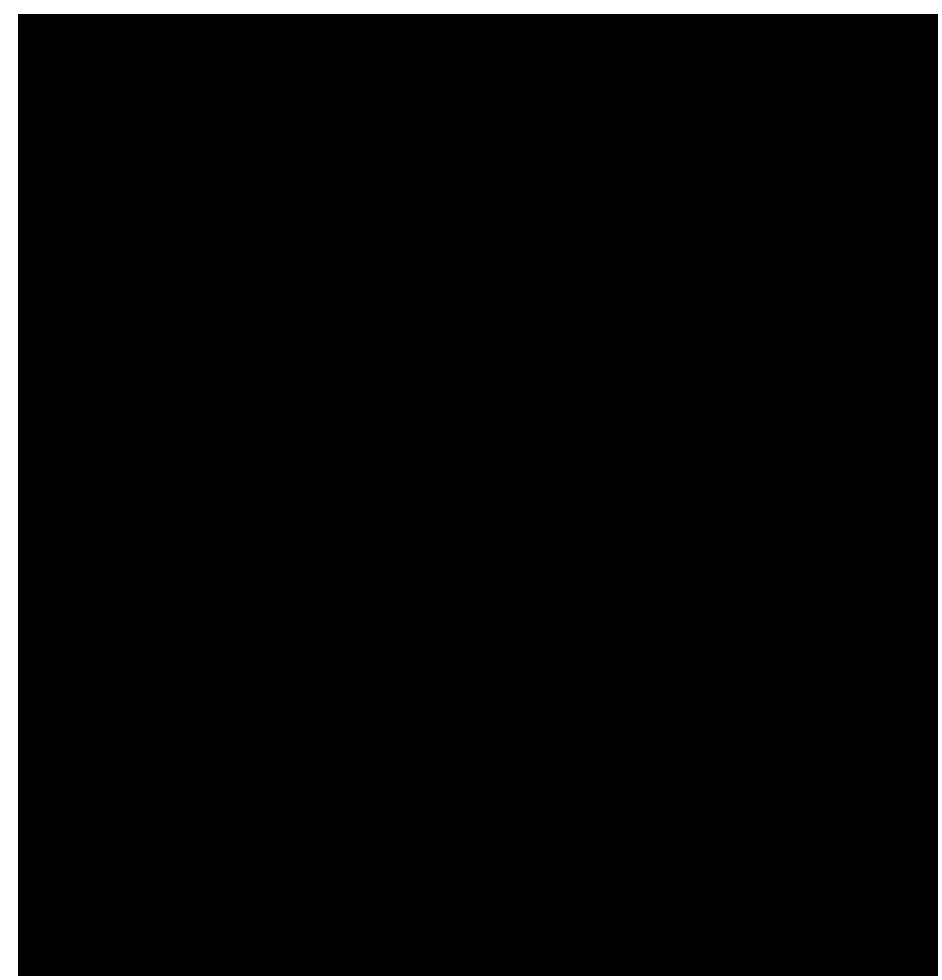

Figure 5.9 Log/log plot displaying a compilation of maximum global normal fault Displacement/Length data. Four Dmax/L gradients are shown for reference. From Kim and Sanderson (2005) and references therein.

\subsubsection{Fault Displacement/Length Relationships in the Northern}

\section{Graben}

Displacement/Length data collected in this study span two orders of magnitude, with $95 \%$ of faults between $10-1000 \mathrm{~m}$ of maximum displacement and $1-30 \mathrm{~km}$ in length. Margins of error for displacement and length measurements are $\pm 10 \mathrm{~m}$, and \pm $300 \mathrm{~m}$, respectively. Figure 5.10 shows maximum Displacement/Length data from this study compared to existing Displacement/length data from a global compilation of normal faults (A Nicol, unpub. data). The global data are sourced from a variety of 
different tectonic settings with different rheological properties. Fault Displacement/length data from this study are consistent with the global compilation (Fig. 5.10). Displacement/Length ratios in Figure 5.10 range from $\sim 10^{-1}-10^{-2}$ for the data gathered in this study, and $\sim 10^{-1}-10^{-3}$ for the global dataset. Displacement/Length ratios also range from $\sim 10^{-1}-10^{-3}$ when the data from this study and the global dataset are combined (Fig. 5.10). These data show both a similar slope (0.77) and variability to the global dataset (slope of 0.80 ). Combining the data from this study with the global dataset results in a slope of 0.82 . These slopes of $<1$ imply that normal fault Displacement/Length relationships do not vary significantly with fault scale. However, it is apparent that the global dataset has an inherent bias of higher data density in the mid-range (0.1 - $10 \mathrm{~m}$ displacement and $100-1000 \mathrm{~m}$ length) than at the high and low ends of the Displacement/length scale. This uneven density of data may result in calculation of erroneously low Displacement/Length ratios and $\mathrm{n}$ values.

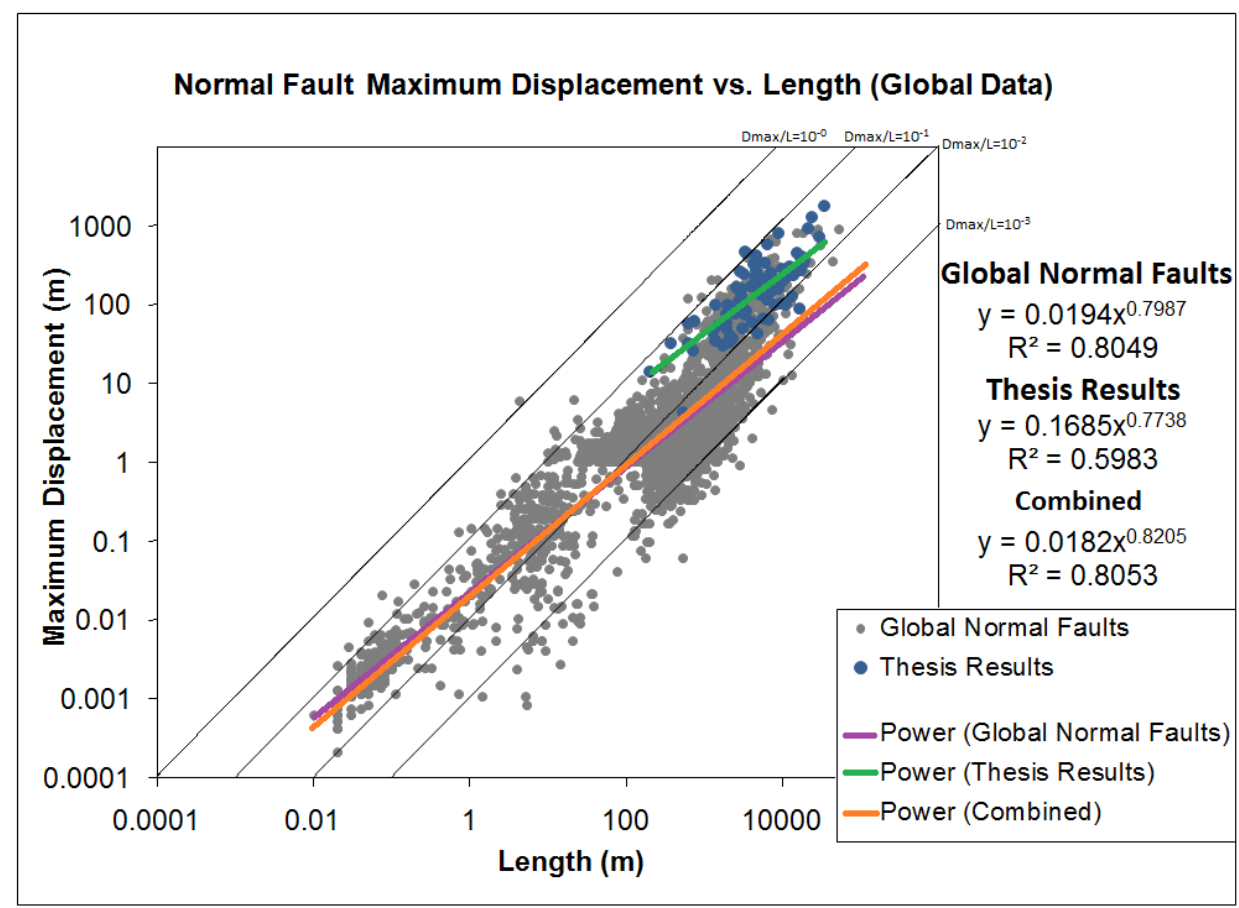

Figure 5.10 Log/log Displacement/Length plot for a compilation of global normal fault data Global normal fault data (grey circles) is compared to the Displacement/Length data gathered during this thesis (blue circles). Power law trendlines are provided for the global data, the results of this thesis, and a combination of the two. Four Dmax/L gradients are shown for reference. Global normal fault data are from MFRG 1973; Ruzich 1977; Muraoka and Kamata 1983; Villemin and Sunwoo 1987; Krantz 1988; Walsh and Watterson 1988; Opheim and Gudmundsson 1989; Marrett and Allmendinger 1991; Peacock and Sanders 1991; Gillespie et al. 1992; McGrath 1992; Dawers et al. 1993; Dawers and Anders 1995; Cartwright et al. 1996; Jackson et al. 1996; Nicol et al. 1996; Schlische et al. 1996; Wilkins and Gross 2001; Walsh et al. 2002; Bailey et al. 2005; FIFT Report 2005; Nicol and Walsh 2010. 
Outcrop data from the Taranaki coastline (A Nicol, unpub. Data) are added to the data from this study to extend the Displacement/length analysis for Taranaki Basin normal faults to approximately four orders of magnitude. Due to the recent uplift of the Central North Island (e.g. Pulford and Stern (2004)), faults of Late Miocene age, similar to those in this study, are exposed in outcrop along sea cliffs. These data are combined with Displacement/Length data from 2D seismic reflection studies from faults to the north of the study area (e.g. Giba (2010)) and this study to create a Taranaki Basin compilation dataset. Without the inclusion of outcrop data, a meaningful slope is difficult to discern. Inclusion of this unpublished data allows calculation of a Taranaki Displacement/Length trend with a mean Displacement/Length ratio of $10^{-2}$, and a slope of 1.44 (Fig. 5.11). As the slope value is $>1$, this trend implies that the fault Displacement/Length relationship is scale dependant, and that making inferences about how large faults grow cannot be informed by small faults, and vice versa. These results are inconsistent with the work shown in Figure 5.9 of Kim and Sanderson (2005) and references therein. It is also of interest that the Taranaki Displacement/Length slope of 1.44 (gathered from faults spanning approximately four orders of magnitude in displacement and length in a single region) reaches a different conclusion than global compilations of data (which individually span approximately one to two orders of magnitude in displacement and length in a single region).

Figure 5.11 also shows the maximum Displacement/Length ratio from this study for each fault coloured by the time horizon associated with the measurement. These data are consistent with previous data from the Taranaki Basin (A Nicol, unpub. data) which have at least one order of magnitude variation in displacement for a given length and vice versa. This order of magnitude scatter in the data is typical of other fault properties (e.g. Childs et al. (2009)). In general an upward increasing Displacement/Length trend from young to older faults is interpreted. Here, younger horizons have faults with lower displacements than faults of comparable length with maximum displacements on older horizons. While not conclusive, these data suggest that near maximum fault lengths are set early, with faults growing mainly by the accrual of displacement and are consistent with the coherent fault growth model of Childs et al. (2009) seen in Figure 5.8a. 
Maximum Displacement/Length data are compared for new, reactivated, and faults associated with the Southern Intrusive Complex in Figure 5.12. Faults antithetic to reactivated surfaces are considered as new faults for this analysis. The three fault types display similar Displacement/Length ratios ranging from $\sim 10^{-1}-10^{-2}$. The slopes for each fault type vary slightly, at 0.80 for new faults, 1.0 for reactivated faults, and 0.72 for faults associated with the Southern Intrusive Complex. Slopes of $\leq 1$ shown by the three fault types imply that normal fault Displacement/Length relationships do not vary significantly with fault scale or fault type. However, drawing trendlines from this dataset spanning only 2 orders of magnitude of displacement and length is not as robust as comparing data over $\sim 4$ or more orders of magnitude, as seen in Figure 5.11 which has a much steeper slope of 1.44 .

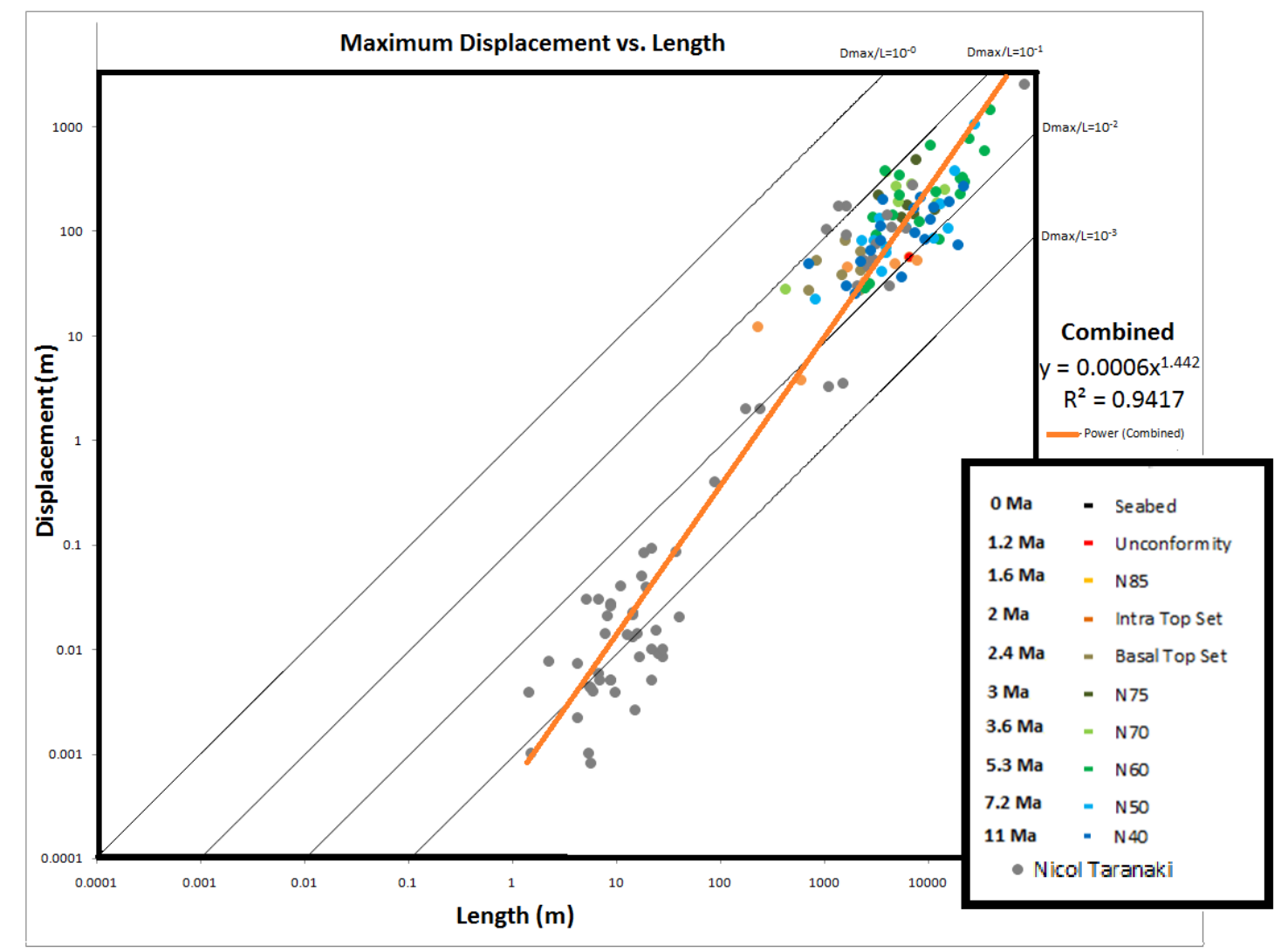

Figure 5.11 Log/log Maximum Displacement/Length plot for Taranaki Basin data.Data is coloured by time horizon to allow comparison of Displacement/Length relationship between time horizons. Grey filled circles are Taranaki Basin Displacement/Length data from both outcrop and seismic data (A Nicol, unpub. data). A power law trendline for a combination of thesis results and the Taranaki Basin data is shown. Four Dmax/L gradients are shown for reference.

This inconsistency between the Displacement/Length relationships of small and large faults is either because outcrop data from the Taranaki Basin (A Nicol, unpub. data) are 
not a representative sample (and a scale invariant relationship exists between fault displacement and length), or fault growth in displacement and length varies with fault scale.

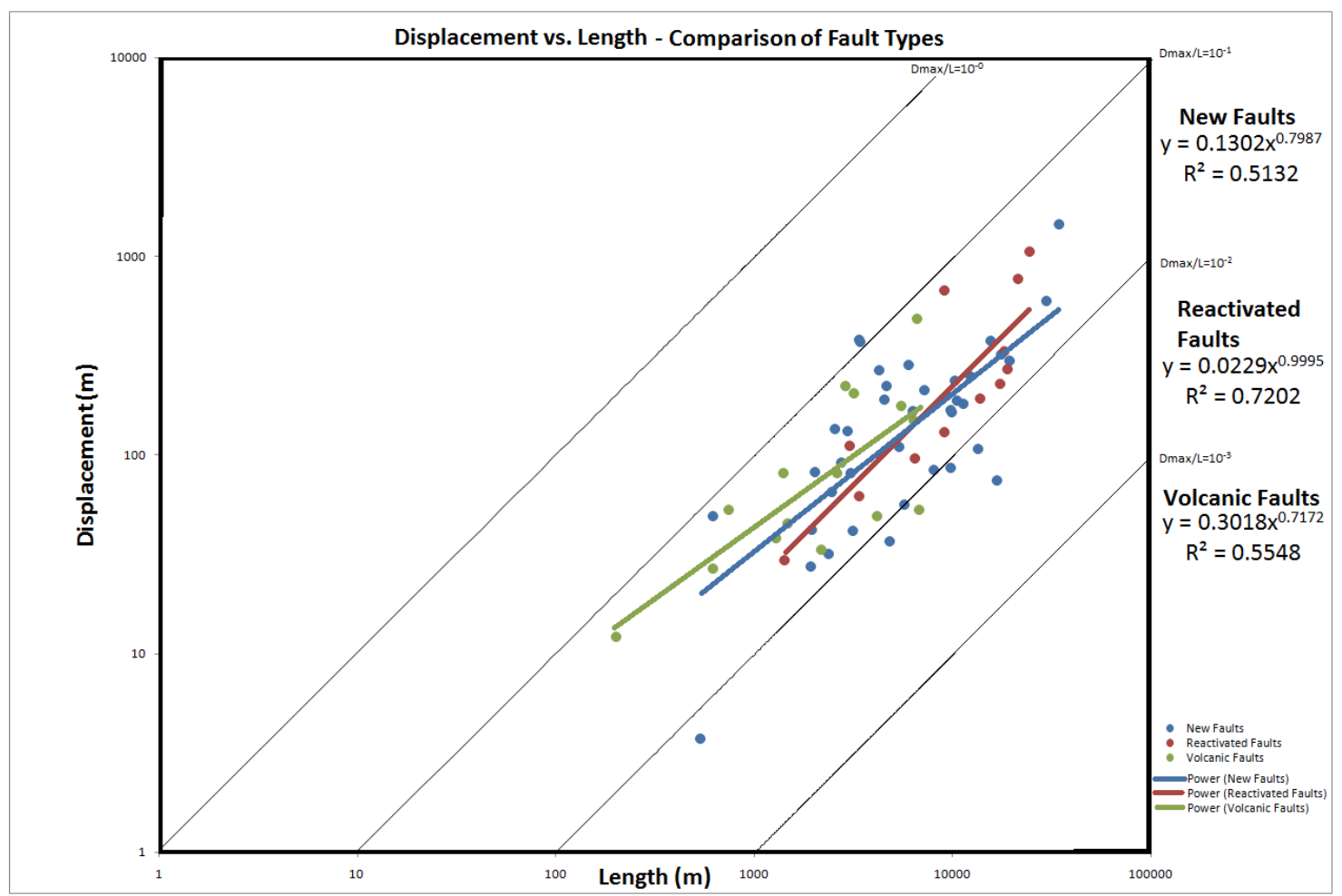

Figure 5.12 Log/log maximum Displacement/Length plot for all faults except those antithetic to reactivated structures. Data is not grouped by time horizon or fault to facilitate calculation of Displacement/Length ratios and $\mathrm{n}$ values. Data for new faults are displayed in blue, reactivated fault data are shown in red, and data for volcanic faults in green. Trendlines with their equations and $\mathbf{n}$ value are provided for each data type. Four Dmax/L gradients are shown for reference.

\subsubsection{Backstripped Fault Growth Profiles}

Fault growth histories are displayed in the form of backstripped Displacement/Length profiles. Growth profiles for new faults (Fig. 5.13) typically display fault Initiation followed by progressive decline in length while accruing displacement, before cessation of fault activity. It is important to note that fault length will not always return to zero or close to it at the top of the plot (both because eight faults are still active, and because the resolution provided by the twelve time horizons is not adequate to fully track fault length diminishment).The largest fault in the study area in terms of cumulative displacement (5_072) does not follow this trend, and instead displays approximately stationary tips after initiation. Both of these fault behaviours has been 
observed in previous normal fault growth studies, and indicate coherent fault growth (Cowie \& Scholz, 1992; Dawers et al., 1993; Kim \& Sanderson, 2005). Cumulative throws for new faults range between $20-1400 \mathrm{~m}$, and lengths vary from $\sim 1-33 \mathrm{~km}$, making new faults the largest (in terms of both cumulative throw and length) of the four fault types observed in this study.

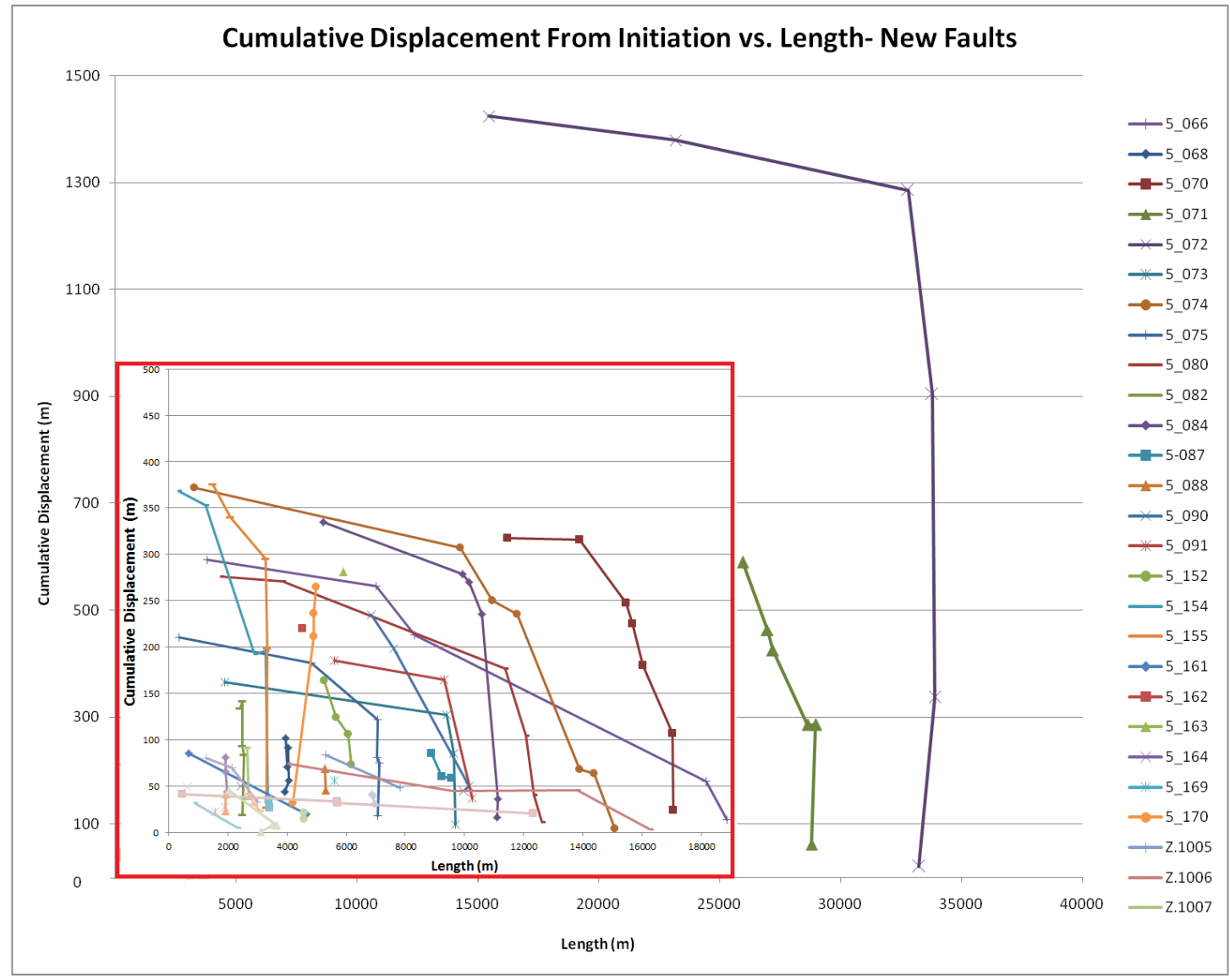

Figure 5.13 Backstripped Displacement/Length profiles for new faults, displaying fault length against cumulative throw. Fault length is taken from Displacement/Length data, with the length of faults at each time horizon plotted. Cumulative throw is also taken from Displacement/Length data. Maximum displacement values corresponding to each fault length are added to give cumulative values. Smaller faults are inset in a zoomed image for clarity.

As with new faults, reactivated faults (Fig. 5.14) display fault Initiation followed by progressive decline in length while accruing displacement, before cessation of fault activity. Two faults (5_156 and Z.1002) display initially stationary tips, which change to retreating tips after displacing two time horizons. Cumulative throws for reactivated faults range between $\sim 20-1000 \mathrm{~m}$, and lengths vary from $<1-23 \mathrm{~km}$. Growth profiles for faults antithetic to reactivated structures are typically be identical in shape to those of new faults and are thus not shown, though they are much smaller in magnitudes of 
displacement and length. Cumulative throws for faults antithetic to reactivated structures range between $\sim 20-200 \mathrm{~m}$, and lengths vary from $\sim 1-11 \mathrm{~km}$.

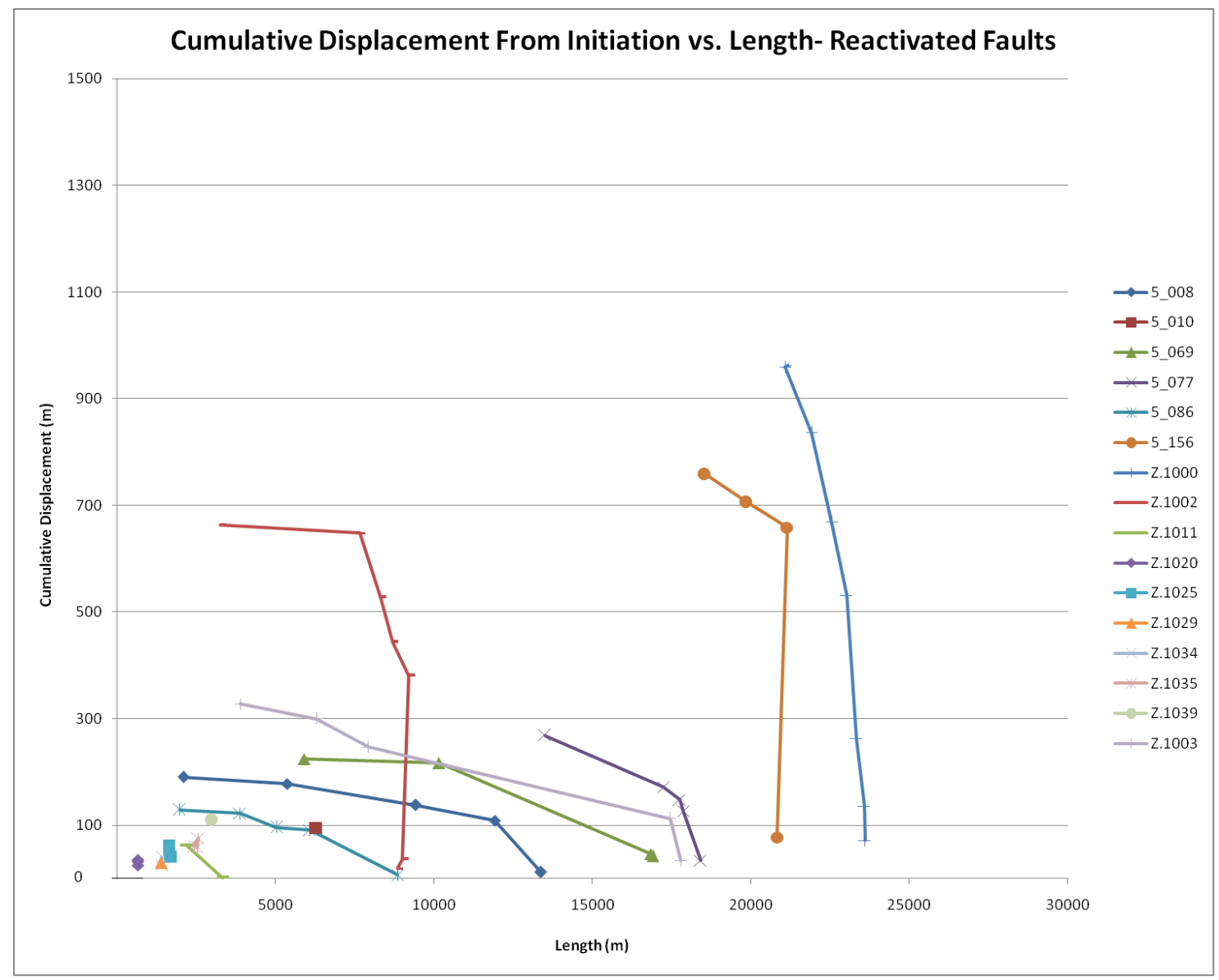

Figure 5.14 Backstripped Displacement/Length Profiles for reactivated faults, displaying fault length against cumulative throw. Fault length is taken from Displacement/Length data, with the length of faults at each time horizon plotted. Cumulative throw is also taken from Displacement/Length data. Maximum displacement values corresponding to each fault length are added to give cumulative values.

Growth profiles for volcanic faults (Fig. 5.15) are similar to those of new and reactivated faults (fault Initiation followed by progressive decline in length while accruing displacement, before cessation of fault activity). As with new faults, two faults (Z.1054 and Z.1061) display initially stationary tips, which change to retreating tips after displacing two to three time horizons. Cumulative throws for volcanic faults range between $\sim 20-450 \mathrm{~m}$, and lengths vary from $\sim 1-7 \mathrm{~km}$. 


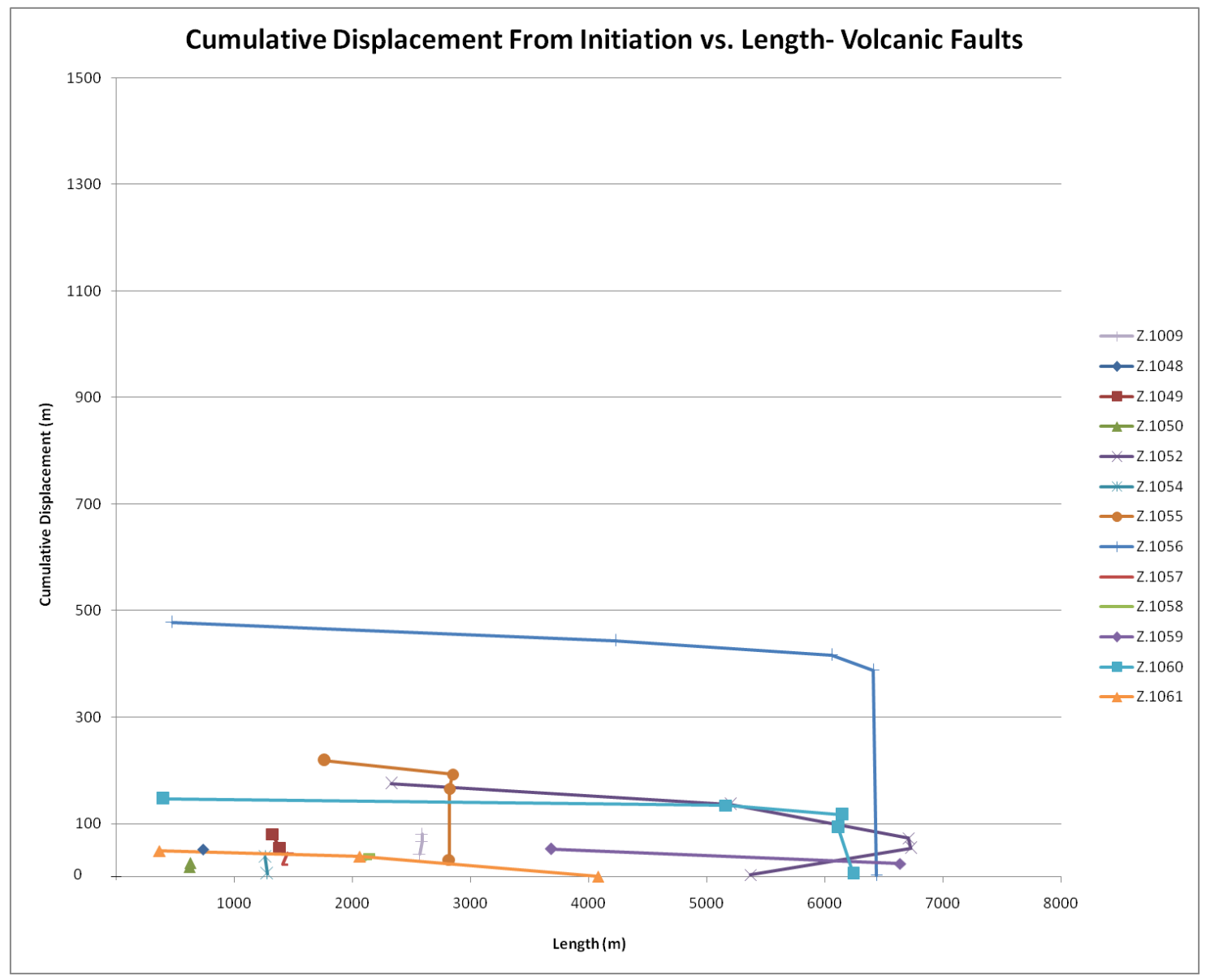

Figure 5.15 Backstripped Displacement/Length Profiles for volcanic faults, displaying fault length against cumulative throw. Fault length is taken from Displacement/Length data, with the length of faults at each time horizon plotted. Cumulative throw is also taken from Displacement/Length data. Maximum displacement values corresponding to each fault length are added to give cumulative values.

The relationship between the maximum cumulative throw of a fault (as an approximation of fault size) and the cessation of fault activity (in Myr before present) is shown in Figure 5.16. These data provide information for the question as to whether small faults cease activity first in response to localisation of strain onto larger faults (e.g. Nicol et al. (1996); Jackson (1999)). Small faults (maximum throw <100 m) can be seen to become inactive first, at $\sim 11 \mathrm{Ma}$ (though the actual cessation age of these faults will be between the $11 \mathrm{Ma}$ horizon which recorded maximum displacement, and 7.2 Ma). Faults of this size continue to become inactive throughout the 11 Myrs of observed fault activity. At $\sim 5.3 \mathrm{Ma}$, the maximum throw of faults becoming inactive increases to $>200 \mathrm{~m}$. $~ 50 \%$ of faults become inactive between 3.6 and $2 \mathrm{Ma}$, all with maximum throws $<450 \mathrm{~m}$. At $\sim 1.2 \mathrm{Ma}$, the size of faults becoming inactive increased to those with a maximum throw of up to $\sim 1050 \mathrm{~m}$. The largest faults, with maximum 
throws of up to $\sim 1500 \mathrm{~m}$ either ceased activity at/are still active at approximately present day. As a general trend, Figure 5.17 shows that in a population of normal faults, the greater the maximum cumulative throw on a fault is (the larger the fault), the later it becomes inactive.

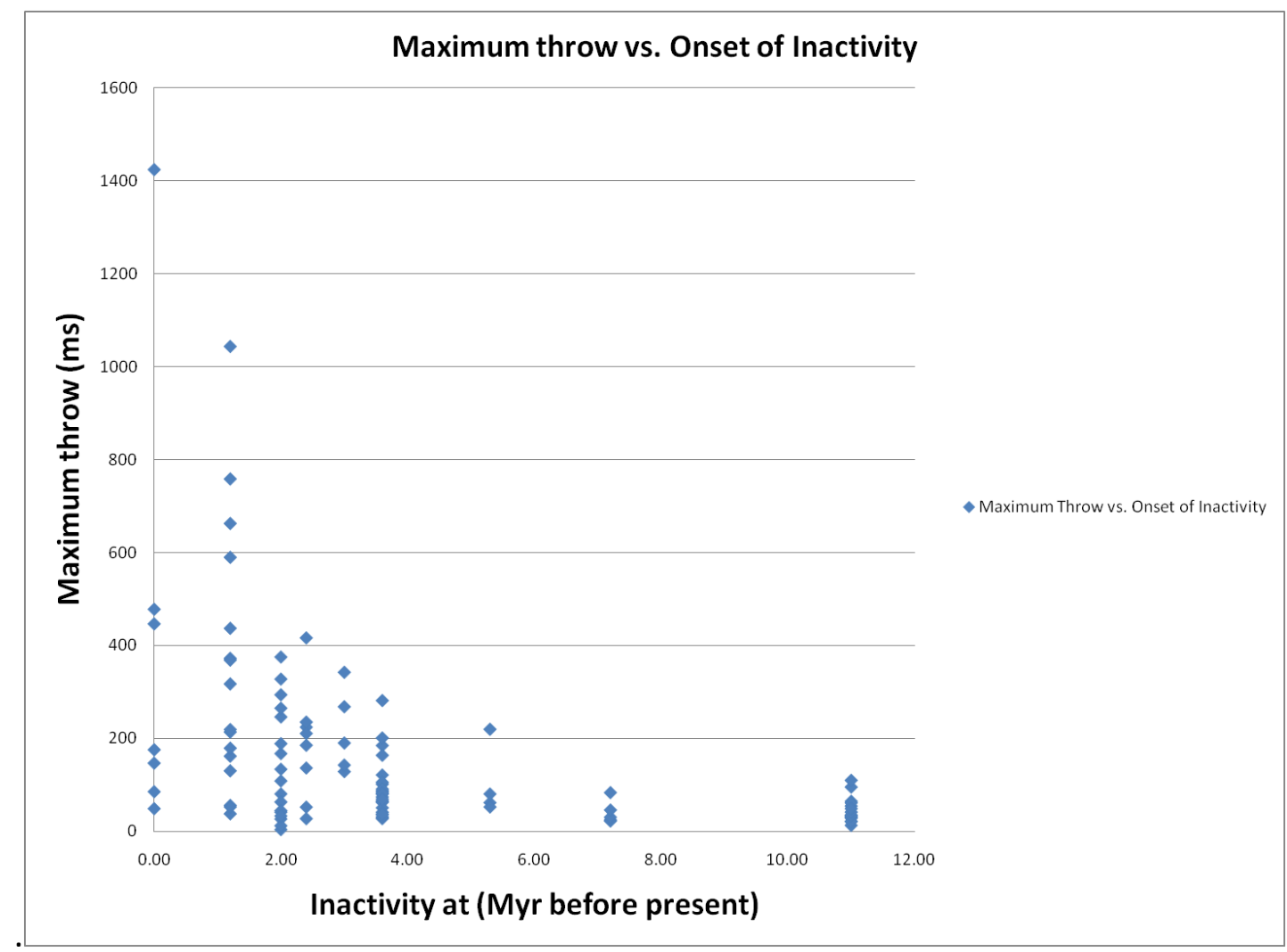

Figure 5.16 Plot of maximum cumulative fault throw vs. onset of inactivity. This plot shows a distinct trend of smaller faults (faults with less throw) becoming inactive first.

\subsection{Discussion}

\subsubsection{Support for Fault Growth Models}

Like other studies of fault growth (e.g. Childs et al. (2003)) the overprinting of past fault geometry by the maximum extent of a fault hampers efforts to understand the evolutionary path taken to reach maturity. 110 displacement profiles have been generated from normal faults in the study area, with fault Displacement/Length data gathered from these. These faults follow one of two growth behaviors; as displacement accrues through time they either appear to maintain their length until a time close to where they cease where lengths decrease ( $5 \%$ of faults), and alternately 
where their length decreases continuously from a maximum at initiation (95\% of faults). Both new and reactivated faults show the same general behavior, appearing to initiate at or very near their maximum lateral extent. Fault length is not retained close to fault inactivity, and faults with the lowest cumulative throws can be seen to become inactive earlier. This pattern of fault growth is explained by the Coherent fault model of Childs et al. (2009).

The Displacement/Length $\mathrm{n}$ value of 1.44 for a combined dataset of Taranaki Basin normal faults spanning $~ 4$ orders of magnitude is consistent with studies that suggest fault Displacement/Length relationships vary with fault scale (e.g. Anderson (1951); Watterson (1986); Walsh and Watterson (1988a); Marrett and Allmendinger (1991); Gillespie et al. (1992)). This result from faults occurring in a single geologic setting is of particular interest, as previous research by Cowie and Scholz (1992) states that the Displacement/Length ratio of faults is altered by material properties of rock; thus any Displacement/Length scaling relationships determined from a combination of data from diverse geologic settings (as is done in Figure 5.9 in the work of Kim and Sanderson (2005) are likely illusory. This may be because of different fault growth mechanisms acting at different scales, notably the progressive localisation of strain onto larger faults at the expense of smaller faults during fault system development (e.g. Walsh et al. (2002)).

Values of $n>1$ are theorised by Dawers et al. (1993) to be also related to the linear relationship that exists between fault slip increment and fault rupture length that is recorded for individual earthquake events (e.g. Scholz (1982). Dawers et al. (1993)) argue based on observations of fault Displacement/Length data from the Bishop Tuff, that while the linear relationship between fault slip increment and rupture length is correct for an individual slip event, it becomes non-linear in an upward increasing fashion when rupture length is considered relative to the cumulative slip from many slip events. Thus, smaller faults that have experienced fewer slip events (e.g. Taranaki Basin outcrop faults used in this study) should have lower Displacement/Length ratios than larger faults that have experienced more slip events (e.g. the faults mapped in this study). This theory may explain the slope of 1.44 for Taranaki Basin data in Figure 5.11. 


\subsubsection{Implications for Crustal Scale Tectonics}

Progressive localisation of strain on larger faults at the expense of displacement accumulation on smaller faults in the population is a possible reason for the majority ( 95\%) of faults becoming inactive towards present day (Meyer et al., 2002). While some of the smaller faults (Lengths $<15 \mathrm{~km}$, displacements $<200 \mathrm{~m}$ ) may succumb to localisation of strain onto larger faults (Fig. 5.7), this mechanism is unable to explain the displacement accumulation of these larger faults. A major cessation of activity on faults (all faults decrease in length by $20-60 \%$ ) in the study area occurred between 3.6 $\mathrm{Ma}$ (N70) to $3 \mathrm{Ma}$ (N75), with fault continuing to become inactive until present day. The largest and most recently active faults have not shown a corresponding increase in displacement on younger time horizons as would be expected if these faults were accommodating strain previously taken up by smaller faults (Figs. 5.13 5.15). The displacement of large faults also decreases from 3.6 Ma (N70) towards the present (Figs. 5.4 -5.6), indicating a reduction a reduction in the strain this region was accommodating. Strain profiles of the study area demonstrate the decrease in overall strain since $3.6 \mathrm{Ma}$ (Fig. 5.7). This suggests that while progressive localisation of strain may occur it cannot account for the reduction in strain causing the cessation of activity on the majority ( $95 \%$ ) of faults in this study.

The latest extension phase in the Taranaki Basin began 12 Myr ago, and has moved south and east in a series of punctuated steps (Giba et al., 2010). While commonly described as a back arc setting (e.g King and Thrasher (1996)), rift faults initiated after volcanism in the Taranaki Basin, and proceeded to dissect volcanic features (e.g. Giba et al. (2010). This would suggest intra-arc rifting better describes this latest phase of extension in the Taranaki basin. The presence of both arc volcanoes and extensional faults indicates that the subducting Pacific plate had a strong influence on both the magnitude and location of strain accommodated in the overriding Australian plate. To the north east of the study area at the time of the majority of faults became inactive (3.6 Ma), the Havre Trough is interpreted to be opening (Wysoczanski et al., 2010). The parallelism between the remnant Colville Arc and present day Kermadec Arc (Section 2.5) indicates either the location of the subduction hinge has migrated seaward, and/or that the dip of the slab has changed (Manea \& Gurnis, 2007). A change in the 
geometry of the slab underlying the North Island could account for decreasing strain in the study area since $3.6 \mathrm{Ma}$ (Fig. 5.7). The present location of arc front volcanoes with respect to arc volcanism 5-7 Myr ago (Section 2.5) indicates a south east migration of volcanism parallel to the slab hinge of $\sim 100 \mathrm{~km}$ (Seebeck et al., 2014b). A complimentary change in the location of intra-arc rifting from the Taranaki Basin to the Taupo Volcanic Zone has also occurred during this time.

\subsection{Conclusions}

- Two fault tip behaviours are observed in the study area; stationary and retreating. Peak strain of 0.07 was experienced at $5.3 \mathrm{Ma}$, with strain decreasing by $50 \%$ from a value of 0.06 at $3.6 \mathrm{Ma}$ to a value of 0.03 at $3 \mathrm{Ma}$. From 3 Ma strain decreased towards its present day value of $\sim 0$.

- $95 \%$ of both new and reactivated faults have apparent maximum lengths at or near their age of initiation.

- The majority ( 95\%) of faults decrease in length from initiation as displacement accrues.

- A minority ( $5 \%)$ of faults maintain apparent length until near the cessation of their activity.

- Fault displacement accumulation is consistent with the coherent fault growth model, whereby faults accrue displacement as part of a kinematically coherent system where fault growth is primarily achieved by increase in cumulative displacement rather than length.

- Displacement/length data compiled from the Taranaki Basin, including data from this study, indicates that large faults accrue displacement differently to smaller faults which implies fault growth in displacement and length is scale dependant. 


\section{Chapter 6 Conclusions}

The following are conclusions based on results of the thesis as a whole:

- Two predominant fault types are identified in this study. New faults (inclusive of faults associated with Pliocene intrusive volcanism) make up $50 \%$ of faults analysed. The remaining $50 \%$ of faults are reactivated (inclusive of faults that are antithetic to reactivated faults).

- Faults began to initiate at $11 \mathrm{Ma}$ in the west of the study area, with peak normal displacement and fault initiation at 5.3 Ma. Initiation of and accrual of displacement on smaller faults (displacements $\sim 20-500 \mathrm{~m}$, lengths $\sim 1-10$ $\mathrm{km}$ ) continued from $3 \mathrm{Ma}$, with $80 \%$ of faults inactive by $1.2 \mathrm{Ma}$.

- Eight faults displace the seafloor or underlying reflection and are considered potentially active. Estimated maximum $M_{\mathbf{W}} 2.14$ indicates these faults pose minimal seismic hazard, however there is uncertainty about the likely $\boldsymbol{M}_{\mathbf{w}}$ of an earthquake on these faults.

- Faults observed in this study are predominantly dip slip in nature and show no evidence for either up dip rotation in strike of the fault planes, or strike-slip motion during their growth. Comparison with normal fault trends in the TVZ < $300 \mathrm{kyr}$ in age indicates little difference in the kinematics of rifting over the past $11 \mathrm{Ma}$, and indicates the locus of extension has migrated south east with time.

- Two fault tip behaviours are observed in the study area; stationary and retreating. Peak strain of 0.07 was experienced at $5.3 \mathrm{Ma}$, with strain decreasing by $50 \%$ from a value of 0.06 at $3.6 \mathrm{Ma}$ to a value of 0.03 at $3 \mathrm{Ma}$. From 3 Ma strain decreased towards its present day value of $\sim 0$.

- $95 \%$ of both new and reactivated faults have apparent maximum lengths at or near their age of initiation.

- The majority ( 95\%) of faults decrease in length from initiation as displacement accrues. 
- A minority ( $5 \%)$ of faults maintain apparent length until near the cessation of their activity.

- Fault displacement accumulation is consistent with the coherent fault growth model, whereby faults accrue displacement as part of a kinematically coherent system where fault growth is primarily achieved by increase in cumulative displacement rather than length.

- Displacement/length data compiled from the Taranaki Basin, including data from this study, indicates that large faults accrue displacement differently to smaller faults which implies fault growth in displacement and length is scale dependant. 


\section{References}

Anderson, E. M. (1951). The dynamics of faulting and dyke formation with applications to Britain: Hafner Pub. Co.

ARCO Petroleum. (1992). Arawa-1 Final well report - PR 1824. Wellington: Ministry of Economic Development New Zealand

Axen, G. J. (1992). Pore Pressure, Stress Increase, and Fault Weakening in Low-Angle Normal Faulting. Journal of Geophysical Research-Solid Earth, 97(B6), 8979-8991.

Bache, F., Sutherland, R., Stagpoole, V., Herzer, R., Collot, J., \& Rouillard, P. (2012). Stratigraphy of the southern Norfolk Ridge and the Reinga Basin: A record of initiation of TongaKermadec-Northland subduction in the southwest Pacific. Earth and Planetary Science Letters, 321, 41-53.

Badley, M. E. (1985). Practical seismic interpretation.

Ballance, P. F. (1976). Evolution of Upper Cenozoic Magmatic Arc and Plate Boundary in Northern New-Zealand. Earth and Planetary Science Letters, 28(3), 356-370.

Bergmann, S. C. (1991). The Kola Miocene submarine andesite stratovolcano hydrocarbon reservoir, northern Taranaki Basin, New Zealand. Paper presented at the New Zealand Oil Expl. Conf. 2011.

Bonilla, M. G., Mark, R. K., \& Lienkaemper, J. J. (1984). Statistical Relations among Earthquake Magnitude, Surface Rupture Length, and Surface Fault Displacement. Bulletin of the Seismological Society of America, 74(6), 2379-2411.

Bradley, B. A., \& Cubrinovski, M. (2011). Near-source Strong Ground Motions Observed in the 22 February 2011 Christchurch Earthquake. Seismological Research Letters, 82(6), 853865.

Brothers, R. N. (1984). Subduction Regression and Oceanward Migration of Volcanism, NorthIsland, New-Zealand. Nature, 309(5970), 698-700.

Cartwright, J. (2011). Diagenetically induced shear failure of fine-grained sediments and the development of polygonal fault systems. Marine and Petroleum Geology, 28(9), 15931610.

Childs, C., Manzocchi, T., Walsh, J. J., Bonson, C. G., Nicol, A., \& Schopfer, M. P. J. (2009). A geometric model of fault zone and fault rock thickness variations. Journal of Structural Geology, 31(2), 117-127.

Childs, C., Nicol, A., Walsh, J. J., \& Watterson, J. (2003). The growth and propagation of synsedimentary faults. Journal of Structural Geology, 25(4), 633-648.

Chopra, S., \& Marfurt, K. J. (2007). Seismic Attributes for Prospect Identification and Reservoir Characterisation Tulsa, OK U.S.A: Society of Exploration Geophysicists 
Clark, R. M., \& Cox, S. J. D. (1996). A modern regression approach to determining fault displacement-length scaling relationships. Journal of Structural Geology, 18(2-3), 147152.

Cohen, C. R., Christianson, L. J., Bates, C. R., Laney, R. P., \& Morton, G. A. (2006). Pogo New Zealand's $3 D$ seismic: new standards and structural/stratigraphic insights in the Taranaki Basin Houston: Pogo Producing Company.

Cole, J. W., \& Lewis, K. B. (1981). Evolution of the Taupo-Hikurangi Subduction System. Tectonophysics, 72(1-2), 1-21.

Cowie, P. A., \& Scholz, C. H. (1992). Displacement Length Scaling Relationship for Faults - Data Synthesis and Discussion. Journal of Structural Geology, 14(10), 1149-1156.

Crowley, J., \& Crocker, S. J. (1989). Well Completion Report Okoki-1 - PR 1495. Wellington: Ministry of Economic Development New Zealand

Dawers, N. H., Anders, M. H., \& Scholz, C. H. (1993). Growth of Normal Faults - DisplacementLength Scaling. Geology, 21(12), 1107-1110.

Diamond Shamrock Exploration Oil Co (NZ). (1984). Final Well Report Taimana-1 - PR 1026. Wellington: Ministry of Economic Development New Zealand

Elliott, D. (1976). Energy-Balance and Deformation Mechanisms of Thrust Sheets. Philosophical Transactions of the Royal Society a-Mathematical Physical and Engineering Sciences, 283(1312), 289-+.

England, P., Engdahl, R., \& Thatcher, W. (2004). Systematic variation in the depths of slabs beneath arc volcanoes. Geophysical Journal International, 156(2), 377-408.

Faulkner, D. R., Jackson, C. A. L., Lunn, R. J., Schlische, R. W., Shipton, Z. K., Wibberley, C. A. J., \& Withjack, M. O. (2010). A review of recent developments concerning the structure, mechanics and fluid flow properties of fault zones. Journal of Structural Geology, 32(11), 1557-1575.

Ferrill, D. A., \& Morris, A. P. (2003). Dilational normal faults. Journal of Structural Geology, 25(2), 183-196.

Finkbeiner, T., Barton, C. A., \& Zoback, M. D. (1997). Relationships among in-situ stress, fractures and faults, and fluid flow: Monterey formation, Santa Maria basin, California. Aapg Bulletin-American Association of Petroleum Geologists, 81(12), 1975-1999.

Fossen, H., \& Hesthammer, J. (1997). Geometric analysis and scaling relations of deformation bands in porous sandstone. Journal of Structural Geology, 19(12), 1479-1493.

Giba, M. (2010). The Evolution of Tertiary Normal Faults in the Taranaki Basin, New Zealand. (Doctor of Philosophy in Geology), University College Dublin, Dublin.

Giba, M., Nicol, A., \& Walsh, J. J. (2010). Evolution of faulting and volcanism in a back-arc basin and its implications for subduction processes. Tectonics, 29. 
Giba, M., Walsh, J. J., \& Nicol, A. (2012). Segmentation and growth of an obliquely reactivated normal fault Journal of Structural Geology, 39 (2012), 253-267.

Giba, M., Walsh, J. J., Nicol, A., Mouslopoulou, V., \& Seebeck, H. (2013). Investigation of the spatio-temporal relationship between normal faulting and arc volcanism on millionyear time scales. Journal of the Geological Society, 170(6), 951-962.

Gillespie, P. A., Walsh, J. J., \& Watterson, J. (1992). Limitations of Dimension and Displacement Data from Single Faults and the Consequences for Data-Analysis and Interpretation. Journal of Structural Geology, 14(10), 1157-1172.

Hatherton, T., Davey, F. J., \& Hunt, T. M. (1979). Geophysical Anomalies and Igneous Bodies Off the West-Coast, North Island. Journal of the Royal Society of New Zealand, 9(1), 13-28.

Ilg, B. R., Hemmings-Sykes, S., Nicol, A., Baur, J., Fohrmann, M., Funnell, R., \& Milner, M. (2012). Normal faults and gas migration in an active plate boundary, southern Taranaki Basin, offshore New Zealand. Aapg Bulletin, 96(9), 1733-1756.

Jackson, J. (1999). Fault death: a perspective from actively deforming regions. Journal of Structural Geology, 21(8-9), 1003-1010.

Johnston, A. G. (2014). Interactions Between the Prograding Giant Foresets Formation and a Subsiding Depocentre: Insights From the Parihaka 3D \& ES89 2D Seismic Surveys. (Master of Science Petroleum Geoscience ), Victoria University of Wellington

Kamp, P. J. J. (1984). Neogene and Quaternary Extent and Geometry of the Subducted Pacific Plate beneath North Island, New-Zealand - Implications for Kaikoura Tectonics. Tectonophysics, 108(3-4), 241-266.

Kanamori, H., \& Anderson, D. L. (1975). Theoretical Basis of Some Empirical Relations in Seismology. Bulletin of the Seismological Society of America, 65(5), 1073-1095.

Kim, Y. S., \& Sanderson, D. J. (2005). The relationship between displacement and length of faults: a review. Earth-Science Reviews, 68(3-4), 317-334.

King, P. R. (2000). Tectonic reconstructions of New Zealand: 40 Ma to the present. New Zealand Journal of Geology and Geophysics, 43(4), 611-638.

King, P. R., \& Thrasher, G. P. (1996). Cretaceous-Cenozoic Geology and Petroleum Systems of the Taranaki Basin, New Zealand. Lower Hutt Institute of Geological \& Nuclear Sciences Limited.

Lamb, S. (2011). Cenozoic tectonic evolution of the New Zealand plate-boundary zone: A paleomagnetic perspective. Tectonophysics, 509(3-4), 135-164.

Lovitz, G., \& Bates, R. (2008a). PEP 38489 - Toro 3D Seismic Survey Interpretation report. Wellington Ministry of Economic Development New Zealand.

Lovitz, G., \& Bates, R. (2008b). Toro 3D Seismic Survey Interpretation report - PR 3935. Wellington Ministry of Economic Development New Zealand. 
Manea, V., \& Gurnis, M. (2007). Subduction zone evolution and low viscosity wedges and channels. Earth and Planetary Science Letters, 264(1-2), 22-+.

Marrett, R., \& Allmendinger, R. W. (1991). Estimates of Strain Due to Brittle Faulting - Sampling of Fault Populations. Journal of Structural Geology, 13(6), 735-738.

McDouall Stuart Research. (2009). Options for Developing the potential of New Zealand's Oil, Gas and Minerals Sector. Retrieved from https://www.med.govt.nz/sectorsindustries/natural-resources/oil-and-gas/petroleum-expert-reports/McDouall-Stuartreport-pdf

Meyer, V., Nicol, A., Childs, C., Walsh, J. J., \& Watterson, J. (2002). Progressive localisation of strain during the evolution of a normal fault population. Journal of Structural Geology, 24(8), 1215-1231.

Morgans, H. (2006a). Foraminiferal Biostratigraphy of the Early Miocene to Pleistocene Sequences in Witiora-1, Taimana-1, Arawa-1 and Okoki-1. Lower Hutt: GNS Science.

Morgans, H. (2006b). PR3534 - Foramaniferal Biostratigraphy of the early Miocene to Pleistocene Sequences in Witiora-1, Taimana-1, Arawa-1 and Okoki-1 (M. o. E. Development Ed.). Lower Hutt: GNS Science

Mouslopoulou, V., Nicol, A., Walsh, J. J., Begg, J. G., Townsend, D. B., \& Hristopulos, D. T. (2012). Fault-slip accumulation in an active rift over thousands to millions of years and the importance of paleoearthquake sampling. Journal of Structural Geology, 36, 71-80.

Mumme, T. C., Lamb, S. H., \& Walcott, R. I. (1989). The Raukumara Paleomagnetic Domain Constraints on the Tectonic Rotation of the East Coast, North Island, New-Zealand, from Paleomagnetic Data. New Zealand Journal of Geology and Geophysics, 32(3), 317326.

Nakamura, K., \& Jacob, K. (1976). Volcanos as Indicators of Tectonic Stress Orientation Aleutians and Alaska. Transactions-American Geophysical Union, 57(12), 1006-1006.

New Zealand Petroleum and Minerals. (2014a). Block Offer 2014 Permit Details and Maps. Retrieved from http://www.nzpam.govt.nz/cms/investors/permits/blockoffers/previous/2014/overview-block-offer-2014-permits/details-maps

New Zealand Petroleum and Minerals. (2014b). Block Offers prior to 2012. Retrieved from http://www.nzpam.govt.nz/cms/investors/permits/block-offers/previous/block-offersbefore-2012

New Zealand Petroleum and Minerals. (2015). New Zealand Petroleum Basins. Wellington Ministry of Business, Innovation \& Employment.

Nicol, A., \& Wallace, L. M. (2007). Temporal stability of deformation rates: Comparison of geological and geodetic observations, Hikurangi subduction margin, New Zealand. Earth and Planetary Science Letters, 258(3-4), 397-413.

Nicol, A., Walsh, J., Berryman, K., \& Nodder, S. (2005). Growth of a normal fault by the accumulation of slip over millions of years. Journal of Structural Geology, 27(2), 327342. 
Nicol, A., Walsh, J. J., Watterson, J., \& Gillespie, P. A. (1996). Fault size distributions - Are they really power-law? Journal of Structural Geology, 18(2-3), 191-197.

NZ Oil \& Gas Ltd. (1984a). Witiora-1 Completion Report Wellington: Ministry of Economic Development New Zealand

NZ Oil \& Gas Ltd. (1984b). Witiora-1 Completion Report - PR 1037. Wellington: Ministry of Economic Development New Zealand

Paterson, G. A., Roberts, A. P., Mac Niocaill, C., Muxworthy, A. R., Gurioli, L., Viramonte, J. G., . .. Weider, S. (2010). Paleomagnetic determination of emplacement temperatures of pyroclastic deposits: an under-utilized tool. Bulletin of Volcanology, 72(3), 309-330.

Power, W. L. (2013). Review of Tsunami Hazard in New Zealand (2013 Update). Lower Hutt: GNS Science

Price, R. C., Gamble, J. A., Smith, I. E. M., Stewart, R. B., Eggins, S., \& Wnight, I. C. (2005). An integrated model for the temporal evolution of andesites and rhyolites and crustal development in New Zealand's North Island. Journal of Volcanology and Geothermal Research, 140(1-3), 1-24.

Pulford, A., \& Stern, T. (2004). Pliocene exhumation and landscape evolution of central North Island, New Zealand: The role of the upper mantle. Journal of Geophysical ResearchEarth Surface, 109(F1).

Reilly, C., Nicol, A., Walsh, J. J., \& Seebeck, H. (2015). Evolution of faulting and plate boundary deformation in the Southern Taranaki Basin, New Zealand. Tectonophysics, 651, 1-18.

Schlagenhauf, A., Manighetti, I., Malavieille, J., \& Dominguez, S. (2008). Incremental growth of normal faults: Insights from a laser-equipped analog experiment. Earth and Planetary Science Letters, 273(3-4), 299-311.

Schlische, R. W., Young, S. S., Ackermann, R. V., \& Gupta, A. (1996). Geometry and scaling relations of a population of very small rift-related normal faults. Geology, 24(8), 683686.

Scholz, C. H. (1982). Scaling Laws for Large Earthquakes - Consequences for Physical Models. Bulletin of the Seismological Society of America, 72(1), 1-14.

Scholz, C. H., Dawers, N. H., Yu, J. Z., \& Anders, M. H. (1993). Fault Growth and Fault Scaling Laws - Preliminary-Results. Journal of Geophysical Research-Solid Earth, 98(B12), 21951-21961.

Sdrolias, M., \& Muller, R. D. (2006). Controls on back-arc basin formation. Geochemistry Geophysics Geosystems, 7.

Seebeck, H., Nicol, A., Giba, M., Pettinga, J., \& Walsh, J. (2014a). Geometry of the subducting Pacific plate since $20 \mathrm{Ma}$, Hikurangi margin, New Zealand. Journal of the Geological Society, 171(1), 131-143. 
Seebeck, H., Nicol, A., Villamor, P., Ristau, J., \& Pettinga, J. (2014b). Structure and kinematics of the Taupo Rift, New Zealand. Tectonics, 33(6), 1178-1199.

Sherburn, S., \& White, R. S. (2006). Tectonics of the Taranaki region, New Zealand: earthquake focal mechanisms and stress axes. New Zealand Journal of Geology and Geophysics, 49(2), 269-279.

Soliva, R., Schultz, R. A., \& Benedicto, A. (2005). Three-dimensional displacement-length scaling and maximum dimension of normal faults in layered rocks. Geophysical Research Letters, 32(16).

Stagpoole, V., \& Nicol, A. (2008). Regional structure and kinematic history of a large subduction back thrust: Taranaki Fault, New Zealand. Journal of Geophysical Research-Solid Earth, 113(B1).

Stern, T., Houseman, G., Salmon, M., \& Evans, L. (2013). Instability of a lithospheric step beneath western North Island, New Zealand. Geology, 41(4), 423-426.

Stern, T. A. (1987). Asymmetric Back-Arc Spreading, Heat-Flux and Structure Associated with the Central Volcanic Region of New-Zealand. Earth and Planetary Science Letters, 85(13), 265-276.

Stern, T. A., Stratford, W. R., \& Salmon, M. L. (2006). Subduction evolution and mantle dynamics at a continental margin: Central North Island, New Zealand. Reviews of Geophysics, 44(4).

Strogen, D. P., \& King, P. R. (2014). A new Zealandia-wide seismic horizon naming scheme (Vol. 2014/34): GNS Science.

Syracuse, E. M., \& Abers, G. A. (2006). Global compilation of variations in slab depth beneath arc volcanoes and implications. Geochemistry Geophysics Geosystems, 7.

Telford, C., \& Murray, D. (2008). MA-02A Well Completion Report - PR4275. Wellington: Ministry of Economic Development.

Townend, J., \& Zoback, M. D. (2000). How faulting keeps the crust strong. Geology, 28(5), 399402.

Veeken, P. H. C. (2006). Seismic Stratigraphy, Basin Analysis and Reservoir Characterization (Vol. 37). Oxford Elsevier

Veritas DGC Asia Pacific Ltd. (2005). PR3460 - Parihaka 3D Marine Seismic Survey - Acquisition and Processing Report. Wellington Ministry of Economic Development New Zealand.

Veritas Geophysical Asia Pacific Pte. Ltd. (2007). PR3741 - Toro 3D Seismic Survey Final Survey Report. Wellington: Ministry of Economic Development New Zealand.

Villamor, P., \& Berryman, K. (2001). A late Quaternary extension rate in the Taupo Volcanic Zone, New Zealand, derived from fault slip data. New Zealand Journal of Geology and Geophysics, 44(2), 243-269. 
Walcott, R. I. (1987). Geodetic Strain and the Deformational History of the North-Island of New-Zealand during the Late Cainozoic. Philosophical Transactions of the Royal Society a-Mathematical Physical and Engineering Sciences, 321(1557), 163-181.

Wallace, L. M., Beavan, J., McCaffrey, R., \& Darby, D. (2004). Subduction zone coupling and tectonic block rotations in the North Island, New Zealand. Journal of Geophysical Research-Solid Earth, 109(B12).

Walsh, J. J., Nicol, A., \& Childs, C. (2002). An alternative model for the growth of faults. Journal of Structural Geology, 24(11), 1669-1675.

Walsh, J. J., \& Watterson, J. (1988a). Analysis of the Relationship between Displacements and Dimensions of Faults. Journal of Structural Geology, 10(3), 239-247.

Walsh, J. J., \& Watterson, J. (1988b). Dips of Normal Faults in British Coal Measures and Other Sedimentary Sequences. Journal of the Geological Society, 145, 859-873.

Watterson, J. (1986). Fault Dimensions, Displacements and Growth. Pure and Applied Geophysics, 124(1-2), 365-373.

Wells, D. L., \& Coppersmith, K. J. (1994). New Empirical Relationships among Magnitude, Rupture Length, Rupture Width, Rupture Area, and Surface Displacement. Bulletin of the Seismological Society of America, 84(4), 974-1002.

WesternGeco. (2012). PR4582 - Parihaka 3D PSTM Final Processing Report. . Wellington: New Zealand Petroleum and Minerals

Wood, R., Lamarche, G., Herzer, R., Delteil, J., \& Davy, B. (1996). Paleogene seafloor spreading in the southeast Tasman sea. Tectonics, 15(5), 966-975.

Wright, I. C., Parson, L. M., \& Gamble, J. A. (1996). Evolution and interaction of migrating crossarc volcanism and backarc rifting: An example from the southern Havre Trough (35 degrees 20'-37 degrees S). Journal of Geophysical Research-Solid Earth, 101(B10), 22071-22086.

Wysoczanski, R. J., Todd, E., Wright, I. C., Leybourne, M. I., Hergt, J. M., Adam, C., \& Mackay, K. (2010). Backarc rifting, constructional volcanism and nascent disorganised spreading in the southern Havre Trough backarc rifts (SW Pacific). Journal of Volcanology and Geothermal Research, 190(1-2), 39-57.

Xu, S. S., Nieto-Samaniego, A. F., \& Alaniz-Alvarez, S. A. (2005). Power-law distribution of normal fault displacement and length and estimation of extensional strain due to normal faults: A case study of the Sierra de San Miguelito, Mexico. Acta Geologica Sinica-English Edition, 79(1), 36-42.

Yielding, G., Bretan, P., \& Freeman, B. (2010). Fault seal calibration: a brief review. Geological Society, London, Special Publications, 347(1), 243-255.

Zhang, X., Sanderson, D. J., Harkness, R. M., \& Last, N. C. (1996). Evaluation of the 2-D permeability tensor for fractured rock masses. International Journal of Rock Mechanics and Mining Sciences \& Geomechanics Abstracts, 33(1), 17-37. 
Zink, K. G., \& Sykes, S. (2009). Geochemical database and interpretation of 10 oils from several New Zealand basins. Lower Hutt: GNS Science 


\section{Appendix}

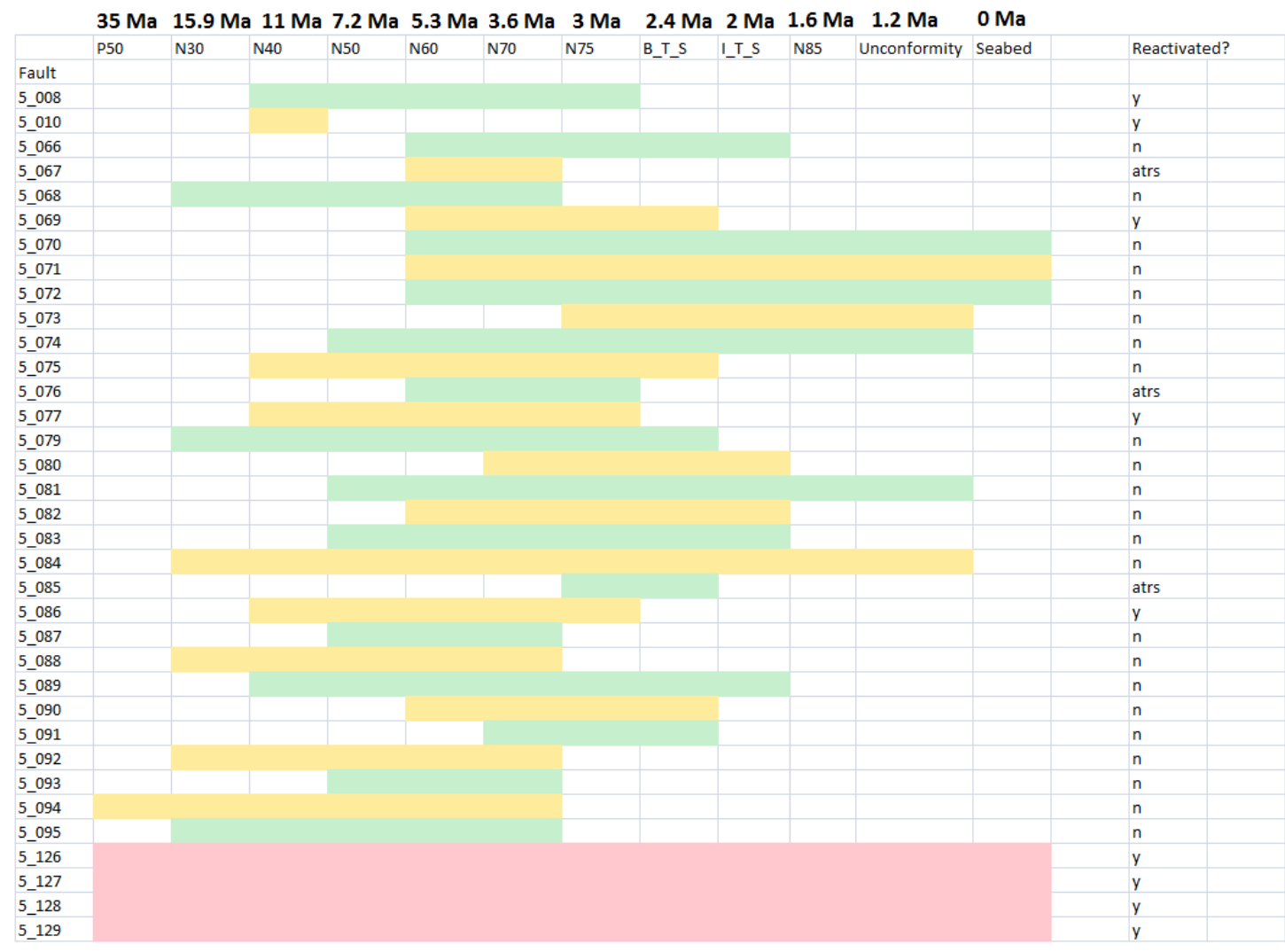

Appendix Table 1 Fault activity table displaying the time horizons at which each fault in the study area was active, along with its type - part 1 of 3 . Fault names are on the $Y$ axis, and the 12 time horizons used in the thesis are on the $X$ axis. Coloured cells represent the period through which a given fault was active. Coloured cells alternate from green to yellow to avoid confusing adjacent faults. Red cells show that no time horizon data intersects with the fault. The Reactivated? Column states the faults reactivation status: $Y$ means yes the fault is reactivated, $N$ means no the fault is not reactivated, Atrs means the fault is attached to a reactivated structure, and $V$ means the fault is volcanic. 


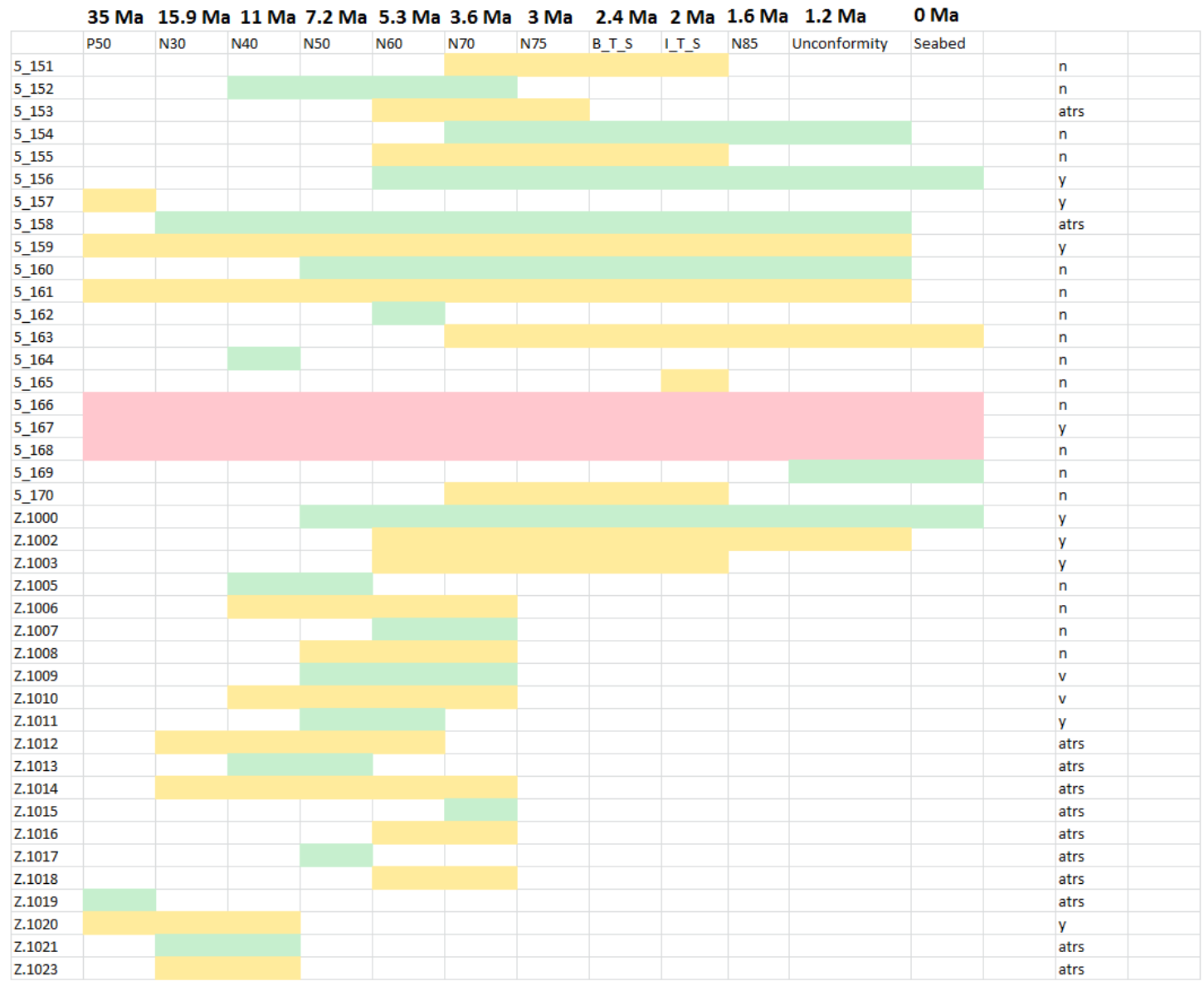

Appendix Table 2 Fault activity table displaying the time horizons at which each fault in the study area was active, along with its type - part 2 of 3 . Fault names are on the $Y$ axis, and the 12 time horizons used in the thesis are on the $X$ axis. Coloured cells represent the period through which a given fault was active. Coloured cells alternate from green to yellow to avoid confusing adjacent faults. Red cells show that no time horizon data intersects with the fault. The Reactivated? Column states the faults reactivation status: $\mathbf{Y}$ means yes the fault is reactivated, $\mathbf{N}$ means no the fault is not reactivated, Atrs means the fault is attached to a reactivated structure, and $V$ means the fault is volcanic. 


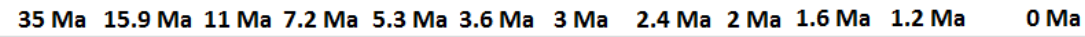

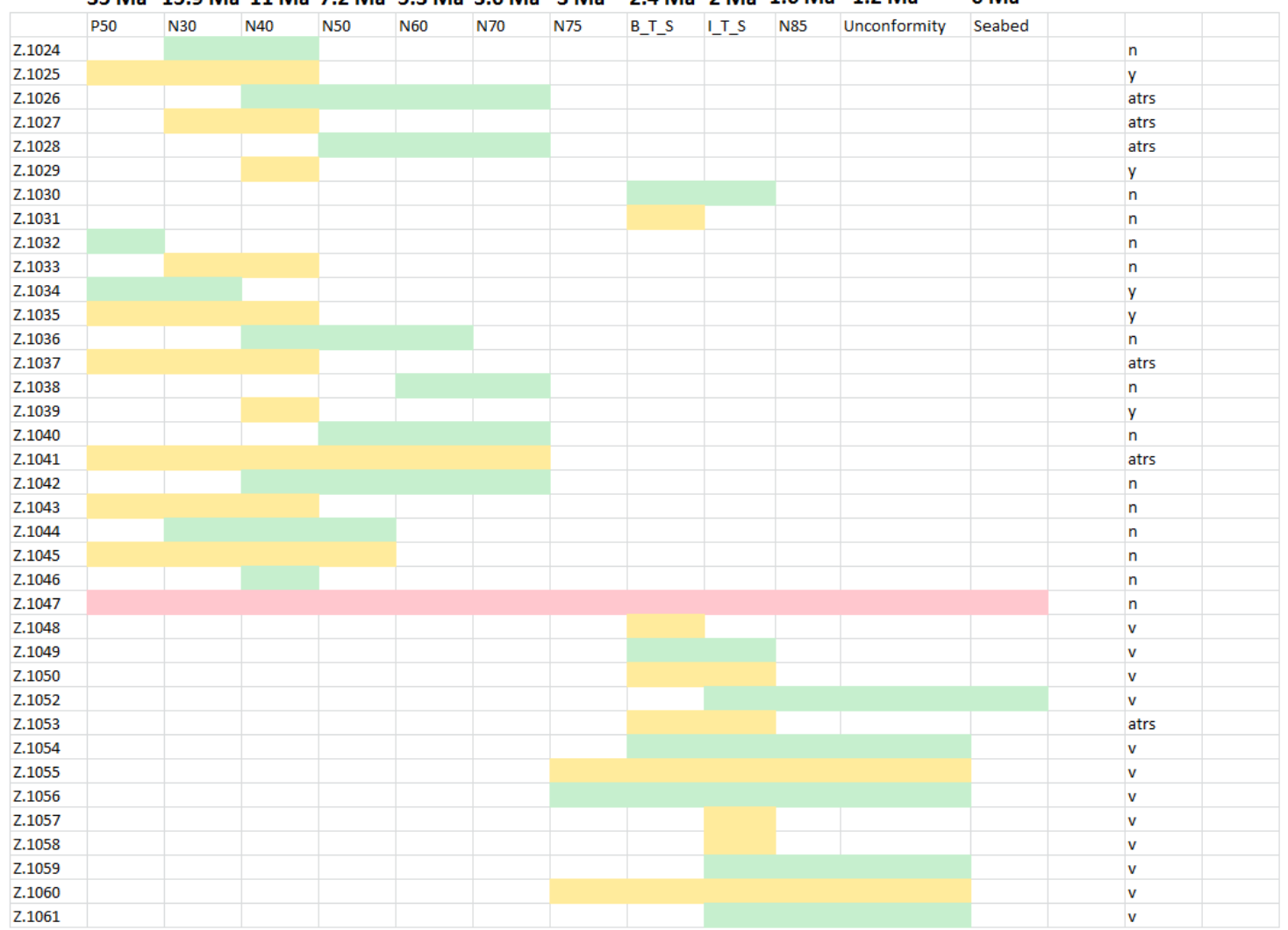

Appendix Table 3 Fault activity table displaying the time horizons at which each fault in the study area was active, along with its type - part 3 of 3 . Fault names are on the $Y$ axis, and the 12 time horizons used in the thesis are on the $X$ axis. Coloured cells represent the period through which a given fault was active. Coloured cells alternate from green to yellow to avoid confusing adjacent faults. Red cells show that no time horizon data intersects with the fault. The Reactivated? Column states the faults reactivation status: $\mathrm{Y}$ means yes the fault is reactivated, $\mathrm{N}$ means no the fault is not reactivated, Atrs means the fault is attached to a reactivated structure, and $V$ means the fault is volcanic. 


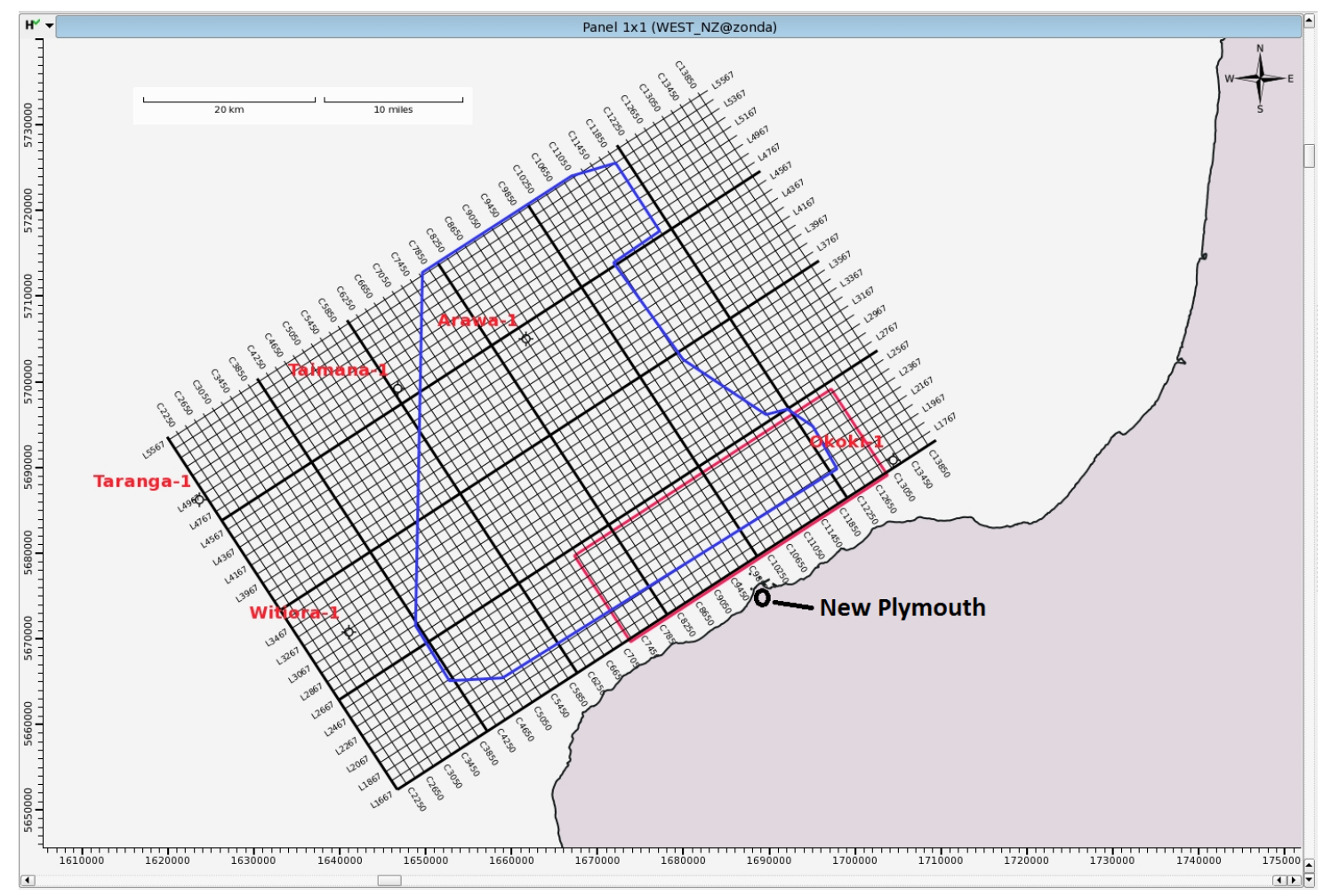

Appendix Figure 1

Map displaying the geometry and location of inlines and crosslines in the Parihaka 3D seismic reflection volume. The above map shows the distribution and numbering scheme for the inlines and crosslines of the Parihaka 3D survey. Every $400^{\text {th }}$ crossline and every $200^{\text {th }}$ inline is displayed. The Parihaka and Toro 3D seismic reflection surveys are represented by blue and red polygons, respectively. The XY coordinate grid is NZ Geodetic 2000. 


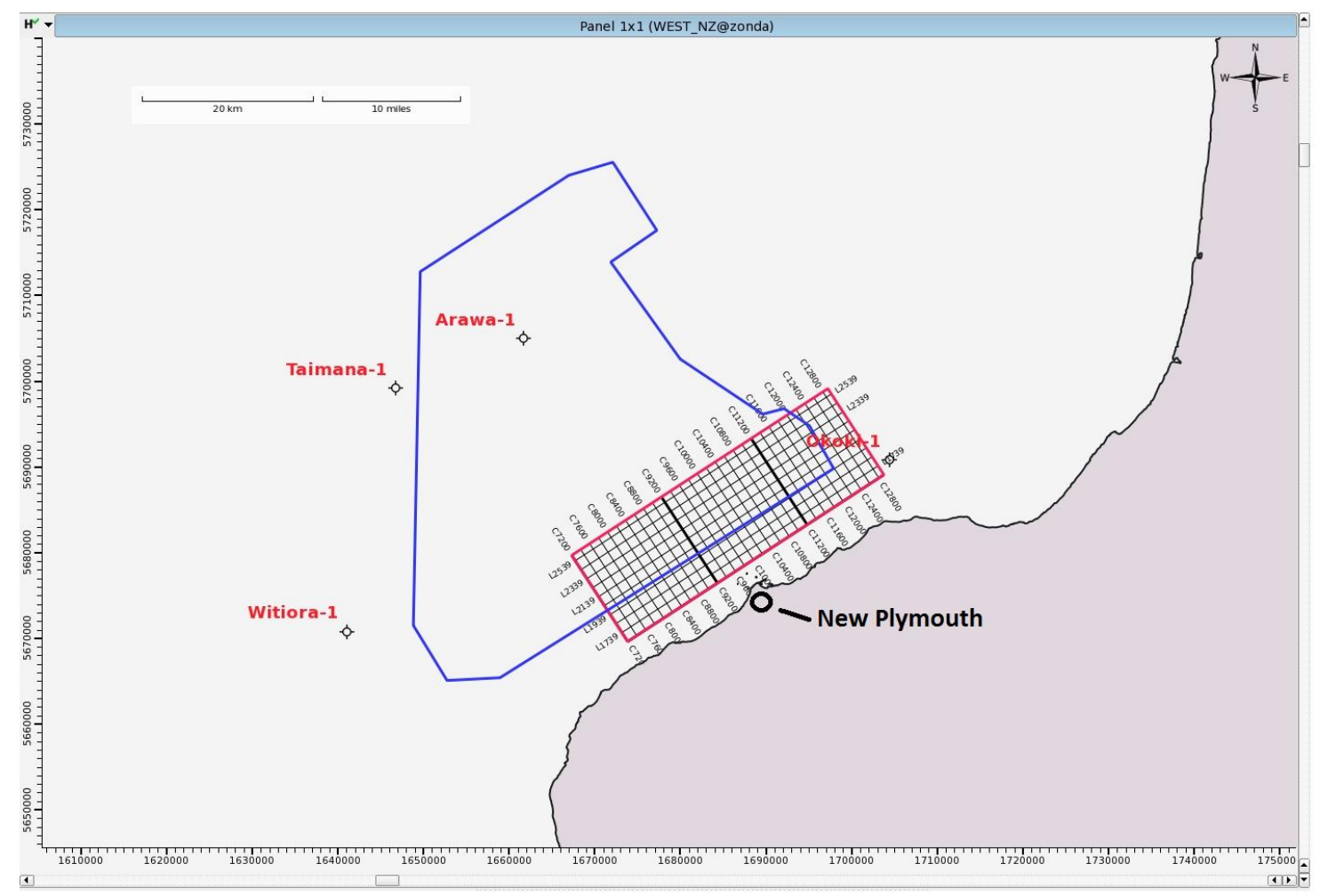

Appendix Figure 2 Map displaying the geometry and location of inlines and crosslines in the Toro 3D seismic reflection volume. The above map shows the distribution and numbering scheme for the inlines and crosslines of the Toro 3D survey. Every $400^{\text {th }}$ crossline and every $200^{\text {th }}$ inline is displayed. The Parihaka and Toro 3D seismic reflection surveys are represented by blue and red polygons, respectively. The XY coordinate grid is NZ Geodetic 2000.

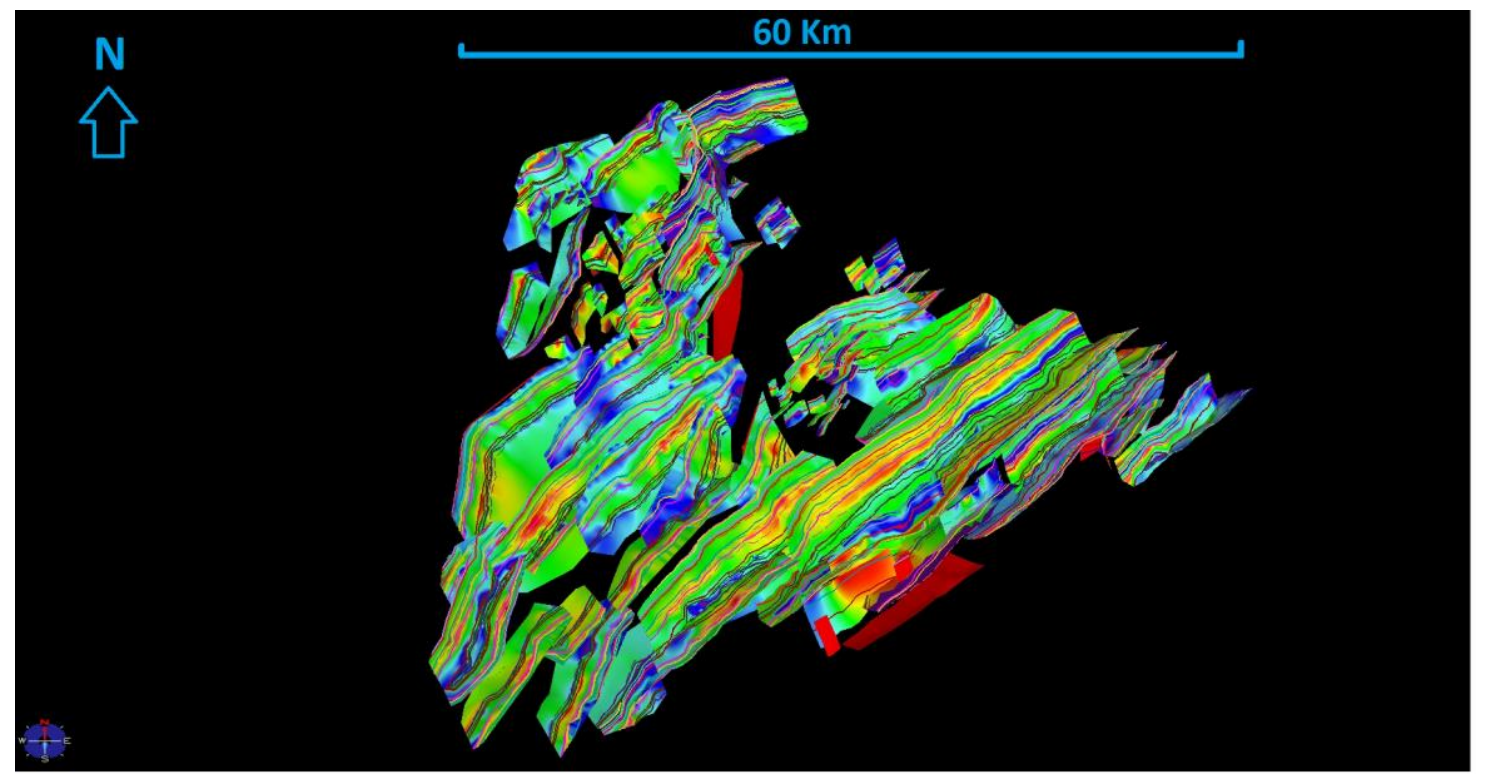

Appendix Figure $3 \quad$ 3D view of fault throw contours and fault intersection polygons for all faults in the study area, as seen in TrapTester. Throw contours of all faults mapped in the study area are displayed in 3D. Lines on fault planes represent fault intersection polygons, with different coloured lines representing different time horizons. Solid lines are footwall polygons, and broken lines are hangingwall polygons. 


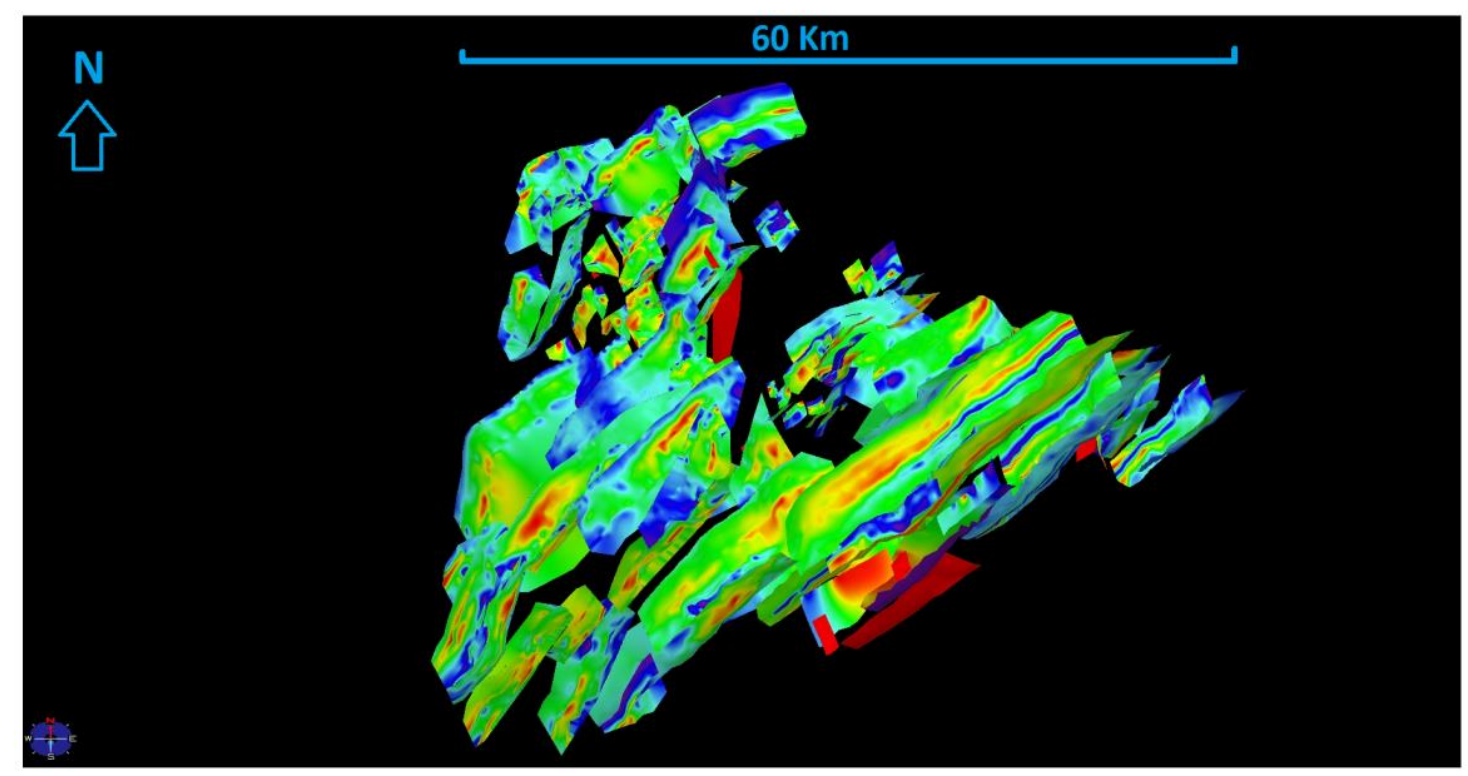

Appendix Figure 4

3D view of fault throw contours with fault intersection polygons removed for all faults in the study area, as seen in TrapTester. Throw contours of all faults mapped in the study area are displayed in 3D. Hot fault plane colours represent areas of greater throw, cold colours represent areas of lesser throw. 

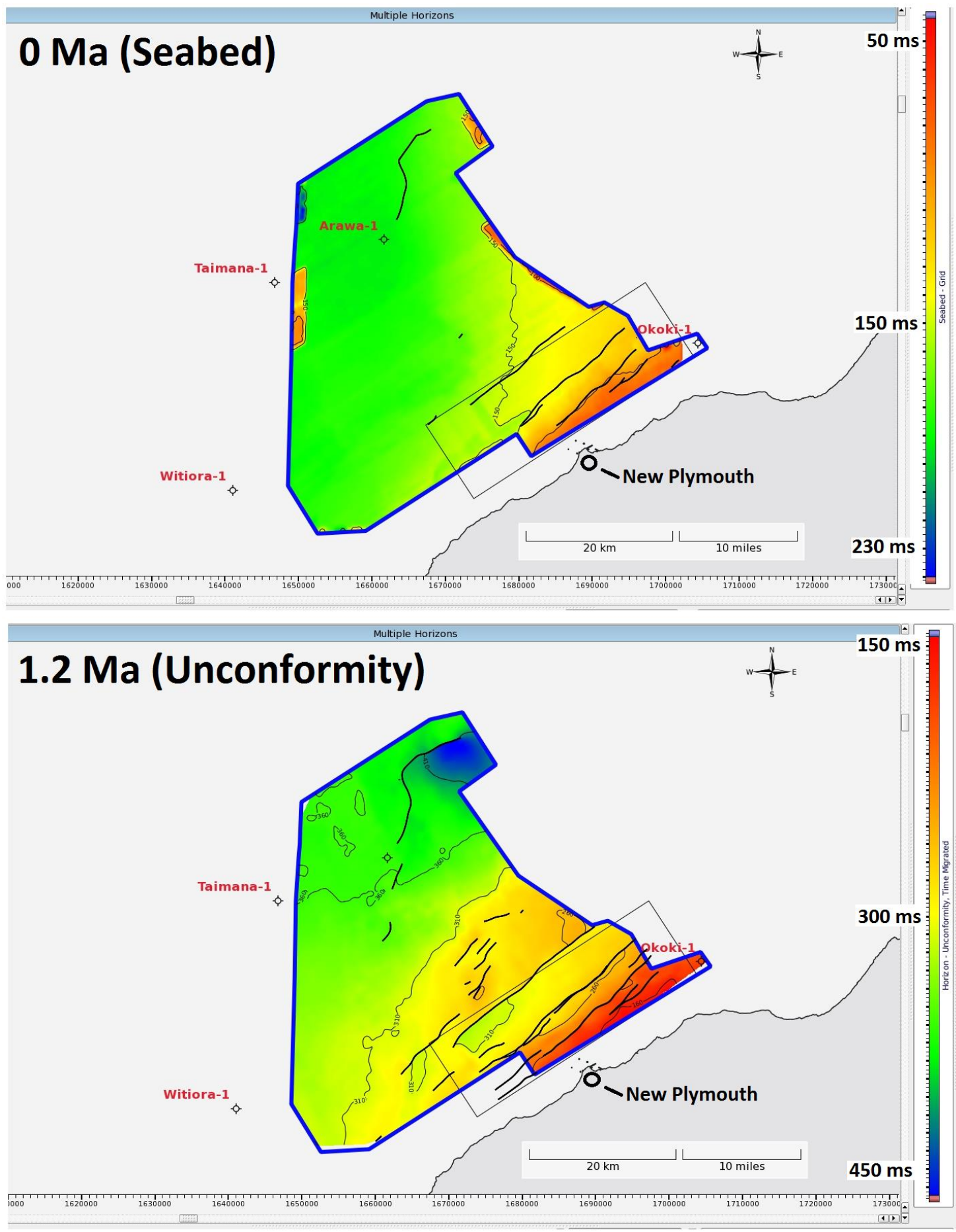

Appendix Figure $5 \quad$ Horizon grids for the Seabed and Unconformity time horizons. Contoured grids of the $0 \mathrm{Ma}$ (Seabed) and 1.2 Ma (Unconformity) time horizons are shown. Faults are shown by black polylines, with depth contours shown every $50 \mathrm{~ms}$. The colour-depth scale is given on the right, with cold colours representing deeper areas, and hot colours representing elevated areas. The blue border polygon is the combined Parihaka and Toro 3D seismic reflection survey gridding boundary, and the thin black polygon is the Toro 3D seismic reflection survey boundary. The $\mathrm{XY}$ coordinate grid is NZ Geodetic 2000. 


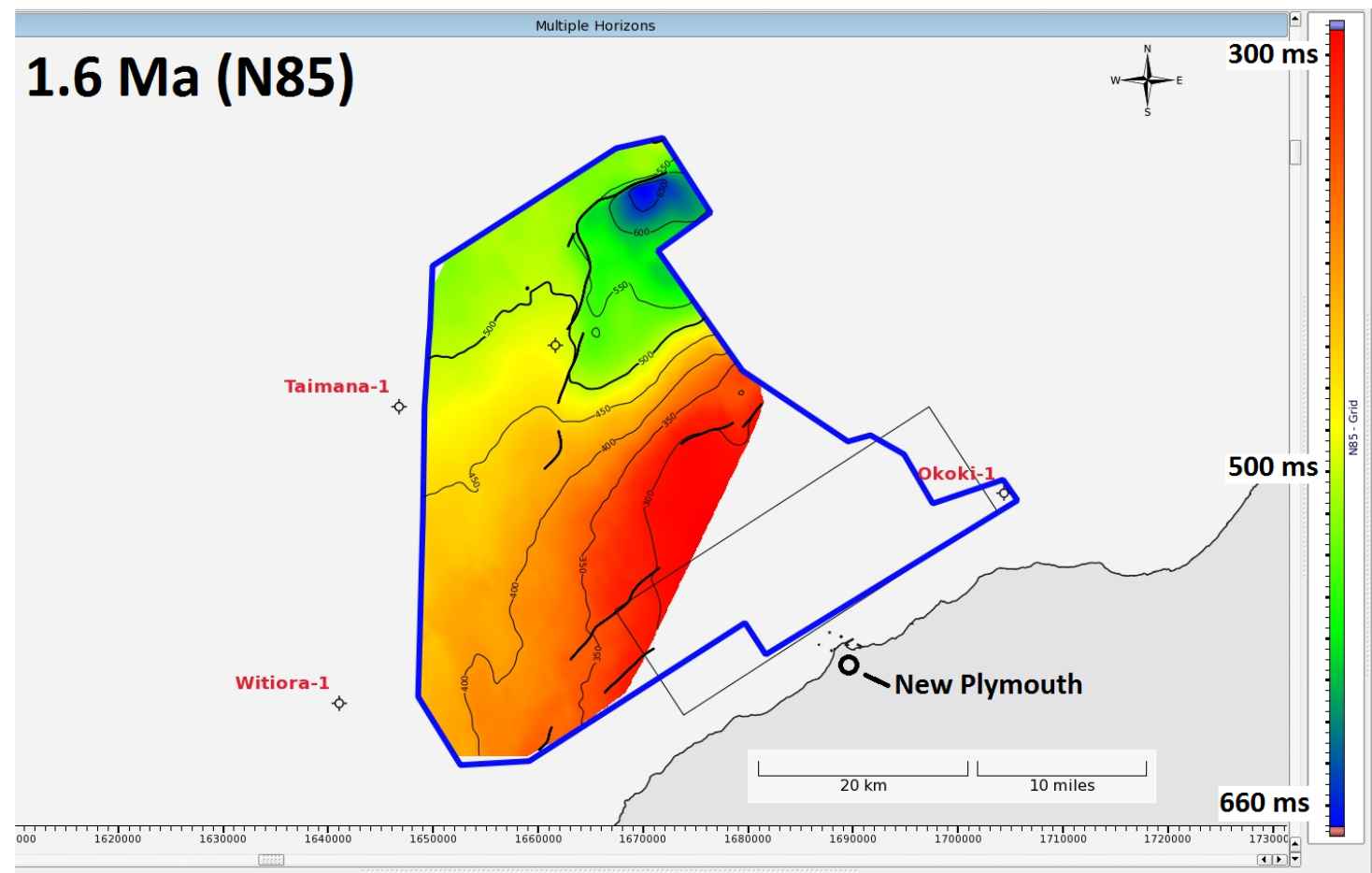

\section{Ma (Intra Top Set)}

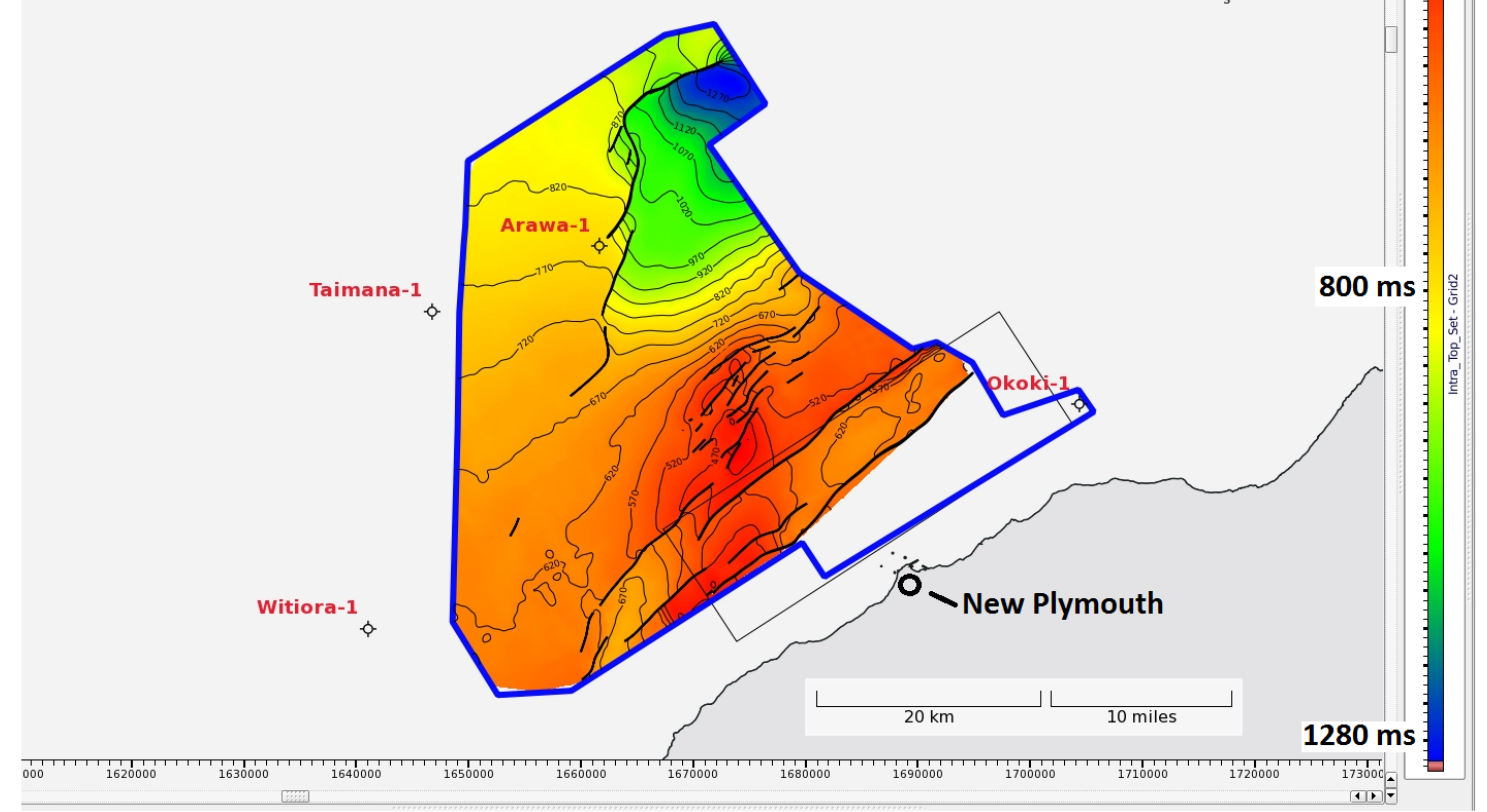

Appendix Figure $6 \quad$ Horizon grids for the N85 and Intra Top Set time horizons. Contoured grids of the 1.6 Ma (N85) and $2 \mathrm{Ma}$ (Intra Top Set) time horizons are shown. Faults are shown by black polylines, with depth contours shown every $50 \mathrm{~ms}$. The colour-depth scale is given on the right, with cold colours representing deeper areas, and hot colours representing elevated areas. The blue border polygon is the combined Parihaka and Toro 3D seismic reflection survey gridding boundary, and the thin black polygon is the Toro 3D seismic reflection survey boundary. The XY coordinate grid is NZ Geodetic 2000. 


\subsection{Ma (Basal Top Set)}

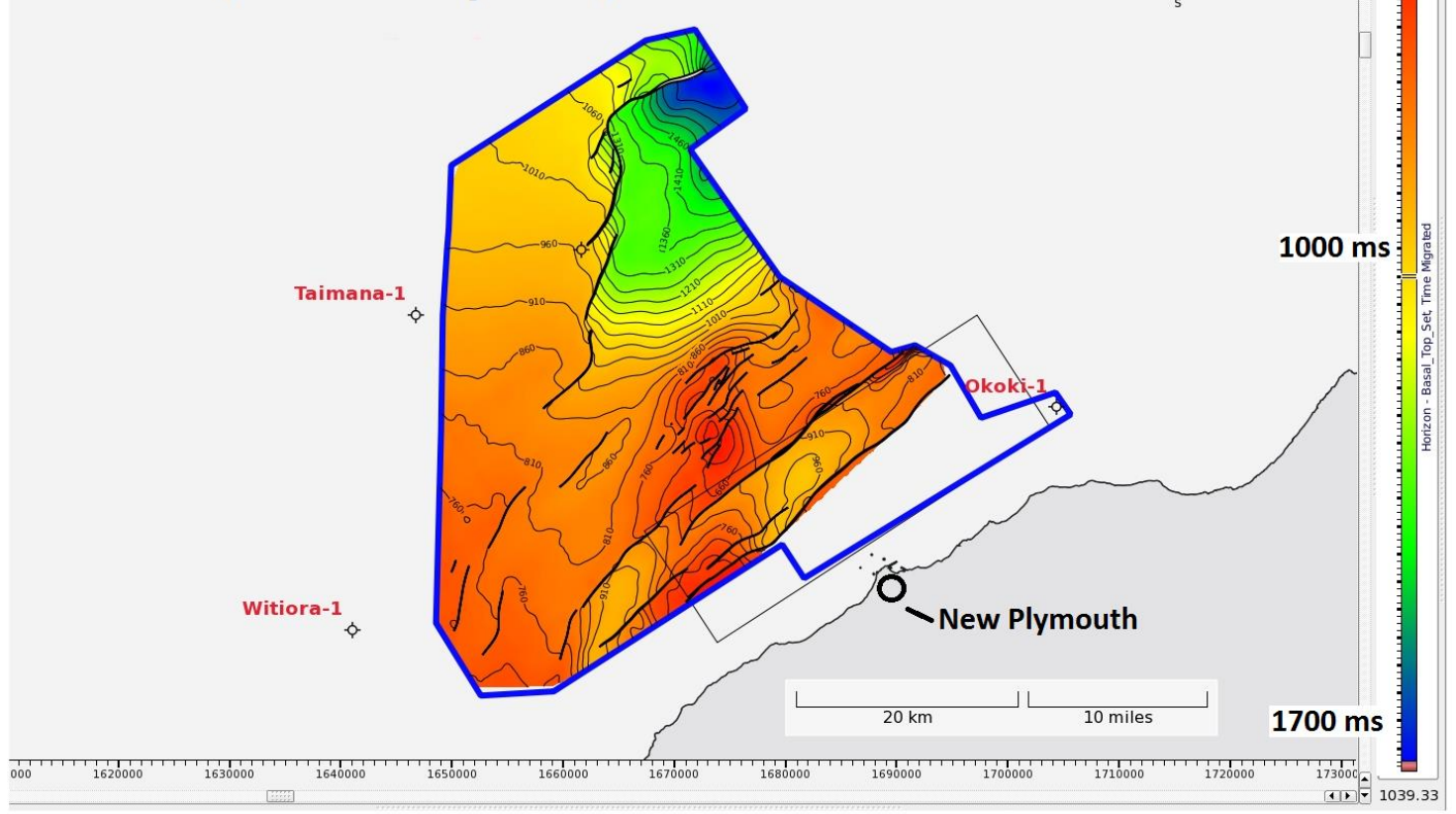

\section{$3 \mathrm{Ma}$ (N75)}

Multiple Horizons

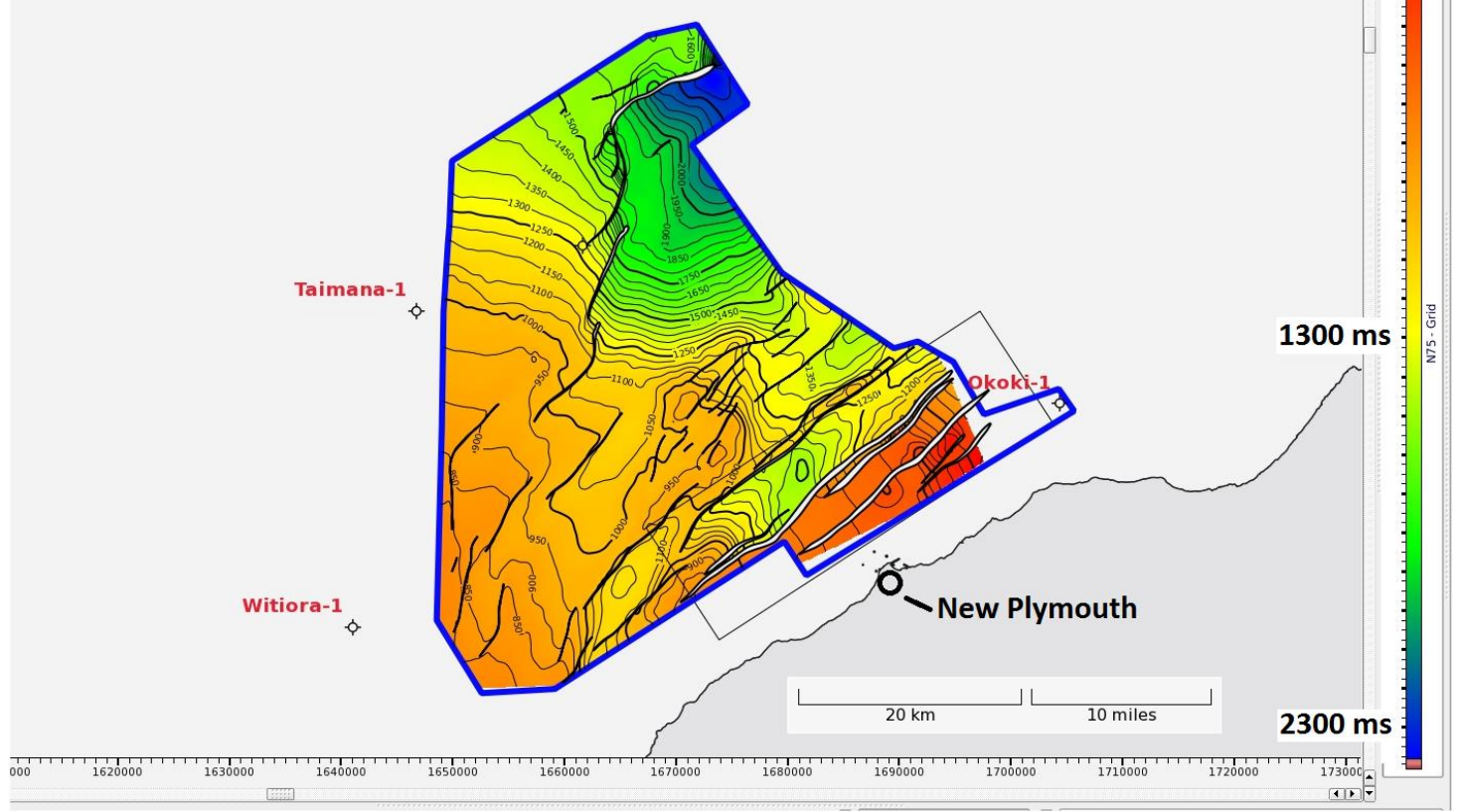

\section{Appendix Figure 7}

Horizon grids for the Basal Top Set and N75 time horizons. Contoured grids of the 2.4 Ma (Basal Top Set) and $3 \mathrm{Ma}$ (N75) time horizons are shown. Faults are shown by black polylines, with depth contours shown every $50 \mathrm{~ms}$. The colour-depth scale is given on the right, with cold colours representing deeper areas, and hot colours representing elevated areas. The blue border polygon is the combined Parihaka and Toro 3D seismic reflection survey gridding boundary, and the thin black polygon is the Toro 3D seismic reflection survey boundary. The XY coordinate grid is NZ Geodetic 2000. 

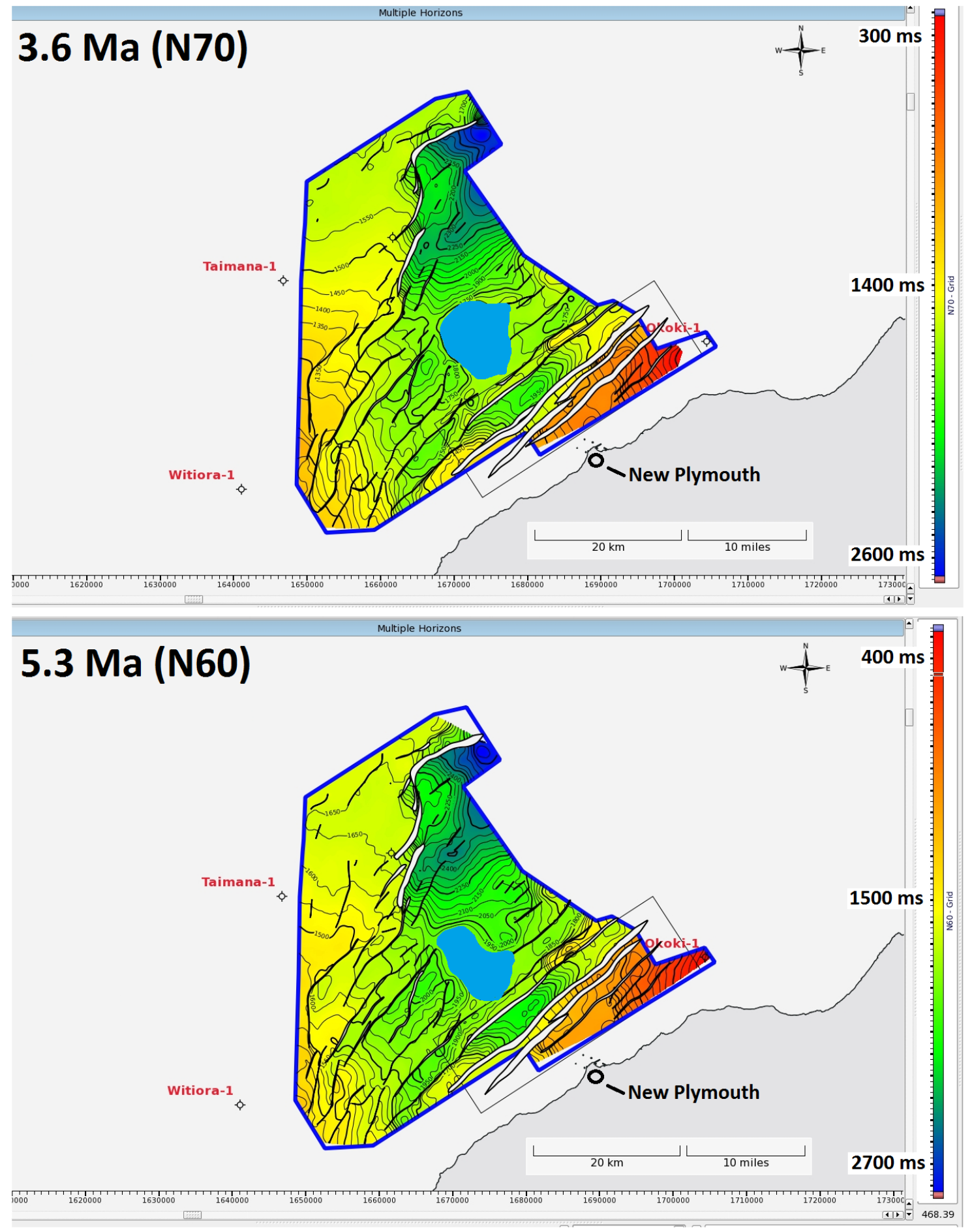

\section{Appendix Figure 8}

Horizon grids for the N70 and N60 time horizons. Contoured grids of the $\mathbf{3 . 6}$ $\mathrm{Ma}$ (N70) and 5.3 Ma (N60) time horizons are shown. Faults are shown by black polylines, with depth contours shown every $\mathbf{5 0} \mathrm{ms}$. The colour-depth scale is given on the right, with cold colours representing deeper areas, and hot colours representing elevated areas. The blue border polygon is the combined Parihaka and Toro 3D seismic reflection survey gridding boundary, and the thin black polygon is the Toro 3D seismic reflection survey boundary. The blue polygon in the centre of the image masks the Southern Intrusive Complex. The XY coordinate grid is NZ Geodetic 2000. 


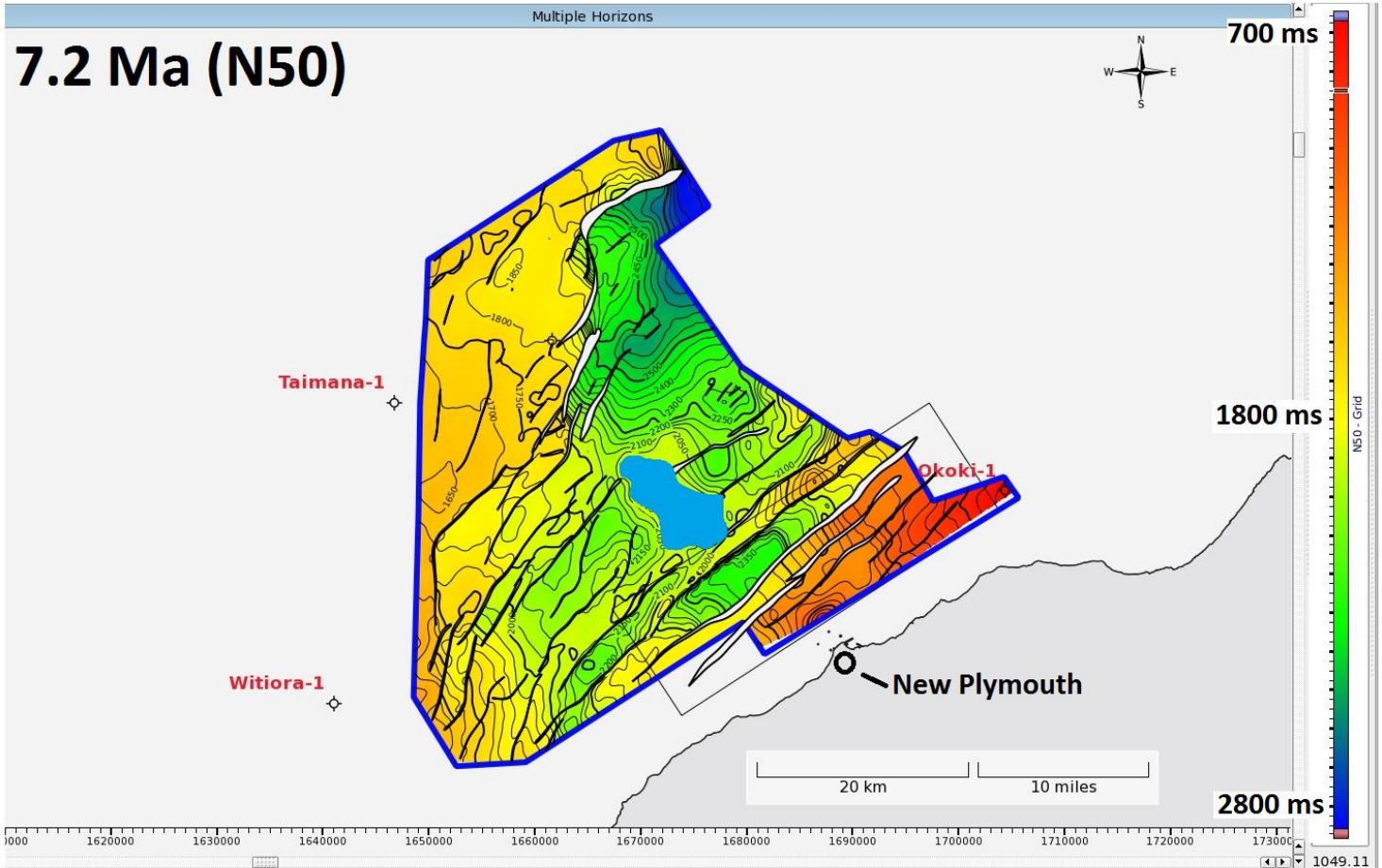

$11 \mathrm{Ma}$ (N40)

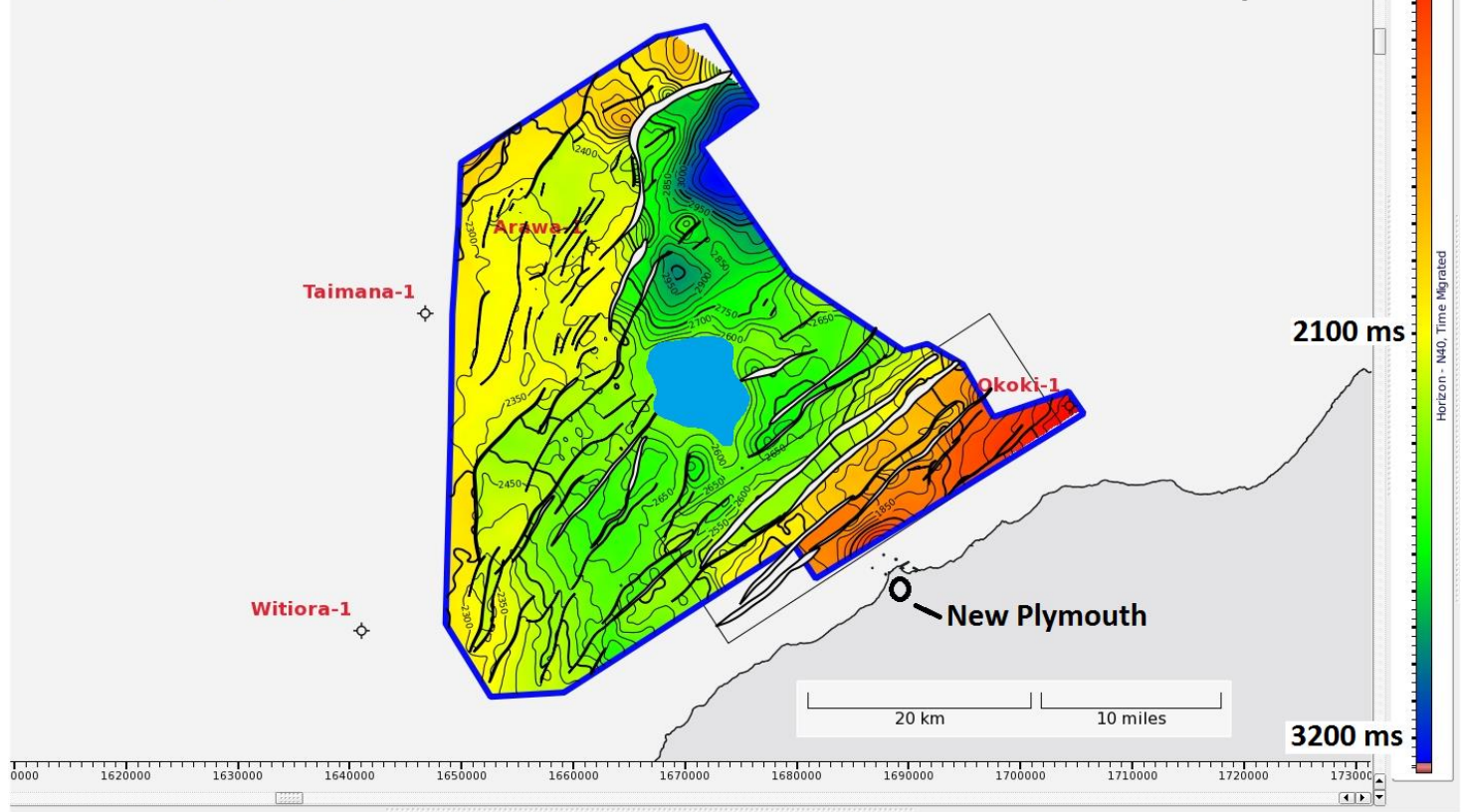

Appendix Figure 9

Horizon grids for the N50 and N40 time horizons. Contoured grids of the $\mathbf{7 . 2}$ Ma (N50) and 11 Ma (N40) time horizons are shown. Faults are shown by black polylines, with depth contours shown every $50 \mathrm{~ms}$. The colour-depth scale is given on the right, with cold colours representing deeper areas, and hot colours representing elevated areas. The blue border polygon is the combined Parihaka and Toro 3D seismic reflection survey gridding boundary, and the thin black polygon is the Toro 3D seismic reflection survey boundary. The blue polygon in the centre of the image masks the Southern Intrusive Complex. The XY coordinate grid is NZ Geodetic 2000. 

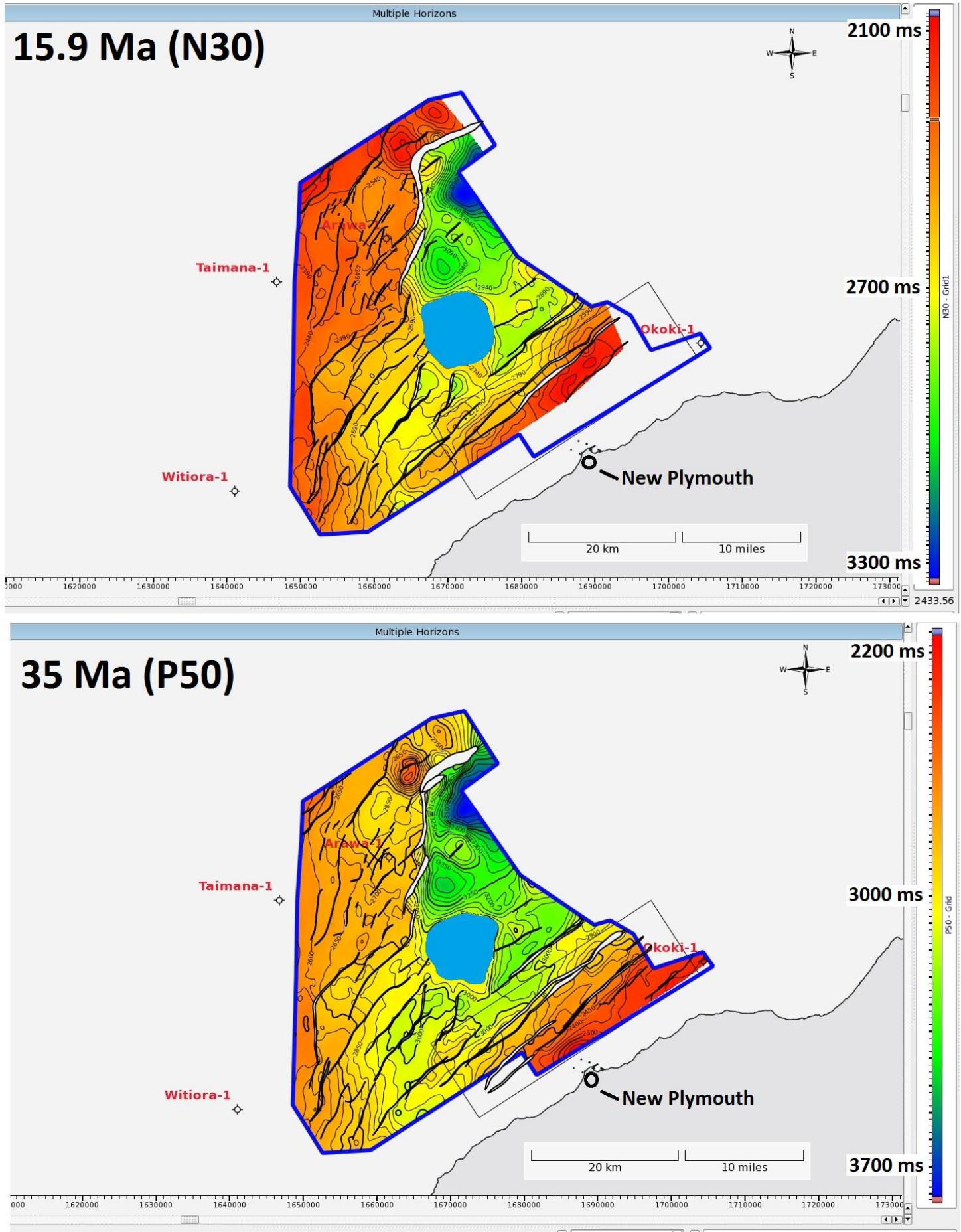

Appendix Figure $10 \quad$ Horizon grids for the $\mathrm{N50}$ and $\mathrm{N40}$ time horizons. Contoured grids of the $15.9 \mathrm{ma}$ (N30) and $35 \mathrm{Ma}$ (P50) time horizons are shown. Faults are shown by black polylines, with depth contours shown every $\mathbf{5 0}$ ms. The colour-depth scale is given on the right, with cold colours representing deeper areas, and hot colours representing elevated areas. The blue border polygon is the combined Parihaka and Toro 3D seismic reflection survey gridding boundary, and the thin black polygon is the Toro 3D seismic reflection survey boundary. The blue polygon in the centre of the image masks the Southern Intrusive Complex The XY coordinate grid is NZ Geodetic 2000. 
1.2 - $0 \mathrm{Ma}$ Isochron (Unconformity - Seabed)

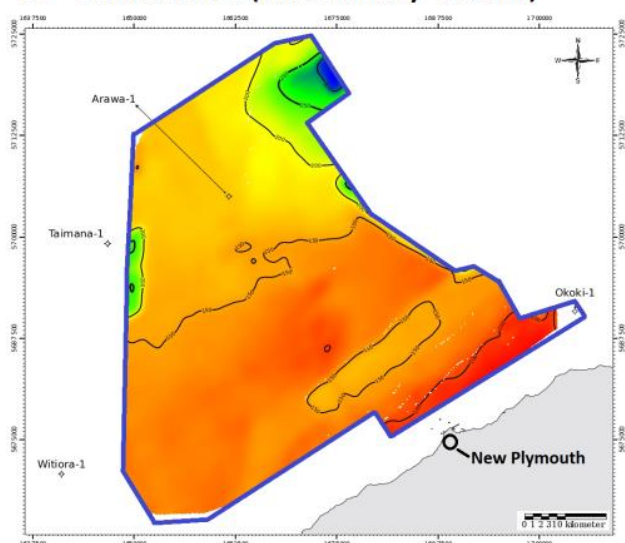

2 - 1.6 Ma Isochron (Intra Top Set - N85)
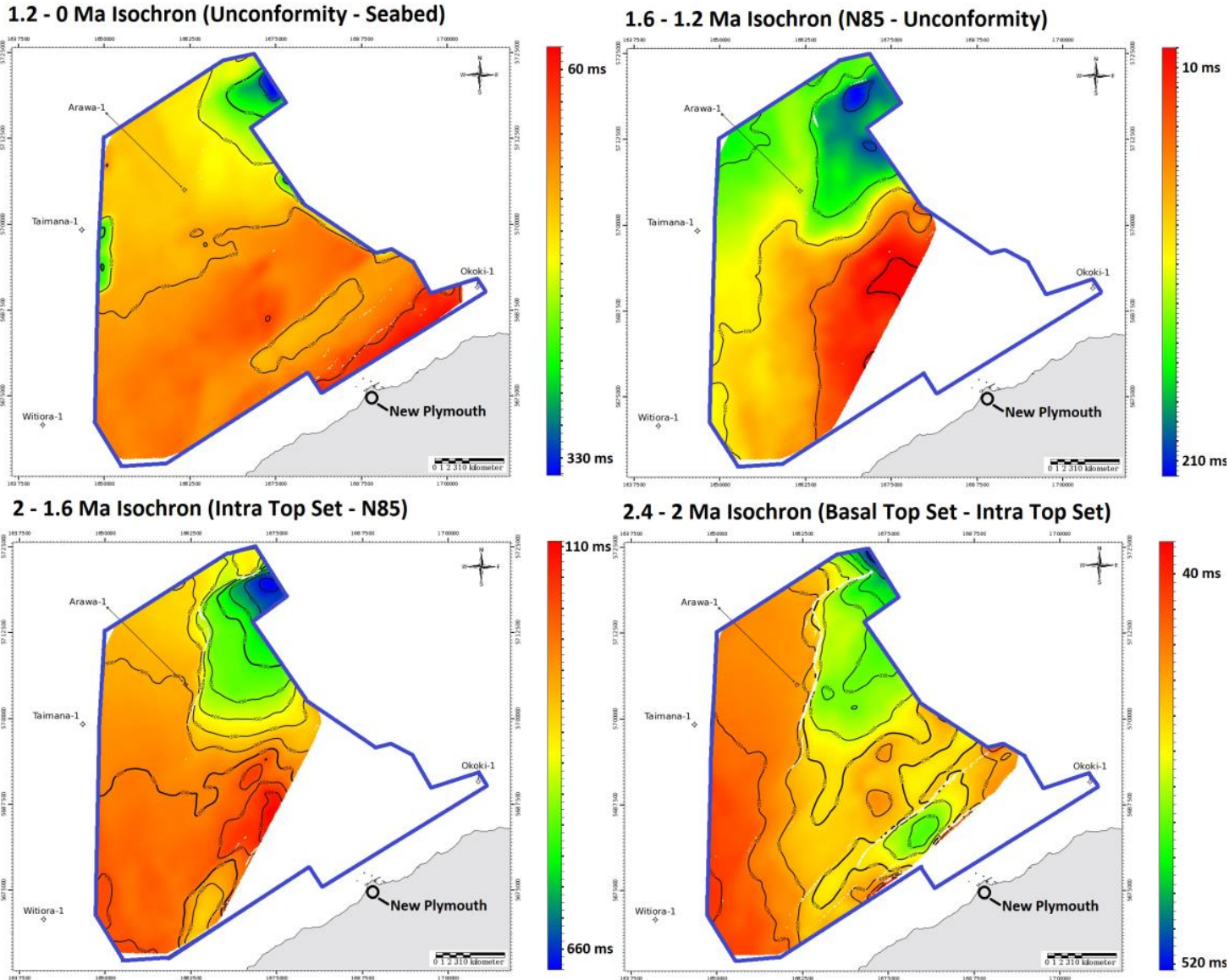

2.4 - 2 Ma Isochron (Basal Top Set - Intra Top Set)

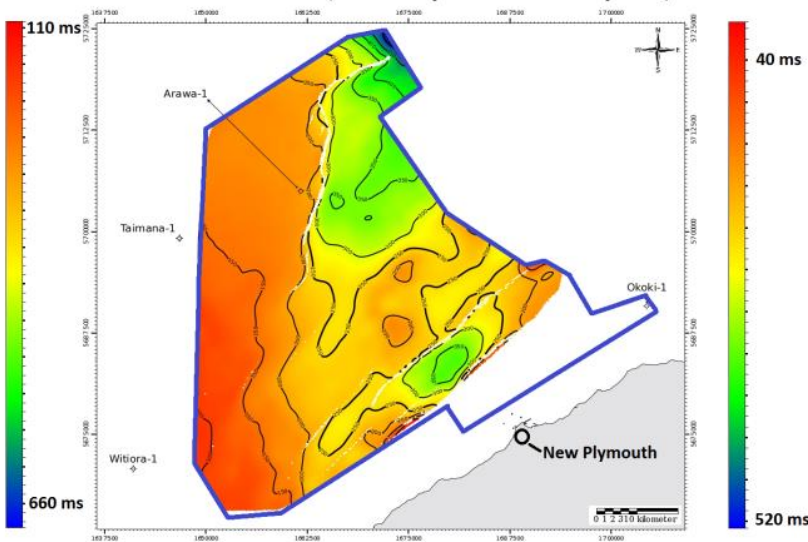

3 - 2.4 Ma Isochron (N75 - Basal Top Set)

3.6 - 3 Ma Isochron (N70 - N75)
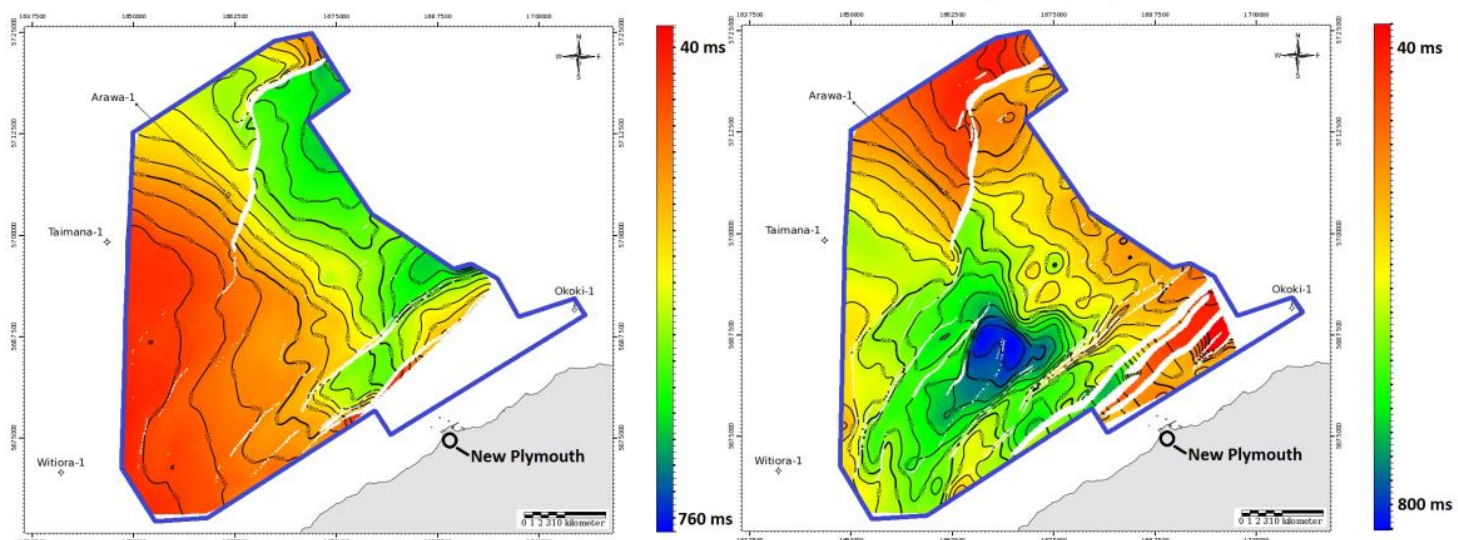

Appendix Figure 11

Isochron (time-thickness) maps for time horizons between 0 and $3.6 \mathrm{Ma}$.

The isochron maps display sediment thicknesses in the intervals between the younger six time horizons. The blue polygon represents the combined Parihaka and Toro 3D seismic reflection survey gridding boundary. The XY coordinate grid is NZ Geodetic 2000. 

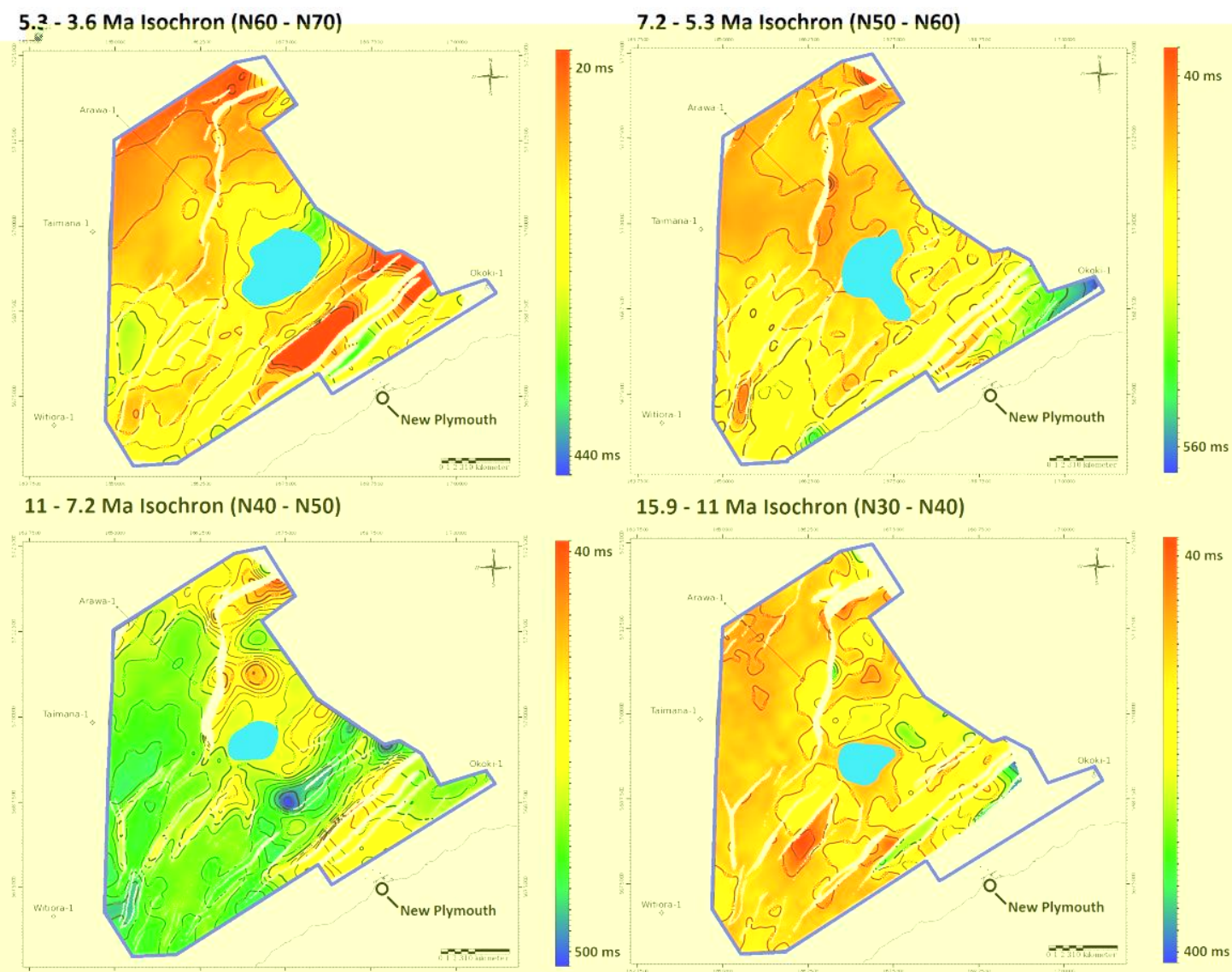

11 - 7.2 Ma Isochron (N40 - N50)

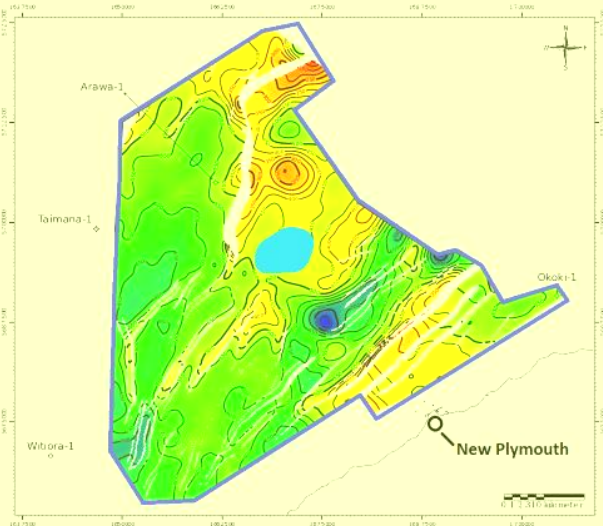

35 - 15.9 Ma Isochron (P50 - N30)

35 - 0 Ma Isochron (P50 - Seabed)
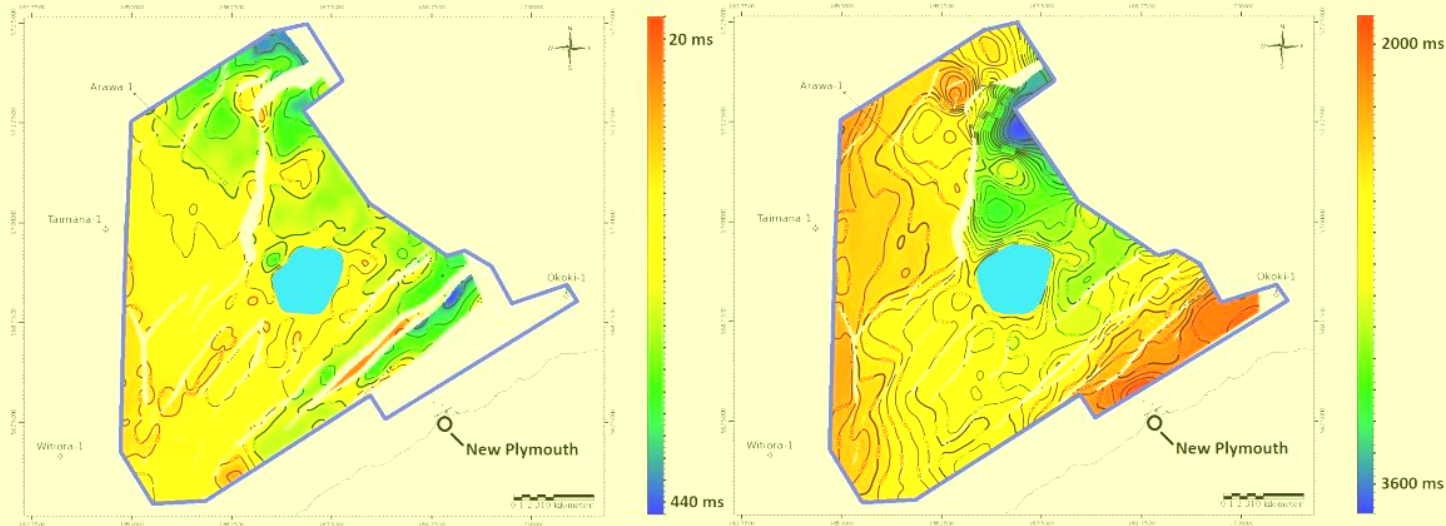

Appendix Figure 12

Isochron (time-thickness) maps for time horizons between 3.6 and $35 \mathrm{Ma}$. The isochron maps display sediment thicknesses in the intervals between the older six horizons. The isochron map at the bottom right (P50 - Seabed) gives the thickness between the very bottom and very top horizon. The blue polygon represents the combined Parihaka and Toro 3D seismic reflection survey gridding boundary. The blue shaded area in the centre of the images masks the Southern Intrusive Complex. The XY coordinate grid is NZ Geodetic 2000. 


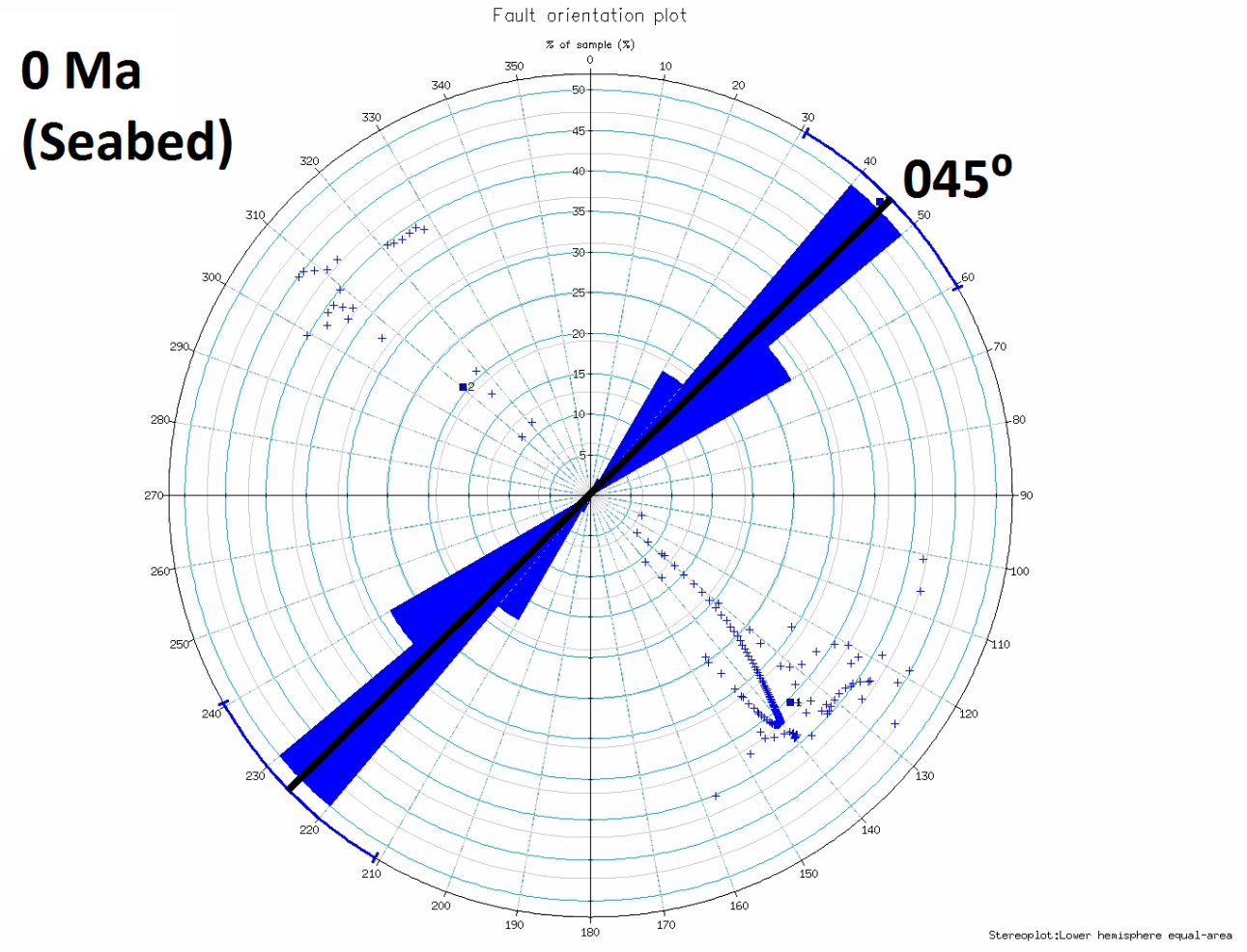

\subsection{Ma}
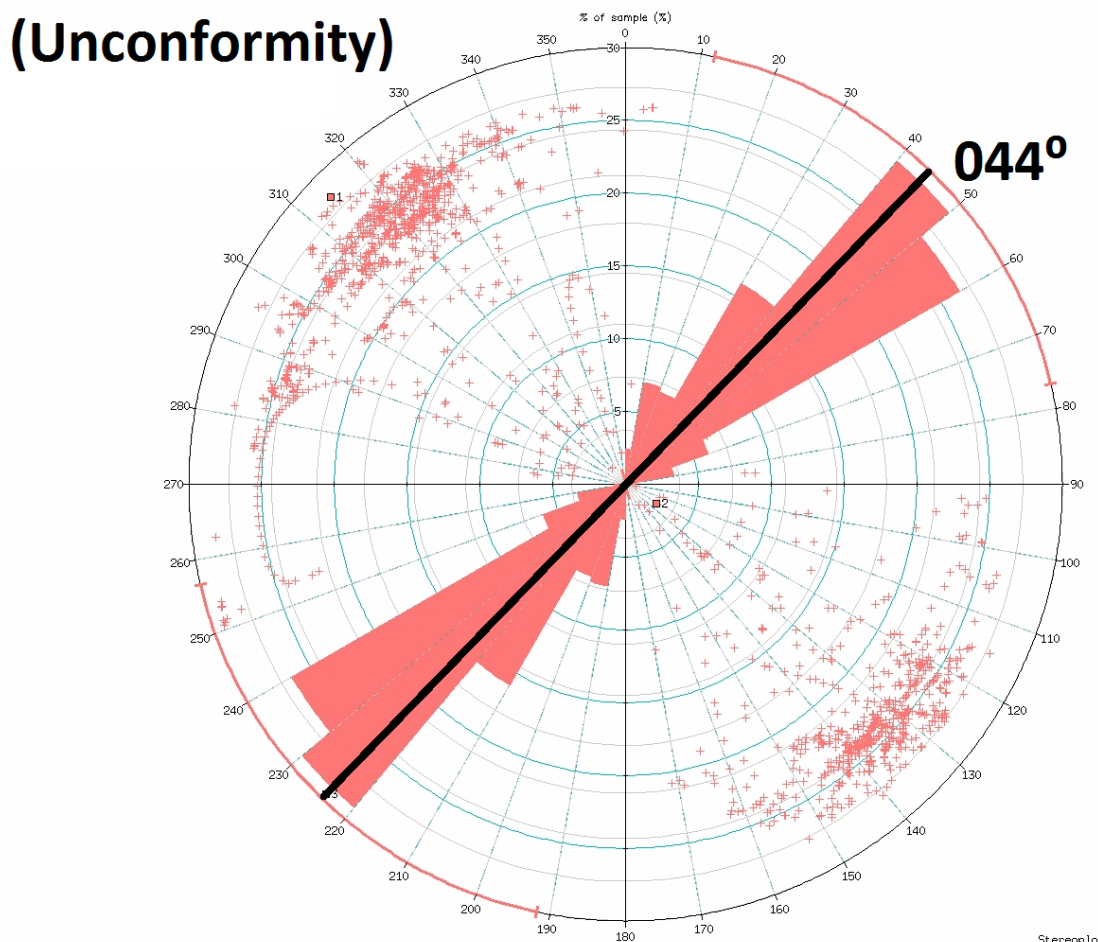

Appendix Figure 13 Rose plots of the $0 \mathrm{Ma}$ (Seabed) and 1.2 Ma (Unconformity) time horizons. Plots show the percentage distribution of fault strike direction for the given time horizon, with percentage given by the light blue circles, and black circles representing dip. The range of fault strike directions is given by the coloured part of the outermost black circle. The average fault strike direction for the time horizon is given by a solid black line. Poles to fault planes are plotted in order to observe fault dip distribution. 


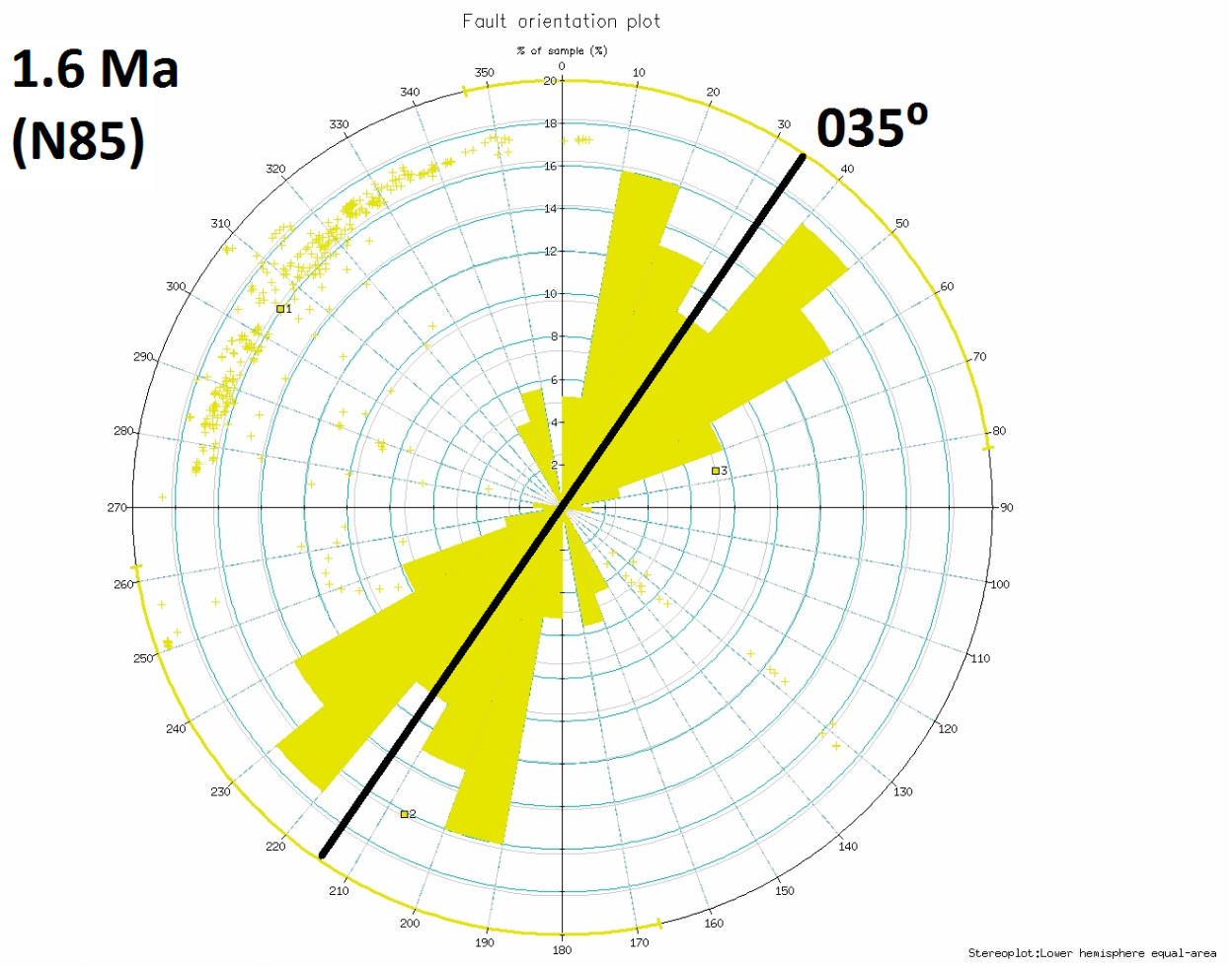

\section{$2 \mathrm{Ma}$}

\section{(Intra Top Set)}

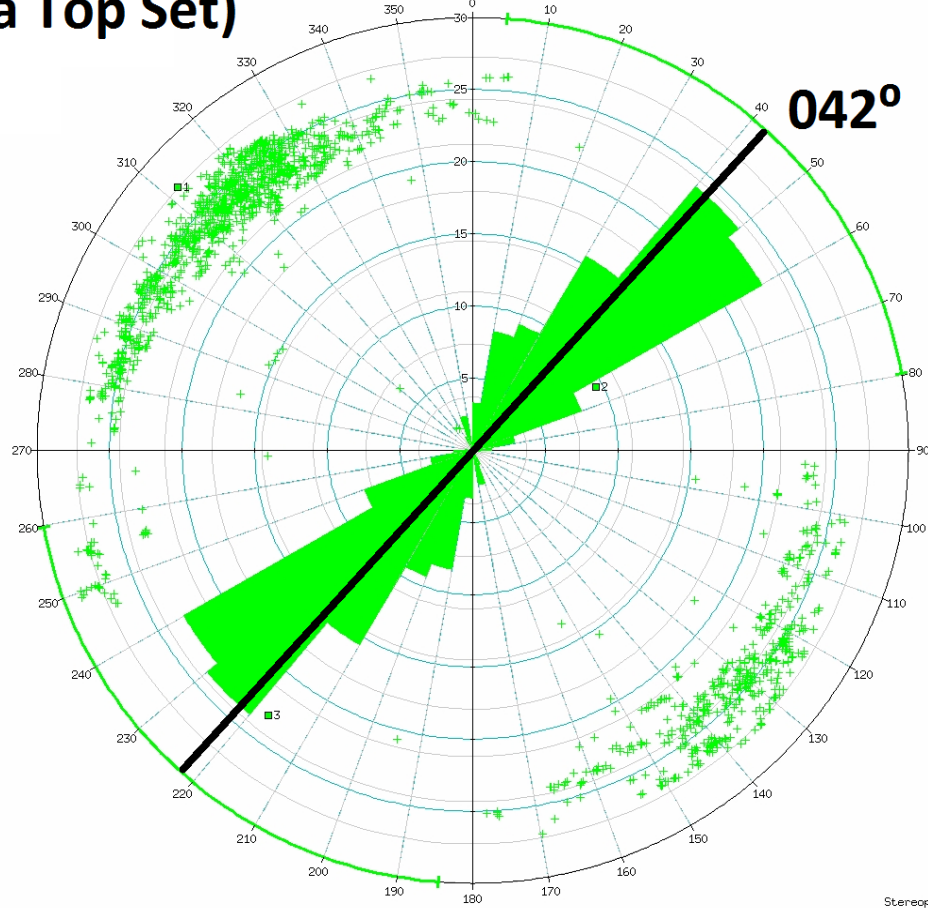

Appendix Figure $14 \quad$ Rose plots of the 1.6 Ma (N85) and $2 \mathrm{Ma}$ (Intra Top Set) time horizons. Plots show the percentage distribution of fault strike direction for the given time horizon, with percentage given by the light blue circles, and black circles representing dip. The range of fault strike directions is given by the coloured part of the outermost black circle. The average fault strike direction for the time horizon is given by a solid black line. Poles to fault planes are plotted in order to observe fault dip distribution. 


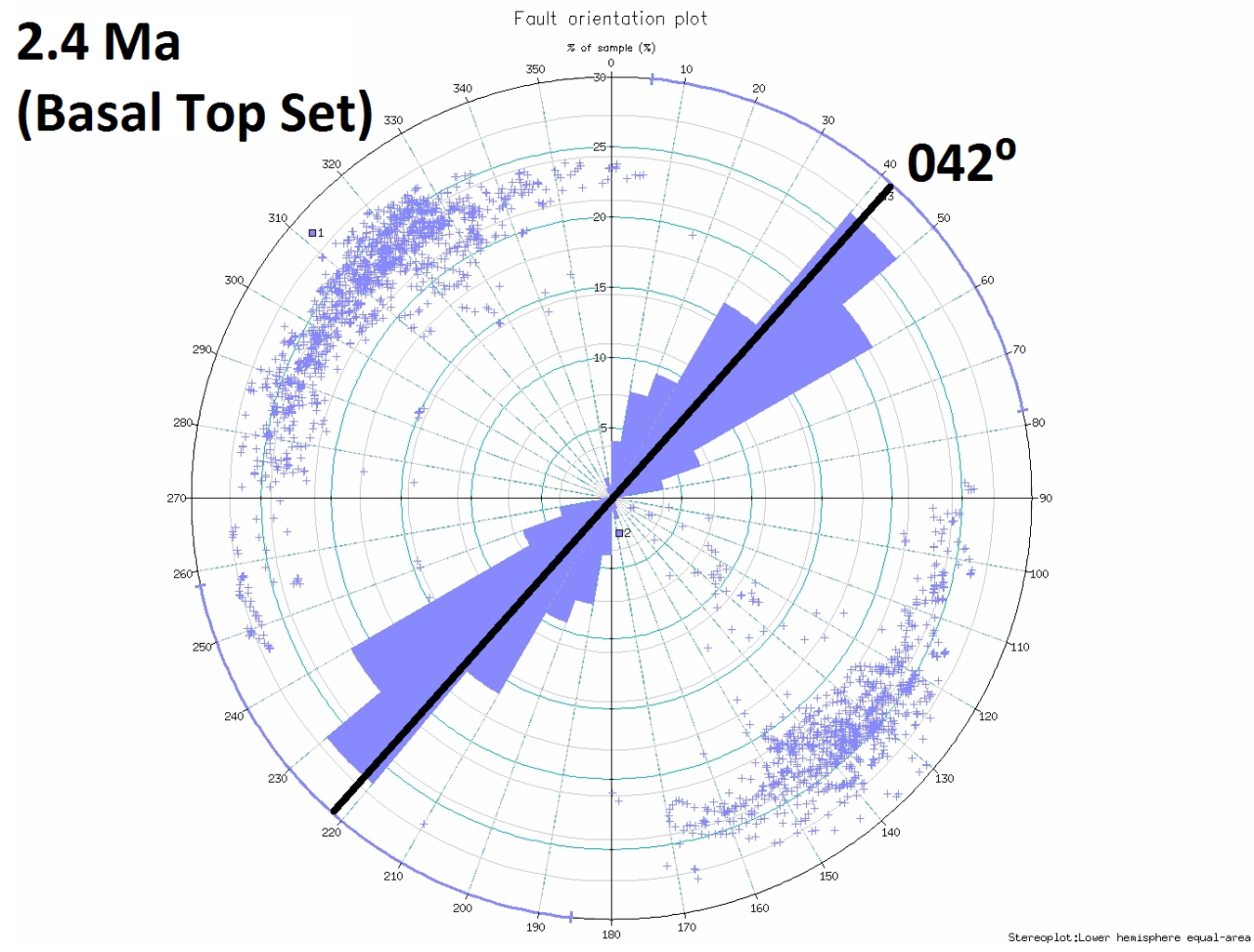

\section{$3 \mathrm{Ma}$ (N75)}

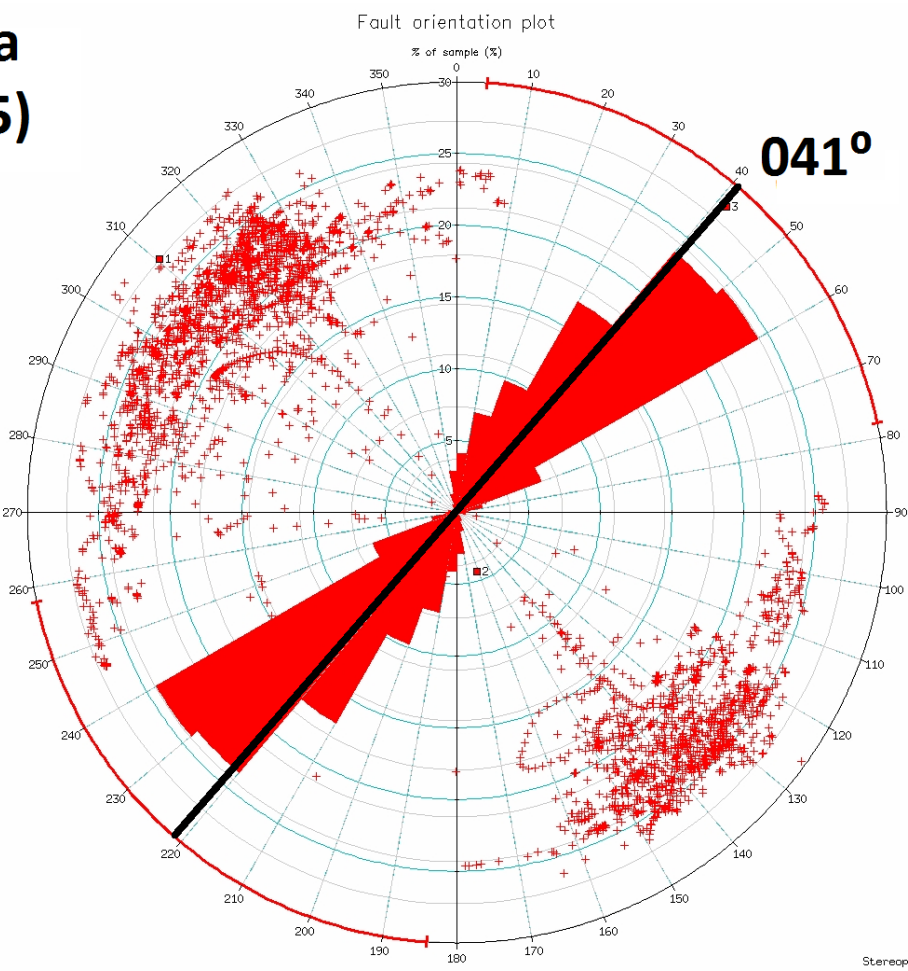

Appendix Figure 15

Rose plots of the 2.4 Ma (Basal Top Set) and $3 \mathrm{Ma}$ (N75) time horizons. Plots show the percentage distribution of fault strike direction for the given time horizon, with percentage given by the light blue circles, and black circles representing dip. The range of fault strike directions is given by the coloured part of the outermost black circle. The average fault strike direction for the time horizon is given by a solid black line. Poles to fault planes are plotted in order to observe fault dip distribution. 

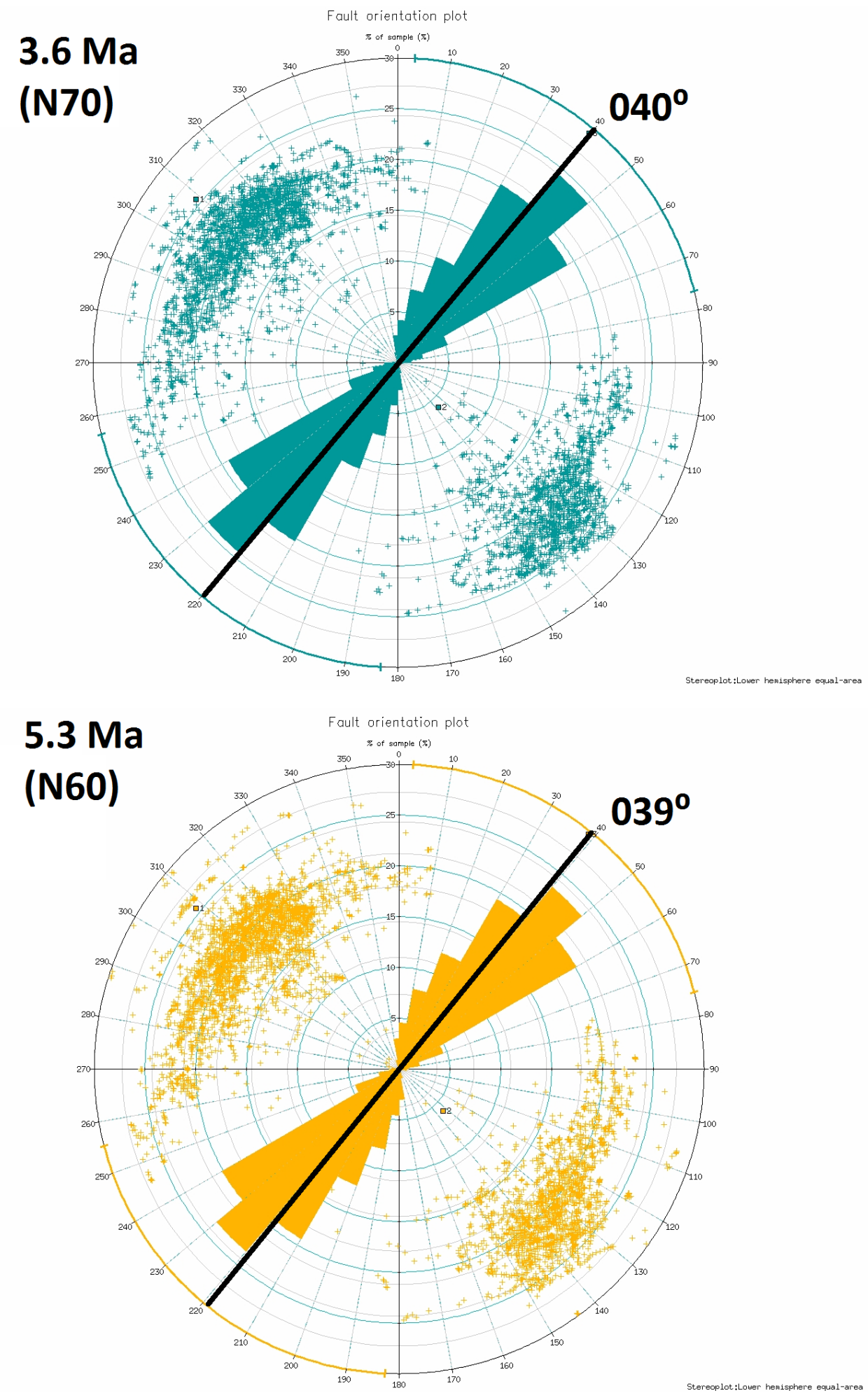

Appendix Figure 16 Rose plots of the 3.6 Ma (N70) and 5.3 Ma (N60) time horizons. Plots show the percentage distribution of fault strike direction for the given time horizon, with percentage given by the light blue circles, and black circles representing dip. The range of fault strike directions is given by the coloured part of the outermost black circle. The average fault strike direction for the time horizon is given by a solid black line. Poles to fault planes are plotted in order to observe fault dip distribution. 

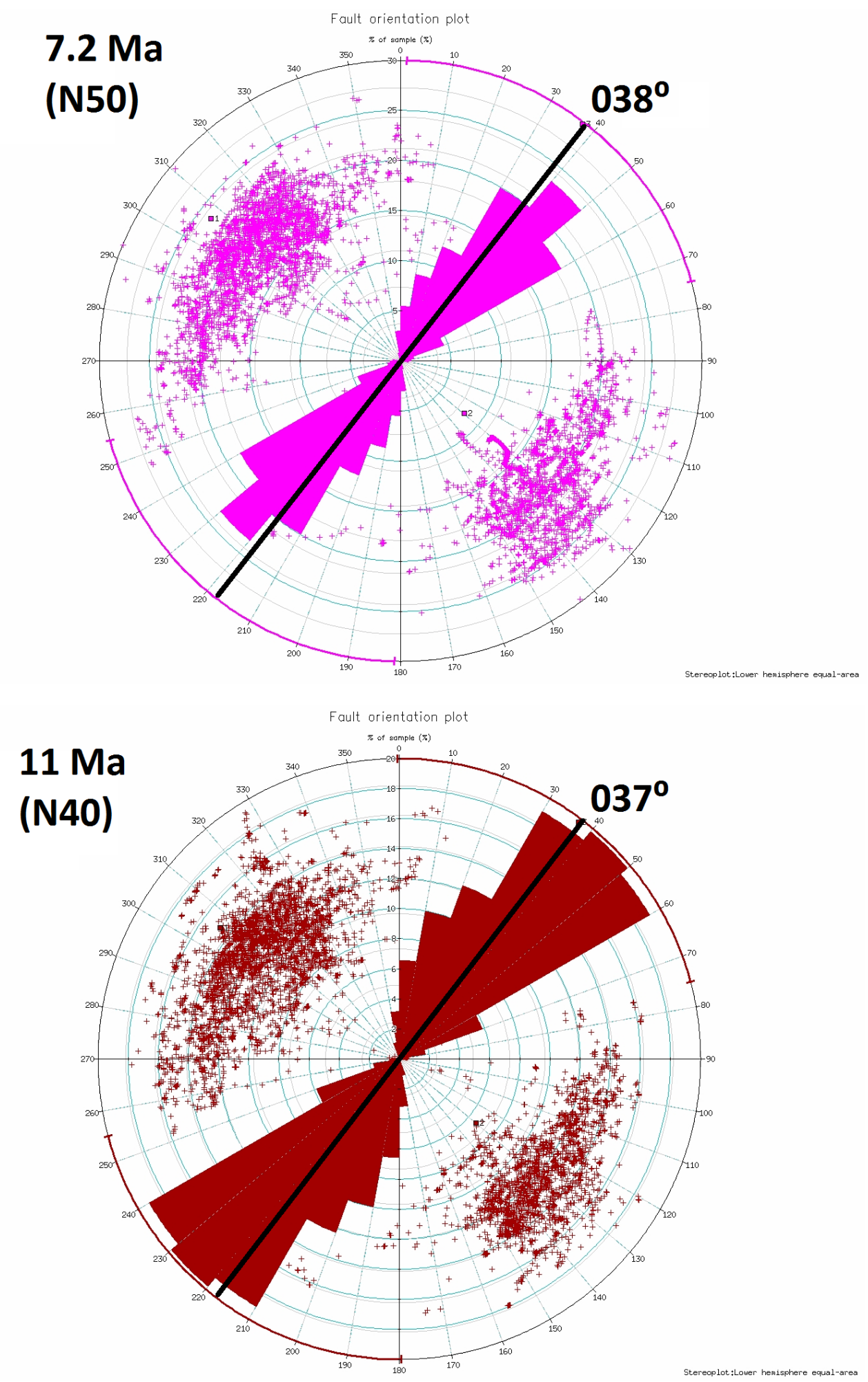

Appendix Figure $17 \quad$ Rose plots of the 7.2 Ma (N50) and $11 \mathrm{Ma}$ (N40) time horizons. Plots show the percentage distribution of fault strike direction for the given time horizon, with percentage given by the light blue circles, and black circles representing dip. The range of fault strike directions is given by the coloured part of the outermost black circle. The average fault strike direction for the time horizon is given by a solid black line. Poles to fault planes are plotted in order to observe fault dip distribution. 

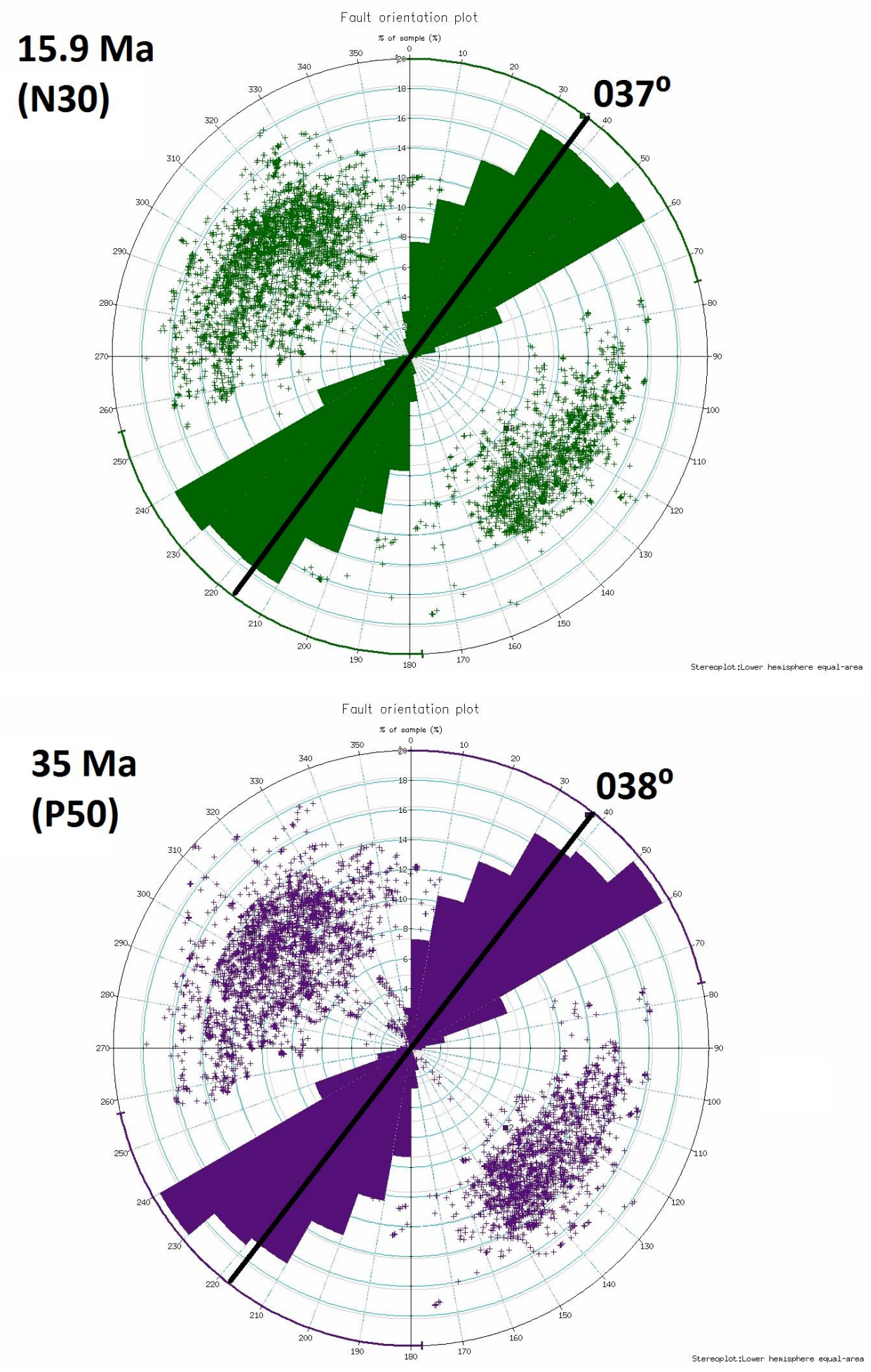

Appendix Figure $18 \quad$ Rose plots of the 15.9 Ma (N30) and $35 \mathrm{Ma}$ (P50) time horizons. Plots show the percentage distribution of fault strike direction for the given time horizon, with percentage given by the light blue circles, and black circles representing dip. The range of fault strike directions is given by the coloured part of the outermost black circle. The average fault strike direction for the time horizon is given by a solid black line. Poles to fault planes are plotted in order to observe fault dip distribution. 

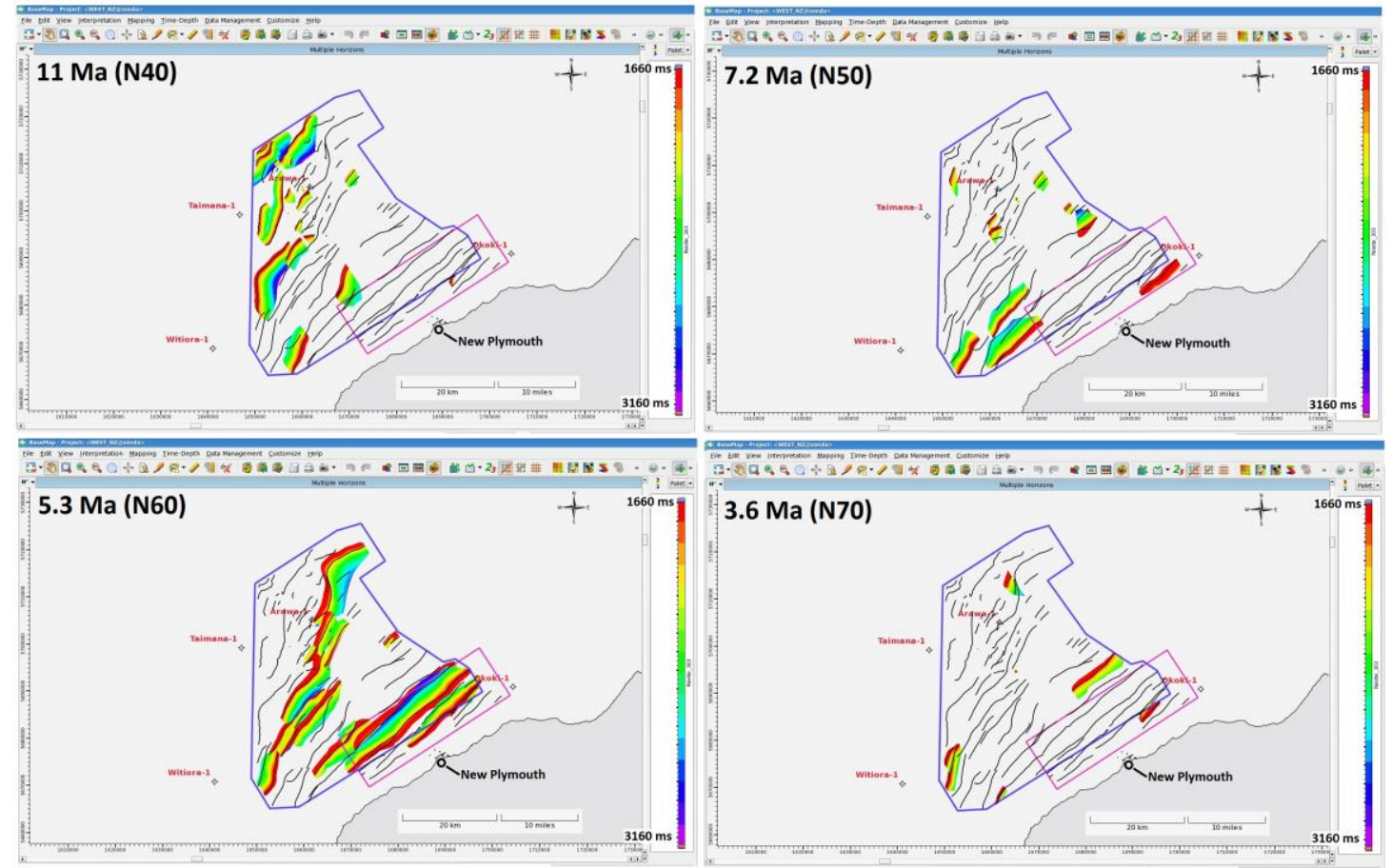

Appendix Figure $19 \quad$ Fault initiation maps for the 11 - $3.6 \mathrm{Ma}$ time horizons. Four maps displaying which faults initiated at each of the 11 - 3.6 Ma time horizons (Given at top left of each map). Whole fault planes are displayed, with coloured contours representing the depth to which they penetrate. A colour-depth scale is given to the right of each map. Black fault polylines are traces of faults at 5.3 Ma (period of maximum activity) for comparison. The Parihaka and Toro 3D seismic reflection surveys are represented by blue and red polygons, respectively. The XY coordinate grid is NZ Geodetic 2000. 

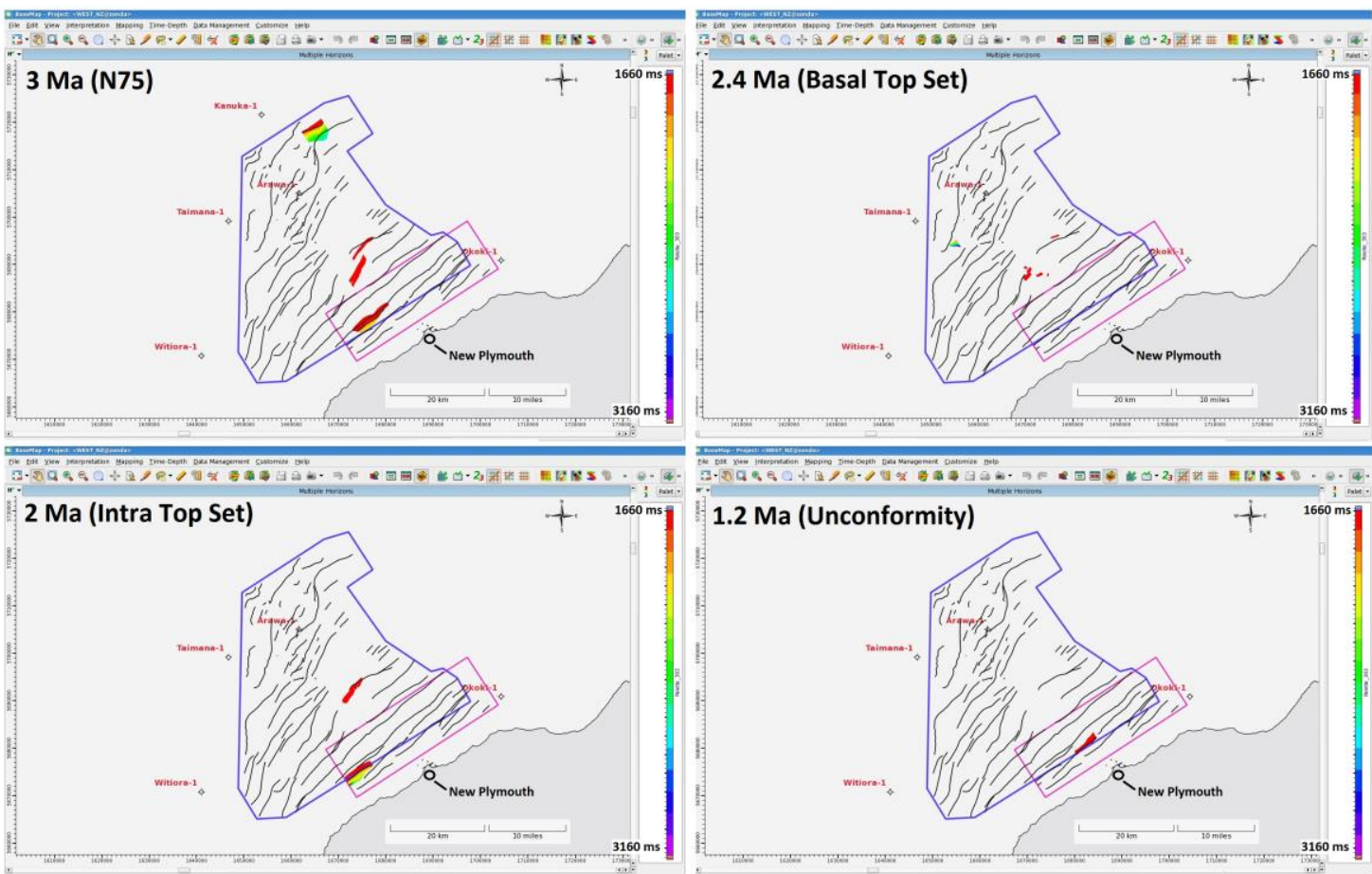

Appendix Figure $20 \quad$ Fault initiation maps for the $3-1.2 \mathrm{Ma}$ time horizons. Four maps displaying which faults initiated at each of the 3- 1.2 Ma time horizons (Given at top left of each map). Two time horizons (N85 and Seabed) did not have any faults born at them, and are hence omitted. Whole fault planes are displayed, with coloured contours representing the depth to which they penetrate. A colour-depth scale is given to the right of each map. Black fault polylines are traces of faults at 5.3 Ma (period of maximum activity) for comparison. The Parihaka and Toro 3D seismic reflection surveys are represented by blue and red polygons, respectively. The $\mathrm{XY}$ coordinate grid is NZ Geodetic 2000. 

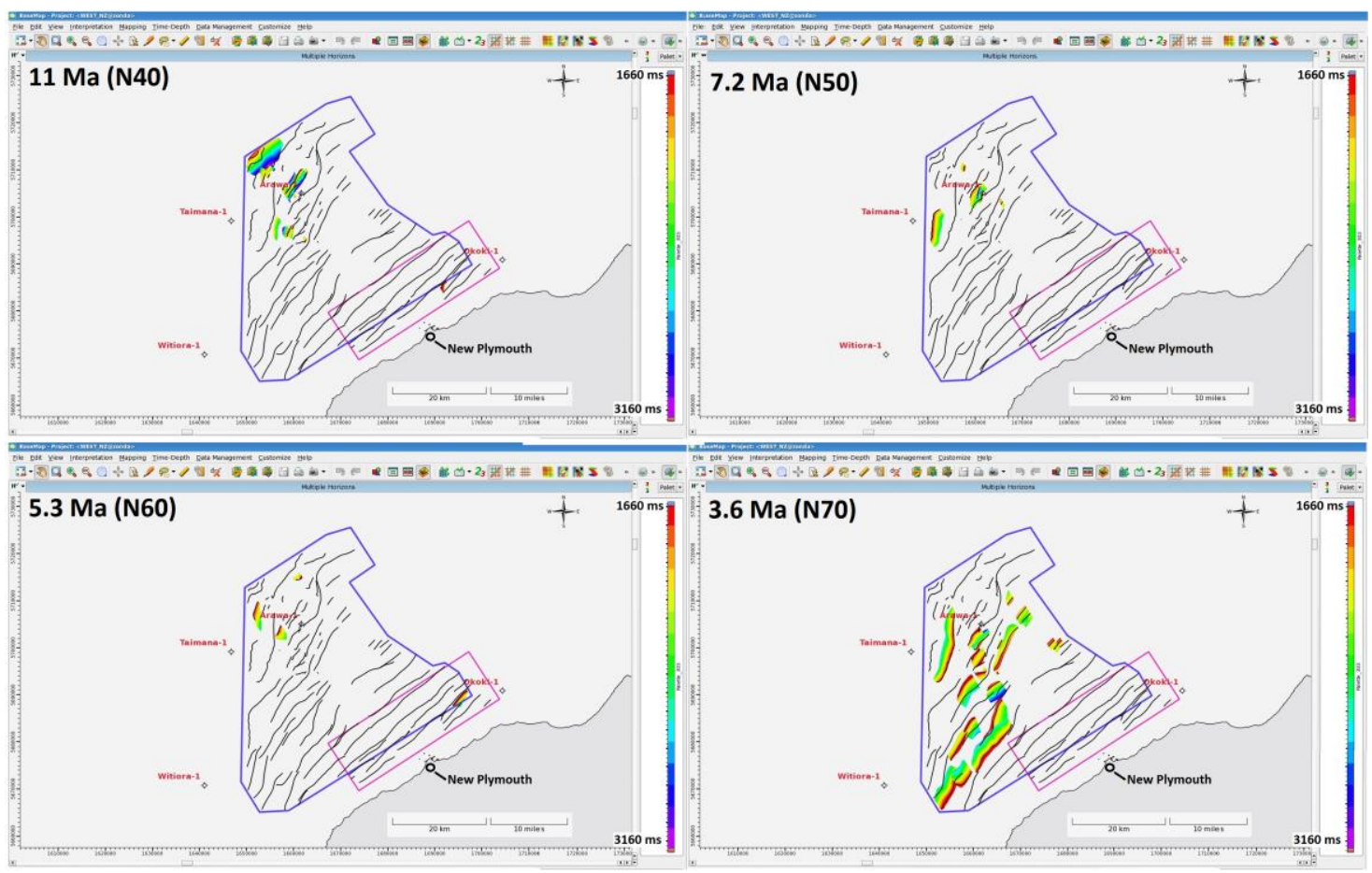

Appendix Figure $21 \quad$ Fault inactivity maps for the 11 - $3.6 \mathrm{Ma}$ time horizons. Four maps displaying which faults became inactive at each of the 11- 5.3 Ma time horizons (Given at top left of each map). Whole fault planes are displayed, with coloured contours representing the depth to which they penetrate. A colour-depth scale is given to the right of each map. Black fault polylines are traces of faults at 5.3 Ma (period of maximum activity) for comparison. The Parihaka and Toro 3D seismic reflection surveys are represented by blue and red polygons, respectively. The $\mathrm{XY}$ coordinate grid is NZ Geodetic 2000. 


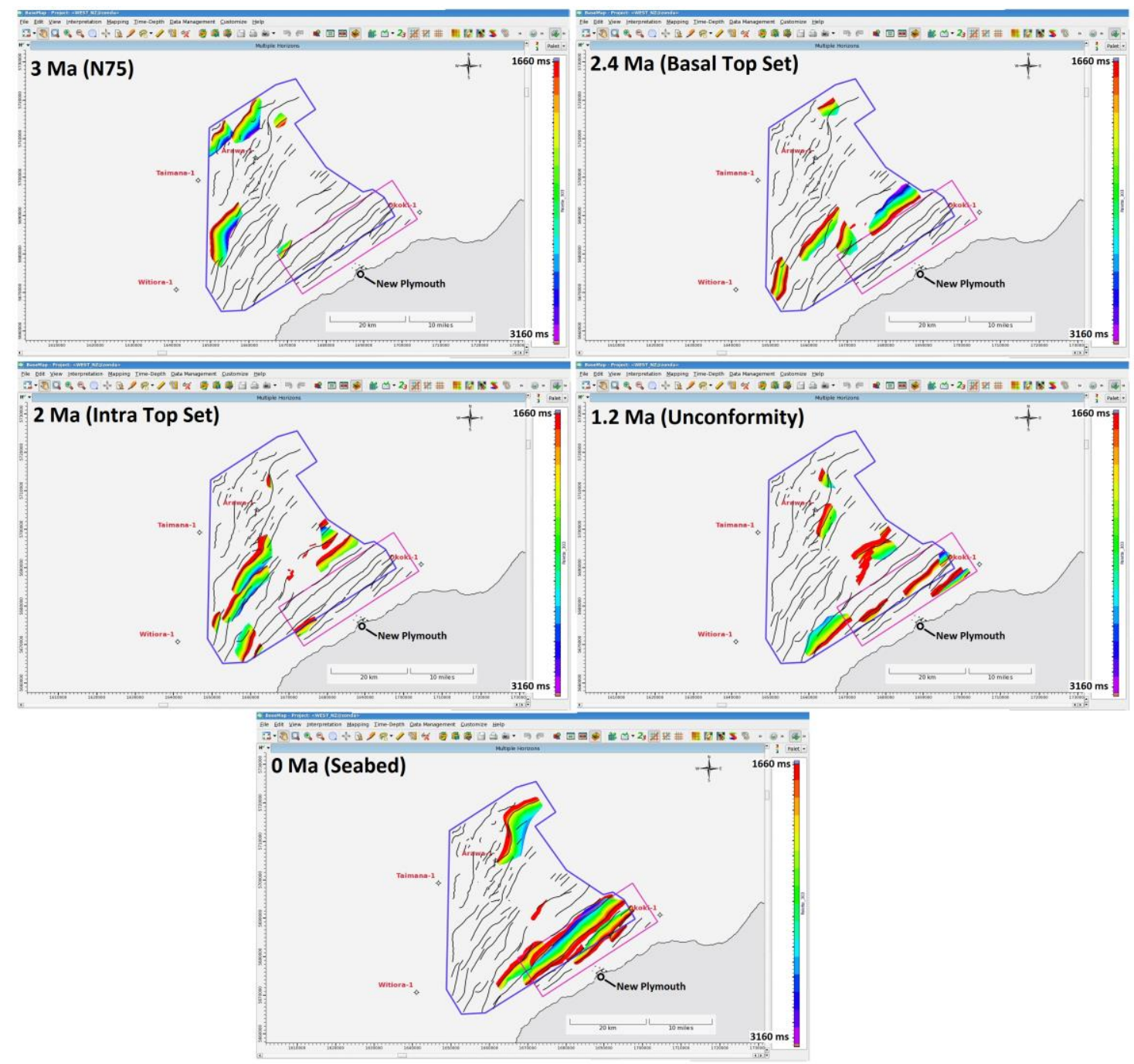

Appendix Figure 22 Fault inactivity maps for the 3-0 Ma time horizons. Five maps displaying which faults became inactive at each of the 3-0 Ma time horizons (Given at top left of each map). No faults became inactive at the N85 time horizon, which is omitted. Whole fault planes are displayed, with coloured contours representing the depth to which they penetrate. A colour-depth scale is given to the right of each map. Black fault polylines are traces of faults at 5.3 Ma (period of maximum activity) for comparison. The Parihaka and Toro 3D seismic reflection surveys are represented by blue and red polygons, respectively. The XY coordinate grid is NZ Geodetic 2000. 


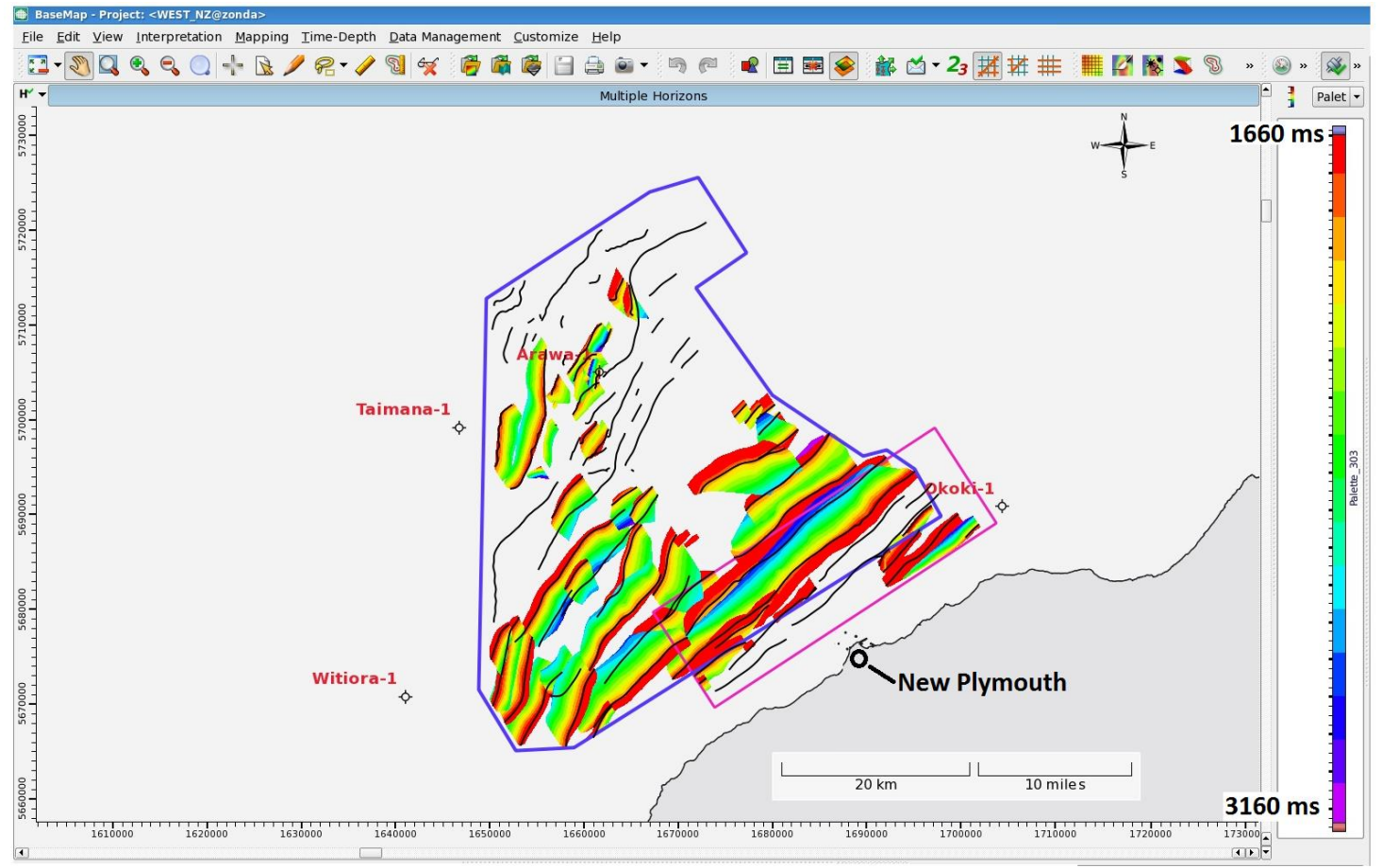

Appendix Figure $23 \quad$ Map displaying locations of new faults. Contoured faults are new faults, and black fault polylines are traces of faults at 5.3 Ma (period of maximum activity) for comparison. The Parihaka and Toro 3D seismic reflection surveys are represented by blue and red polygons, respectively. The XY coordinate grid is NZ Geodetic 2000.

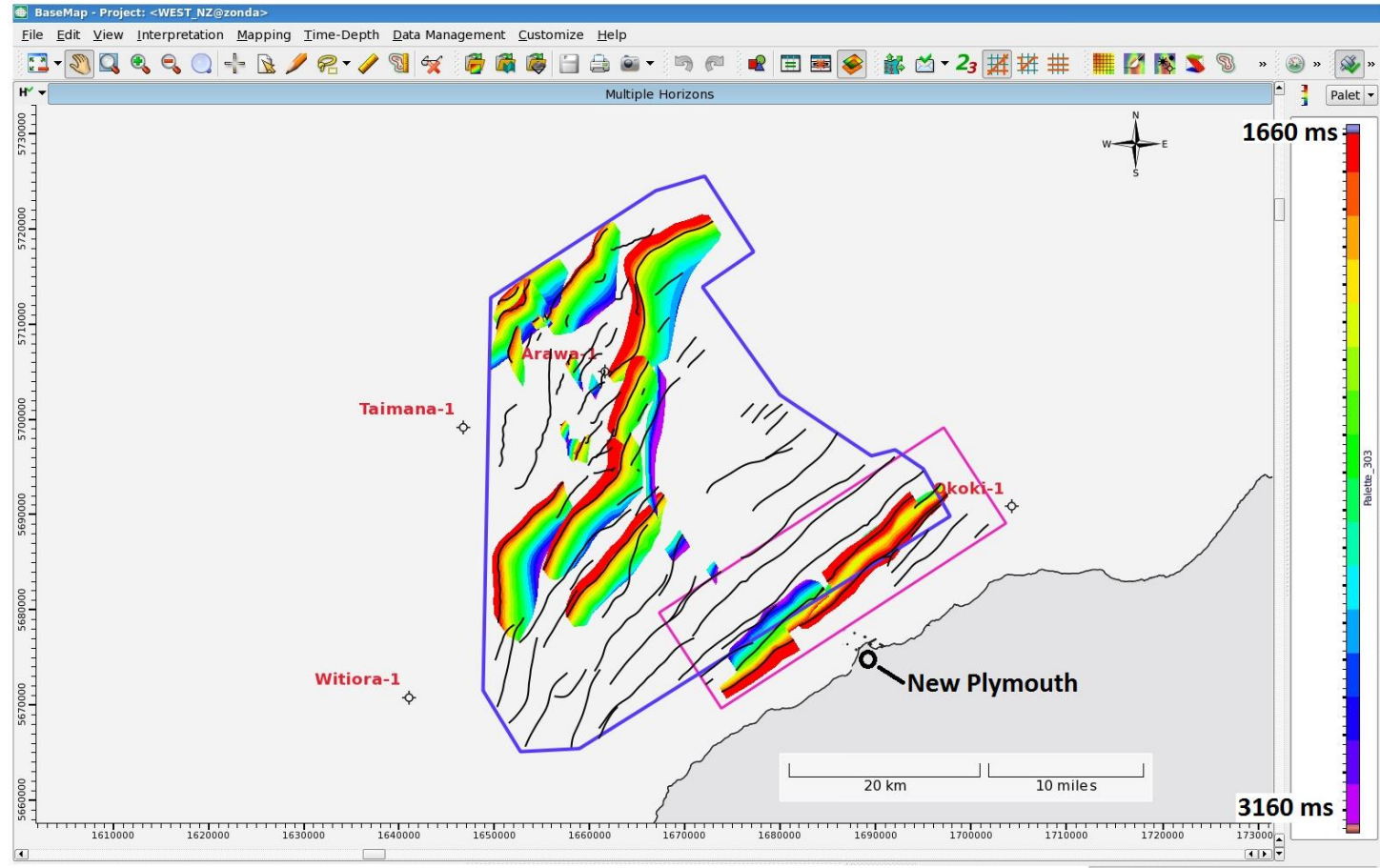

Appendix Figure 24 Map displaying locations of reactivated faults. Contoured faults are reactivated faults, and black fault polylines are traces of faults at $5.3 \mathrm{Ma}$ (period of maximum activity) for comparison. The Parihaka and Toro 3D seismic reflection surveys are represented by blue and red polygons, respectively. The XY coordinate grid is NZ Geodetic 2000. 


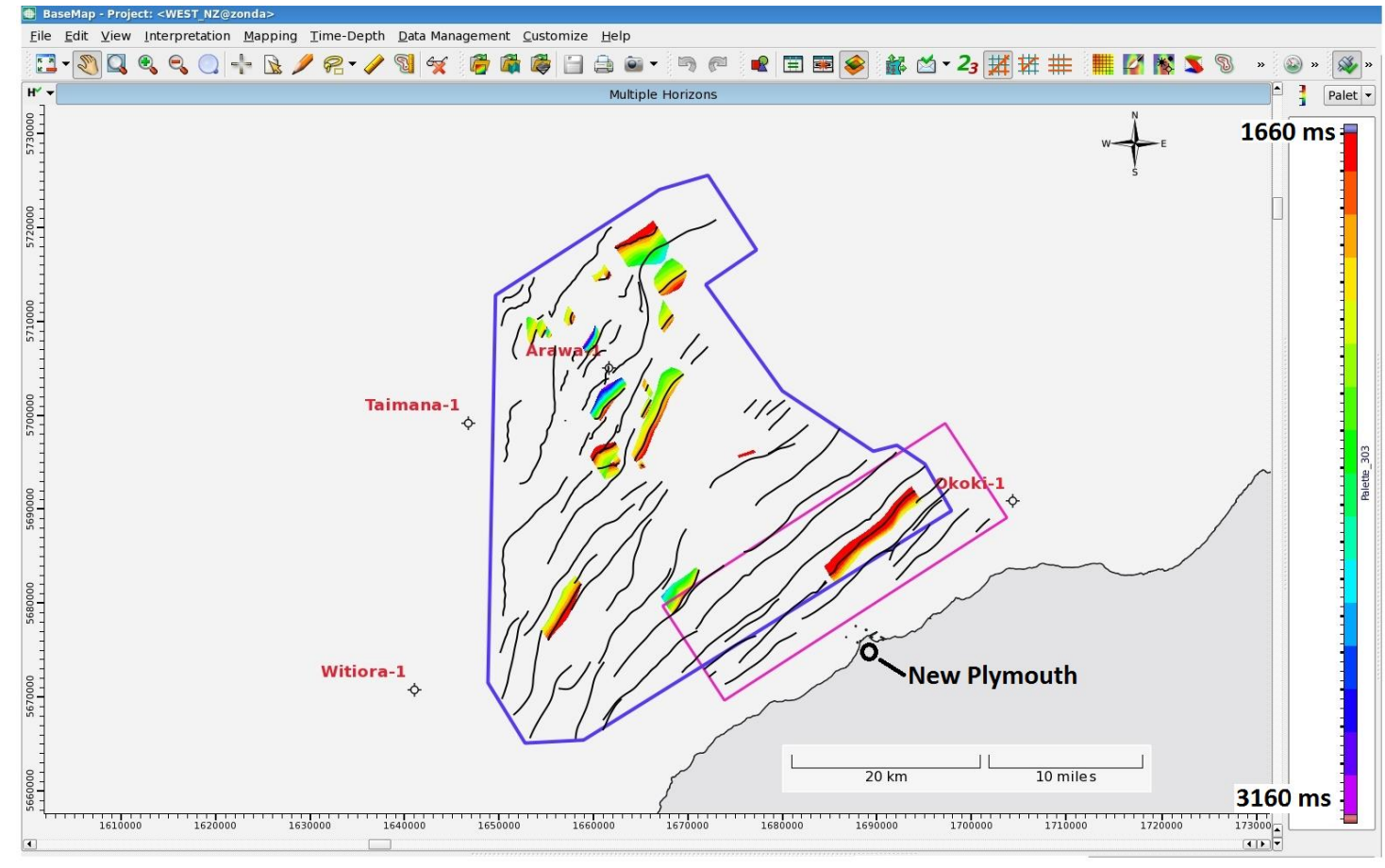

Appendix Figure $25 \quad$ Map displaying locations of faults antithetic to reactivated structures. Contoured faults are faults antithetic to reactivated structures, and black fault polylines are traces of faults at 5.3 Ma (period of maximum activity) for comparison. The Parihaka and Toro 3D seismic reflection surveys are represented by blue and red polygons, respectively. The $\mathrm{XY}$ coordinate grid is NZ Geodetic 2000. 


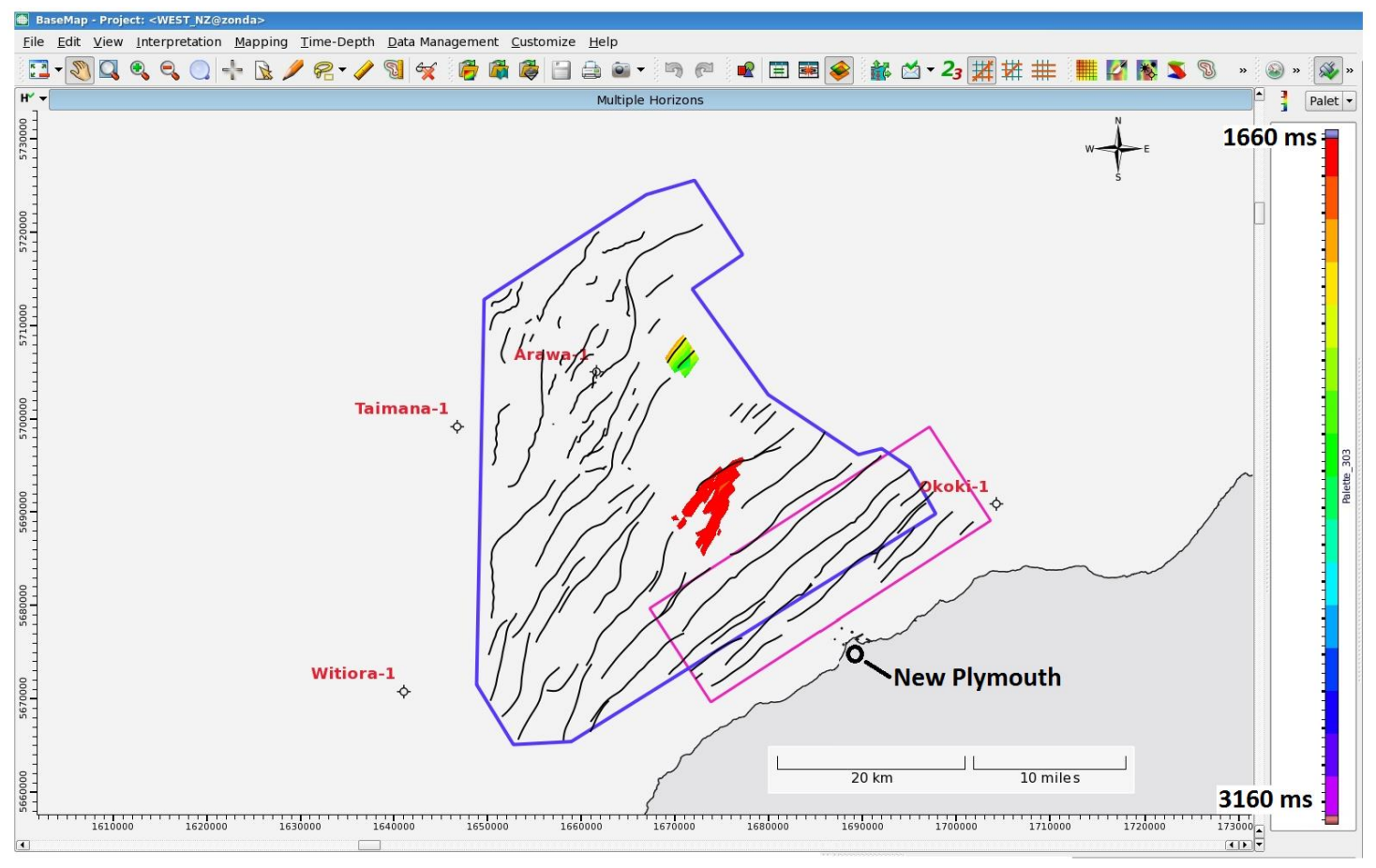

Appendix Figure $26 \quad$ Map displaying locations of volcanic faults. Contoured faults are volcanic faults, and black fault polylines are traces of faults at 5.3 Ma (period of maximum activity) for comparison. The Parihaka and Toro 3D seismic reflection surveys are represented by blue and red polygons, respectively. The XY coordinate grid is NZ Geodetic 2000 . The XY coordinate grid is NZ Geodetic 2000. 


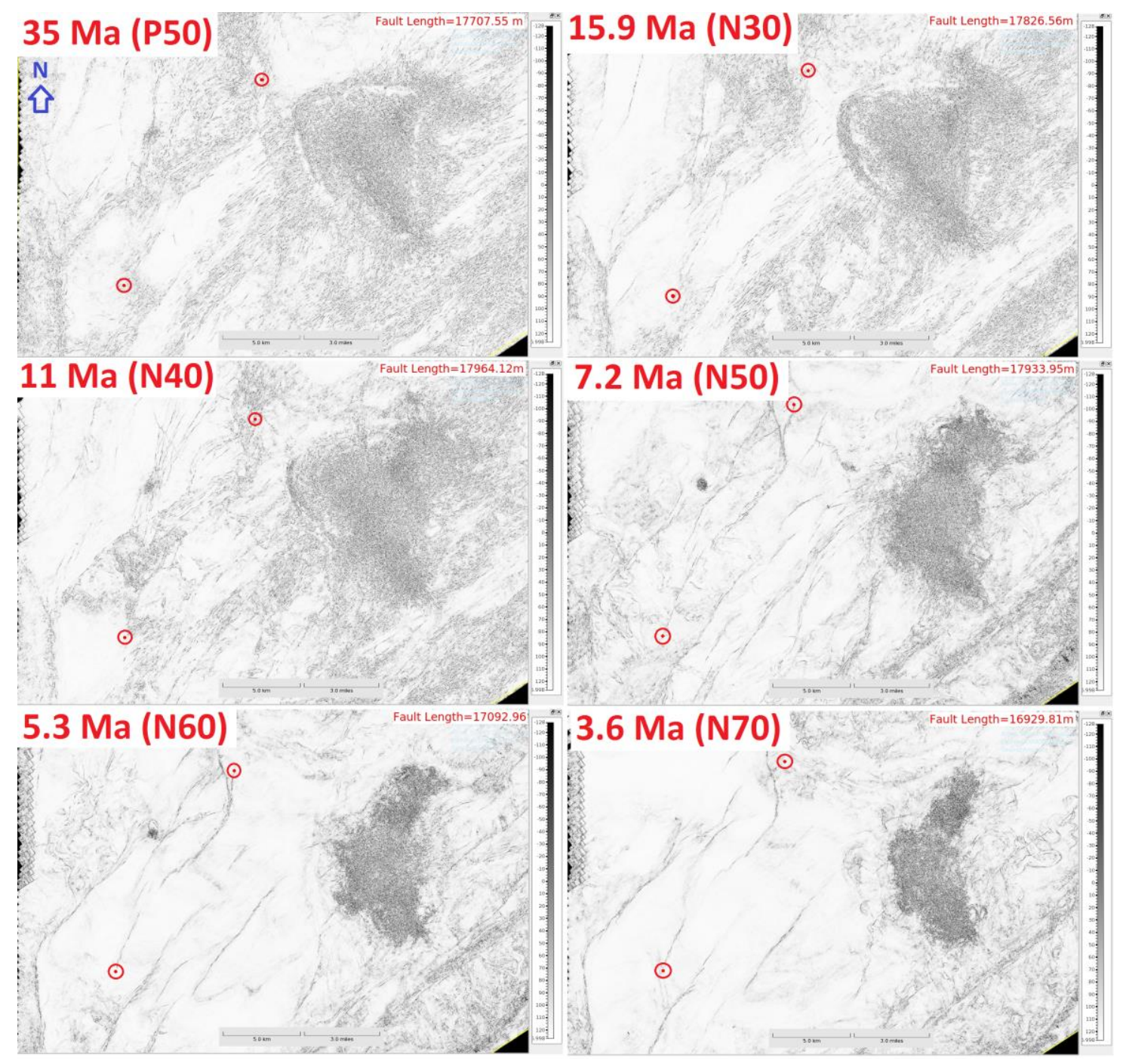

Appendix Figure $27 \quad$ Coherency attribute images displaying stationary fault tip locations (Part 1 Fault Z.1003). Locations of fault tips (bullseye symbols) are displayed from oldest to youngest time horizon. Fault length is given at the top right of the image. Each coherency image is taken at the average depth of its respective time horizon grid (3000, 2700, 2100, 1800, 1500, and 1400 ms TWTT, respectively). 


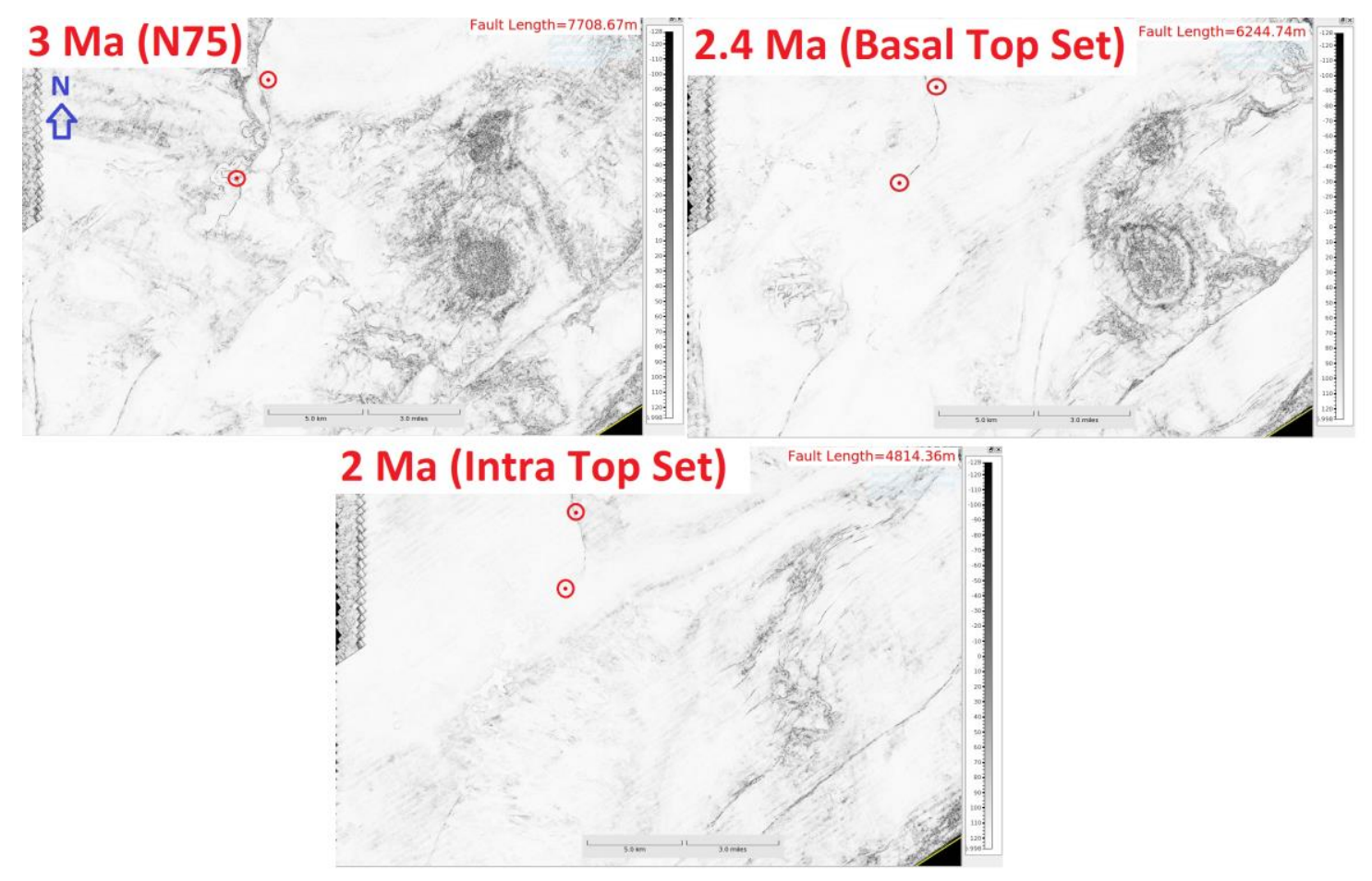

Appendix Figure $28 \quad$ Coherency attribute images displaying stationary fault tip locations (part 2 Fault Z.1003). Locations of fault tips (bullseye symbols) are displayed from oldest to youngest time horizon. Fault length is given at the top right of the image. Each coherency image is taken at the average depth of its respective time horizon grid (1300, 1000, and $800 \mathrm{~ms}$ TWTT, respectively). 

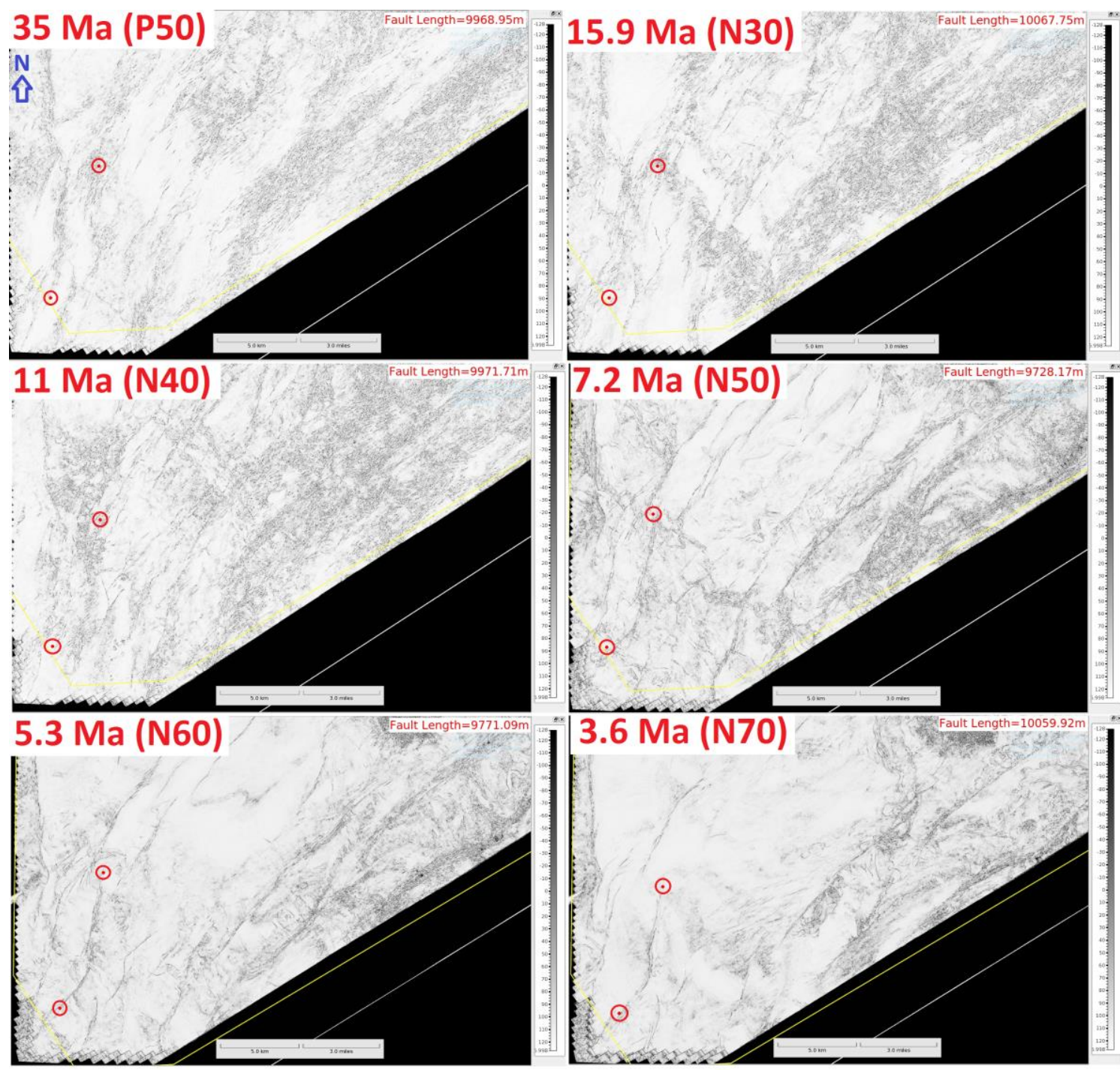

Appendix Figure 29

Coherency attribute images displaying retreating fault tip locations (part 1 Fault 5_090). Locations of fault tips (bullseye symbols) are displayed from oldest to youngest time horizon. Fault length is given at the top right of the image. Each coherency image is taken at the average depth of its respective time horizon grid $(3000,2700,2100,1800,1500$, and 1400 ms TWTT, respectively).

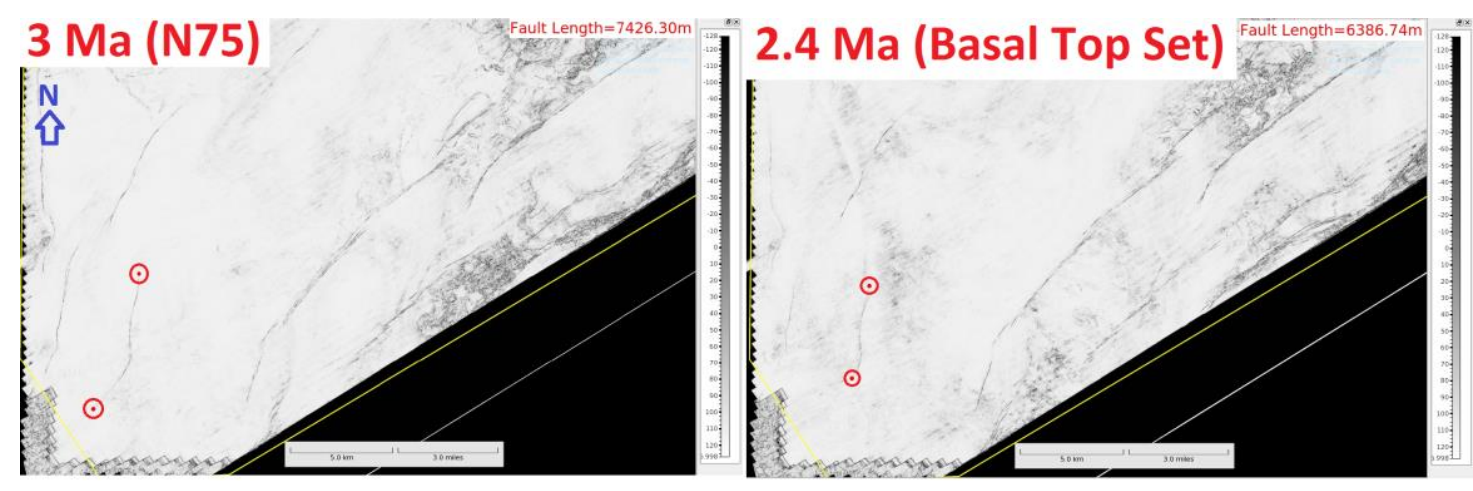

Appendix Figure $30 \quad$ Coherency attribute images displaying retreating fault tip locations (part 2fault 5_090). Locations of fault tips (bullseye symbols) are displayed from oldest to youngest time horizon. Fault length is given at the top right of the image. Each coherency image is taken at the average depth of its respective time horizon grid (1300 and $1000 \mathrm{~ms}$ TWTT, respectively). 


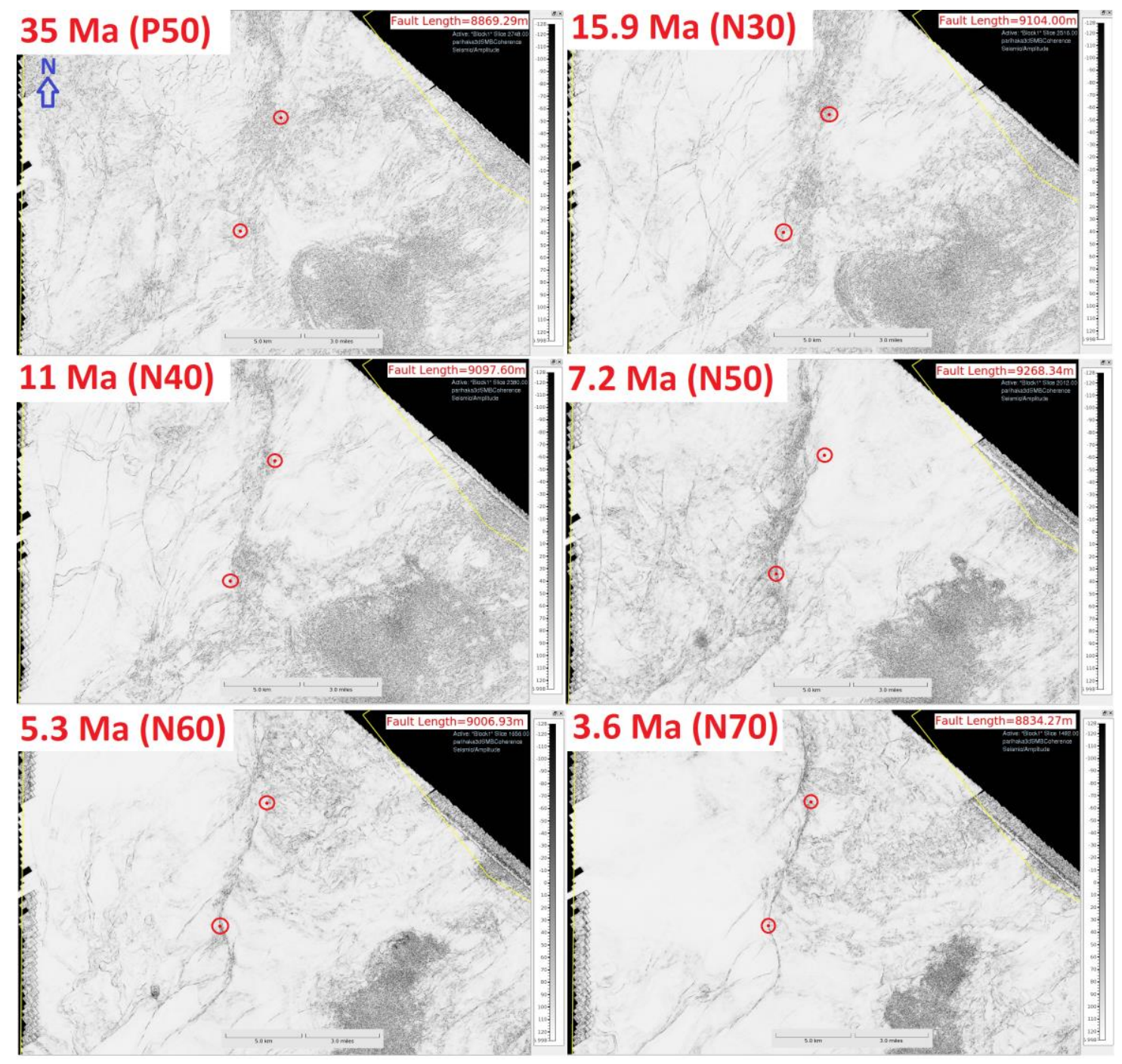

Appendix Figure $31 \quad$ Coherency attribute images displaying potentially propagating fault tip locations (part 1 - Fault- z.1002). Locations of fault tips (bullseye symbols) are displayed from oldest to youngest time horizon. Fault length is given at the top right of the image. Each coherency image is taken at the average depth of its respective time horizon grid $(3000,2700,2100,1800,1500$, and 1400 ms TWTT, respectively). 


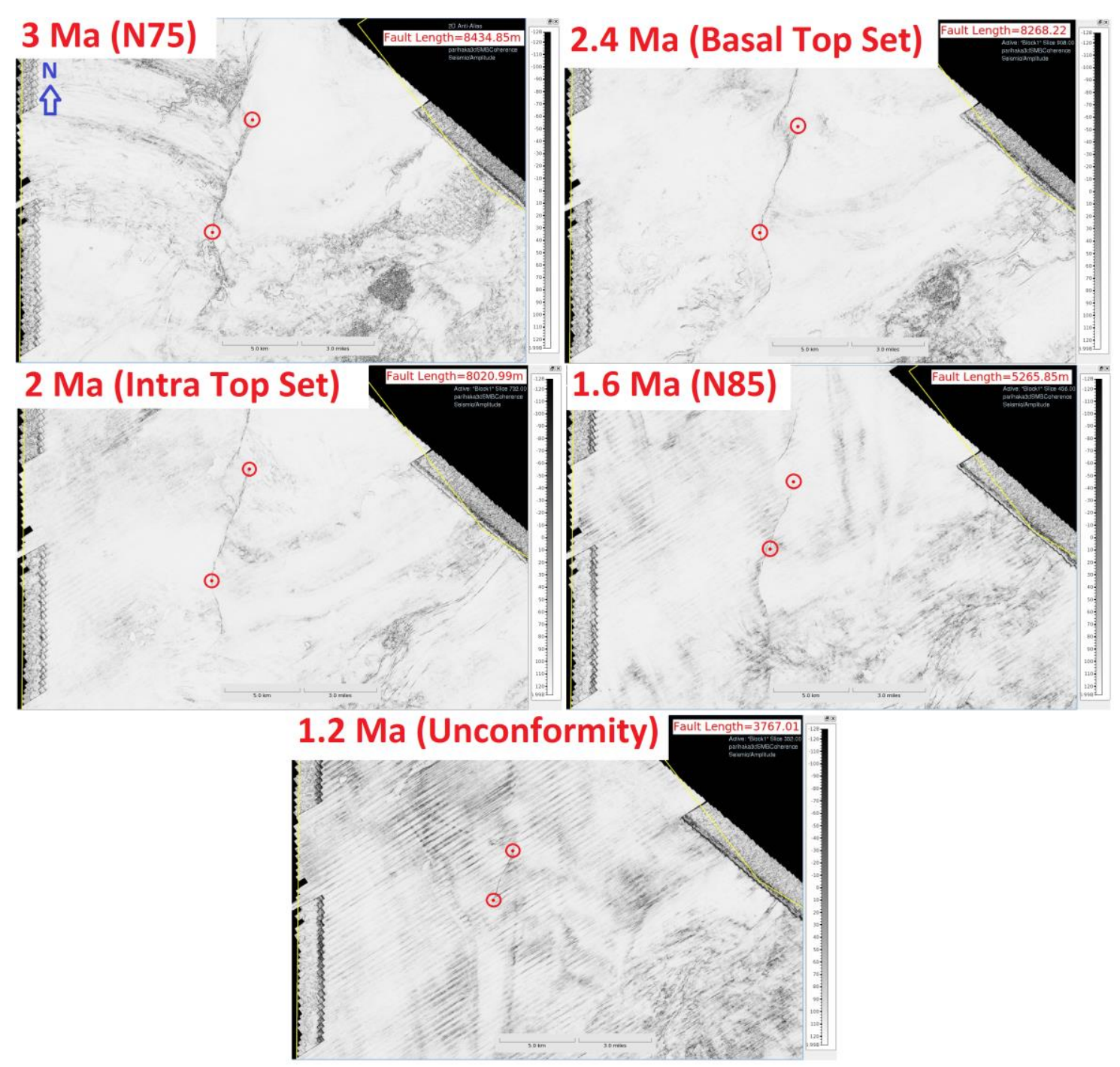

Appendix Figure $32 \quad$ Coherency attribute images displaying potentially propagating fault tip locations (part 2 - Fault- z.1002). Locations of fault tips (bullseye symbols) are displayed from oldest to youngest time horizon. Fault length is given at the top right of the image. Each coherency image is taken at the average depth of its respective time horizon grid $(1300,1000,800,500$, and $300 \mathrm{~ms}$ TWTT, respectively). 


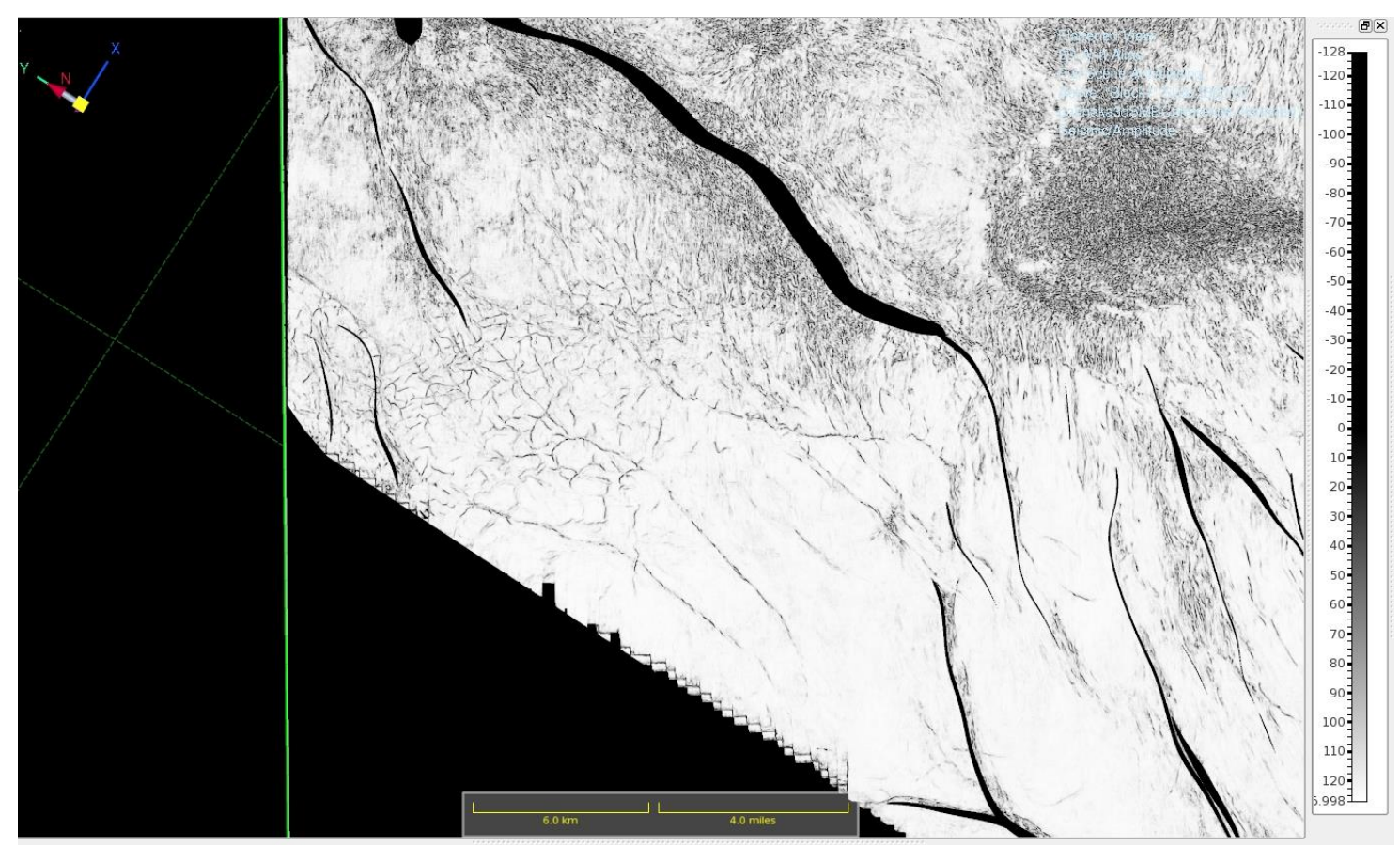

Appendix Figure $33 \quad$ Coherency time slice at $\mathbf{2 8 2 0}$ ms displaying polygonal faults observed in the Parihaka 3D coherency volume. Polygonal faults are the crosshatched structures visible in the bottom left hand corner of the time slice. 


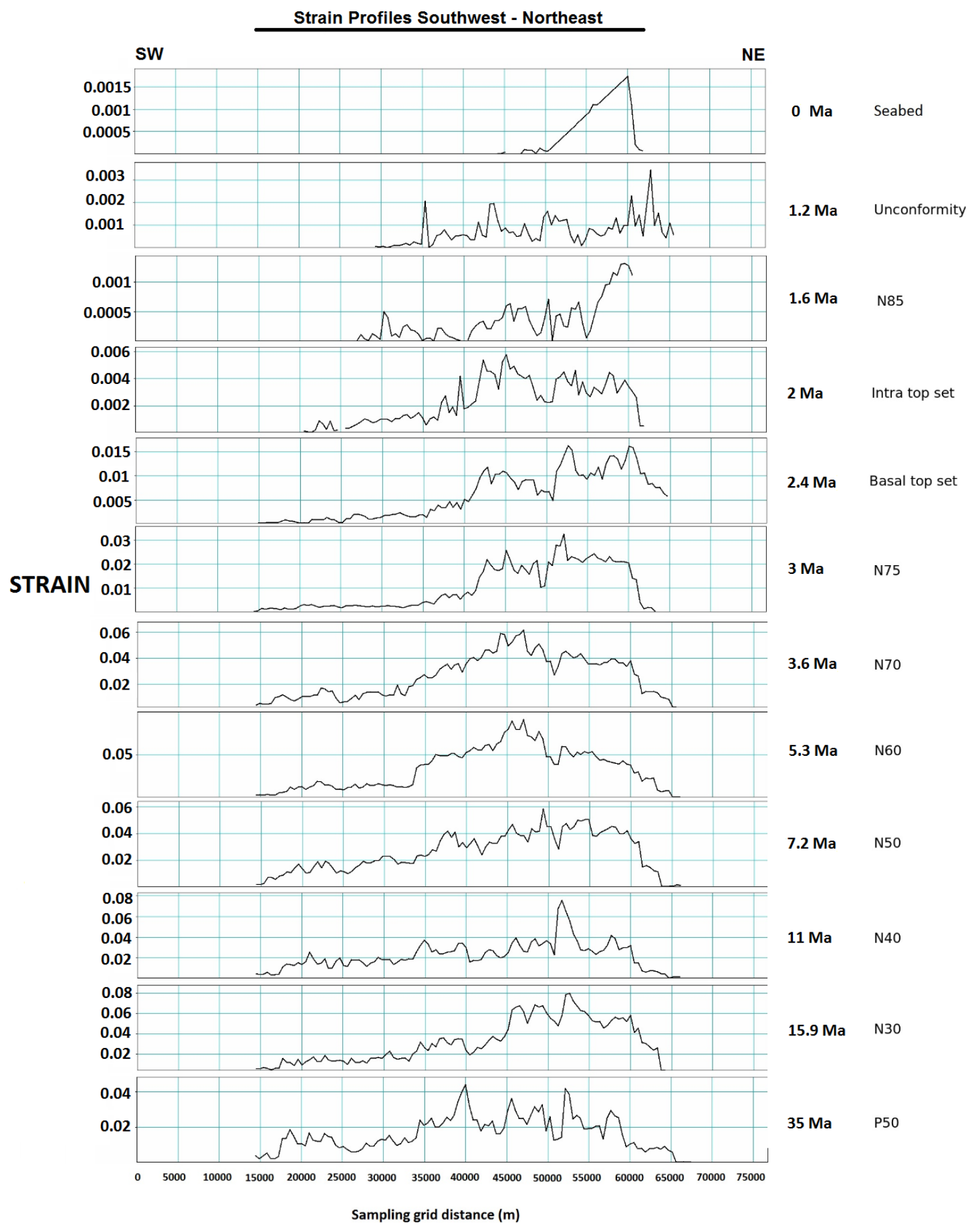

Appendix Figure $34 \quad$ Plot displaying raw strain profiles as seen in TrapTester. Each image is one of twelve southwest - northeast strain profiles calculated for each of the twelve time horizons, displayed from youngest to oldest. Sampling grid spacing is set to $200 \mathrm{~m}$, with sampling grid distance in metres on the $x$ axis, and strain on the $y$ axis. Strain units are displayed at a varied scale for each time horizon, as TrapTester sums strain for each time horizon independently, and provide best fit values. 


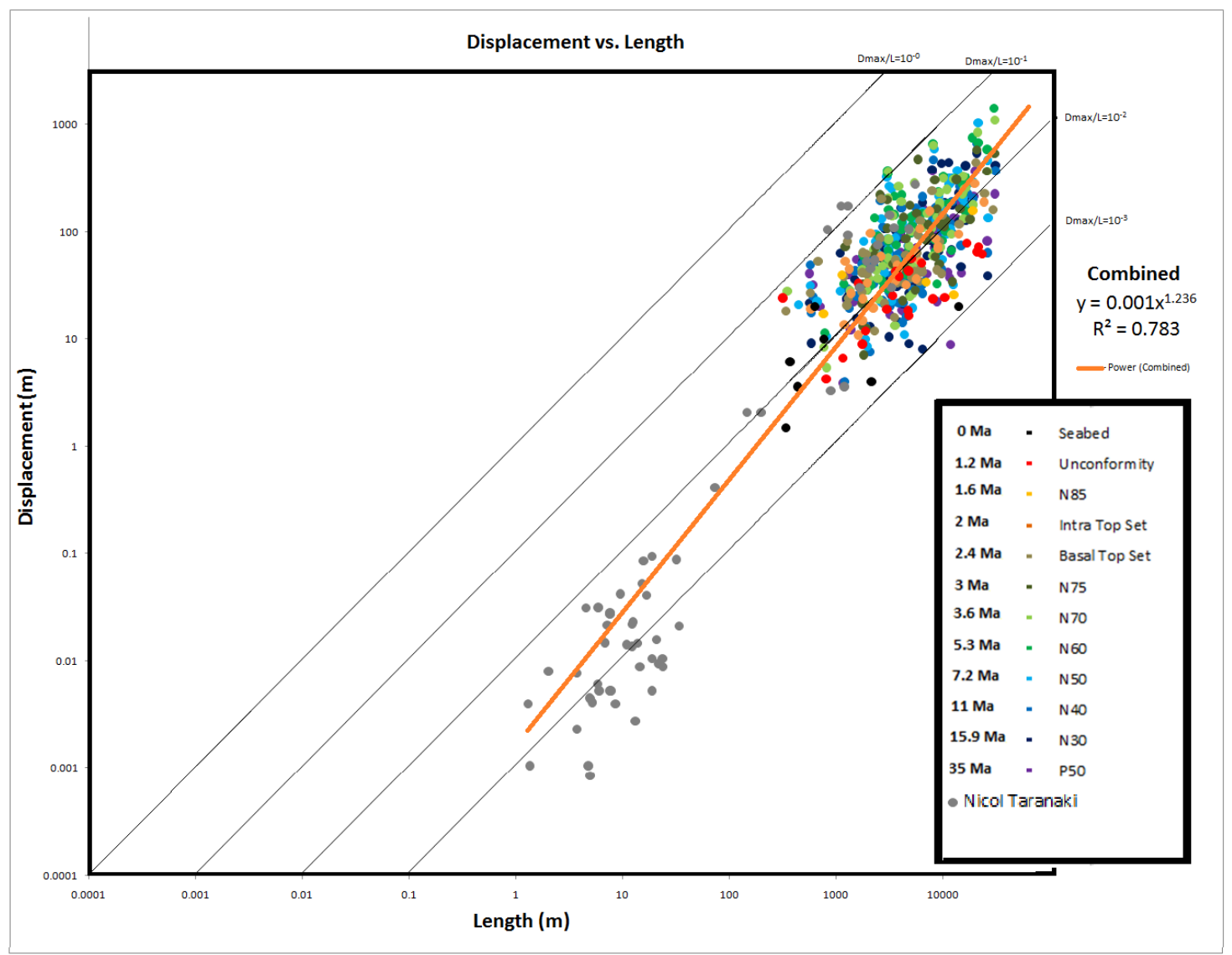

Appendix Figure $35 \quad$ Log/log Displacement/Length plot for all data gathered in the study area, combined with unpublished Taranaki data from A Nicol. Displacement/Length plot shows values for every fault at every time horizon in the study area. Data is grouped by time horizon to allow comparison of Displacement/Length relationships between time horizons. Grey filled circles are Taranaki Basin Displacement/Length data from both outcrop and seismic data (A Nicol, unpub. data). A power law trendline for a combination of thesis results and the A Nicol data is shown. Four Dmax/L gradients are shown for reference. 